\title{
Preclinical Assessment of Novel Radiopaque UHMWPE Sublaminar Wires in a Growth-Guidance System for Early Onset Scoliosis Correction
}

Citation for published version (APA):

Roth, A. K. (2017). Preclinical Assessment of Novel Radiopaque UHMWPE Sublaminar Wires in a Growth-Guidance System for Early Onset Scoliosis Correction. [Doctoral Thesis, Maastricht University]. Maastricht University. https://doi.org/10.26481/dis.20170210ar

Document status and date:

Published: 01/01/2017

DOI:

10.26481/dis.20170210ar

Document Version:

Publisher's PDF, also known as Version of record

Please check the document version of this publication:

- A submitted manuscript is the version of the article upon submission and before peer-review. There can be important differences between the submitted version and the official published version of record.

People interested in the research are advised to contact the author for the final version of the publication, or visit the DOI to the publisher's website.

- The final author version and the galley proof are versions of the publication after peer review.

- The final published version features the final layout of the paper including the volume, issue and page numbers.

Link to publication

\footnotetext{
General rights rights.

- You may freely distribute the URL identifying the publication in the public portal. please follow below link for the End User Agreement:

www.umlib.nl/taverne-license

Take down policy

If you believe that this document breaches copyright please contact us at:

repository@maastrichtuniversity.nl

providing details and we will investigate your claim.
}

Copyright and moral rights for the publications made accessible in the public portal are retained by the authors and/or other copyright owners and it is a condition of accessing publications that users recognise and abide by the legal requirements associated with these

- Users may download and print one copy of any publication from the public portal for the purpose of private study or research.

- You may not further distribute the material or use it for any profit-making activity or commercial gain

If the publication is distributed under the terms of Article $25 \mathrm{fa}$ of the Dutch Copyright Act, indicated by the "Taverne" license above, 


\author{
Preclinical Assessment of Novel \\ Radiopaque UHMWPE Sublaminar Wires in a \\ Growth-Guidance System for \\ Early Onset Scoliosis Treatment
}

Alex Kristian Roth 


\section{Copyright}

(C)Alex Roth, 2016. All rights reserved

ISBN 978-94-6332-135-8

\section{Research Funding}

This research forms part of the Project P2.05 Spineguide of the research program of the BioMedical Materials institute, co-funded by the Dutch Ministry of Economic Affairs.

Financial Support for the publication of this thesis was provided by:

Maastricht University

DSM Biomedical

Stichting Kliniek en Wetenschap Orthopaedie

Annafonds | NOREF

Nederlandse Vereniging voor Biomaterialen en Tissue Engineering

\section{Cover Design}

Rudy Roth \& Alex Roth

\section{Printing}

GVO drukkers \& vormgevers B.V. 


\section{Preclinical Assessment of Novel \\ Radiopaque UHMWPE Sublaminar Wires in a \\ Growth-Guidance System for \\ Early Onset Scoliosis Treatment}

op gezag van de Rector Magnificus, prof. dr. Rianne M. Letschert

volgens het besluit van het College van Decanen,

in het openbaar te verdedigen

op vrijdag 10 februari 2017 om 12.00 uur

door

Alex Kristian Roth

Geboren op 8 mei 1987 te Eindhoven 


\section{Promotor}

Prof. dr. L.W. van Rhijn

\section{Copromotores}

Dr. J.J. Arts

Dr. P.C. Willems

\section{Beoordelingscommissie}

Prof. dr. P.R.G. Brink (voorzitter)

Prof. dr. R.M. Castelein (UMC Utrecht)

Prof. dr. P. Habibovic

Dr. H. Van Santbrink

Prof. dr. ir. G.J. Verkerke (Rijksuniversiteit Groningen) 
7 Chapter 1

Thesis Rationale and Motivation

17

Chapter 2

Background Information

49

Chapter 3

Radiopaque UHWMPE Sublaminar Cables for Spinal Deformity Correction:

Preclinical Mechanical and Radiopacifier Leaching Assessment

Supplement to Chapter 3

Wear Characterization of Radiopaque UHMWPE Cables: an Observational Study

81

\section{Chapter 4}

Novel Radiopaque Ultra-High Molecular Weight Polyethylene Sublaminar Wires in a Growth-Guidance System for the Treatment of Early-Onset Scoliosis: Feasibility in a Large Animal Study

Supplement to Chapter 4

Longitudinal Sliding Friction between a Sublaminar Wire and a Spinal Rod:

UHMPWE Cables versus Metal Cables

\section{Chapter 5}

Range of Motion in Segmental Versus Non-segmental UHWMPE Sublaminar Wire Growth-Guidance Type Constructs for Early Onset Scoliosis Correction

Chapter 6

The Biomechanical Behavior of Segmental Versus Non-Segmental UHMWPE Sublaminar Wire Constructs in a Patient-Specific Finite Element Model of the Thoracolumbar Spine

\section{Chapter 7}

Large Animal Models in Fusionless Scoliosis Correction Research: a Literature Review

\section{Chapter 8}

The Development of a Representative Porcine Early Onset Scoliosis Model with a Standalone Posterior Spinal Tether

General Discussion

207 Valorization

211 Nederlandse Samenvatting

217 List of Publications

219 Dankwoord

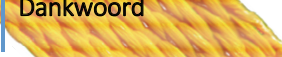





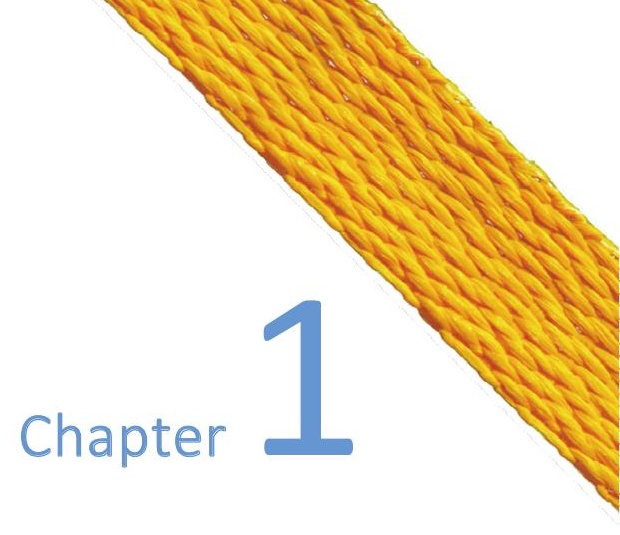

Thesis Rationale and Motivation 
Chapter 1

1 


\section{INTRODUCTION}

Scoliosis is a complex three-dimensional deformity of the spine, which was first described by Hippocrates in the fifth century B.C. The Greek word 'skoliosis' literally means crookedness. Adolescent idiopathic scoliosis (AIS) is the most common type of scoliosis, accounting for approximately $85 \%$ of all cases and generally occurring in 2-3\% of the population [1]. The treatment of AIS has been well conceived, with exercise therapy, orthotic brace treatment, and surgical intervention generally considered as the successive treatment stages for scoliotic curves with increasing severity. The objective of all these treatment options is to stop curve progression, with surgical treatment offering the potential for partial to full curve correction.

Early onset scoliosis (EOS) is characterized by onset before the age of ten years without distinction of etiology [2, 3]. Scoliosis is most progressive during periods of rapid growth. EOS is especially worrisome due to the long duration of remaining growth. Approximately $70 \%$ of all curves in EOS patients are progressive and will require some kind of treatment, with reports of surgical rates as high as 56\% [4]. The golden standard in surgical treatment of AIS, instrumented posterior spinal fusion using pedicle screws and rods, is not suitable for EOS patients as it is associated with severe complications. By the age of ten, spinal length has reached approximately $65 \%$ of its mature length and thoracic cage volume has reached only $50 \%$ of its mature volume [5]. Early definitive fusion in EOS patients stops further spinal and thoracic cage growth, and can severely influence pulmonary function as a result. 43\%-64\% of EOS patients who have undergone early fusion suffer from restrictive pulmonary disease [6], characterized by a forced vital capacity of less than $50 \%$ of age-matched controls. Furthermore, continued anterior spinal growth after posterior fusion can result in progressive spinal curvature with increased vertebral rotation, which is known as the 'crankshaft phenomenon' [7].

Growth-friendly spinal implants have been developed to accommodate spinal and thoracic cage growth for EOS patients. Distinction can be made between distractionbased and growth-guidance type constructs [3]. Distraction-based implants, namely growing rods and the vertical expandable prosthetic titanium rib (VEPTR), are anchored at only the proximal and distal deformity ends, and require repeated rod distractions for spinal growth. Lengthening procedures require repeated surgeries, which have been shown to be most effective in intervals of approximately 6 months [8]. The frequent hospitalization periods are associated with high societal healthcare costs $[9,10]$, and have a huge psychosocial impact on patients and their families [11, 12]. Magnetically expandable growing rods have been introduced within the last decade to address these issues [13-15], but instrumentation related complications such as break-out and rod fracture are reportedly higher than conventional growing rods [16]. Wound-related issues and instrumentation prominence are frequently occurring complications for all types of growing rods [17]. Due to suboptimal correction offered by growing rods and 
1 the high risk of rod breakage, a definitive fusion procedure is required at skeletal maturity [18].

Growth-guidance type constructs do not require repeated surgical lengthening procedures, but employ sliding anchors along a fixed rod to accommodate spinal growth. The Luque trolley, introduced in the 1970's, is the original growth-guidance type construct, and relies on sliding of metal sublaminar wires along a spinal rod for growth $[19,20]$. The Shilla system employs non-constraining pedicle screws as the sliding anchor members [21, 22]. Metal-on-metal articulation thus occurs regularly and is required for growth in both these systems. High friction between rods and anchors has been associated with disappointing growth results for the Luque trolley [23, 24], and extensive metallosis has also been reported as a result of metal-on-metal articulation for both systems [22, 25-27].

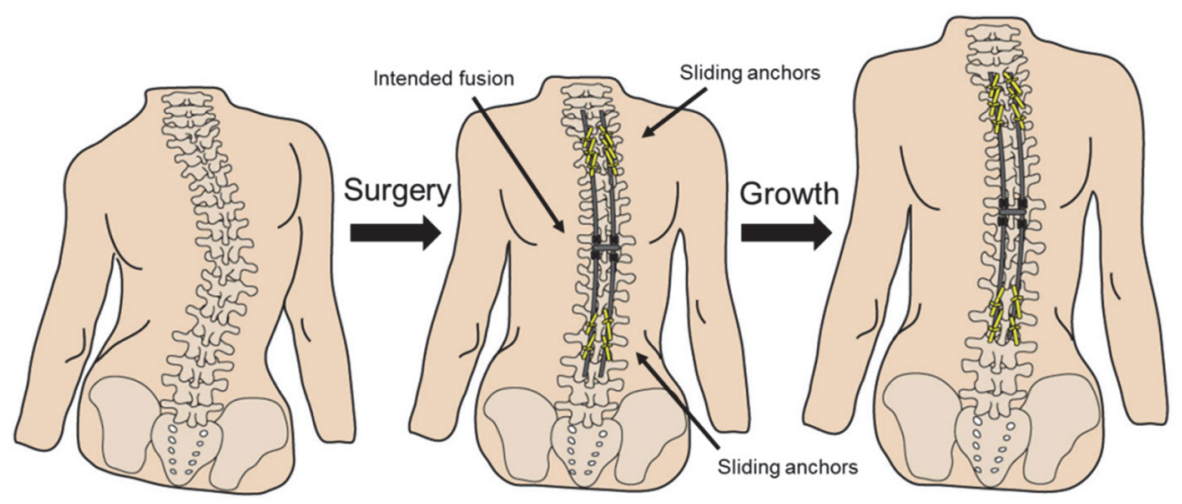

Figure 1 - The proposed growth-guidance construct for the treatment of early onset scoliosis: pedicle screws at the apex and UHMWPE sublaminar wires as sliding anchor members at the proximal and distal construct ends to allow for continued growth after surgery.

The goal of this thesis is to develop and evaluate a new growth-guidance type construct for the surgical treatment of EOS which would allow for maximum growth without the disadvantages of metal-on-metal articulation. We propose the use of woven ultra-high molecular weight polyethylene (UHMWPE) sublaminar wires, secured by means of a knot, as sliding anchors at the proximal and distal ends of a construct with pedicle screws at the apex to prevent rod migration and to allow for curve derotation. The portion above and below the apex is least rotated and deviated from the midline, and thus is the target for growth-guidance. We hypothesize that the use of UHMWPE sublaminar wires instead of metal wires offers three significant advantages: first, longitudinal sliding friction is expected to be substantially decreased, thereby allowing for increased spinal growth. Second, no metal wear particles will be generated. Finally, 
the vastly increased fatigue strength of UHMWPE wires in comparison to metal wires allows for non-segmental constructs (skipped-level fixation) without the risk of wire failure, and thus may allow for reduced surgical exposure in comparison to the traditional Luque trolley.

Woven polymer sublaminar cable systems have already been introduced in the last decade as an improvement in sublaminar wiring technique for the surgical treatment of AIS, but have not been used in growth-guidance type constructs for EOS. The Universal Clamp system (Zimmer Spine SAS, Bordeaux, France) consists of a polyester cable and a metallic clamp $[28,29]$. The Nesplon cable system (Alfresa Pharma, Osaka, Japan) is an UHMWPE cable which is secured using a double-loop sliding knot [30]. The flat, wide profile of these cable systems distributes contact forces over a greater area, thereby increasing possible corrective forces and lowering the risk of cable pull-out in comparison to metal cables. The penetration of woven polymer cables into the spinal canal is less than that of metal wires [31], and cable conformance to the lamina is improved. Both factors are believed to lead to lower neurological injury rates in comparison to metal wires. However, currently available polymer cable systems are radiolucent, precluding radiologic assessment of instrumentation stability during followup. For this reason, a radiopaque woven UHMWPE cable made with Dyneema Purity ${ }^{\circledR}$ Radiopaque fibers has been developed and will be evaluated both in vitro and in vivo within this project. In summary, a growth-guidance construct with novel radiopaque UHMWPE sublaminar wires as sliding anchor members for the surgical treatment of EOS will be developed and evaluated in this thesis.

\section{OBJECTIVES AND THESIS OUTLINE}

The objective of this thesis is to provide a preclinical assessment of a growth-guidance construct with radiopaque UHMWPE sublaminar wires as the sliding anchor members. This thesis is the result of the multi-disciplinary Spineguide project, part of the BioMedical Materials research program, co-funded by the Dutch Ministry of Economic Affairs.

In Chapter 2, more extensive background information covering all the aspects of this thesis is provided. The covered topics are: basic spinal anatomy, the epidemiology of scoliosis and the classification of scoliosis, conservative and surgical treatment options for scoliosis, and an introduction to in vitro, in vivo, and in silico evaluation methods.

The specific objectives of this thesis are:

To assess the suitability of novel woven UHMWPE sublaminar wires made with Dyneema Purity ${ }^{\circledR}$ Radiopaque fibers for clinical application from both a mechanical and biological perspective 
In Chapter 3, the mechanical properties (tensile stiffness, strength, fatigue strength, creep elongation) of radiopaque UHMWPE sublaminar cables are extensively evaluated and compared to a radiolucent analog cable, a titanium sublaminar wire, and literature data available for other sublaminar cable or wire systems. Furthermore, radiopacity was evaluated, radiopacifier leaching was assessed in vitro using different extraction liquids, and in vivo bismuth organ content was quantified after a 24 week implantation period in sheep. In the supplement to Chapter 3, a preliminary observational wear characterization was performed after a dynamic tensile loading regime was applied to a radiopaque UHMWPE cable wrapped around a stainless steel compression plate as a model for the application of the UHMWPE cable as a cerclage cable for fracture fixation or revision total hip arthroplasty.

To assess the potential for continued spinal growth after instrumentation with UHMWPE sublaminar wires

An in vivo evaluation of spinal growth after growth-guidance construct implantation in an immature sheep model is made in Chapter 4. Growth-guidance constructs consisting of standard rods, UHMWPE sublaminar wires as sliding anchors and pedicle screws to prevent rod migration were surgically placed in immature sheep. Serial spinal radiographs were acquired for operated animals and for a group of unoperated animals at regular intervals in order to assess and compare spinal growth. After sacrifice at 24 weeks postoperatively, high resolution peripheral computed tomography (HR-pQCT) scans were made of the excised spines in order to assess the extent of heterotopic bone formation. In a supplement to Chapter 4, the coefficient of friction between various sublaminar wires and various metal spinal rods in longitudinal sliding is quantified. A comparison between a woven radiopaque UHMWPE sublaminar wire and a twisted titanium cable, and between titanium, stainless steel, and cobalt chromium spinal rods is made.

To determine the minimum number of required consecutive construct end levels to be instrumented with UHMWPE sublaminar wires in order to provide adequate correction and fixation of the spinal column while minimizing surgical exposure for EOS patients

Sublaminar wire passage requires some degree of periosteal stripping as the flaval ligament requires sectioning for wire placement, and may lead to ectopic bone formation with subsequent possible growth impediment. In order to preserve as much growth as possible in EOS patients, it is obvious that subperiosteal exposure must be kept to a minimum and thus that non-segmental sublaminar wire constructs would be preferential over segmental constructs. However, sufficient levels should be instrumented in order to provide adequate spinal stabilization and deformity correction. Therefore an optimal balance is sought in Chapter 5, where an in vitro biomechanical comparison of segmental versus different non-segmental UHMWPE 
sublaminar wire growth-guidance type constructs in extracted porcine thoracic spine segments is performed.

To implement realistic biomechanical behavior of the proposed growth-guidance system in a parametric (patient-specific) finite element (FE) model of the spine

A parametric finite element model of the spine was previously developed with the objective of providing a patient-specific assessment of surgical outcome (curve correction) in mind. This preoperative planning tool could potentially aid the surgeon in selecting the optimal combination of construct components, again considering the balance between surgical exposure minimization and providing adequate stability. However, the previous work did not approximate the typical nonlinear behavior of a spinal motion segment. In Chapter 6, the behavior of the L4-L5 motion segment is first optimized through a stepwise build-up of a spinal segment (successive addition of spinal structures) with an iterative adaptation of mechanical properties at each step. A previously reported in vitro study [32], in which a successive stepwise reduction in functional spinal structures was performed, will be used as a reference data for the FE model calibration procedure. Whole spine behavior is subsequently verified by comparing attained ROM values to known literature values. Next, the proposed growthguidance construct, consisting of spinal rods, pedicle screws, and UHMWPE sublaminar wires, is implemented into the model. The in vitro biomechanical comparison of segmental versus different non-segmental UHMWPE sublaminar wire growth-guidance type constructs performed in Chapter 5 is replicated in silico, in order to validate growth-guidance construct component variations.

To develop a large animal model for early onset scoliosis in order to be able to test all aspects of the proposed growth-guidance construct

In Chapter 7, a literature review of large animal models used for preclinical testing of fusionless scoliosis correction devices is provided and recent advances in the creation of an idiopathic-like scoliosis large animal model are described. The development of a porcine experimental scoliosis model intended to be representative of early onset scoliosis is described in Chapter 8. A posterior technique with a stand-alone spinal tether is attempted.

A general discussion with in-depth discussion concerning the clinical relevance and a prospective comparison to emerging techniques is provided in Chapter 9. Recommendations for further research and an outlook towards clinical introduction are also provided. 


\section{REFERENCES}

[1] Weinstein SL. Natural History. Spine (Phila Pa 1976). 1999;24:2592-600.

[2] Williams BA, Matsumoto H, McCalla DJ, Akbarnia BA, Blakemore LC, Betz RR, et al. Development and Initial Validation of the Classification of Early-Onset Scoliosis (C-Eos). J Bone Joint Surg Am. 2014;96:1359-67.

[3] Skaggs DL, Akbarnia BA, Flynn JM, Myung KS, Sponseller PD, Vitale MG, et al. A Classification of Growth Friendly Spine Implants. J Pediatr Orthop. 2014;34:260-74.

[4] Figueiredo UM, James JI. Juvenile Idiopathic Scoliosis. J Bone Joint Surg Br. 1981;63-B:61-6.

[5] Dimeglio A, Canavese F. The Growing Spine: How Spinal Deformities Influence Normal Spine and Thoracic Cage Growth. European spine journal : official publication of the European Spine Society, the European Spinal Deformity Society, and the European Section of the Cervical Spine Research Society. 2012;21:64-70.

[6] Campbell RM, Jr., Smith MD, Mayes TC, Mangos JA, Willey-Courand DB, Kose N, et al. The Characteristics of Thoracic Insufficiency Syndrome Associated with Fused Ribs and Congenital Scoliosis. J Bone Joint Surg Am. 2003;85-A:399-408.

[7] Dubousset J, Herring JA, Shufflebarger H. The Crankshaft Phenomenon. Journal of pediatric orthopedics. 1989;9:541-50.

[8] Akbarnia BA, Breakwell LM, Marks DS, McCarthy RE, Thompson AG, Canale SK, et al. Dual Growing Rod Technique Followed for Three to Eleven Years until Final Fusion: The Effect of Frequency of Lengthening. Spine (Phila Pa 1976). 2008;33:984-90.

[9] Rolton D, Richards J, Nnadi C. Magnetic Controlled Growth Rods Versus Conventional Growing Rod Systems in the Treatment of Early Onset Scoliosis: A Cost Comparison. Eur Spine J. 2015;24:1457-61.

[10] Jenks M, Craig J, Higgins J, Willits I, Barata T, Wood H, et al. The Magec System for Spinal Lengthening in Children with Scoliosis: A Nice Medical Technology Guidance. Appl Health Econ Health Policy. 2014;12:587-99.

[11] Matsumoto H, Williams BA, Corona J, Comer JS, Fisher PW, Neria Y, et al. Psychosocial Effects of Repetitive Surgeries in Children with Early-Onset Scoliosis: Are We Putting Them at Risk? J Pediatr Orthop. 2014;34:172-8.

[12] Suliman S, Mkabile SG, Fincham DS, Ahmed R, Stein DJ, Seedat S. Cumulative Effect of Multiple Trauma on Symptoms of Posttraumatic Stress Disorder, Anxiety, and Depression in Adolescents. Compr Psychiatry. 2009;50:121-7.

[13] Cheung JP, Samartzis D, Cheung KM. A Novel Approach to Gradual Correction of Severe Spinal Deformity in a Pediatric Patient Using the Magnetically-Controlled Growing Rod. Spine J. 2014;14:e7-13.

[14] Cheung KM, Cheung JP, Samartzis D, Mak KC, Wong YW, Cheung WY, et al. Magnetically Controlled Growing Rods for Severe Spinal Curvature in Young Children: A Prospective Case Series. Lancet. 2012;379:1967-74.

[15] Dannawi Z, Altaf F, Harshavardhana NS, El Sebaie H, Noordeen H. Early Results of a Remotely-Operated Magnetic Growth Rod in Early-Onset Scoliosis. Bone Joint J. 2013;95-B:75-80.

[16] Teoh KH, Winson DM, James SH, Jones A, Howes J, Davies PR, et al. Do Magnetic Growing Rods Have Lower Complication Rates Compared with Conventional Growing Rods? Spine J. 2016;16:S40-4. 
[17] Akbarnia BA, Emans JB. Complications of Growth-Sparing Surgery in Early Onset Scoliosis. Spine (Phila Pa 1976). 2010;35:2193-204.

[18] Akbarnia BA, Marks DS, Boachie-Adjei O, Thompson AG, Asher MA. Dual Growing Rod Technique for the Treatment of Progressive Early-Onset Scoliosis: A Multicenter Study. Spine (Phila Pa 1976). 2005;30:S4657.

[19] Luque ER. Paralytic Scoliosis in Growing Children. Clin Orthop Relat Res. 1982:202-9.

[20] Luque ER. Segmental Spinal Instrumentation for Correction of Scoliosis. Clin Orthop Relat Res. 1982:1928.

[21] McCarthy RE, Luhmann S, Lenke L, McCullough FL. The Shilla Growth Guidance Technique for EarlyOnset Spinal Deformities at 2-Year Follow-Up: A Preliminary Report. J Pediatr Orthop. 2014;34:1-7.

[22] McCarthy RE, McCullough FL. Shilla Growth Guidance for Early-Onset Scoliosis: Results after a Minimum of Five Years of Follow-Up. J Bone Joint Surg Am. 2015;97:1578-84.

[23] Mardjetko SM, Hammerberg KW, Lubicky JP, Fister JS. The Luque Trolley Revisited. Review of Nine Cases Requiring Revision. Spine (Phila Pa 1976). 1992;17:582-9.

[24] Pratt RK, Webb JK, Burwell RG, Cummings SL. Luque Trolley and Convex Epiphysiodesis in the Management of Infantile and Juvenile Idiopathic Scoliosis. Spine (Phila Pa 1976). 1999;24:1538-47.

[25] Lukina E, Kollerov M, Meswania J, Wertheim D, Mason P, Wagstaff P, et al. Analysis of Retrieved Growth Guidance Sliding Lsz-4d Devices for Early Onset Scoliosis and Investigation of the Use of Nitinol Rods for This System. Spine (Phila Pa 1976). 2015;40:17-24.

[26] Lukina E, Laka A, Kollerov M, Sampiev M, Mason P, Wagstaff P, et al. Metal Concentrations in the Blood and Tissues after Implantation of Titanium Growth Guidance Sliding Instrumentation. Spine J. 2016;16:380-8.

[27] McCarthy RE, Sucato D, Turner JL, Zhang H, Henson MA, McCarthy K. Shilla Growing Rods in a Caprine Animal Model: A Pilot Study. Clin Orthop Relat Res. 2010;468:705-10.

[28] Gazzeri R, Faiola A, Galarza M, Tamorri M. Universal Clamp System in Thoracolumbar Spinal Fixation: Technical Note. Acta Neurochir (Wien). 2009;151:1673-80.

[29] Mazda K, Ilharreborde B, Even J, Lefevre Y, Fitoussi F, Pennecot GF. Efficacy and Safety of Posteromedial Translation for Correction of Thoracic Curves in Adolescent Idiopathic Scoliosis Using a New Connection to the Spine: The Universal Clamp. Eur Spine J. 2009;18:158-69.

[30] Takahata M, Ito M, Abumi K, Kotani Y, Sudo H, Ohshima S, et al. Comparison of Novel Ultra-High Molecular Weight Polyethylene Tape Versus Conventional Metal Wire for Sublaminar Segmental Fixation in the Treatment of Adolescent Idiopathic Scoliosis. J Spinal Disord Tech. 2007;20:449-55.

[31] Grobler LJ, Gaines RW, Kempff PG. Comparing Mersilene* Tape and Stainless Steel Wire as Sublaminar Spinal Fixation in the Chagma Baboon (Papio Ursinus). Iowa Orthop J. 1997;17:20-31.

[32] Heuer F, Schmidt H, Klezl Z, Claes L, Wilke HJ. Stepwise Reduction of Functional Spinal Structures Increase Range of Motion and Change Lordosis Angle. J Biomech. 2007;40:271-80 
Chapter 1

1 
Chapter 2

2 


\section{SPINAL ANATOMY}

\section{Basic definitions}

Three orthogonal planes are defined as a reference frame for the human body; the coronal or frontal plane is a vertical plane that passes from left to right and divides the body into an anterior (front) and a posterior (back) section. The sagittal plane is a vertical plane that passes from anterior to posterior and divides the body into left and right halves. The transverse or axial plane is a horizontal plane that divides the body into a superior (upper) and inferior (lower) segment (Figure 1).

Relative directional references to anatomical features are also common within anatomical descriptions. In the transverse plane, lateral refers to features to the sides or away from the center of the body, while medial refers to features located towards the middle or center. In the sagittal plane, cranial refers to features located towards the head, while caudal, meaning 'tail' in Latin, refers to features located away from the head. The use of the terms cranial and caudal is restricted to the trunk. Proximal and distal are used to describe parts of a feature that are respectively close to or distant from the main mass of the body in the transverse plane.

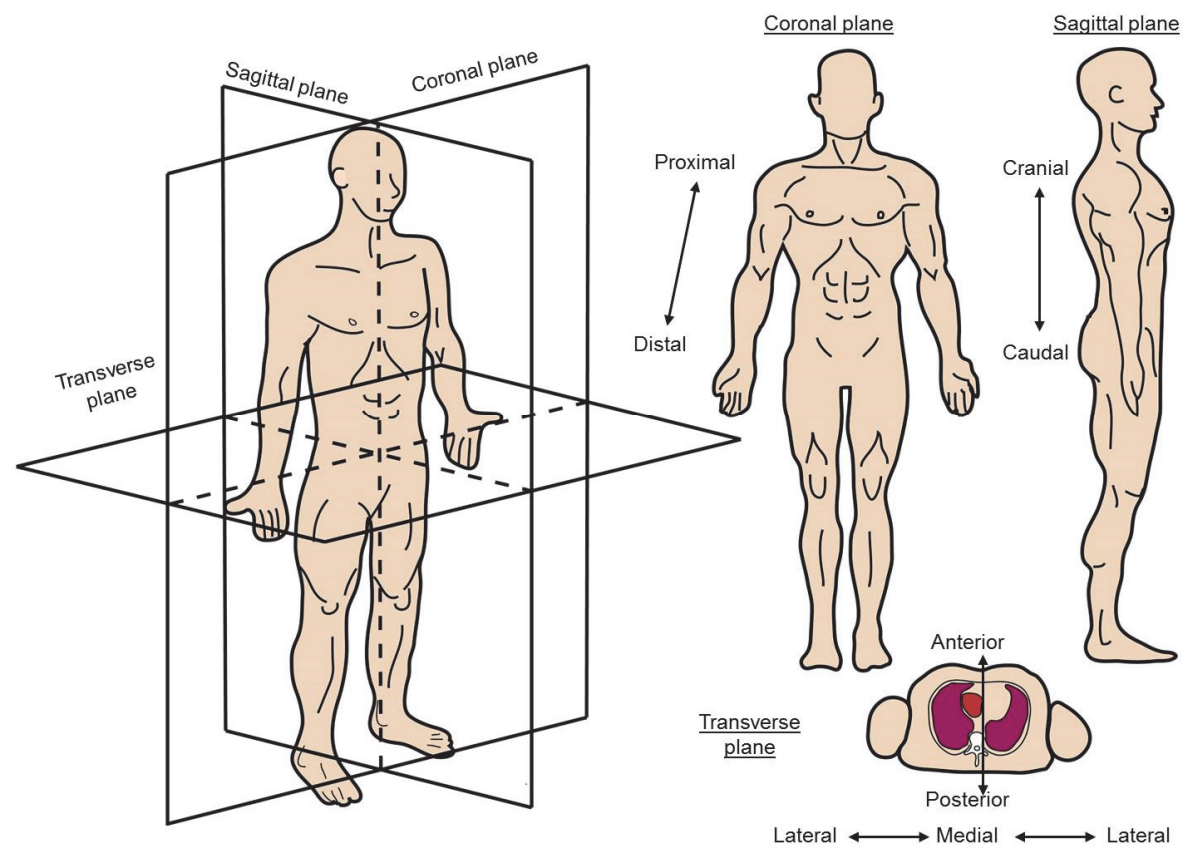

Figure 1 - Anatomical planes and directional definitions. 


\section{Spinal Column}

The human spine is a complex assembly of bony structures known as vertebrae, which are connected by soft tissues such as intervertebral discs, ligaments and muscles to provide structural stability while also allowing motion and mobility.

The sacrum and coccyx (tailbone) form the base of the spine. The sacrum consists of five vertebrae which fuse into a single bone during puberty, while the coccyx is comprised of four fused vertebrae. Above the sacrum, the spine consists of twenty-four articulating vertebrae, which are grouped into three regions: five lumbar vertebrae (L1L5) in the lower back located directly above the sacrum, the twelve thoracic vertebrae of the thorax (T1-T12) with attached ribs, and the seven cervical vertebrae of the neck (C1-C7). Intervertebral discs connect adjacent vertebrae, dissipate energy, and allow for motion. The three different regions of the spine are naturally curved in the sagittal plane (Figure 2); the sacral and thoracic spine exhibit a natural convex curvature, referred to as kyphosis, while the lumbar and cervical regions of the spine exhibit a natural concave curvature known as lordosis.

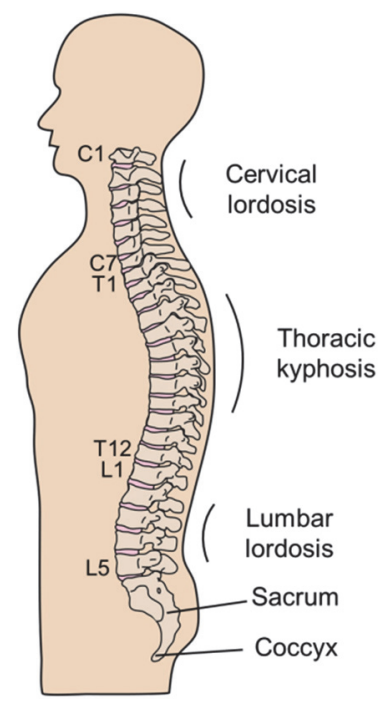

Figure 2 - Cervical, thoracic and lumbar spinal anatomy and curvature.

\section{Vertebral Anatomy}

Although the dimensions and proportions vary substantially, lumbar, thoracic, and cervical vertebrae all share the same basic anatomy (Figure 3). Vertebral bodies carry the majority of a person's body weight and consist of an inner mass of trabecular 
(cancellous) bone supported by a dense outer shell known as cortical bone. Two pedicles extend posteriorly from the vertebral body to unite the vertebral body and arch, which forms the posterior portion of a vertebra. Two broad plates known as the lamina extend from the pedicles, meeting and connecting at the midline. Two transverse processes extend outwards laterally where the pedicle meets the lamina, while a single spinous process extends outwards posteriorly from the midline at the junction of both laminae. Bilateral articular facets extend in both inferior and superior direction from the junction of the pedicle and the lamina. These facet joints are the only site of direct contact between adjacent vertebrae and determine the range of motion between adjacent levels. At thoracic levels, ribs attach at the posterior ends of the vertebral body at the costovertebral joints which are located at approximately the height of the disc. The ribs extend posterolaterally and articulate with the transverse processes at the costovertebral joints. The vertebral foramina are large central openings running in cranial-caudal direction posterior to the vertebral body that accommodates the spinal canal and hosts the spinal cord. At each level, nerve roots exit the spinal cord through lateral horizontal openings known as the neuroforamina.

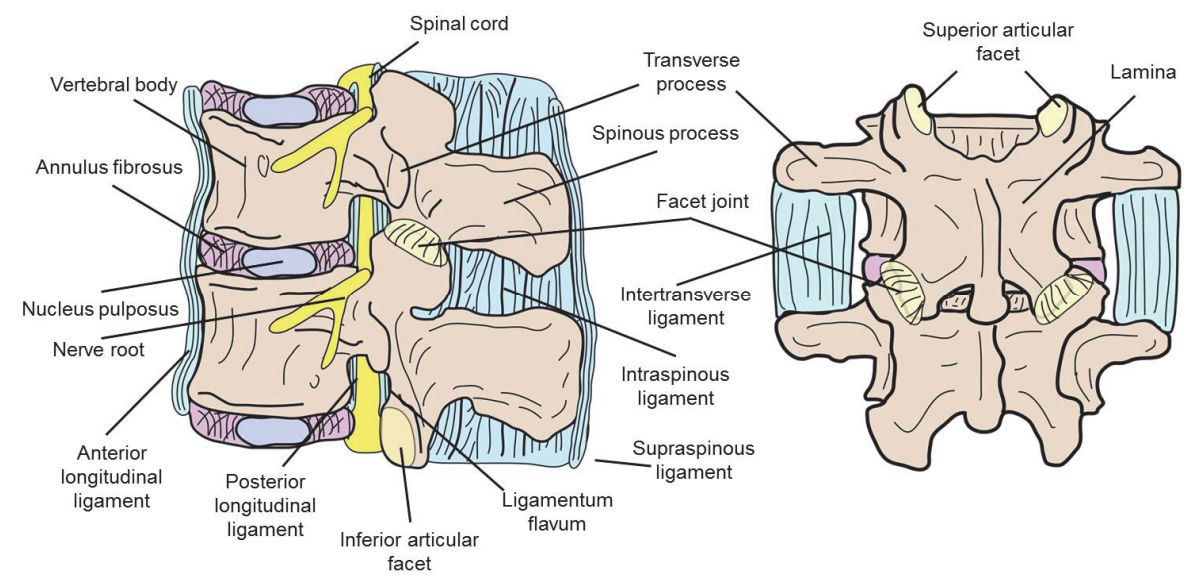

Figure 3 - Anatomy of a lumbar motion segment including vertebral bodies, intervertebral discs, ligaments, facet joints, and the spinal cord.

Intervertebral discs consist of inner gel-like core known as the nucleus which is surrounded by a layered fibrocartilage structure known as the annulus fibrosus. The intervertebral discs allow for motion and dissipate energy during axial compression. Vertebral endplates form the boundaries between vertebral bodies and the intervertebral discs and are comprised of both an osseous and a cartilaginous component. The semi-permeable endplates allow for nutrient transport into the innervated intervertebral discs. 
Ligaments, highly oriented strands of fibrous connective tissue, connect and stabilize the spinal column. Three main ligaments run down the full length of the spine: the anterior longitudinal ligament, the posterior longitudinal ligament, and the supraspinal ligament. The flaval ligament connects the laminae at adjacent levels, while the interspinous and intertransverse ligaments connect adjacent spinous and transverse processes respectively. Capsular ligaments surround and stabilize the facet joints, while the ribs are attached to the vertebral bodies by the radiate ligament and to the transverse process of thoracic vertebrae by the costotransverse ligament.

\section{Spinal Motion}

In the sagittal plane, forward bending is referred to as flexion, while bending backwards is referred to as extension. Movement in the coronal plane is referred to as (left or right) lateral flexion. Rotation in the transverse plane is referred to as axial rotation. Application of a tensile force along the length of spine is termed traction, while compressive load is typically present due to gravity. Intervertebral discs, ligaments and facet joints produce typical nonlinear moment-rotation curves as load is distributed along these elements during in vitro motion segment testing (Figure 4). Facet joints and ligaments restrict motion differentially in the different movement directions.

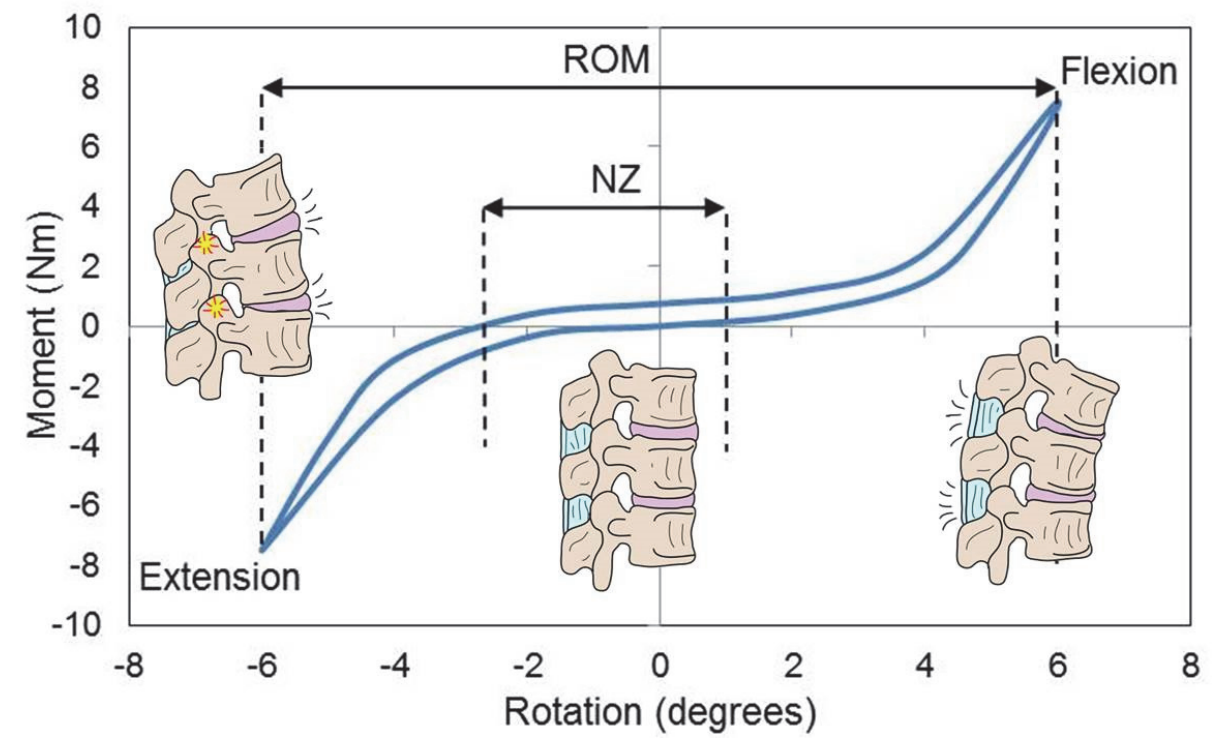

Figure 4 - Typical nonlinear response of a motion segment in flexion/extension during biomechanical tests; the range of motion (ROM) is the total range of deformation upon maximal loading while the neutral zone (NZ) is the range over which movement is possible with little resistance. 


\section{SCOLIOSIS: DEFINITIONS AND EPIDEMIOLOGY}

\section{Defining and Quantifying Scoliosis}

Scoliosis is characterized by an abnormal three-dimensional curvature of the spinal column. Spinal curvature is most commonly measured using Cobb's method [1] on anteroposterior (AP) standing full-spine radiographs. Using this method, lines are drawn along the upper end plate of the upper end vertebrae and along the lower end plate of the lower end vertebrae. The upper and lower end vertebrae are defined as the most tilted vertebrae at the superior and inferior ends of the curvature respectively. The angle between the two drawn lines is the Cobb angle (Figure 5A). A spinal deformity is referred to as scoliosis when the Cobb angle is greater than 10 degrees $\left({ }^{\circ}\right)$ [2]. Cobb's method is also routinely used to quantify the lumbar lordosis and the thoracic kyphosis angles on lateral radiographs (Figure 5B). However, only the spinal curvature angle in the coronal plane is referred to as the Cobb angle.
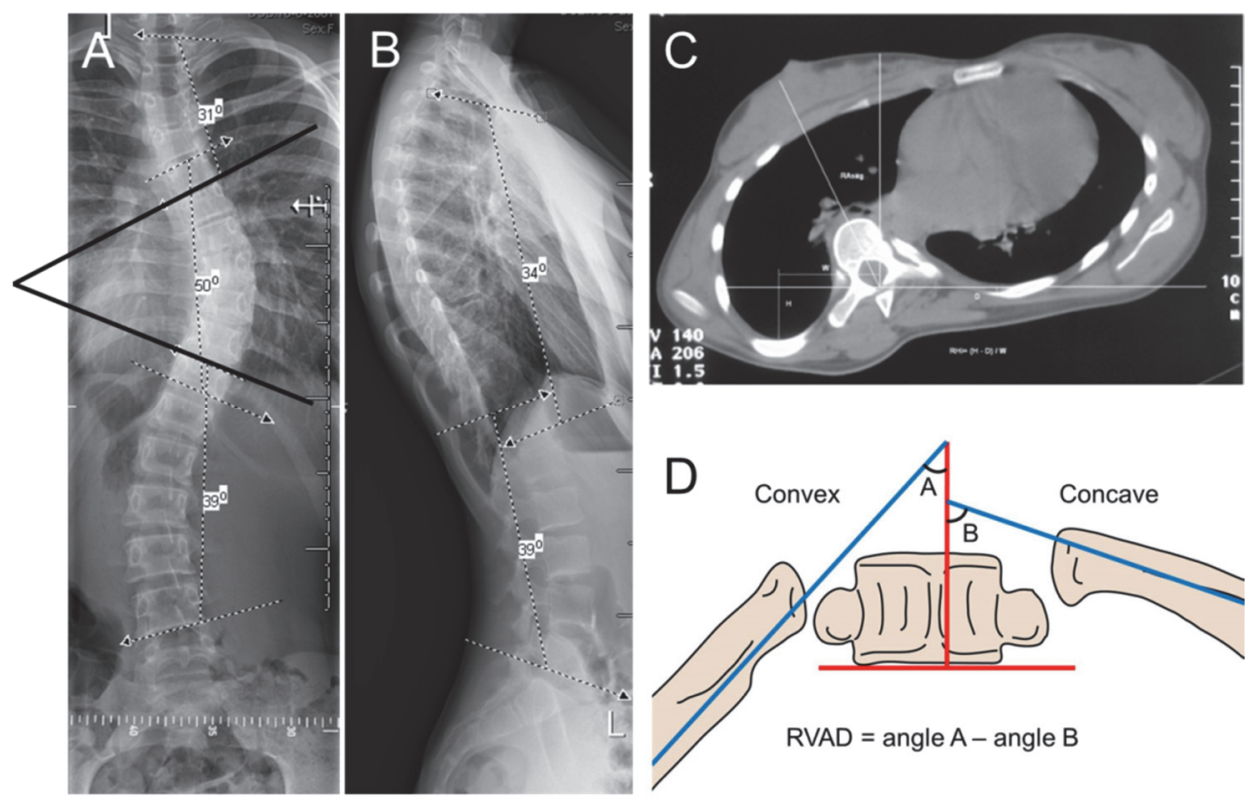

Figure 5 - (A) A radiograph of a typical thoracic idiopathic scoliosis; the Cobb angle is measured in the coronal plane. (B) A similar method can be used to quantify the sagittal spinal profile. (C) Axial rotation is most accurately quantified and illustrated using CT. CT image reprinted from Nowak et al. [3]. (D) The rib vertebral angle difference (RVAD) may be used to distinguish between progressive and resolving infantile curves. 
Scoliosis not only consists of an abnormal coronal plane spinal curvature, but also involves axial rotation of the individual vertebrae. The apical vertebra or apex is defined as the vertebra that is most deviated laterally from the vertical midline that passes through the sacrum, and is typically also the most rotated vertebra in the axial (transverse) plane. The upper- and lower neutral vertebrae are the first vertebrae which are not axially rotated above and below the curvature, and are used to describe the extent of a scoliotic curve (e.g. T5-L2).

Quantifying the extent to which the apical vertebrae is rotated is most accurately performed using computed tomography (CT) images. The rotational angle of the vertebra relative to the thoracic midline can be measured directly on transverse plane CT images (Figure 5C). However, avoiding hazardous health implications associated with frequent and prolonged exposure to iodizing radiation is especially of concern in children [4], and therefore radiography based methods are preferred for juvenile or adolescent patients. Furthermore, supine positioning provides an underestimation of curve severity due to the lack of gravitational loading along the length of the spine. Radiography based measurements can provide an estimate for the axial rotation based on the displacement of the pedicle on the convex side of the curvature relative to the width of the vertebral body evaluated on AP radiographs [5].

The rib vertebral angle difference (RVAD) may be used as a predictive distinction measure between progressive and spontaneously resolving curves for very young patients [6]. To measure the rib vertebral angle, a line is first drawn perpendicular through the inferior endplate of the apical vertebra. Next a line is drawn through the mid-point of the head of the rib and through the mid-point of the neck of the rib. The angle between these two lines is defined as the rib vertebral angle, and the RVAD is the difference between the angles on the concave and convex sides.

\section{Classifying Scoliosis}

Scoliosis is commonly classified according to its etiology. The majority of scoliosis cases (approximately 80\%) are classified as idiopathic, which is defined as scoliosis with unknown underlying anomaly or musculoskeletal condition. Genetic factors plays a crucial role in the pathogenesis of idiopathic scoliosis; $30-40 \%$ of all patients show a positive familial history of idiopathic scoliosis [7], while significantly higher concordance rates have been observed in identical twins as compared to non-identical twins [8]. Idiopathic scoliosis is a complex polygenic disorder, with over 300 single nucleotide polymorphisms having been identified in relation to the progression of idiopathic scoliosis [9].

Congenital scoliosis refers to spinal deformities which are the result of vertebral anomalies present at birth; such anomalies may be a result of either the failure of 
vertebrae to form completely ('hemi-vertebrae', Figure 6) or the failure of vertebrae to segment ('block vertebrae') during development. Congenital scoliosis typically presents before the age of three, and no genetic predisposition has been found.

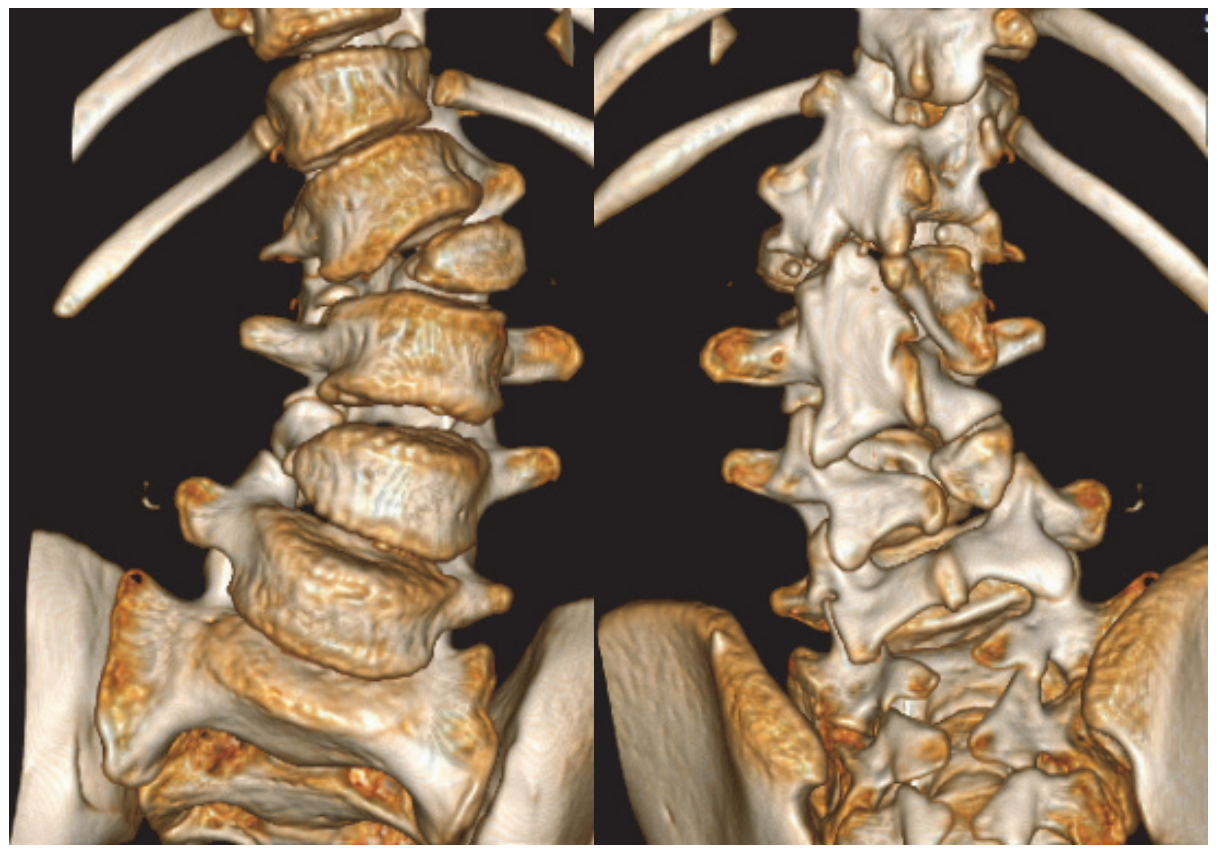

Figure 6 - 3D reconstruction of a CT scan showing a hemi-vertebra as a cause for congenital scoliosis.

Neuromuscular scoliosis arises as a result of neuropathic (nervous system related) or myopathic (muscular system related) conditions. In case the scoliotic deformity is associated with a specific syndrome, scoliosis may also be referred to as syndromic scoliosis. Examples of typical syndromes which are associated with syndromic scoliosis are Rett syndrome, Ehlers-Danlos syndrome, Pratt-Willi syndrome, Marfan syndrome, Down syndrome, and neurofibromatosis. Scoliosis may also be a result of degenerative conditions, trauma, tuberculosis, or tumor formation.

Scoliosis can also be classified according to the age of onset: early onset scoliosis is defined as scoliosis of any etiology developing before the age of 10 [10, 11]. Late onset scoliosis is then defined as scoliosis of any etiology developing after the age of 10 . The age of 5 years may also be encountered as a threshold in the definition of early onset scoliosis [12]. The respiratory system undergoes crucial development until the age of five [13], and scoliosis present before this age thus exhibits unique characteristics and requires specialized attention [14]. However, consensus has recently been reached within the Scoliosis Research Society (SRS): 10 years of age is the accepted threshold for the definition of early onset scoliosis [15]. 
A division between infantile (0-3 years of age), juvenile (4-9 years of age), and adolescent (age 10 to maturity) scoliosis, which relate to periods of rapid, quiescent, and rapid spine growth respectively [16], is also commonly encountered. The term adult scoliosis, denoting onset after the age of 18 , may also be used to describe degenerative scoliosis.

\section{Epidemiology}

Adolescent idiopathic scoliosis (AIS) is by far the most common type of scoliosis, accounting for approximately $85 \%$ of all cases, and occurs in $2-3 \%$ of the population [17]. AIS predominately affects females, with an approximate female-male prevalence ratio of 3:1, which further increases with age and for curves with higher Cobb angles [17]. AIS curves are typically right-convex thoracic curves. Ultimately, less than $0.1 \%$ of the population acquires curves with a magnitude of more than 40 degrees (Table 1) [17].

\begin{tabular}{|c|c|c|}
\hline Cobb angle & Female-to-Male Ratio & Prevalence (\%) \\
\hline$>10^{\circ}$ & $1.4-2: 1$ & $2-3 \%$ \\
\hline$>20^{\circ}$ & $5.4: 1$ & $0.3-0.5 \%$ \\
\hline$>30^{\circ}$ & $10: 1$ & $0.1-0.3 \%$ \\
\hline$>40^{\circ}$ & - & $<0.1 \%$ \\
\hline
\end{tabular}

Table 1 - Prevalence and sex-ratio of scoliosis for different curve magnitudes.

Infantile idiopathic scoliosis accounts for less than $1 \%$ of all idiopathic scoliosis cases [18]. In contrast to AIS, infantile idiopathic scoliosis occurs more often in males, with a 3:2 male-female ratio [18]. Furthermore, curves are typically left-convex. $90 \%$ of all IIS curves resolve spontaneously [6]. A rib vertebral angle difference (RVAD) of more than 20 degrees is an excellent predictive measure to distinguish between progressive and resolving curves [6]. The incidence of congenital scoliosis is approximately 0.5-1 per 1000 live births $[19,20]$.

Between $12-21 \%$ of all idiopathic cases first present between the ages of 4 and 10 and are referred to as juvenile idiopathic scoliosis [21]. Scoliosis is especially worrisome in juvenile patients as 70\% of all curves are progressive and will require some kind of treatment, with reports of surgical rates as high as 56\% [22]. Curve types for juvenile idiopathic scoliosis are very similar to adolescent curve types, but intraspinal abnormalities such as syringomyelia (cyst in the spinal cord) or Arnold-Chiari malformation (in which the lower part of the brain extends into the cervical spine) occur in approximately $20 \%$ of all juvenile patients [23]. 
For neuromuscular scoliosis, incidence varies per specific affection or syndrome: $25 \%$ in cerebral palsy patients (with two affected limbs), 67\% in spinal muscle atrophy patients, $80 \%$ in Friedreich ataxia patients, $90 \%$ in Duchenne muscular dystrophy patients, and $100 \%$ in patients with Myelodysplasia at thoracic level [24]. Down syndrome is the most common genetic disorder in humans with a prevalence of 1 in 600-800 live births and an incidence of scoliosis ranging between 9-52\% [25, 26]. Marfan syndrome (prevalence: 1 in 10,000) is one of the most common syndromes causing spinal deformities; $60 \%$ of patients present with scoliosis and $40 \%$ with kyphosis. Ultimately $25-50 \%$ of Marfan patients with spinal deformities will require surgery [27]. For Rett syndrome (1 in 10,000 prevalence), incidence of scoliosis has been reported to range between $36 \%$ and 100\% [28]. More than 50\% of Prader-Willi syndrome patients (incidence 1 in 15,000) will develop a scoliotic deformity [29], while 10-20\% of neurofibromatosis type-1 patients (incidence 1 in 4,000) will develop scoliosis [30].

While the overall incidence is low for neuromuscular or syndromic scoliosis, the age of onset is typically much lower and a substantially higher percentage of patients will ultimately require surgery. Furthermore, surgery is associated with a substantial higher rate of both intraoperative and postoperative complications [31], such as dural tears or leaks, neurological deficits, pulmonary problems, increased bleeding during surgery, poor wound healing, and infections.

\section{SCOLIOSIS TREATMENT}

The long-term effects of untreated adolescent idiopathic scoliosis are generally limited to back pain and cosmesis related issues. Although scoliosis patients likely experience more frequent back pain than the general population, it does not seem to cause excessive disability. In terms of body satisfaction and self-image, untreated scoliosis patients score lower than the general population [32]. For AIS, spinal curves of 20 degrees or less are considered mild and are routinely observed and reevaluated at six to twelve month intervals until skeletal maturity. Curves that progress beyond 20-25 degrees require treatment; at first non-surgical treatment will be attempted. The objective of conservative treatment in growing patients is to limit spinal deformity progression and ideally to ultimately avoid surgical treatment. If curves continue to progress beyond 50 degrees, surgical treatment is required as deformity progression is likely to continue throughout adulthood.

In contrast to adolescent idiopathic scoliosis, the natural course of untreated early onset scoliosis shows devastating increases in mortality rates, with a direct correlation to age of onset [33]. In this study by Pehrsson et al., mortality was most increased in infantile scoliosis patients followed by juvenile scoliosis patients, while adolescent scoliosis patients did not show increased mortality. In the studied group, $40 \%$ of the 
deaths were caused by respiratory failure. $90 \%$ of these patients had been diagnosed with scoliosis before the age of 9. Postmortem findings in four patients who died of cardiopulmonary failure between the ages of 8-18 showed very small lungs with marked decreases in the number of alveoli, and an underdeveloped right ventricle [34]. The study by Pehrsson et al. emphasizes the importance of timely treatment for early onset scoliosis patients.

\section{Non-surgical treatment}

For adolescent idiopathic scoliosis patients, conservative treatment generally consists of exercise therapy and/or orthotic brace treatment (Figure 7). The highest level of evidence for the efficacy of bracing versus observation as a means to prevent curve progression to 50 degrees or more was provided in 2013 in the Bracing in Adolescent Idiopathic Scoliosis Trial (BRAIST) [35]. The duration of daily brace wear (in hours) was positively associated with the rate of success (prevention of curve progression beyond 50 degrees); wearing a brace for an average of at least 12.9 hours was associated with a success rate of $90-93 \%$. The rate of treatment failure was $58 \%$ in the observation group.
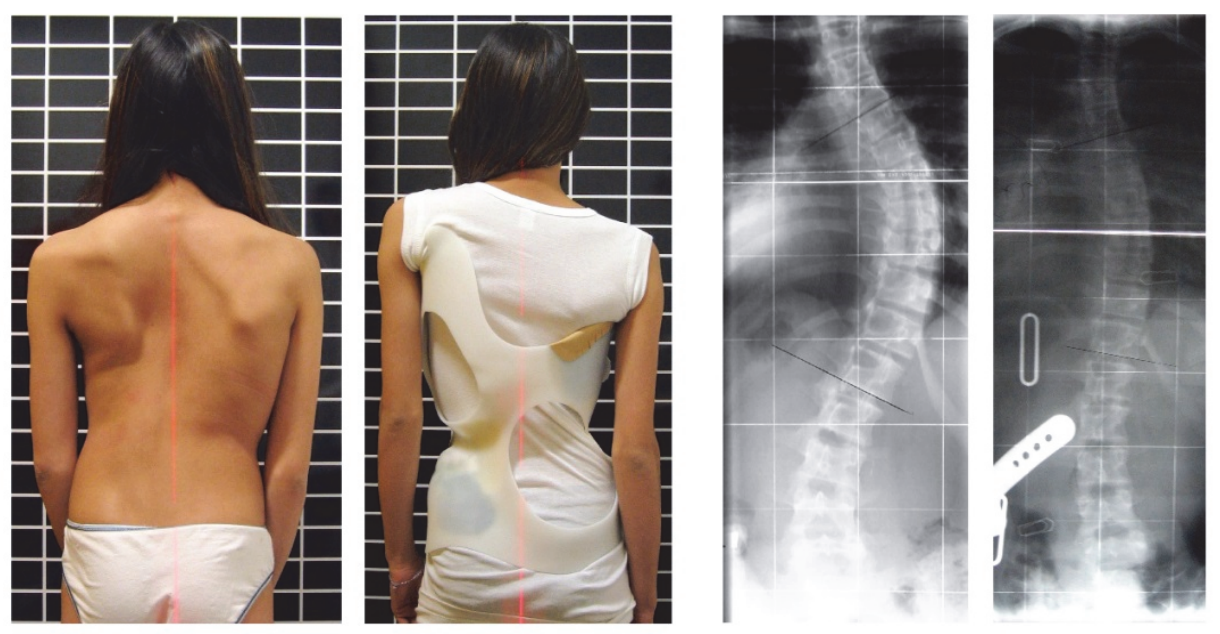

Figure 7 - Photographs and radiographs before and after applying a brace. Orthotic bracing does not lead to permanent correction, but may prevent curve progression beyond a surgical threshold in adolescent patients. Image reprinted from Weiss [36].

For early-onset scoliosis patients, bracing tends to be ineffective in approximately 50\% of patients [37]. For this reason, so-called derotational casting is generally performed for patients with documented progression (more than 10-20 degrees or progression past 25 degrees) but low magnitude curves (<60 degrees) or patients with anticipated 
progression (RVAB $>20$ degrees). Derotational casting (Figure 8 ) is performed according to a protocol described by Mehta [38]. Patients are intubated and anesthetized. Traction is applied through the neck and the pelvis using a specially designed table which allows $360^{\circ}$ access to the trunk. Spinal derotation is attained by applying an anterior force to the ribs on the convex side, and a posterior force to the ribs on the concave side of the deformity. Windows are cut out in the front and back of the cast for comfort and to allow for breathing. Casts are routinely changed at 2-4 month intervals to accommodate growth and to maximize derotational forces.
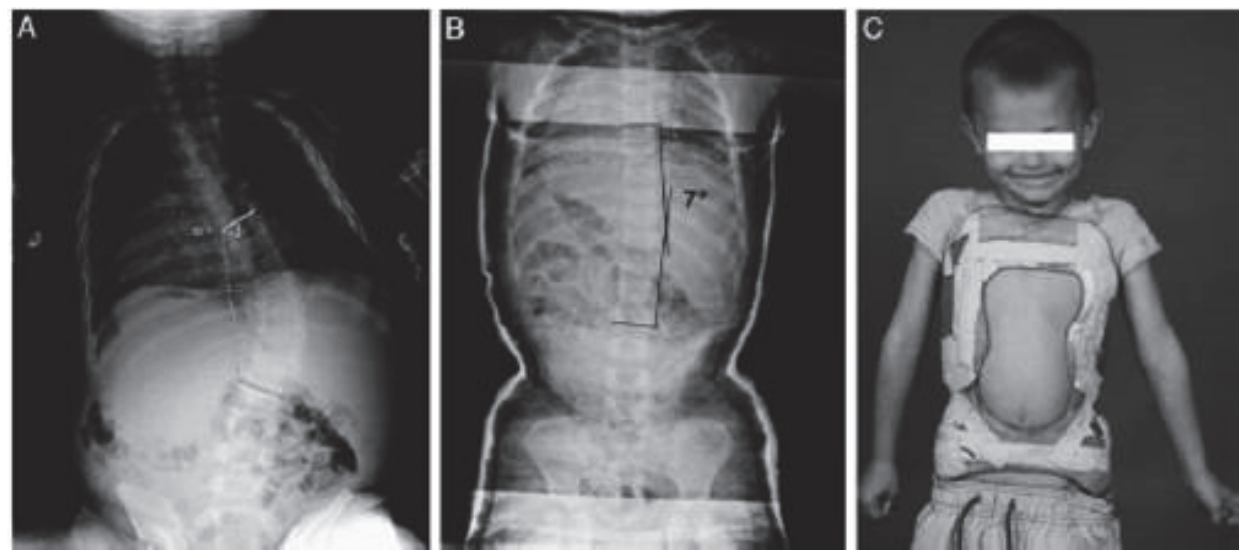

Figure 8 - Radiographs of a 3 year old boy with a scoliosis measuring more than $50^{\circ}$ before and after applying a cast. Windows are typically cut out in the front and back for comfort. Image reprinted with permission from Tis et al. [39].

\section{Surgical Treatment: Spinal fusion}

Traditionally, the goal of surgical treatment of scoliosis has been attaining maximum correction as feasible along with a solid spinal fusion to prevent further curve progression. During a spinal fusion procedure, a series of adjacent vertebrae is stimulated to fuse together so that relative motion becomes inconceivable. At first this was done using only bone grafts, requiring long term bedrest and external mobilization in order to attain a solid fusion. Russell Hibbs pioneered fusion surgery for spinal deformities between 1911 and 1919 [40], dissecting subperiosteally, excising facet joints, using bone graft, and closing periosteum over the fusion area as is still done today. In 1955, Paul Harrington revolutionized modern surgical scoliosis correction by changing the surgical objective from preventing curve progression towards attaining deformity correction by introducing spinal instrumentation in the form of laminar hooks and rods [41]. Initially, a single distraction rod held in place by hooks at both ends on the concave side was used, but Harrington quickly realized that a compression rod on the convex side was needed to stabilize the spine [42]. Eduardo Luque advanced the 
way of fixing the rods to the spine by introducing segmental spinal instrumentation in the form of segmental sublaminar wiring [43]. Segmental instrumentation improved multi-dimensional correction and eliminated the need for external immobilization following surgery. Cotrel-Dubousset instrumentation was designed to allow for spinal segments to be compressed or distracted on the same rod using hooks [44]. Although first usage was described in the 1970's [45], the widespread introduction of pedicle screws in the 90's completed the modernizing of spinal instrumentation [46]. Today, a spinal surgeons' toolbox still consists of hooks, sublaminar wires, pedicle screws and rods (Figure 9). Rod fixation may be performed using only a single anchor type, or a combination of anchor types, which is known as a hybrid construct.

Hooks are designed to grasp the lamina and can be placed supra- or infralaminarly. Supralaminar hooks are used where a compressive force is needed, while infralaminar hooks are used where a distractive force is needed. A claw is often formed by combining supralaminar and infralaminar hooks at adjacent levels to maintain grip at the end of a construct. Hooks may also be placed around the transverse process.

Sublaminar wires are passed through the spinal canal and wrap around the lamina completely. The use of sublaminar wires in segmental constructs allowed for much better sagittal plane fixation and correction in comparison to hook only constructs. The first generation sublaminar wires were monofilament wires, typically stainless steel, which were secured by twisting the ends of the wire around each other [47]. Second generation sublaminar wires consist of multi-filament (titanium) cables which are cinched using a cable crimp [48, 49]. Flat polymeric bands, which are secured to the metal rod using a metal clamp, have recently been introduced as an alternative to traditional metal sublaminar wires [50-52]. Advancements in sublaminar wire design first addressed neurological injury risks, while the introduction of flat polymeric bands also addresses failure mechanisms through both cable breakage or bone break-out.
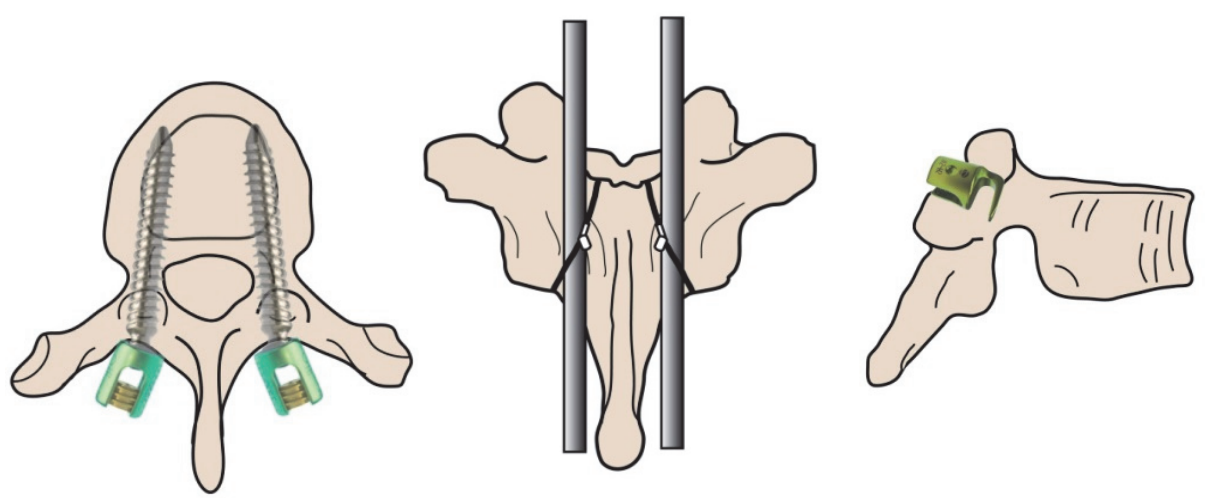

Figure 9-Spinal instrumentation: pedicle screws, laminar wires, and laminar hooks. 
Pedicle screws are currently the most common means of spinal fixation and allow for fixation of both the anterior and posterior column of the spine, thus offering superior correction. Modern day pedicle screws are generally polyaxial tulip head screws. The polyaxial head facilitates alignment of multiple levels relative to the longitudinal rod. Set screws are used to lock the moving head and rod, which are tightened to a set level using a break-off mechanism. Radiographs of an idiopathic scoliosis patient before and after surgical correction are shown in Figure 10.

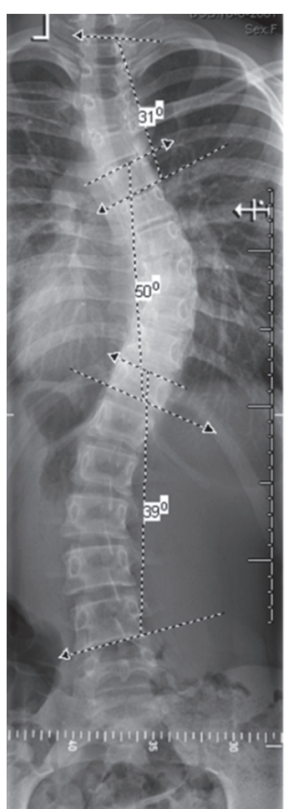

Preoperative
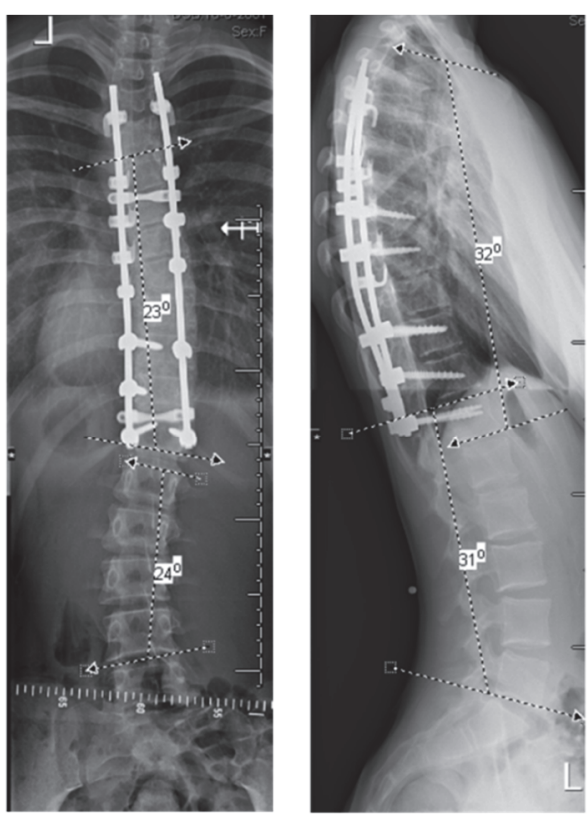

Postoperative

Figure 10 - Pre- and postoperative radiographs of an adolescent idiopathic scoliosis patient; preoperatively the curve measured $50^{\circ}$ which was corrected to $23^{\circ}$ using a posterior hybrid pedicle screw and hook construct.

Rods may vary in diameter between 3.5-6.35 millimeters ( $\mathrm{mm}$ ) and may consist of stainless steel, titanium, or cobalt chromium. The bending stiffness of a rod is proportional to the fourth power of the radius; a small increase in rod diameter thus has a large effect on rod resistance to bending. Rod composition also has an influence on rod stiffness; stainless steel has an elastic modulus of approximately $190 \mathrm{GPa}$, versus 116 GPa for titanium alloy, and $210 \mathrm{GPa}$ for $\mathrm{CoCr}$ alloys [53]. Rods are generally contoured to match the sagittal profile of the spine prior to insertion. Rod curvature may also be adjusted in situ. 
In the late 1960's, an alternative to traditional posterior instrumentation was introduced by Dwyer and colleagues [54]. Using an open anterior approach, vertebral screws and a cable were inserted on the convex side of the spine. In the 1970's, the Dwyer cable was replaced by the Zielke system, which consisted of a flexible rod and vertebral screws [55]. The introduction of the anterior video-assisted thorascopic approach in the 1990's led to a tremendous increase in the popularity of anterior scoliosis surgery [56]. The anterior thorascopic approach may require fewer number of fused vertebrae for carefully selected patients (based on curve types), and offers improved postoperative pain and cosmesis [57]. However, the posterior approach remains the preferred technique amongst spinal surgeons.

\section{Surgical Treatment: Growth-Friendly Spine Implants}

In early general conception, a short but straight spine as a result of early fusion was better than a long and crooked spine. However, early fusion for EOS patients is associated with frequent complications. Dubousset et al. [58] recognized the importance of combined anterior and posterior fusion for early onset scoliosis when they described the crankshaft phenomenon: deformity progression after posterior spinal fusion due to continued anterior growth and resulting vertebral rotation. However, reoperation rates for EOS patients treated by combined anterior and posterior fusion due to coronal decompensation and/or curve progression are still fairly high, ranging between 24-39\% [59-61]. More importantly, early definitive fusion can severely influence pulmonary function; $43 \%-64 \%$ of EOS patients who have undergone early fusion suffer from restrictive pulmonary disease [62], which is defined by a forced vital capacity of less than $50 \%$ of age-matched controls. Low pulmonary function has also been shown to correlate to low quality of life [63].

The risk of deformity progression is highest during periods of accelerated growth. The length of the thoracolumbar spine (T1-S1) increases by approximately 2.2 centimeters $(\mathrm{cm})$ per year $(\mathrm{y})$ during the first five years of life. Between the ages of six and ten years, spinal growth slows to approximately $1 \mathrm{~cm} / \mathrm{y}$. During the pubertal growth spurt, spinal growth increases again to approximately $1.8 \mathrm{~cm} / \mathrm{y}$ [13]. At birth, the thoracic cage volume is only $6 \%$ of its mature volume, increasing to $30 \%$ by the age of five, and $50 \%$ by the age of ten [13]. The number of pulmonary alveolar cells increases most dramatically during the first two years of life, with cell multiplication ending around the age of eight or nine [14]. After that period, lung growth continues through alveolar cell hypertrophy.

As early spinal fusion has detrimental cardiopulmonary effects, alternative 'growth friendly' surgical techniques have been developed. These techniques can be classified according to the forces that these implants exert on the spine: distraction based, compression based, and growth-guidance implants [11]. 


\section{Distraction based implants}

Distraction based implants correct spinal deformities by applying a distractive force on the concave side of the deformity. These implants are anchored at only the proximal and distal ends of the deformity at the vertebrae, the ribs, and/or the pelvis. The earliest growing rod system was a modified single Harrington rod which required periodical surgical lengthening [64]. Postoperatively, fulltime external bracing was required until definitive fusion surgery at spinal maturity. Furthermore, instrumentation related complications such as rod breakage or hook dislodgement frequently occurred. The use and success of growing rod systems increased tremendously with the introduction of dual rod systems, the improvement of construct anchors, and the introduction of end-to-end tandem connectors [65]. Several studies have indicated that spinal length increases achieved using growing rods is comparable to a child without scoliosis $[65,66]$.
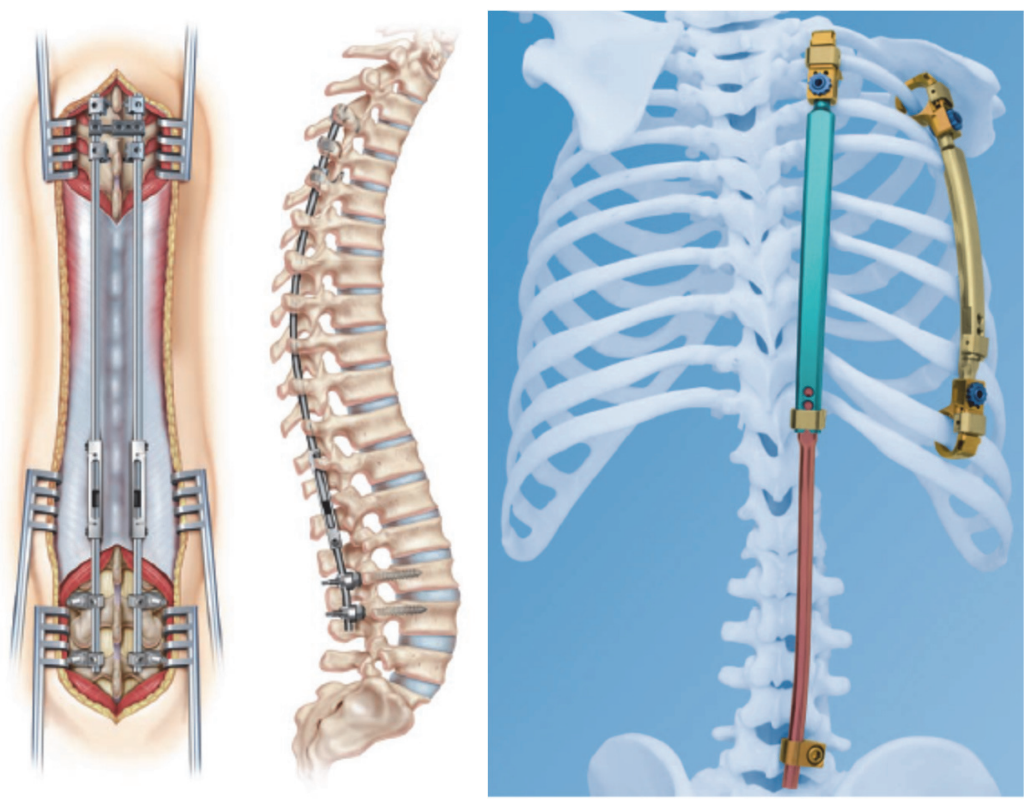

Figure 11 - Distraction based systems for early onset scoliosis correction: growing rods and the vertical expandable prosthetic titanium rib (VEPTR). Images reprinted with permission from Akbarnia et al.[12] and the VEPTR II-Surgical Guide (Synthes).

The vertical expandable prosthetic titanium rib (VEPTR) was initially developed to treat thoracic insufficiency syndrome and chest wall deformities (fused ribs) due to congenital scoliosis through expansion thoracoplasty procedures $[67,68]$. The device grasps on to two ribs, and is able to indirectly provide spinal deformity correction. More 
recently, the device has also been used to treat other spinal deformities such as idiopathic scoliosis, syndromic scoliosis, and kyphosis. A hybrid construct of growing rods in combination with the VEPTR is also often used.

However, there are a few distinct disadvantages to the use of growing rods and the VEPTR. Instrumentation breakout and rod breakage are still frequently occurring complications associated with growing rods and the VEPTR [69]. Furthermore, correction offered by distraction based is limited, with typical Cobb angle reductions of less than 50\%. For both reasons, a definitive spinal fusion procedure is typically performed upon reaching skeletal maturity [65]. Lengthening procedures have been shown to be most effective in intervals of 6 months or less [70]. A law of diminishing returns appears to hold for distraction based implants as the effect of each subsequent lengthening period decreases over time [71]. Diminishing returns are most likely due to the frequent occurrence of spontaneous spinal fusion, which has been reported to be as high as $89 \%$ [72]. Spontaneous spinal fusion likely results as a combination of instrumentation related factors (spinal immobilization), the local disturbance of spinal musculature and periosteum, and the rapid bone forming potential in immature patients [69]. Furthermore, repeated lengthening procedures have a tremendous impact on patients' lives and their psychosocial well-being [73]. Instrumentation prominence and wound related problems also still occur frequently [74].

Magnetic controlled growing rods (MCGR) have recently been introduced as a means to avoid repeated lengthening procedures [75-77]. Lengthening procedures can be performed non-invasively at the outpatient clinic using a magnetic remote control device which enables controlled distraction. Achieved correction rates is similar to traditional growing rod systems [77]; a definitive spinal fusion procedure thus is still likely to be required upon reaching skeletal maturity. The rates of deep and superficial infection are reduced with MCGR, but the rate of instrumentation related complications appears to be increased in comparison to traditional growing rods [78]. Furthermore, the initial cost price is rather high $[79,80]$, which may prove to be a limitation in many countries (especially in developing countries). MCGR are also rather bulky, which may result in instrumentation prominence or wound healing issues [75, 77]. Further research and long-term follow-up is necessary to fully assess complication rates, costeffectivity, and overall efficacy.

\section{Compression based implants}

Spinal growth modulation through compression based implants is an emerging technique as an alternative to bracing which may preserve growth for skeletally immature adolescent patients presenting with moderate, idiopathic curves. Compression based implants rely on the Hueter-Volkmann principle for spinal deformity correction; bone growth is suppressed by increased compression forces on the growth 
plate and accelerated due to tensile forces. Applying compression will halt growth on the curve convexity, allowing continued growth on the concavity to correct the deformity. Compression based anterior devices may be indicated for patients with curves between 30-60 degrees which demonstrate 50\% flexibility and show little rotation or kyphosis. However, they are not intended for EOS patients. Shape memory alloy staples and flexible anterior spinal tethers have been tested clinically with promising results $[81,82]$, but none of the devices for spinal growth modulation have been approved for human use by the FDA and thus are still investigational.

\section{Growth-guidance systems}

Growth-guidance systems provide immediate deformity correction and subsequently guide growth along a straight path through the sliding of implants along the inserted rods. The Luque trolley was the first of such systems, and typically consisted of two Lshaped rods fixed segmentally using metal sublaminar wires [43, 83]. However, deformity control was unsatisfactory and growth results were disappointing as spontaneous spinal fusion occurred frequently [84, 85]. Extensive metallosis has also been reported $[84,85]$.
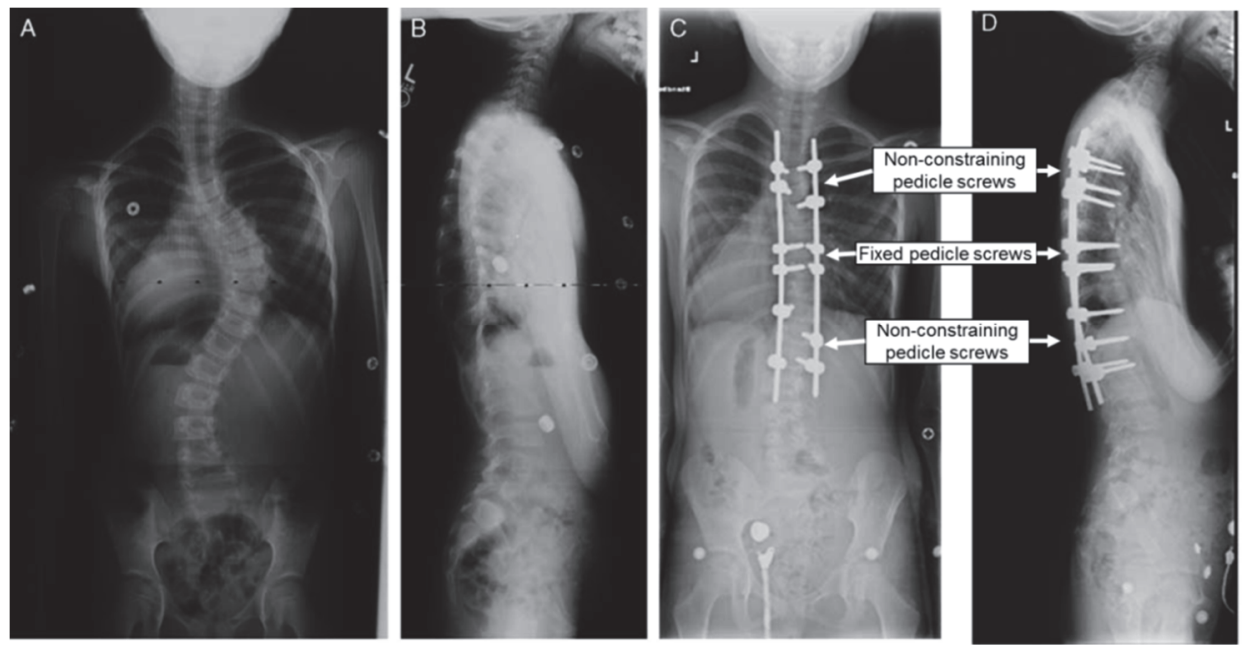

Figure 12 - Preoperative and postoperative radiographs of a 7 year old female patient with Marfan syndrome who was treated with the Shilla system. Image reprinted with permission from Luhmann et al. [95].

The Shilla ${ }^{\mathrm{TM}}$ system is a modernized growth-guidance system which utilizes flanged set screws designed to capture the rod within the pedicle screw but not completely lock the rods to allow for unconstrained longitudinal sliding [86, 87] (Figure 12 C,D). Intended fusion is performed at the curve apex in order to attain rotational correction, 
while unconstrained sliding is allowed at both the proximal and distal curve ends (Figure 13). However, the metal-on-metal articulation will inevitably lead to the generation of metallic wear particles [88]. Although the amount of wear particles generated appears to be relatively low [89], metallic wear particles are much more reactive than polyethylene wear particles [90]. The presence of metallic wear particles is worrisome as the elicited macrophage-mediated inflammatory response may lead to osteolysis and subsequent instrumentation failure through implant loosening [91]. The presence of metallosis induced sinus or seroma formation requiring revision, with concomitant high soft tissue metal ion concentrations in patients with growth-guidance type instrumentation has recently been reported [92, 93]. Furthermore, the matter of 'unconstrained' sliding is debatable, as the force produced by longitudinal growth needs to overcome considerable friction force caused by the rod-set screw contact.

Ouellet et al. [94] have recently described a modernized Luque trolley, which uses specially designed gliding anchors to connect side-by-side rods (Figure 12 A,B). Each rod is fixed using pedicle screws at either the proximal or distal curve end. Four rods are thus inserted into each patient. This system is still in the preclinical testing phase, with clinical trials expected to start soon.

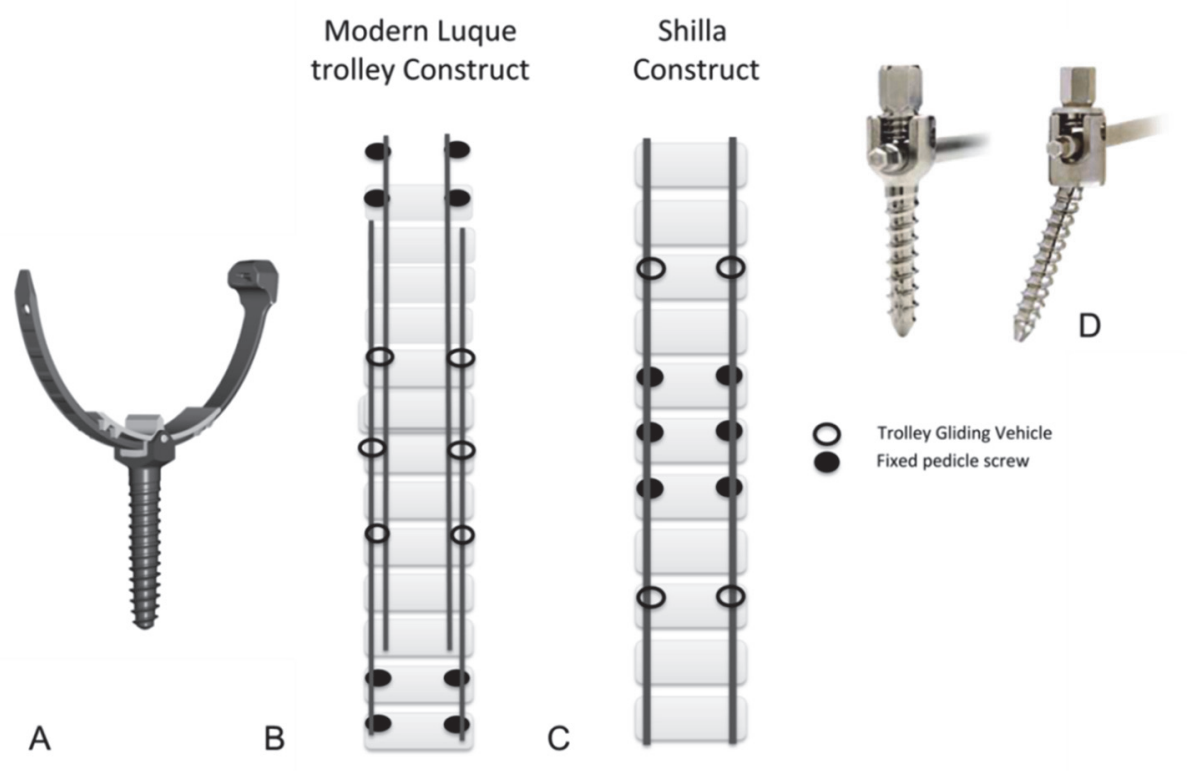

Figure 13 - (A) The trolley guiding vehicle (TGV) which is used to secure side-by-side rods as used in the (B) modern Luque trolley as described by Ouellet et al. [94] (C) In a Shilla construct, pedicle screws are used at the apex to secure rods, while non-constraining pedicle screws allow for sliding at the proximal and distal construct ends. (D) Normal versus flanged set screws used in the ShillaTM system to allow for unconstrained longitudinal sliding at the proximal and distal curve ends. Image adapted from Ouellet et al. and the Medtronic ShillaTM - Surgical Technique Guidebook. 
The LSZ-4D system is a growth-guidance system produced by Conmet (Moscow, Russia) consisting of titanium hook fixtures and titanium rectangular rods. Hook fixtures are locked at the apex, and free sliding is allowed at the proximal and distal construct ends (Figure 14).
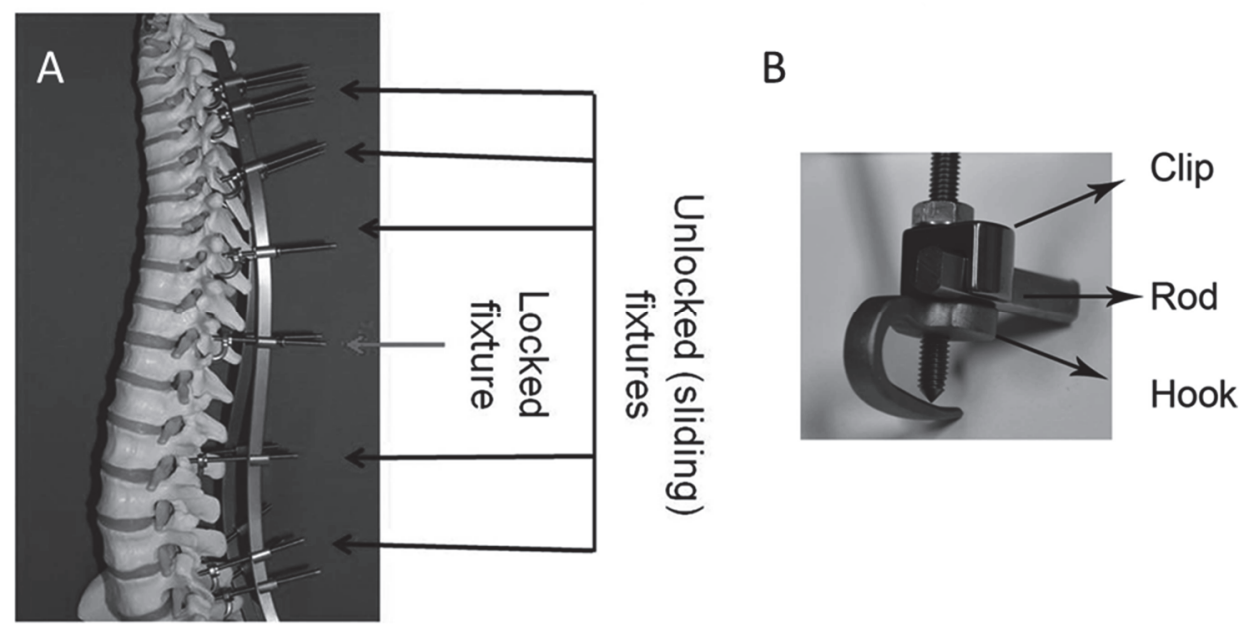

Figure 14 - Illustration of the LSZ-4D titanium growth-guidance system. Image reprinted with permission from Lukina et al. [93].

\section{PRECLINICAL ASSESSMENT OF NOVEL IMPLANTS}

Spinal implants are subjected to a wide variety of loads during daily activities in the human body. Identifying and characterizing possible modes of failure is at least as important as characterization of the modes of action and therapeutic efficacy of medical devices. Whereas in vivo animal experiments or in vitro biomechanical testing using (animal) cadaveric spine segments are commonly used methods to demonstrate potential clinical efficacy, in vitro mechanical testing is commonly employed to identify and characterize modes of failure. In silico analysis using computer models can provide valuable insight into disease processes or treatment options, but require careful validation and interpretation.

\section{In vitro mechanical testing}

The most common and simplest way to characterize mechanical properties of materials is to pull a specimen apart and measure the force and deformation. Force is measured in Newtons ( $\mathrm{N})$, and the amount of stretch in a specimen (deformation) is measured in millimeters $(\mathrm{mm})$. To account for different specimen sizes, load and deformation 
measures may be normalized to be independent of specimen size. Load is normalized by dividing the force by the original cross-sectional area in a measure termed stress $(\sigma)$, and is typically expressed in $\mathrm{N} / \mathrm{m}^{2}$ or Pascal $(\mathrm{Pa})$. Larger magnitudes may be expressed as $\mathrm{N} / \mathrm{mm}^{2}$ or mega pascal (MPa). Strain $(\varepsilon)$ is the normalized deformation and is calculated by dividing the change in length by the original length and thus expressed as a percentage. Mechanical properties are typically best illustrated using a loaddeformation or stress-strain curve (Figure 15).

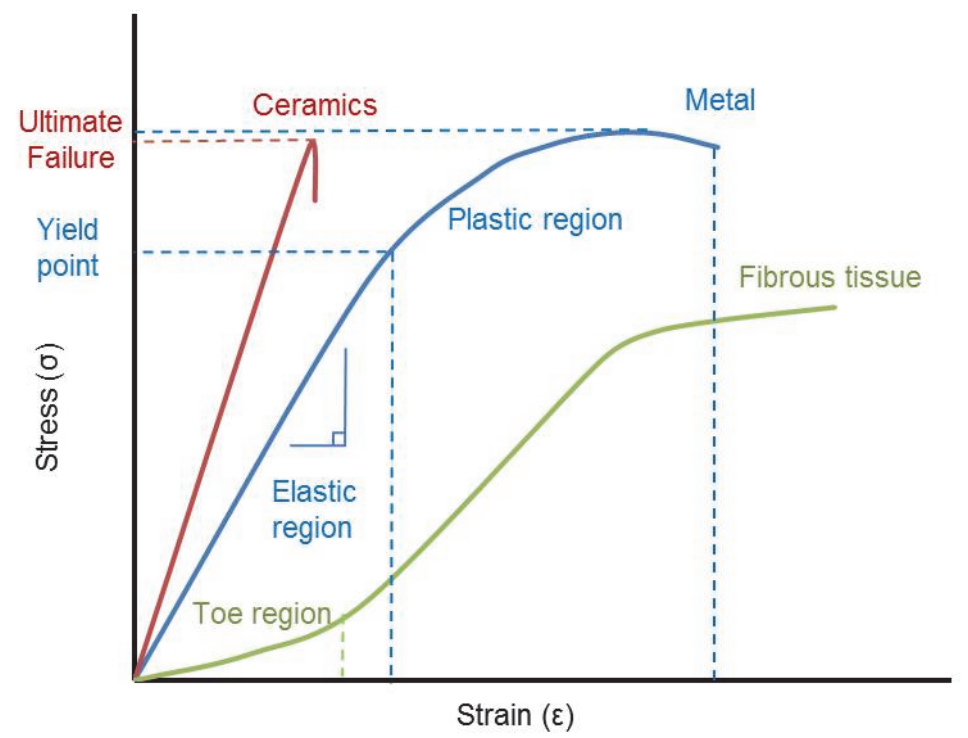

Figure 15 - Typical stress-strain or load-deformation curves for different materials; brittle materials such as ceramics fail after small deformations and a linear stress strain response. Metals show plastic deformation beyond a yield point prior to ultimate failure. Biological (fibrous) tissues typically show an initial toe region, during which all fibers align.

Different materials show different behavior on stress-strain curves. Many materials show an initial linear relation between load and displacement; the slope of the line determines the stiffness of the material which is termed the elastic or Young's Modulus (E) in normalized form. After removal of the load in the linear region of the curve, the material will return to its original dimensions; this deformation is termed elastic deformation. If a material is loaded beyond the linear region of the curve, local damage occurs and deformation becomes irreversible; the deformation beyond the elastic region is termed plastic deformation. Test specimens are typically instantaneously loaded until failure. Brittle materials will fail at a certain load without plastic deformation, while ductile materials, like polymers for example, exhibit substantial plastic deformation before failure. The load at the onset of permanent deformation is termed yield strength, while the load at complete failure is termed ultimate strength. 
The strength of a material may also be related to its hardness; a measure for the amount of indentation after application of load through a sharp object.

Orthopedic implants are subjected to multiple repeated load cycles over many years and thus multiple modes of implant failure are possible. Many repeated subcritical loads into the plastic deformation region may result into micro damage which accumulates over time. Eventually, this will lead to complete failure due to fatigue. The endurance limit of a material is termed the fatigue strength, and is defined as the load at which a specified number of cycles can be tolerated without failure. Depending on the patient group and application, the number of cycles for fatigue testing typically ranges between 1 million and 10 million [96].

Materials also show different behavior to sustained loading. Creep is the tendency of a material to slowly deform (permanently) as a result of constant stress. The same underlying phenomenon also leads to stress relaxation; the amount of stress required to maintain a certain deformation decreases slowly over time. Ultimately, creep may also lead to total failure.

Relative motion between parts can lead to mechanical damage and the release of small particles due to wear. Abrasive wear typically occurs when two different materials articulate; the harder material will plow into the softer material, causing considerable damage and creating wear particles. Third-body wear may occur when a third articulating body is introduced between two contacting surfaces. Adhesive wear may occur when irregularities on contact surfaces lead to high localized stresses causing irregularities on the two surfaces to fuse and break off. Wear may also occur due to fatigue as a result of point loading, or with large sliding distances and considerable local heat generation. The eventual formation of fatigue cracks parallel to the loading surface may lead to the flaking of particulate debris. Wear debris may stimulate a biological response; macrophages will attempt to engulf and excrete particles. However, if cells cannot clear the debris, a foreign body response with chronic inflammation and the formation of foreign body giant cells will occur.

\section{In vitro biomechanical spine testing}

In vitro biomechanical testing allows for a direct quantification of the relation between the applied bending moment and the resulting angle of rotation in (animal) cadaveric spine segments. Single or multiple motion segments can be tested, with measurements generally repeated for multiple conditions, allowing for accurate characterization of the biomechanical influence of spinal instrumentation introduction or functional spinal structure removal. Specially designed testing rigs are designed to subject spine segments to pure bending moments, meaning that each spinal levels experiences an equal bending moment. Motion capture camera systems are used to track markers 


\section{Chapter 2}

firmly attached to each spinal level in order to quantify the relative motions between adjacent spinal levels during the loading protocol.

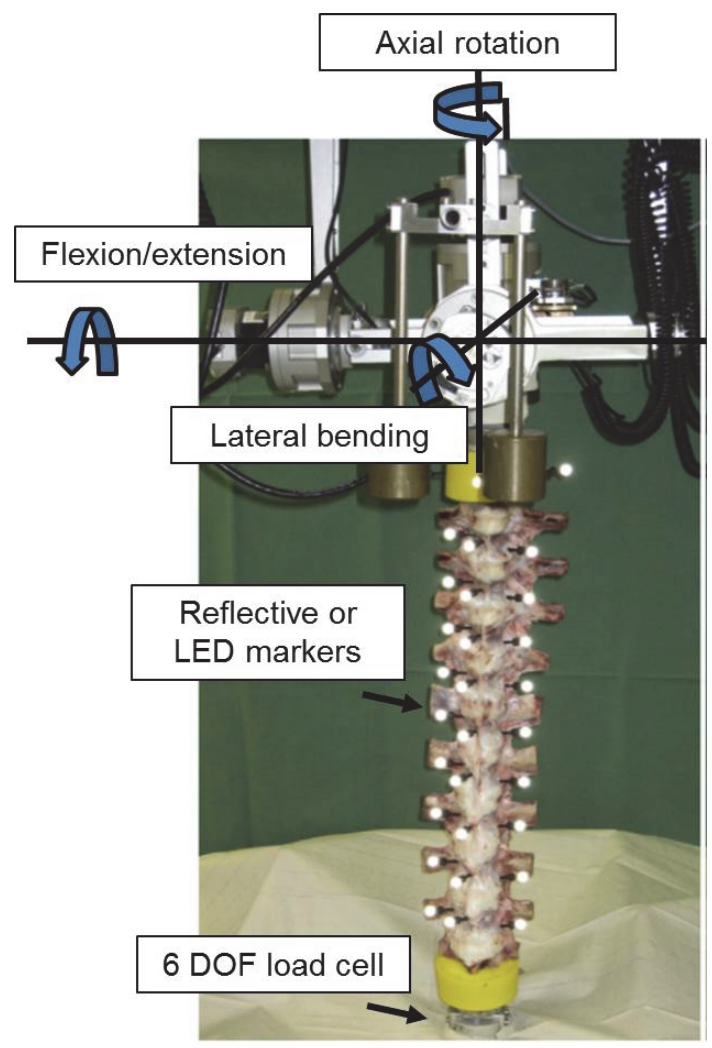

Figure 16 - Example of an in vitro spine test apparatus. A motion tracking system follows reflective or LED markers, placed on each vertebral body in order to calculate relative rotations. Pure bending moments may be applied by gimbals for example. A 6 degree of freedom (DOF) load cell verifies applied bending moments. Figure adapted from Wilke et al. [97].

\section{In vivo (animal) testing}

Despite the extensive increase in in vitro testing capabilities in the last decades, in vivo evaluation of novel spinal implants remains imperative. In vitro testing does not take the host response into account, which may range from a foreign body response to new bone formation and muscular adaptation. The objectives posed for animal trials can include proving conceptual feasibility, proving biological or mechanical safety, or demonstrating the absence of serious adverse events. The interpretation of animal studies requires careful consideration, and proper control groups should always be included in the design of animal experiments. Every animal model exhibits limitations, 
and a careful analysis of the differences between the animal model and the clinical scenario should be made. The ethics of animal testing are guided by the 3 R's as first described by Russel and Birch [98]: replacement, reduction, and refinement. Animal experiments are only approved if there are no methods which replace animal experiments, the number of animals used is reduced to a minimum, and careful attention is paid to minimize potential pain, suffering or distress and enhance welfare of the animals. Institutional and national regulatory boards carefully monitor animal experiments to ensure that performed animal experiments follow these guidelines.

\section{Finite element modeling of the spine}

Computer models can provide valuable insight into normal and pathological biomechanics of the spine, the effects of surgical spinal structure releases, and the biomechanical effects of spinal instrumentation addition, which may be unattainable otherwise. For instance, the internal stresses within pedicle screws or other spinal implants cannot be fully characterized using in vitro biomechanical tests. Finite element (FE) models convert a single very complex problem into a multitude of very simple problems by dividing the geometry of large structures into much smaller 'elements.' Finite element models require the prescription of material formulations (how does a material behave when loads are applied) for each element, and boundary conditions (is the structure free to move or rotate) for each node. Computer models always require careful validation (corroboration of experimental results), and their limitations must always be considered during the interpretation of the results. 


\section{REFERENCES}

[1] Cobb JR. Outline for the Study of Scoliosis. American Academy of Orthopedic Surgeons - Instructional Course Letters. 1948;5:261-75.

[2] Kane WJ. Scoliosis Prevalence: A Call for a Statement of Terms. Clin Orthop Relat Res. 1977:43-6.

[3] Nowak R, Szota J, Mazurek U. Vitamin D Receptor Gene (Vdr) Transcripts in Bone, Cartilage, Muscles and Blood and Microarray Analysis of Vitamin D Responsive Genes Expression in Paravertebral Muscles of Juvenile and Adolescent Idiopathic Scoliosis Patients. BMC Musculoskelet Disord. 2012;13:259.

[4] Miglioretti DL, Johnson E, Williams A, Greenlee RT, Weinmann S, Solberg LI, et al. The Use of Computed Tomography in Pediatrics and the Associated Radiation Exposure and Estimated Cancer Risk. JAMA Pediatr. 2013;167:700-7.

[5] Nash CL, Jr., Moe JH. A Study of Vertebral Rotation. J Bone Joint Surg Am. 1969;51:223-9.

[6] Mehta MH. The Rib-Vertebra Angle in the Early Diagnosis between Resolving and Progressive Infantile Scoliosis. J Bone Joint Surg Br. 1972;54:230-43.

[7] Cowell HR, Hall JN, MacEwen GD. Genetic Aspects of Idiopathic Scoliosis. A Nicholas Andry Award Essay, 1970. Clin Orthop Relat Res. 1972;86:121-31.

[8] Kesling KL, Reinker KA. Scoliosis in Twins. A Meta-Analysis of the Literature and Report of Six Cases. Spine (Phila Pa 1976). 1997;22:2009-14; discussion 15.

[9] Ogilvie JW. Update on Prognostic Genetic Testing in Adolescent Idiopathic Scoliosis (Ais). J Pediatr Orthop. 2011;31:S46-8.

[10] Williams BA, Matsumoto H, McCalla DJ, Akbarnia BA, Blakemore LC, Betz RR, et al. Development and Initial Validation of the Classification of Early-Onset Scoliosis (C-Eos). J Bone Joint Surg Am. 2014;96:1359-67.

[11] Skaggs DL, Akbarnia BA, Flynn JM, Myung KS, Sponseller PD, Vitale MG, et al. A Classification of Growth Friendly Spine Implants. J Pediatr Orthop. 2014;34:260-74.

[12] Akbarnia BA. Management Themes in Early Onset Scoliosis. J Bone Joint Surg Am. 2007;89 Suppl 1:4254.

[13] Dimeglio A, Canavese F. The Growing Spine: How Spinal Deformities Influence Normal Spine and Thoracic Cage Growth. European spine journal : official publication of the European Spine Society, the European Spinal Deformity Society, and the European Section of the Cervical Spine Research Society. 2012;21:64-70.

[14] Campbell RM, Jr., Smith MD. Thoracic Insufficiency Syndrome and Exotic Scoliosis. J Bone Joint Surg Am. 2007;89 Suppl 1:108-22.

[15] El-Hawary R, Akbarnia BA. Early Onset Scoliosis - Time for Consensus. Spine Deformity. 2015;3:105-6.

[16] James JI. Idiopathic Scoliosis; the Prognosis, Diagnosis, and Operative Indications Related to Curve Patterns and the Age at Onset. J Bone Joint Surg Br. 1954;36-B:36-49.

[17] Weinstein SL. Natural History. Spine (Phila Pa 1976). 1999;24:2592-600.

[18] Riseborough EJ, Wynne-Davies R. A Genetic Survey of Idiopathic Scoliosis in Boston, Massachusetts. J Bone Joint Surg Am. 1973;55:974-82. 
[19] Giampietro PF, Blank RD, Raggio CL, Merchant S, Jacobsen FS, Faciszewski T, et al. Congenital and Idiopathic Scoliosis: Clinical and Genetic Aspects. Clin Med Res. 2003;1:125-36.

[20] Hedequist D, Emans J. Congenital Scoliosis: A Review and Update. J Pediatr Orthop. 2007;27:106-16.

[21] Lenke LG, Dobbs MB. Management of Juvenile Idiopathic Scoliosis. J Bone Joint Surg Am. 2007;89 Suppl 1:55-63.

[22] Figueiredo UM, James JI. Juvenile Idiopathic Scoliosis. J Bone Joint Surg Br. 1981;63-B:61-6.

[23] Gupta P, Lenke LG, Bridwell KH. Incidence of Neural Axis Abnormalities in Infantile and Juvenile Patients with Spinal Deformity. Is a Magnetic Resonance Image Screening Necessary? Spine (Phila Pa 1976). 1998;23:206-10.

[24] SRS. Http://Www.Srs.Org/Patient_and_Family/Scoliosis/Neuromuscular_Scoliosis/. In: Society SR, editor.

[25] Milbrandt TA, Johnston CE, 2nd. Down Syndrome and Scoliosis: A Review of a 50-Year Experience at One Institution. Spine (Phila Pa 1976). 2005;30:2051-5.

[26] Diamond LS, Lynne D, Sigman B. Orthopedic Disorders in Patients with Down's Syndrome. Orthop Clin North Am. 1981;12:57-71.

[27] Levy BJ, Schulz JF, Fornari ED, Wollowick AL. Complications Associated with Surgical Repair of Syndromic Scoliosis. Scoliosis. 2015;10:14.

[28] Gabos PG, Inan M, Thacker M, Borkhu B. Spinal Fusion for Scoliosis in Rett Syndrome with an Emphasis on Early Postoperative Complications. Spine (Phila Pa 1976). 2012;37:E90-4.

[29] Greggi T, Martikos K, Lolli F, Bakaloudis G, Di Silvestre M, Cioni A, et al. Treatment of Scoliosis in Patients Affected with Prader-Willi Syndrome Using Various Techniques. Scoliosis. 2010;5:11.

[30] Crawford AH, Herrera-Soto J. Scoliosis Associated with Neurofibromatosis. Orthop Clin North Am. 2007;38:553-62, vii.

[31] Reames DL, Smith JS, Fu KM, Polly DW, Jr., Ames CP, Berven SH, et al. Complications in the Surgical Treatment of 19,360 Cases of Pediatric Scoliosis: A Review of the Scoliosis Research Society Morbidity and Mortality Database. Spine (Phila Pa 1976). 2011;36:1484-91.

[32] Weinstein SL, Dolan LA, Spratt KF, Peterson KK, Spoonamore MJ, Ponseti IV. Health and Function of Patients with Untreated Idiopathic Scoliosis: A 50-Year Natural History Study. JAMA. 2003;289:559-67.

[33] Pehrsson K, Larsson S, Oden A, Nachemson A. Long-Term Follow-up of Patients with Untreated Scoliosis. A Study of Mortality, Causes of Death, and Symptoms. Spine (Phila Pa 1976). 1992;17:1091-6.

[34] Davies G, Reid L. Effect of Scoliosis on Growth of Alveoli and Pulmonary Arteries and on Right Ventricle. Arch Dis Child. 1971;46:623-32.

[35] Weinstein SL, Dolan LA, Wright JG, Dobbs MB. Effects of Bracing in Adolescents with Idiopathic Scoliosis. N Engl J Med. 2013;369:1512-21.

[36] Weiss HR. Is There a Body of Evidence for the Treatment of Patients with Adolescent Idiopathic Scoliosis (Ais)? Scoliosis. 2007;2:19.

[37] Smith JR, Samdani AF, Pahys J, Ranade A, Asghar J, Cahill P, et al. The Role of Bracing, Casting, and Vertical Expandable Prosthetic Titanium Rib for the Treatment of Infantile Idiopathic Scoliosis: A SingleInstitution Experience with 31 Consecutive Patients. Clinical Article. J Neurosurg Spine. 2009;11:3-8.

[38] Mehta MH. Growth as a Corrective Force in the Early Treatment of Progressive Infantile Scoliosis. J Bone Joint Surg Br. 2005;87:1237-47. 


\section{Chapter 2}

[39] Tis JE, Karlin LI, Akbarnia BA, Blakemore LC, Thompson GH, McCarthy RE, et al. Early Onset Scoliosis: Modern Treatment and Results. J Pediatr Orthop. 2012;32:647-57.

[40] Hibbs RA. A Report of Fifty-Nine Cases of Scoliosis Treated by the Fusion Operation. By Russell A. Hibbs, 1924. Clin Orthop Relat Res. 1988:4-19.

[41] Harrington PR. Treatment of Scoliosis. Correction and Internal Fixation by Spine Instrumentation. J Bone Joint Surg Am. 1962;44-A:591-610.

[42] Harrington PR. Technical Details in Relation to the Successful Use of Instrumentation in Scoliosis. Orthop Clin North Am. 1972;3:49-67.

[43] Luque ER. Segmental Spinal Instrumentation for Correction of Scoliosis. Clin Orthop Relat Res. 1982:1928.

[44] Cotrel Y, Dubousset J, Guillaumat M. New Universal Instrumentation in Spinal Surgery. Clin Orthop Relat Res. 1988;227:10-23.

[45] Roy-Camille R, Roy-Camille M, Demeulenaere C. [Osteosynthesis of Dorsal, Lumbar, and Lumbosacral Spine with Metallic Plates Screwed into Vertebral Pedicles and Articular Apophyses]. Presse Med. 1970;78:1447-8.

[46] Suk SI, Lee CK, Kim WJ, Chung YJ, Park YB. Segmental Pedicle Screw Fixation in the Treatment of Thoracic Idiopathic Scoliosis. Spine (Phila Pa 1976). 1995;20:1399-405.

[47] Raney EM. Hooks and Wires--Tried and True Plus How To: Posna1-Daycourse, April 29, 2009. J Pediatr Orthop. 2011;31:S81-7.

[48] Huhn SL, Wolf AL, Ecklund J. Posterior Spinal Osteosynthesis for Cervical Fracture/Dislocation Using a Flexible Multistrand Cable System: Technical Note. Neurosurgery. 1991;29:943-6.

[49] Songer MN, Spencer DL, Meyer PR, Jr., Jayaraman G. The Use of Sublaminar Cables to Replace Luque Wires. Spine (Phila Pa 1976). 1991;16:S418-21.

[50] Jouve JL, de Gauzy JS, Blondel B, Launay F, Accadbled F, Bollini G. Use of the Universal Clamp for Deformity Correction and as an Adjunct to Fusion: Preliminary Results in Scoliosis. J Child Orthop. 2010;4:73-80.

[51] La Rosa G, Giglio G, Oggiano L. Surgical Treatment of Neurological Scoliosis Using Hybrid Construct (Lumbar Transpedicular Screws Plus Thoracic Sublaminar Acrylic Loops). Eur Spine J. 2011;20 Suppl 1:590-4.

[52] Mazda K, Ilharreborde B, Even J, Lefevre Y, Fitoussi F, Pennecot GF. Efficacy and Safety of Posteromedial Translation for Correction of Thoracic Curves in Adolescent Idiopathic Scoliosis Using a New Connection to the Spine: The Universal Clamp. Eur Spine J. 2009;18:158-69.

[53] Ratner BD. Biomaterials Science : An Introduction to Materials in Medicine. San Diego: Academic Press; 1996.

[54] Dwyer AF, Newton NC, Sherwood AA. An Anterior Approach to Scoliosis. A Preliminary Report. Clin Orthop Relat Res. 1969;62:192-202.

[55] Zielke K, Berthet A. [Vds--Ventral Derotation Spondylodesis--Preliminary Report on 58 Cases]. Beitr Orthop Traumatol. 1978;25:85-103.

[56] Newton PO, Wenger DR, Mubarak SJ, Meyer RS. Anterior Release and Fusion in Pediatric Spinal Deformity. A Comparison of Early Outcome and Cost of Thoracoscopic and Open Thoracotomy Approaches. Spine (Phila Pa 1976). 1997;22:1398-406. 
[57] Betz RR, Harms J, Clements DH, 3rd, Lenke LG, Lowe TG, Shufflebarger HL, et al. Comparison of Anterior and Posterior Instrumentation for Correction of Adolescent Thoracic Idiopathic Scoliosis. Spine (Phila Pa 1976). 1999;24:225-39.

[58] Dubousset J, Herring JA, Shufflebarger H. The Crankshaft Phenomenon. Journal of pediatric orthopedics. 1989;9:541-50.

[59] Goldberg CJ, Gillic I, Connaughton O, Moore DP, Fogarty EE, Canny GJ, et al. Respiratory Function and Cosmesis at Maturity in Infantile-Onset Scoliosis. Spine (Phila Pa 1976). 2003;28:2397-406.

[60] Karol LA, Johnston C, Mladenov K, Schochet P, Walters P, Browne RH. Pulmonary Function Following Early Thoracic Fusion in Non-Neuromuscular Scoliosis. J Bone Joint Surg Am. 2008;90:1272-81.

[61] Vitale MG, Matsumoto H, Bye MR, Gomez JA, Booker WA, Hyman JE, et al. A Retrospective Cohort Study of Pulmonary Function, Radiographic Measures, and Quality of Life in Children with Congenital Scoliosis: An Evaluation of Patient Outcomes after Early Spinal Fusion. Spine (Phila Pa 1976). 2008;33:1242-9.

[62] Campbell RM, Jr., Smith MD, Mayes TC, Mangos JA, Willey-Courand DB, Kose N, et al. The Characteristics of Thoracic Insufficiency Syndrome Associated with Fused Ribs and Congenital Scoliosis. J Bone Joint Surg Am. 2003;85-A:399-408.

[63] Vitale MG, Matsumoto H, Roye DP, Jr., Gomez JA, Betz RR, Emans JB, et al. Health-Related Quality of Life in Children with Thoracic Insufficiency Syndrome. J Pediatr Orthop. 2008;28:239-43.

[64] Moe JH, Kharrat K, Winter RB, Cummine JL. Harrington Instrumentation without Fusion Plus External Orthotic Support for the Treatment of Difficult Curvature Problems in Young Children. Clin Orthop Relat Res. 1984:35-45.

[65] Akbarnia BA, Marks DS, Boachie-Adjei O, Thompson AG, Asher MA. Dual Growing Rod Technique for the Treatment of Progressive Early-Onset Scoliosis: A Multicenter Study. Spine (Phila Pa 1976). 2005;30:S4657.

[66] Thompson GH, Akbarnia BA, Kostial P, Poe-Kochert C, Armstrong DG, Roh J, et al. Comparison of Single and Dual Growing Rod Techniques Followed through Definitive Surgery: A Preliminary Study. Spine (Phila Pa 1976). 2005;30:2039-44.

[67] Campbell RM, Jr., Smith MD, Hell-Vocke AK. Expansion Thoracoplasty: The Surgical Technique of Opening-Wedge Thoracostomy. Surgical Technique. J Bone Joint Surg Am. 2004;86-A Suppl 1:51-64.

[68] Campbell RM, Jr., Smith MD, Mayes TC, Mangos JA, Willey-Courand DB, Kose N, et al. The Effect of Opening Wedge Thoracostomy on Thoracic Insufficiency Syndrome Associated with Fused Ribs and Congenital Scoliosis. J Bone Joint Surg Am. 2004;86-A:1659-74.

[69] Akbarnia BA, Emans JB. Complications of Growth-Sparing Surgery in Early Onset Scoliosis. Spine (Phila Pa 1976). 2010;35:2193-204.

[70] Akbarnia BA, Breakwell LM, Marks DS, McCarthy RE, Thompson AG, Canale SK, et al. Dual Growing Rod Technique Followed for Three to Eleven Years until Final Fusion: The Effect of Frequency of Lengthening. Spine (Phila Pa 1976). 2008;33:984-90.

[71] Sankar WN, Skaggs DL, Yazici M, Johnston CE, 2nd, Shah SA, Javidan P, et al. Lengthening of Dual Growing Rods and the Law of Diminishing Returns. Spine (Phila Pa 1976). 2011;36:806-9.

[72] Cahill PJ, Marvil S, Cuddihy L, Schutt C, Idema J, Clements DH, et al. Autofusion in the Immature Spine Treated with Growing Rods. Spine (Phila Pa 1976). 2010;35:E1199-203. 


\section{Chapter 2}

[73] Matsumoto H, Williams BA, Corona J, Comer JS, Fisher PW, Neria Y, et al. Psychosocial Effects of Repetitive Surgeries in Children with Early-Onset Scoliosis: Are We Putting Them at Risk? J Pediatr Orthop. 2014;34:172-8.

[74] Bess S, Akbarnia BA, Thompson GH, Sponseller PD, Shah SA, El Sebaie H, et al. Complications of GrowingRod Treatment for Early-Onset Scoliosis: Analysis of One Hundred and Forty Patients. J Bone Joint Surg Am. 2010;92:2533-43.

[75] Akbarnia BA, Cheung K, Noordeen H, Elsebaie H, Yazici M, Dannawi Z, et al. Next Generation of GrowthSparing Techniques: Preliminary Clinical Results of a Magnetically Controlled Growing Rod in 14 Patients with Early-Onset Scoliosis. Spine (Phila Pa 1976). 2013;38:665-70.

[76] Cheung JP, Samartzis D, Cheung KM. A Novel Approach to Gradual Correction of Severe Spinal Deformity in a Pediatric Patient Using the Magnetically-Controlled Growing Rod. Spine J. 2014;14:e7-13.

[77] Dannawi Z, Altaf F, Harshavardhana NS, El Sebaie H, Noordeen H. Early Results of a Remotely-Operated Magnetic Growth Rod in Early-Onset Scoliosis. Bone Joint J. 2013;95-B:75-80.

[78] Teoh KH, Winson DM, James SH, Jones A, Howes J, Davies PR, et al. Do Magnetic Growing Rods Have Lower Complication Rates Compared with Conventional Growing Rods? Spine J. 2016;16:S40-4.

[79] Rolton D, Richards J, Nnadi C. Magnetic Controlled Growth Rods Versus Conventional Growing Rod Systems in the Treatment of Early Onset Scoliosis: A Cost Comparison. Eur Spine J. 2015;24:1457-61.

[80] Jenks M, Craig J, Higgins J, Willits I, Barata T, Wood H, et al. The Magec System for Spinal Lengthening in Children with Scoliosis: A Nice Medical Technology Guidance. Appl Health Econ Health Policy. 2014;12:587-99.

[81] Betz RR, Ranade A, Samdani AF, Chafetz R, D'Andrea LP, Gaughan JP, et al. Vertebral Body Stapling: A Fusionless Treatment Option for a Growing Child with Moderate Idiopathic Scoliosis. Spine (Phila Pa 1976). 2010;35:169-76.

[82] Samdani AF, Ames RJ, Kimball JS, Pahys JM, Grewal H, Pelletier GJ, et al. Anterior Vertebral Body Tethering for Idiopathic Scoliosis: Two-Year Results. Spine (Phila Pa 1976). 2014;39:1688-93.

[83] Luque ER. Paralytic Scoliosis in Growing Children. Clin Orthop Relat Res. 1982:202-9.

[84] Mardjetko SM, Hammerberg KW, Lubicky JP, Fister JS. The Luque Trolley Revisited. Review of Nine Cases Requiring Revision. Spine (Phila Pa 1976). 1992;17:582-9.

[85] Pratt RK, Webb JK, Burwell RG, Cummings SL. Luque Trolley and Convex Epiphysiodesis in the Management of Infantile and Juvenile Idiopathic Scoliosis. Spine (Phila Pa 1976). 1999;24:1538-47.

[86] McCarthy RE, Luhmann S, Lenke L, McCullough FL. The Shilla Growth Guidance Technique for EarlyOnset Spinal Deformities at 2-Year Follow-Up: A Preliminary Report. J Pediatr Orthop. 2014;34:1-7.

[87] McCarthy RE, McCullough FL. Shilla Growth Guidance for Early-Onset Scoliosis: Results after a Minimum of Five Years of Follow-Up. J Bone Joint Surg Am. 2015;97:1578-84.

[88] McCarthy RE, Sucato D, Turner JL, Zhang H, Henson MA, McCarthy K. Shilla Growing Rods in a Caprine Animal Model: A Pilot Study. Clin Orthop Relat Res. 2010;468:705-10.

[89] Singh V, Simpson J, Rawlinson J, Hallab N. Growth Guidance System for Early-Onset Scoliosis: Comparison of Experimental and Retrieval Wear. Spine (Phila Pa 1976). 2013;38:1546-53.

[90] Kaufman AM, Alabre Cl, Rubash HE, Shanbhag AS. Human Macrophage Response to Uhmwpe, Tialv, Cocr, and Alumina Particles: Analysis of Multiple Cytokines Using Protein Arrays. J Biomed Mater Res A. 2008;84:464-74. 
[91] Cunningham BW, Orbegoso CM, Dmitriev AE, Hallab NJ, Sefter JC, Asdourian P, et al. The Effect of Spinal Instrumentation Particulate Wear Debris. An in Vivo Rabbit Model and Applied Clinical Study of Retrieved Instrumentation Cases. Spine J. 2003;3:19-32.

[92] Lukina E, Laka A, Kollerov M, Sampiev M, Mason P, Wagstaff P, et al. Metal Concentrations in the Blood and Tissues after Implantation of Titanium Growth Guidance Sliding Instrumentation. Spine J. 2016;16:380-8.

[93] Lukina E, Kollerov M, Meswania J, Wertheim D, Mason P, Wagstaff P, et al. Analysis of Retrieved Growth Guidance Sliding Lsz-4d Devices for Early Onset Scoliosis and Investigation of the Use of Nitinol Rods for This System. Spine (Phila Pa 1976). 2015;40:17-24.

[94] Ouellet JA, Ferland CE, Racloz G, Klein K, Richter H, Steffen T, et al. Evaluation of the Modern Luque Trolley Construct for Treatment of Early Onset Scoliosis Using a Gliding Implant in an Immature Animal Model. J Spinal Disord Tech. 2015.

[95] Luhmann SJ, McCarthy RE. A Comparison of Shilla Growth Guidance System and Growing Rods in the Treatment of Spinal Deformity in Children Less Than 10 Years of Age. J Pediatr Orthop. 2016.

[96] Kurtz SM, Edidin AA. Spine Technology Handbook. Amsterdam ; Boston: Elsevier Academic Press; 2006.

[97] Wilke HJ, Mathes B, Midderhoff S, Graf N. Development of a Scoliotic Spine Model for Biomechanical in Vitro Studies. Clin Biomech (Bristol, Avon). 2015;30:182-7.

[98] Russell WMS, Burch RL. The Principles of Humane Experimental Technique. London,: Methuen; 1959 
Chapter 2

2 


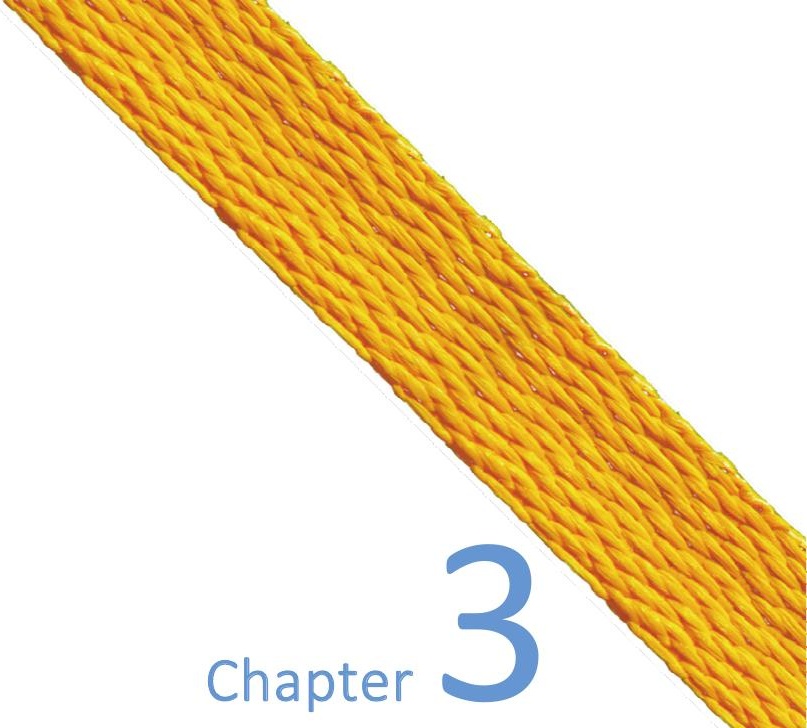

\section{Radiopaque UHWMPE Sublaminar Cables for Spinal Deformity Correction: Preclinical Mechanical and Radiopacifier Leaching Assessment} Jacobus J. Arts 


\section{ABSTRACT}

Polymeric sublaminar cables have a number of advantages over metal cables in the field of spinal deformity surgery, with decreased risk of neurological injury and potential for higher correction forces as the two most predominant. However, currently available polymer cables are radiolucent, precluding postoperative radiological assessment of instrumentation stability and integrity. This study provides a preclinical assessment of a woven UHMWPE cable made with radiopaque UHMWPE fibers. Our primary goal was to determine if the addition of a radiopacifier negatively affects the mechanical properties of UHMWPE woven cables. Tensile strength, stiffness, fatigue strength, and creep elongation were determined, and compared to a radiolucent analog UHMWPE cable, a titanium cable, and to literature data available for a different UHMWPE cable. Results show that the mechanical properties of woven UHMWPE cables were not deleteriously affected by the addition of homogeneously dispersed bismuth oxide particles within each fiber. Radiopacity was evaluated and radiopacifier leaching was assessed in vitro using different extraction liquids, with limited amounts of bismuth oxide released in all liquids, well below the toxicological threshold. Finally, in vivo bismuth organ content was quantified after a 24 week implantation period in sheep. Tissue concentrations lower than generally accepted therapeutic dosages for use against gastrointestinal disorders, well below toxic levels, were discovered. These results substantiate controlled clinical introduction of these radiopaque UHMWPE cables. 


\section{INTRODUCTION}

Pedicle screw usage has become increasingly widespread in the surgical treatment of thoracolumbar spinal disorders. However, there are cases in which pedicle screw usage may be problematic and alternative techniques like sublaminar wiring may be preferred. The insertion of thoracic pedicle screws may be technically demanding when vertebral anatomy is distorted, for example in scoliosis patients [1], which may preclude the placement of thoracic pedicle screws [2]. Misplaced pedicle screws may lead to serious neurological injury, vascular injury or dural sac tears [3]. Sublaminar wiring is generally faster than pedicle screw placement [4], which may be a reason to favor this technique in the fragile neuromuscular scoliosis patient group [4] as longer operative time is associated with increased complication rates. Gradually applying tension intraoperatively to the sublaminar wires allows for gradual curve correction. Unlike hooks [5], sublaminar wires do not impinge on the spinal canal and are not prone to laminar dislodgement [6]. Sublaminar wiring may also be a valuable technique in osteoporotic adult spinal deformity patients. Whereas the pull-out strength of pedicle screws decreases dramatically with decreasing bone mineral density, the failure strength using sublaminar wiring remains constant with decreasing bone mineral density [7]. Pedicle screw augmentation with sublaminar wires has been shown to provide firmer and stiffer fixation in comparison to pedicle screw fixation alone [8]. Sublaminar wires may therefore also be of great value as a supplementary fixation method.

Drawbacks and concerns related to the use of (metal) sublaminar wires have mainly focused on higher overall neurological complication rates [9], which are most often attributed to repeated contusions to the spinal cord during insertion of the rods and tightening of the wires [10]. Multi-strand cables were introduced in the early 1990's and offer significant advantages over monofilament wires: the braided cables offer higher static tensile and fatigue strengths $[10,11]$. Furthermore, their intrinsic flexibility and pliability allow for greater ease of insertion and tension adjustment [12]. The penetration of multi-stranded cables into the spinal canal is less than that of monofilament wires [13]. The improved cable conformance to the shape of the lamina is believed to lead to lower neurological injury rates, although evidence is still lacking.

Soft, flat polymeric sublaminar cable systems have been introduced in the last decade as a further improvement in sublaminar wiring technique. The Universal Clamp System (Zimmer Spine SAS, Bordeaux, France) consists of a polyester cable and a metallic clamp $[14,15]$. The Nesplon Cable System (Alfresa Pharma, Osaka, Japan) is an ultra-high molecular weight polyethylene (UHMWPE) cable which is secured using a double-loop sliding knot [16]. The flat, wide profile of these cable systems distributes contact forces over a greater area, thereby increasing possible corrective forces and lowering the risk of cable pull-out in comparison to metal cables. Both cable systems have been used 
clinically to treat scoliosis with satisfactory results in both the coronal and sagittal planes [17-19]. The expected substantially greater fatigue strength of UHMWPE cables in comparison to metal cables has significant clinical importance, as it allows for application in non-segmental constructs [20]. Knotted locking allows for sliding of the cable along a spinal rod, and can thereby accompany spinal growth, as evidenced in vivo [21]. These two properties may potentially allow for the application of UHMWPE cables in a growth-guidance construct for early onset scoliosis patients. However, currently available polymer cable systems are radiolucent, precluding radiologic assessment of instrumentation stability during follow-up.

For this reason, a radiopaque woven UHMWPE cable has been developed using a radiopaque UHMWPE fiber, containing bismuth oxide $\left(\mathrm{Bi}_{2} \mathrm{O}_{3}\right)$ as a radiopacifier (Dyneema Purity ${ }^{\circledR}$ Radiopaque fiber). We have previously assessed these radiopaque UHMWPE cables for biocompatibility and overall instrumentation stability in a large animal model [21]. In the current study, we aim to determine if the addition of a radiopacifier negatively affects the mechanical properties of UHMWPE woven cables by comparing the mechanical properties of the radiopaque UHMWPE cable to an analog UHMWPE cable without the added radiopacifier (control) in a clinically relevant test setup. A comparison to data published by Dickman et al. [22] for different sublaminar wire and cable systems is also made. The mechanical properties evaluated for the looped cables (including the knotted locking mechanism) are tensile strength and stiffness, fatigue strength, and creep elongation. Furthermore, we evaluate the radiopacity and assess the in vitro and in vivo leaching of the bismuth oxide radiopacifier. First, in vitro leaching using three different extraction liquids (cyclohexane, ethanol and saline) for 72 hours at $50{ }^{\circ} \mathrm{C}$ is evaluated. In relation to in vivo leaching, the bismuth oxide content found in different organs after a 24 week implantation period in sheep [21] is also reported.

\section{MATERIALS AND METHODS}

\section{Material specification}

Two UHMWPE sublaminar cables were used in this study: (1) a radiopaque $4 \mathrm{~mm}$ wide woven UHMWPE sublaminar cable made with Dyneema Purity ${ }^{\circledR}$ Radiopaque fibers (Figure $1 \mathrm{~A}$, will be referred to as DPR cable) and (2) a $4 \mathrm{~mm}$ radiolucent analog UHMWPE sublaminar cable made with natural white Dyneema Purity ${ }^{\circledR}$ fibers (Figure 1B, will be referred to as DP cable). To introduce radiopacity, submicron sized bismuth oxide $\left(\mathrm{Bi}_{2} \mathrm{O}_{3}\right)$ particles are physically incorporated and homogeneously distributed in Dyneema Purity ${ }^{\circledR}$ fibers during the gel spinning process (Figure 1G) [21]. The diameter and number of fibers in both the natural white Dyneema Purity ${ }^{\circledR}$ cables and Dyneema 
Purity ${ }^{\circledR}$ Radiopaque cables are the same, as is the woven structure of both cables, shown in Figure $1 \mathrm{E}$ and $1 \mathrm{~F}$ respectively. UHMWPE sublaminar cables were manufactured by DSM Biomedical (Geleen, the Netherlands), and sterilized by ethylene oxide treatment before all tests.

A titanium sublaminar cable (Atlas ${ }^{\circledR}$ cable system, Medtronic Sofamor Danek, Memphis, TN, USA) was used as a control in static tensile tests (Figure 1C). Data published by Dickman et al. [22] for the Atlas ${ }^{\circledR}$ titanium sublaminar cable, and the SecureStrand ${ }^{\mathrm{TM}}$ cable system (Smith \& Nephew, Memphis TN, USA) will be used as a comparison for creep elongation and fatigue strength values. The SecureStrand ${ }^{\mathrm{TM}}$ is a $1 \mathrm{~mm}$ diameter braided UHMWPE cable with 120 filaments/fiber and 8 fibers braided in diamond cable fashion. The titanium Atlas ${ }^{\circledR}$ cable is a twisted $1 \mathrm{~mm}$ diameter cable, consisting of 49 filaments $(7 \times 7)$.
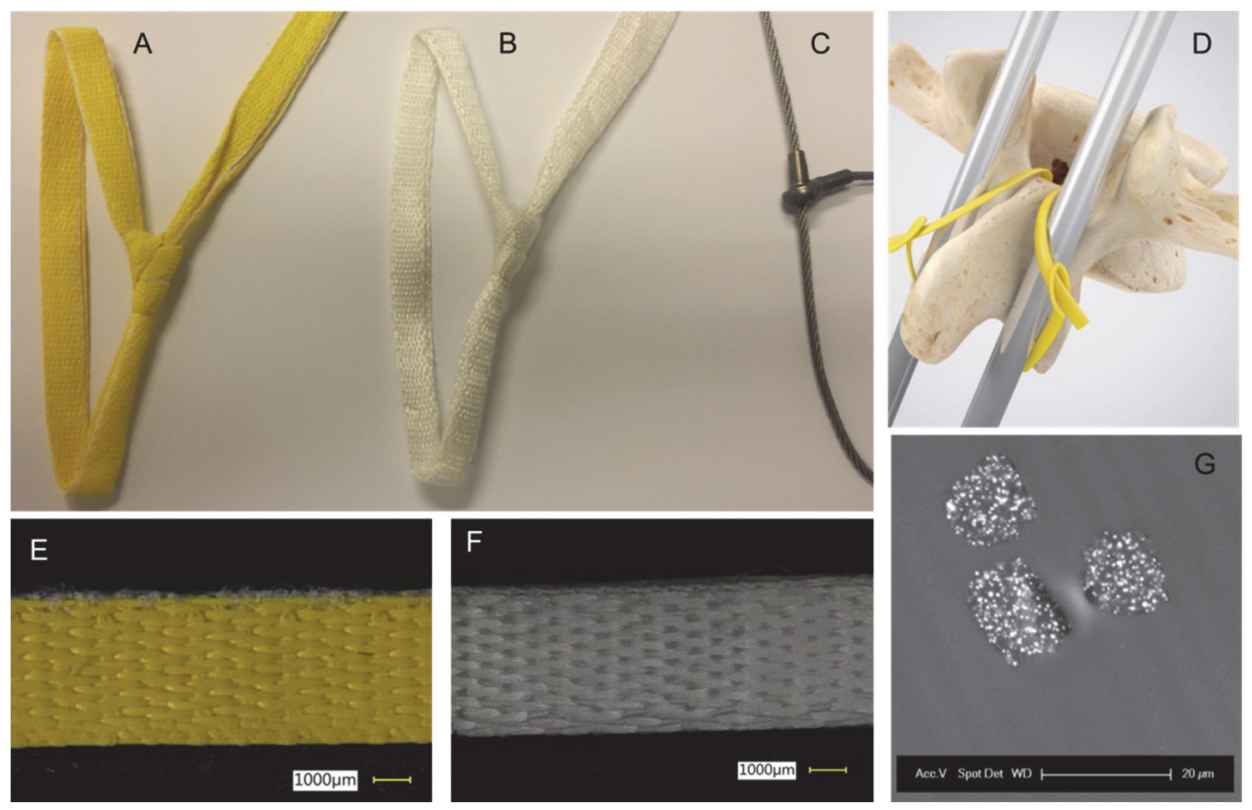

Figure 1 - (A) Radiopaque UHMWPE (DPR) cable (B) radiolucent analog UHMWPE (DP) cable (C) titanium Atlas $^{\circledR}$ cable. (D) Illustration of the application of the DPR cable as a sublaminar wire. Woven structure comparison between (E) DPR cable and (F) the DP cable. (G) Backscatter scanning electron microscopy (SEM) image showing the homogeneously distributed submicron sized bismuth oxide particles within the fiber (acceleration voltage $25 \mathrm{kV}$ ).

Mechanical tests were performed using looped samples including the locking mechanism, which closely resembles the clinical application as a sublaminar wire (Figure 1D). A modified double-looped sliding knot is used to secure the tested UHMWPE cables [21]. The double-looped sliding knot is tied off using a single square knot throw, tensioned 
using a custom tensioning device to $500 \mathrm{~N}$, and finally tied-off using six additional square knot throws. The titanium sublaminar cable was tightened and secured using a metal crimp, according to the manufacturer's recommendations.

\section{Radiopacity assessment}

Digital radiographs of the radiolucent UHMWPE cable (DP), radiopaque UHWMPE cable (DPR) and the titanium Atlas ${ }^{\circledR}$ cable were acquired using a clinical computed radiography machine (Siemens Multix Fusion Digital, Siemens Healthcare $\mathrm{GmbH}$, Erlangen, Germany). Images were acquired using an acceleration voltage of $45 \mathrm{kV}$ and a tube current-exposure time product of $4.2 \mathrm{mAs}$. Radiopacity was quantified relative to an aluminum step wedge (0.4-5.2 mm in $0.4 \mathrm{~mm}$ steps, Artinis Medical Systems, Elst, the Netherlands), which was placed beside the cables during image acquisition. Regional gray-value intensities were determined using Synedra View Personal (Synedra Information Technologies, Innsbruck, Austria) by two independent observers (A.R, K.B) performing two measurements each. The radiopacity was quantified for the following cables and views: (1) DP cable lateral/side view, (2) DPR cable lateral/side view, (3) knot, (4) DPR cable frontal view four layers, (5) titanium Atlas ${ }^{\circledR}$ cable, and (6) the titanium cable crimp.

\section{Mechanical Testing}

Tensile strength, tensile stiffness, fatigue strength and creep elongation were determined for looped UHWMPE (DPR and DP) cables using various material testing machines fitted with Clevis grips (Figure 2A). The diameter of the pins was $10 \mathrm{~mm}$ and the distance between the longitudinal axes of the two parallel pins was $40 \mathrm{~mm}$. Tensile strength and stiffness of the loops were determined at an actuator displacement speed of $1 \mathrm{~mm} / \mathrm{s}$. The stiffness was determined from the initial (linear) slope of the loaddisplacement curve between $100 \mathrm{~N}$ and $500 \mathrm{~N}$. Load was divided by a factor two when calculating the stiffness to account for load distribution among both legs of the loop. Fatigue strength, defined as the highest peak load at which three consecutive samples did not fail during 5 million cycles of loading, was determined using both a servohydraulic material testing machine (MTS Bionix 858, MTS, Eden Prairie, MN, USA) and an electrodynamic material testing machine (MTS Acumen 3, MTS, Eden Prairie, MN, USA). The cycle minimum load was $10 \%$ of the peak load. Testing on the servo-hydraulic machine was performed at a frequency of $5 \mathrm{~Hz}$, while testing on the electrodynamic machine was performed at $10 \mathrm{~Hz}$. 

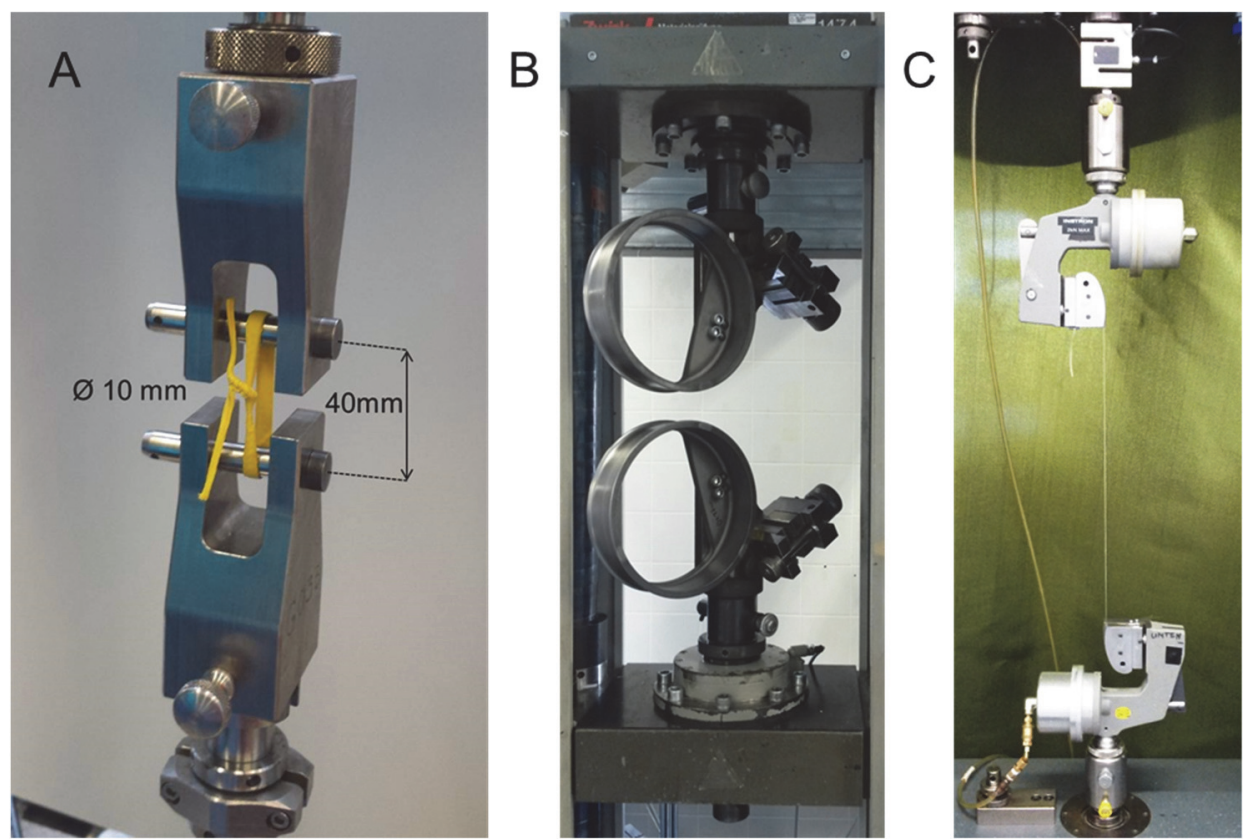

Figure 2 - (A) The Clevis-grips used to test looped samples. (B) The rope grips and load reduction rollers used to quantify the tensile strength of single cable strands. (C) The pneumatic fiber grips used to test individual fibers.

Creep was determined at $37{ }^{\circ} \mathrm{C}$ and at room temperature using double-spindle materials test machines. A Zwick Z010 (Zwick GmbH, Ulm, Germany) machine was used to perform tests at room temperature, while a Zwick 1484 (Zwick GmbH, Ulm, Germany) machine fitted with a climate chamber (ETE 220 LN2, Weiss Technik, Vienna, Austria) was used to perform tests at $37{ }^{\circ} \mathrm{C}$. At $37{ }^{\circ} \mathrm{C}$, a load of $500 \mathrm{~N}$ was applied and held for 72 hours, and creep elongation was calculated from a preload of $100 \mathrm{~N}$. At room temperature, a load of $475 \mathrm{~N}$ was applied and held for 24 hours. Creep elongation was calculated from a preload of $45 \mathrm{~N}$, in order to make a comparison to data published by Dickman et al. [22]. For comparative purposes, uniaxial tensile strength of individual UHMWPE fibers and the woven UHMWPE cables without knot was determined with a Zwick 1474 material testing machine using pneumatic fiber grips (for fibers, Figure 2C) and rope grips fitted with load reduction rollers for cables without knot (Figure 2B). These tests were performed with actuator displacement speeds of $150 \mathrm{~mm} / \mathrm{min}$ and $250 \mathrm{~mm} / \mathrm{min}$ respectively.

A comparison of tensile and fatigue strength, stiffness, and creep elongation values was made using the Mann-Whitney U-test for independent samples. Statistical significance 
was set at $p<0.05$. Statistical analyses were performed using standard software (IBM SPSS Statistics, Version 21.0; IBM Corp, Armonk, NY).

\section{Radiopacifier leaching: in vitro analysis}

In vitro leaching of bismuth oxide particles from the DPR cable was evaluated in triplicate in three different extraction solutions: cyclohexane (UvaSol ${ }^{\circledR}$, Merck Millipore, Darmstadt, Germany), ethanol (LiChrosolv ${ }^{\circledR}$, Merck Millipore, Darmstadt, Germany), and 0.9\% saline ( $\mathrm{NaCl}$ min. 99.5\%, Merck Millipore, Darmstadt, Germany in Milli-Q water). Samples were prepared according to ISO 10993-12:2007, which prescribes an extraction ratio of 0.2 grams of solid material per milliliter of extraction fluid. Extraction was performed using intact cable samples (approximately $1.0 \mathrm{~g}$ ) in closed glass bottles (vessels for headspace gas chromatography) in a GC oven at $50 \pm 1{ }^{\circ} \mathrm{C}$ for $72( \pm 1)$ hours. The samples were shaken twice a day for circulation of the extraction solutions. After extraction at $50{ }^{\circ} \mathrm{C}$ for 72 hours and removal of the cable sample, the extraction liquid was evaporated in the presence of sulfuric acid $\left(\mathrm{H}_{2} \mathrm{SO}_{4}\right.$, Suprapur ${ }^{\circledR}$, Merck Millipore, Darmstadt, Germany). After full evaporation, the remaining residue was dissolved in diluted nitric acid $\left(\mathrm{HNO}_{3}\right.$, Suprapur ${ }^{\circledR}$, Merck Millipore, Darmstadt, Germany). Bismuth content was determined in these samples using elemental analysis via inductively coupled plasma atomic emission spectroscopy (ICP-AES, iCAP6500, ThermoFisher Scientific, Waltham, MA, USA).

\section{Radiopacifier leaching: in vivo analysis}

DPR sublaminar cables were implanted in twelve immature sheep at five thoracolumbar spinal levels. A detailed description of the operative technique has previously been published [21]. All animals were sacrificed 24 weeks postoperatively. The animal procedures were approved by the Animal Ethical Committee of the Maastricht University Medical Center (approval number: DEC 2011-122). Liver, kidney, cerebral spinal fluid, and muscle biopsies (adjacent to instrumentation) were taken at random from three animals. Samples from three unoperated control animals were also analyzed to attain natural reference values. All samples were microwave-digested in $65 \%$ nitric acid $\left(\mathrm{HNO}_{3}\right.$, Suprapur ${ }^{\circledR}$, Merck Millipore, Darmstadt, Germany). Liver and kidneys were homogenized prior to digestion. Bismuth content was determined using inductively coupled plasma mass spectrometry (ICP-MS, Perkin Elmer DRC-e, Waltham, MA, USA). 


\section{RESULTS}

\section{Radiopacity assessment}

A radiograph of the DP cable, DPR cables placed at different orientations, and the titanium Atlas ${ }^{\circledR}$ cable along with an aluminum (Al) step wedge is depicted in Figure 3A. The woven UHMWPE cables have a flat, wide profile and are secured using a doublelooped sliding knot, resulting in a double-stranded loop at all locations. Thus radiopacity is dependent on the view angle and the number of stacked cable layers. For the DPR cable, radiopacity values in the lateral view (2) and for the knot (3) are similar to the titanium Atlas ${ }^{\circledR}$ cable. In the frontal view, radiopacity is lower, but increases with an increasing number of stacked layers. All aluminum equivalent radiopacity values are shown in Table 1. A lateral radiograph showing the in vivo radiopacity of the DPR cables as used in a lumbar construct along with titanium pedicle screws and $4.75 \mathrm{~mm}$ cobalt chromium rods in an immature sheep model [21] is given in Figure 3B.

\begin{tabular}{|c|c|c|}
\hline Cable & Region of Interest/View & Radiopacity \\
\hline DP cable & Lateral view & $0.9 \pm 0.0 \mathrm{~mm} \mathrm{Al}$ \\
\hline \multirow[t]{3}{*}{ DPR cable } & Lateral view & $7.0 \pm 0.2 \mathrm{~mm} \mathrm{Al}$ \\
\hline & Knot & $6.5 \pm 0.2 \mathrm{~mm} \mathrm{Al}$ \\
\hline & Frontal view (four layers) & $1.8 \pm 0.0 \mathrm{~mm} \mathrm{Al}$ \\
\hline \multirow[t]{2}{*}{ Titanium Atlas ${ }^{\circledR}$ cable } & Lateral/frontal view & $7.1 \pm 0.3 \mathrm{~mm} \mathrm{Al}$ \\
\hline & Cable crimp & $12.6 \pm 0.1 \mathrm{~mm} \mathrm{Al}$ \\
\hline
\end{tabular}

Table 1 - Aluminum equivalent radiopacity values for the regions shown in Figure 3A. Values were determined by two independent observers performing two measurements each. 

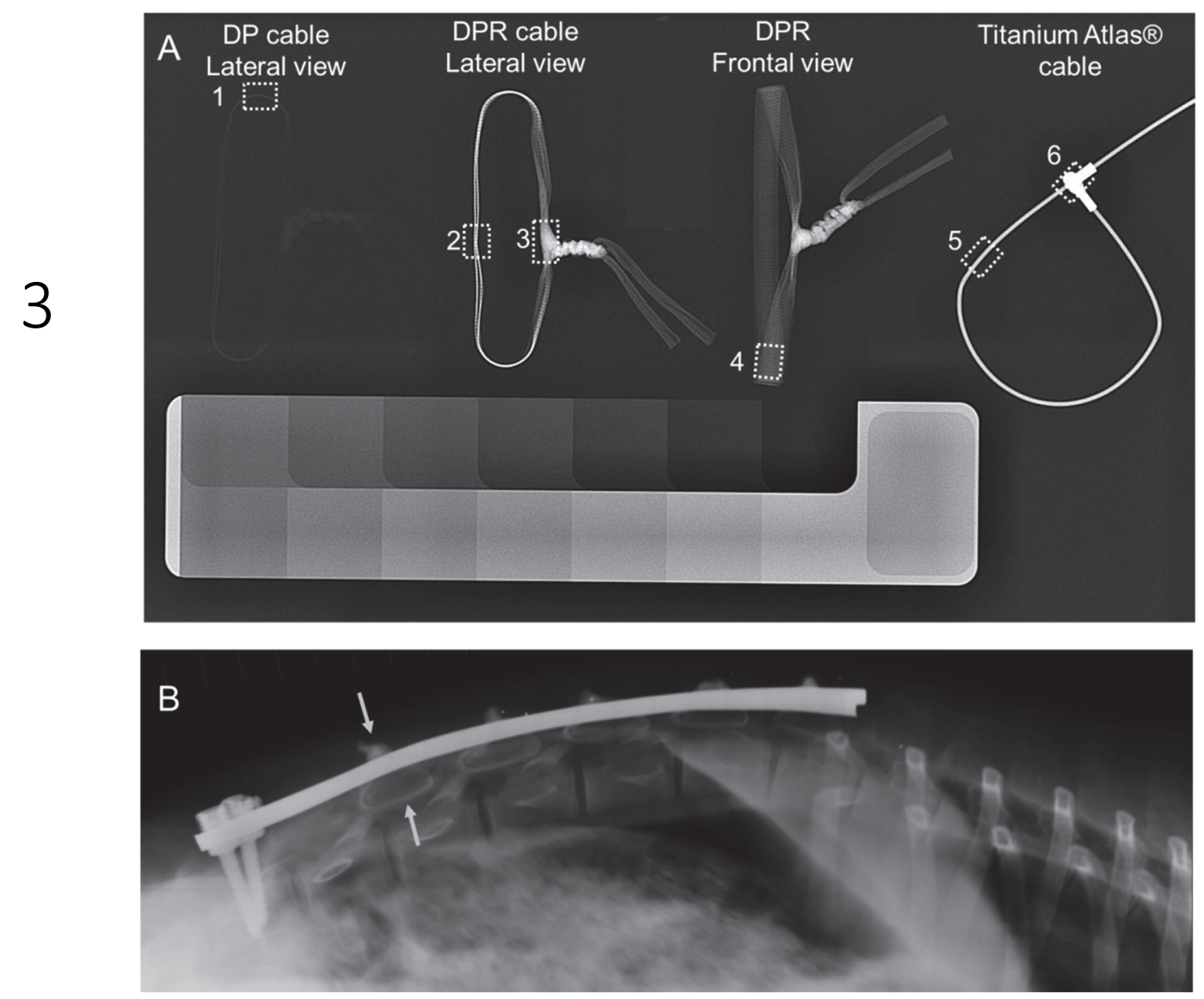

Figure 3 - (A) Radiograph (45 kV $4.2 \mathrm{mAs}$ ) comparing the radiopacity of the DP cable (view 1 ) to different views of DPR cable (views 2-4), and the titanium Atlas ${ }^{\circledR}$ cable (views 5-6) relative to a 0.4:0.4:5.2 mm aluminum step wedge. (B) In vivo lateral radiograph (90 kV $80 \mathrm{mAs}$ ) of DPR cables (T12-L3) in a lumbar spinal construct along with dual pedicle screws (L5) and dual $4.75 \mathrm{~mm}$ cobalt chromium rods in an immature sheep model.

\section{Mechanical Testing}

Results of mechanical tests are summarized in Table 2. The tensile strength and the fatigue strength of both UHMWPE cables (DPR and DP) are substantially greater than both the titanium Atlas ${ }^{\circledR}$ cable and the SecureStrand $^{\top M}$ cable. The measured tensile stiffness of the DPR and DP cables is greater than or at least comparable to the stiffness of the titanium cable $(p=0.008, p=0.076)$. The stiffness of the Securestrand ${ }^{\mathrm{TM}}$ cable is lower than all other cable systems, which may be attributable to a number of factors, including different pretension levels, a different number of fibers, different locking techniques, and different behavior between woven and braided constructions. Creep 
elongation is greater for all UHMWPE cables (DPR, DP, and Securestrand ${ }^{\mathrm{TM}}$ ) in comparison to the titanium cable. Creep elongation for the DP and DPR cables are lower than for the SecureStrand ${ }^{\mathrm{TM}}$ cable after sustaining a $475 \mathrm{~N}$ load for 24 hours at room temperature.

\begin{tabular}{|c|c|c|c|c|}
\hline & $\begin{array}{l}\text { UHMWPE sublaminar } \\
\text { cable made with } \\
\text { Dyneema Purity } \\
\text { Radiopaque fibers } \\
\text { (DPR cable) }\end{array}$ & $\begin{array}{l}\text { UHMWPE sublaminar } \\
\text { cable made with } \\
\text { Dyneema Purity } \\
\text { fibers (DP cable) }\end{array}$ & $\begin{array}{l}\text { Atlas }^{\circledR} \text { titanium } \\
\text { cable } \\
\text { (Medtronic, } \\
\text { Memphis TN, } \\
\text { USA) }\end{array}$ & $\begin{array}{c}\text { SecureStrand }{ }^{\mathrm{TM}} \\
\text { (Smith \& Nephew }^{\text {Richards, Memphis, }} \\
\text { TN, USA) }\end{array}$ \\
\hline $\begin{array}{c}\text { Tensile Strength } \\
\text { Loop }\end{array}$ & $\begin{array}{c}2232 \pm 105 N^{+\ddagger} \\
(n=5)\end{array}$ & $\begin{array}{c}2493 \pm 143 N^{+\S} \\
(n=5)\end{array}$ & $\begin{array}{c}1100 \pm 54 N^{\ddagger \S} \\
(n=5) \\
1005 \pm 49 N^{*}\end{array}$ & $1565 \pm 71 N^{*}$ \\
\hline $\begin{array}{c}\text { Tensile Stiffness } \\
\text { Loop }\end{array}$ & $\begin{array}{c}503 \pm 39 \mathrm{~N} / \mathrm{mm}^{\ddagger} \\
(\mathrm{n}=5)\end{array}$ & $\begin{array}{c}492 \pm 47 \mathrm{~N} / \mathrm{mm} \\
(\mathrm{n}=5)\end{array}$ & $\begin{array}{c}428 \pm 28 \mathrm{~N} / \mathrm{mm}^{\ddagger} \\
(\mathrm{n}=5) \\
497 \pm 32 \mathrm{~N} / \mathrm{mm}^{*}\end{array}$ & $322 \pm 51 \mathrm{~N} / \mathrm{mm}^{*}$ \\
\hline $\begin{array}{l}\text { Fatigue strength } \\
\text { (runout at } 5 \\
\text { million cycles) }\end{array}$ & $\begin{array}{c}1559 N \\
(n=3)\end{array}$ & $\begin{array}{c}1500 N \\
(n=3)\end{array}$ & $<45 N^{*}$ & $\begin{array}{c}578 \mathrm{~N}^{*} \\
\text { (3 million cycles) }\end{array}$ \\
\hline $\begin{array}{c}\text { Creep elongation } \\
\text { (475N static load, } \\
\left.24 \mathrm{~h}, 20^{\circ} \mathrm{C}\right)\end{array}$ & $\begin{array}{c}2.23 \pm 0.20 \%^{+} \\
(n=5)\end{array}$ & $\begin{array}{c}2.69 \pm 0.20 \%^{+} \\
(n=5)\end{array}$ & $\begin{array}{l}0.74 \% * \\
(356 N)\end{array}$ & $3.22 \% *$ \\
\hline $\begin{array}{c}\text { Creep elongation } \\
(500 \mathrm{~N} \text { static load, } \\
\left.24 \mathrm{~h}, 37^{\circ} \mathrm{C}\right)\end{array}$ & $\begin{array}{c}2.67 \pm 0.29 \%^{+} \\
(n=5)\end{array}$ & $\begin{array}{c}3.01 \pm 0.25 \%^{+} \\
(n=5)\end{array}$ & $\mathrm{n} / \mathrm{a}$ & $\mathrm{n} / \mathrm{a}$ \\
\hline $\begin{array}{c}\text { Creep elongation } \\
\text { (500N static load, } \\
\left.72 \mathrm{~h}, 37^{\circ} \mathrm{C}\right)\end{array}$ & $\begin{array}{c}3.03 \pm 0.32 \%^{+} \\
(n=5)\end{array}$ & $\begin{array}{c}3.39 \pm 0.28 \%^{+} \\
(n=5)\end{array}$ & $\mathrm{n} / \mathrm{a}$ & $\mathrm{n} / \mathrm{a}$ \\
\hline $\begin{array}{l}\text { Tensile strength } \\
\text { single fiber }\end{array}$ & $\begin{array}{c}40.5 \pm 1.2 \mathrm{~N} \\
(n=5)\end{array}$ & $\begin{array}{c}40.7 \pm 0.4 N \\
(n=5)\end{array}$ & $\mathrm{n} / \mathrm{a}$ & $\mathrm{n} / \mathrm{a}$ \\
\hline $\begin{array}{l}\text { Tensile strength } \\
\text { single strand }\end{array}$ & $\begin{array}{c}1146 \pm 60 N \\
(n=10)\end{array}$ & $\begin{array}{c}1170 \pm 50 N \\
(n=10)\end{array}$ & $\mathrm{n} / \mathrm{a}$ & $\mathrm{n} / \mathrm{a}$ \\
\hline
\end{tabular}

Table 2 - Summary of the results of all performed mechanical tests. Dagger $\left({ }^{\dagger}\right)$ symbols denote a statistically significant difference $(p<0.05)$ between the DPR and DP cable. Double-dagger $(\ddagger)$ symbols denote a statistically significant difference $(p<0.05)$ between the DPR and titanium cable. Section $(\S)$ symbols denote a statistically significant difference $(p<0.05)$ between the DP and the titanium cable. An asterisk $(*)$ denotes a value taken from Dickman et al. [22], hence no statistical calculations were performed. Missing data was not available (n/a) in literature. 
Comparing the DPR cable to the DP cable, only slight differences are observed. The tensile strength of the DP cable is greater than the strength of the DPR cable $(p=0.016)$, while there are no significant differences in tensile stiffness $(p=0.917)$, in strength of single strands $(p=0.307)$, or in strength of individual fibers $(p=0.917)$. Representative force-displacement curves are shown in Figure 4A. The fatigue strength of the DPR cable (run-out at 5 million cycles) is slightly higher than for the DP cable, although this difference is negligible. Different overall fatigue behavior is observed, which is best 3 illustrated on a load-cycle number curve plotted on a log-scale (Figure 4B). Creep elongation after 24 hours at room temperature $(p=0.009)$ and after 72 hours at $37^{\circ} \mathrm{C}$ $(p=0.047)$ are both slightly lower for the DPR cable in comparison to the DP cable. Creep elongation after 24 hours at $37^{\circ} \mathrm{C}$ is only marginally higher than at room temperature for both the DP and DPR cable. Differences between the two cables and the majority of the elongation occur primarily in the first hour of testing, as is illustrated in log-log scale load-time curves (Figure 4C, D).
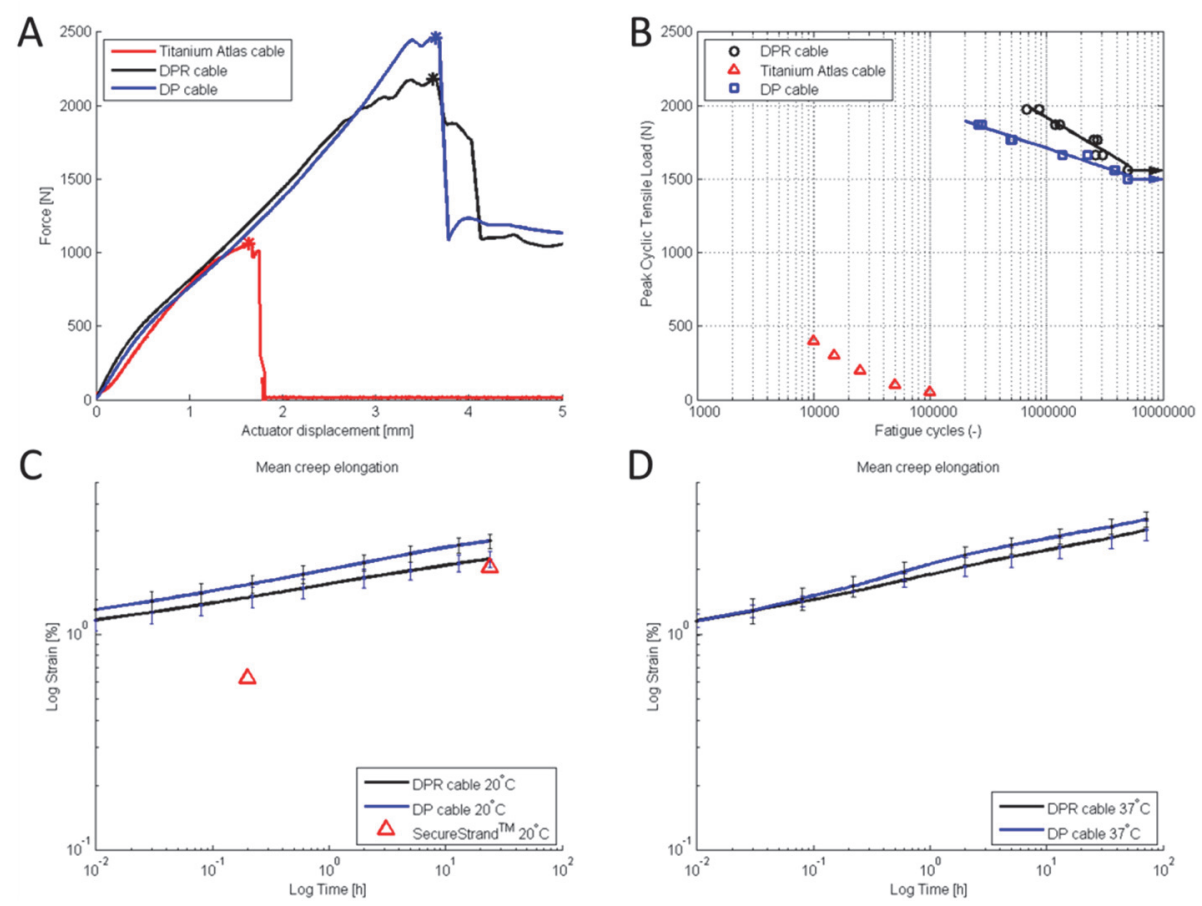

Figure 4 - (A) Representative load-displacement curves for the compared cables in quasi-static tension, (B) Load-cycle to failure curve illustrating the results of the dynamic fatigue tests. Log-log strain-time curves illustrating the results of creep tests at $37^{\circ} \mathrm{C}(\mathrm{C})$ and at room temperature (D). 
Radiopacifier leaching: in vitro analysis

The bismuth content in extraction liquids is shown in Table 3. No significant difference was observed in bismuth content between the cyclohexane and ethanol extraction liquid groups. The bismuth content found in the saline samples was significantly lower than both the cyclohexane and ethanol conditions.

\begin{tabular}{|cr|cc}
\multicolumn{2}{|c|}{ in vitro analysis } & $\begin{array}{c}\text { Leaked bismuth content } \\
{[\mu \mathrm{g} / \mathrm{g} \text { fiber] }}\end{array}$ & $\begin{array}{c}\text { Leaked bismuth } \\
\text { percentage [\%] }\end{array}$ \\
\hline Cyclohexane & Blank & $<0.005$ & 0.0034 \\
\hline \multirow{2}{*}{ Ethanol } & Test & $6.8 \pm 2.8$ & \\
\hline \multirow{2}{*}{ Saline } & Blank & $<0.005$ & 0.0030 \\
& Best & $5.9 \pm 1.5$ & \\
\hline
\end{tabular}

Table 3 - Bismuth content (average of 3 samples) in various extraction liquids after 72 hours at $50{ }^{\circ} \mathrm{C}$, as determined by ICP-AES, expressed quantitatively and as a percentage of the total bismuth content within the fiber.

Radiopacifier leaching: in vivo analysis

The bismuth content in tissue biopsies revealed that the highest concentration of bismuth was found in the kidneys, with considerably lower amounts found in the liver and muscle biopsies, as is expected based on literature [23] (Table 4). Bismuth levels below the limit of detection $(<5 \mu \mathrm{g} / \mathrm{kg})$ were found in all biopsies taken from unoperated control animals. The bismuth levels detected in the kidneys in this study are below levels found after therapeutic dosages of orally administered bismuth compounds in rats $(15-30 \mu \mathrm{g} / \mathrm{g})[24,25]$ and far below toxic levels [26]. 


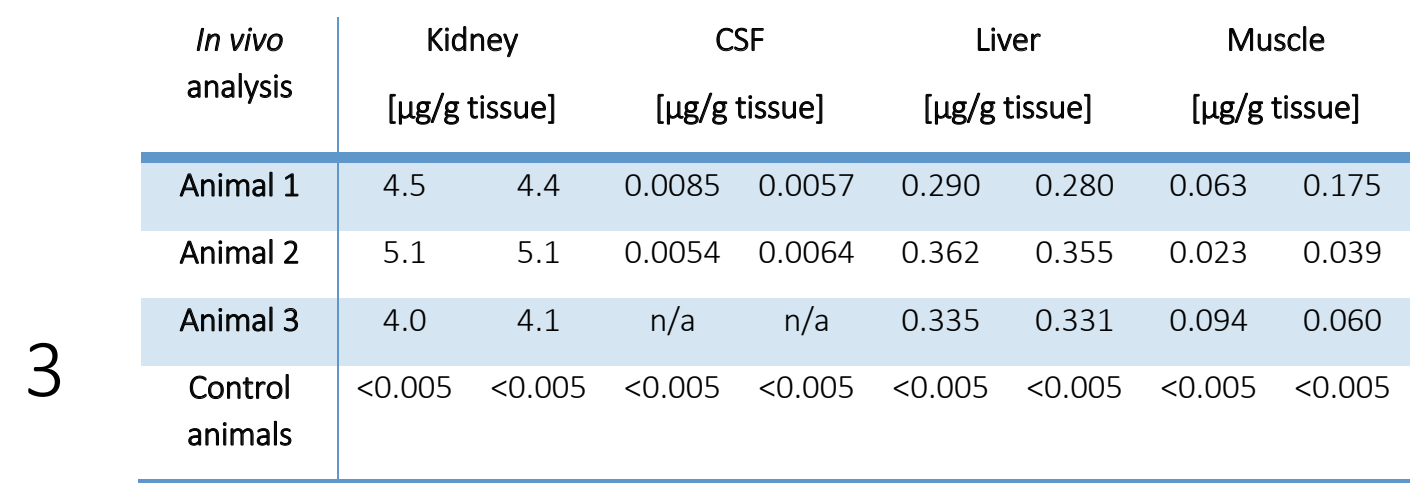

Table 4 - Bismuth content in various tissues (measured in duplicate) after a 24 week implantation period in sheep as determined by ICP-MS.

\section{DISCUSSION}

In this study, we compared the mechanical properties of radiopaque UHMWPE cables to a radiolucent analog UHMWPE cable, a titanium cable and to available literature values for another UHMWPE cable. Furthermore, we assessed their radiopacity, and evaluated the in vitro and in vivo leaching of the bismuth oxide radiopacifier.

The mechanical properties tested of both UHMWPE cables (DPR and DP cables) are superior to metal cables in terms of tensile and fatigue strength, and comparable in terms of tensile stiffness. The mechanical properties of the DPR cable have not been deleteriously affected by the addition of homogeneously dispersed bismuth oxide particles within each fiber, as was shown by the comparison to the DP cable. The DPR cable, DP cable, and the SecureStrand ${ }^{\mathrm{TM}}$ cable (all UHMWPE cables) exhibit higher creep elongation than the currently most commonly used metal cables. Possible clinical implications, in the specific context of spinal deformity correction, would be difficult to extrapolate from these results without a better understanding of actual in situ forces present. In this respect, it should be mentioned that no loss of function was observed during the related large animal model study in which the DPR cables were used [21]. Moreover, relevant literature also reports that no loss of correction was observed after two years in adolescent idiopathic scoliosis patients treated with hybrid constructs consisting of both pedicle screws and UHMWPE sublaminar cables, as reported by Imagama et al. [17]. All in all, both the DPR and DP cables are deemed suitable for clinical application.

Some slight differences in the mechanical properties of the radiopaque UHMWPE (DPR) cable and its radiolucent analog (DP cable) were observed, which we attribute to different behavior occurring within the knot rather than the materials' intrinsic properties. The knot appears to play a crucial role in the failure mechanism and during 
creep behavior. During loading, the knot is gradually tightened. As a result, compression of the cable strands passing through the sliding knot occurs, which consistently leads to stress concentration and failure in this region. As there was no difference in tensile strength of individual fibers or cables without knot, we therefore conclude that the difference in knotted samples arises due to slightly different knot-tightening behavior. This theory is further substantiated by evaluating creep behavior; the measured elongation is a combination of two factors: macroscopic elongation through tightening of the knot and microscopic creep occurring within each fiber. In this context, the observed slight difference between the DPR and DP cables occurs primarily during the first hour of testing, which again points towards the macroscopic knot tightening behavior as the biggest influencing factor. Nonetheless, the most important observation is that the mechanical properties of both DPR and DP cables are within the same range and both higher than the controls.

The radiopacity of the DPR cable in the lateral view is similar to the round titanium cable. The radiopacity is directly correlated with the thickness of the cable, which implies that the radiopacity increases going from frontal view, towards the lateral view and the knot. For the intended application in EOS patients, the low-profile was the most important requirement kept in mind during the cable design process. This implies that radiological assessment would be best performed using lateral radiographs for spinal applications. Lateral radiographs provide adequate potential for assessing cable and complete construct integrity, as we've experienced in our previously described animal studies [21]. When radiopaque UHMWPE fibers are used to produce a woven or braided cable, its radiopacity will be highly dependent on the number of fibers used, their structural configuration, and the amount of surrounding tissue at the specific location.

The use of bismuth as a radiopacifying agent within biomedical implants is appealing due to its high atomic number $\left(Z_{\mathrm{Bi}}=83\right)$, and its well-known biological tolerance [27]. Bismuth (III) complexes are renally clearable via metallothionine, a cysteine-rich protein abundant in the kidneys which has a preferential affinity for bismuth over other elements, regardless of $\mathrm{pH}$ [28]. Bismuth oxide is routinely used as a radiopacifying agent in root end fillers for endodontic surgery in a derivation of Portland cement known as mineral trioxide aggregate (MTA) $[29,30]$. The use of various other bismuth compounds as radiopacifying agent in orthopedic bone cements has also been proposed and investigated [31,32]. Concerning potential toxicity, the in vitro toxicity of bismuth oxide has been well described, with no concerning results reported. No toxicity was observed after administration of bismuth oxide to human peripheral lymphocytes [33] and human proximal tubular cells [34], even at the highest administered doses $(1000 \mu \mathrm{g} / \mathrm{ml}$, and $100 \mu \mathrm{M}(\sim 40 \mu \mathrm{g} / \mathrm{ml})$ respectively). The highest evaluated concentrations in literature mentioned above were substantially higher than the maximum concentration of bismuth found in our in vivo study $(\sim 5 \mu \mathrm{g} / \mathrm{g}$ of tissue, which is approximately equal to $5 \mathrm{\mu g} / \mathrm{ml}$, assuming a density of $1.05 \mathrm{~g} / \mathrm{ml}$ for all tissue 
biopsies). Furthermore, murine fibroblasts exposed to Portland cement containing 15\% wt. bismuth oxide did not show genotoxic or cytotoxic effects in comparison to a control mineral trioxide aggregate [35].

A no-observed-adverse-effect level (NOAEL) for repeated doses of orally administered pure bismuth has previously been established for rats at $1,000 \mathrm{mg} / \mathrm{kg}$ body weight per day by Sano et al. [36]. A tolerable intake value (TI) can be calculated for humans and the intended manner of administration (intramuscular implantation (IM)) by dividing the known NOAEL by the modifying factor, which is the product of three uncertainty factors in accordance with ISO 10993-17. For the intended application, we herein define a first uncertainty factor of 10 for inter-individual variations, a second uncertainty factor of 10 for interspecies variation, and a third uncertainty factor of 10 for the different administration route (IM), so that the TI for intended application in humans is $1 \mathrm{mg} / \mathrm{kg}$ body weight per day. A maximum concentration of $10 \mu \mathrm{g} / \mathrm{g}$ fiber was found to leach during the in vitro study. If $5 \mathrm{~g}$ of cable (approx. $5 \mathrm{~m}$, or dual cables at 10 spinal levels) is implanted in a patient, a maximum of $50 \mu \mathrm{g}$ of $\mathrm{Bi}_{2} \mathrm{O}_{3}$ could become biologically available, based on our in vitro leaching study. In the worst case scenario where this amount would all leach out in 1 day, the margin-of-safety would be 1000 for a person of $50 \mathrm{~kg}$. Thus the amount of bismuth found to leach out of the cable during the in vitro studies is no cause for concern.

Toxicity after acute or chronic exposure to high concentrations of therapeutic bismuth compounds for the treatment of gastrointestinal disorders has been reported. Prolonged exposure to high concentrations of water-insoluble lipophilic bismuth compounds, particularly bismuth subgallate, has been reported to lead to toxicity in the form of encephalopathy $[23,37,38]$. Cerebral spinal fluid (CSF) bismuth concentration is most reflective of the patient's condition, with reports of CSF concentrations of approximately 50-60 $\mathrm{\mu g} / \mathrm{L}$ in bismuth encephalopathy patients [23]. In the current study, bismuth levels below $10 \mu \mathrm{g} / \mathrm{L}$ were found in the CSF after 24 weeks and all animals behaved normally; therefore neurotoxicity is no cause for concern.

Nephrotoxicity has been reported to occur after acute overdose with different bismuth compounds, and is mostly associated with water-soluble, organic bismuth compounds such as colloidal bismuth subcitrate, bismuth sodium tri- or thioglycollamate, bismuth subsalicylate, and bismuth sodium tartrate $[23,38]$. The kidney bismuth levels detected in this study are lower than bismuth levels found after therapeutic dosages of orally administered bismuth compounds $(15-30 \mu \mathrm{g} / \mathrm{g})[24,25]$, and are far below toxic levels [26] and the herein established TI.

This study has a few limitations. First, all mechanical tests were performed under dry conditions, which is not representative of the wet conditions in the human body. However, UHMWPE fibers are not hygroscopic and their mechanical properties are therefore typically hardly affected. Second, most properties were not measured at body 
temperature, but it is expected that the differences at room and body temperature are only marginal. Creep was measured at body temperature, because it is known to be sensitive to temperature. Testing the fatigue strength on two different machines is also a limitation. Creep and fatigue tests have not been performed for cables without the knot or for individual fibers. However, we intentionally focused on the clinical application and comparison to other sublaminar cable systems rather than the fundamental comparison between the DPR and DP cables and fibers per se. In that regard, both the DPR and the DP cables perform equally well and show similar differences in comparison to the other assessed cables.

\section{CONCLUSION}

The mechanical properties of the DPR cable have not been deleteriously affected by the addition of homogeneously dispersed bismuth oxide particles within each fiber, and are superior to the compared sublaminar wire systems in terms of tensile and fatigue strength, while possessing a stiffness at least comparable to metal cables. UHMWPE cables do exhibit higher creep elongation in comparison to metal cables, but so far no negative clinical implications have been reported. Limited amounts of bismuth oxide are released through leaching in vitro, which are well below established tolerable intake. Tissue concentrations lower than therapeutic dosages as used against gastrointestinal disorders, and well below toxic levels, were found after 24 weeks of implantation in sheep. These results suggest that the DPR cables may safely be used as a sublaminar wire, and substantiate controlled clinical trials.

\section{ACKNOWLEDGEMENTS}

The authors would like to thank Armand Wintjens, Ferry Soeters, (DSM Biomedical) and Virginia Ballotta (Eindhoven University of Technology) for their help and support with the mechanical tests, and Fenneke Linker and Judith Muijtjens (DSM) for their toxicology expertise and help and support with the leaching tests respectively. 


\section{REFERENCES}

[1] Liljenqvist UR, Link TM, Halm HF. Morphometric Analysis of Thoracic and Lumbar Vertebrae in Idiopathic Scoliosis. Spine (Phila Pa 1976). 2000;25:1247-53.

[2] Parent S, Labelle H, Skalli W, de Guise J. Thoracic Pedicle Morphometry in Vertebrae from Scoliotic Spines. Spine (Phila Pa 1976). 2004;29:239-48.

[3] Di Silvestre M, Parisini P, Lolli F, Bakaloudis G. Complications of Thoracic Pedicle Screws in Scoliosis Treatment. Spine (Phila Pa 1976). 2007;32:1655-61.

[4] Raney EM. Hooks and Wires--Tried and True Plus How To: Posna1-Daycourse, April 29, 2009. J Pediatr Orthop. 2011;31:S81-7.

[5] Polly DW, Jr., Potter BK, Kuklo T, Young S, Johnson C, Klemme WR. Volumetric Spinal Canal Intrusion: A Comparison between Thoracic Pedicle Screws and Thoracic Hooks. Spine (Phila Pa 1976). 2004;29:63-9.

[6] van Laar W, Meester RJ, Smit TH, van Royen BJ. A Biomechanical Analysis of the Self-Retaining Pedicle Hook Device in Posterior Spinal Fixation. Eur Spine J. 2007;16:1209-14.

[7] Hitchon PW, Brenton MD, Black AG, From A, Harrod JS, Barry C, et al. In Vitro Biomechanical Comparison of Pedicle Screws, Sublaminar Hooks, and Sublaminar Cables. J Neurosurg. 2003;99:104-9.

[8] Hamasaki T, Tanaka N, Kim J, Okada M, Ochi M, Hutton WC. Pedicle Screw Augmentation with Polyethylene Tape: A Biomechanical Study in the Osteoporotic Thoracolumbar Spine. J Spinal Disord Tech. 2010;23:127-32.

[9] Reames DL, Smith JS, Fu KM, Polly DW, Jr., Ames CP, Berven SH, et al. Complications in the Surgical Treatment of 19,360 Cases of Pediatric Scoliosis: A Review of the Scoliosis Research Society Morbidity and Mortality Database. Spine (Phila Pa 1976). 2011;36:1484-91.

[10] Songer MN, Spencer DL, Meyer PR, Jr., Jayaraman G. The Use of Sublaminar Cables to Replace Luque Wires. Spine (Phila Pa 1976). 1991;16:S418-21.

[11] Weiss HR. Is There a Body of Evidence for the Treatment of Patients with Adolescent Idiopathic Scoliosis (Ais)? Scoliosis. 2007;2:19.

[12] Huhn SL, Wolf AL, Ecklund J. Posterior Spinal Osteosynthesis for Cervical Fracture/Dislocation Using a Flexible Multistrand Cable System: Technical Note. Neurosurgery. 1991;29:943-6.

[13] Parsons JR, Chokshi BV, Lee CK, Gundlapalli RV, Stamer D. The Biomechanical Analysis of Sublaminar Wires and Cables Using Luque Segmental Spinal Instrumentation. Spine (Phila Pa 1976). 1997;22:267-73.

[14] Gazzeri R, Faiola A, Galarza M, Tamorri M. Universal Clamp System in Thoracolumbar Spinal Fixation: Technical Note. Acta Neurochir (Wien). 2009;151:1673-80.

[15] Mazda K, Ilharreborde B, Even J, Lefevre Y, Fitoussi F, Pennecot GF. Efficacy and Safety of Posteromedial Translation for Correction of Thoracic Curves in Adolescent Idiopathic Scoliosis Using a New Connection to the Spine: The Universal Clamp. Eur Spine J. 2009;18:158-69.

[16] Takahata M, Ito M, Abumi K, Kotani Y, Sudo H, Ohshima S, et al. Comparison of Novel Ultra-High Molecular Weight Polyethylene Tape Versus Conventional Metal Wire for Sublaminar Segmental Fixation in the Treatment of Adolescent Idiopathic Scoliosis. J Spinal Disord Tech. 2007;20:449-55.

[17] Imagama S, Ito Z, Wakao N, Ando K, Hirano K, Tauchi R, et al. Posterior Surgery for Adolescent Idiopathic Scoliosis with Pedicle Screws and Ultra-High Molecular Weight Polyethylene Tape: Achieving the Ideal Thoracic Kyphosis. J Spinal Disord Tech. 2012. 
[18] Jouve JL, de Gauzy JS, Blondel B, Launay F, Accadbled F, Bollini G. Use of the Universal Clamp for Deformity Correction and as an Adjunct to Fusion: Preliminary Results in Scoliosis. J Child Orthop. 2010;4:73-80.

[19] Sale de Gauzy J, Jouve JL, Accadbled F, Blondel B, Bollini G. Use of the Universal Clamp in Adolescent Idiopathic Scoliosis for Deformity Correction and as an Adjunct to Fusion: 2-Year Follow-Up. J Child Orthop. 2011;5:273-82.

[20] Roth AK, van der Veen AJ, Bogie R, Willems PC, van Rietbergen B, van Rhijn LW, et al. Range of Motion in Segmental Versus Nonsegmental Ultrahigh Molecular Weight Polyethylene Sublaminar Wire Growth Guidance Type Constructs for Early-Onset Scoliosis Correction. Spine (Phila Pa 1976). 2015;40:E1212-8.

[21] Bogie R, Roth A, Faber S, de Jong J, Welting T, Willems P, et al. Novel Radiopaque Uhmwpe Sublaminar Wires in a Growth-Guidance System for the Treatment of Early Onset Scoliosis: Feasibility in a Large Animal Study. Spine (Phila Pa 1976). 2014.

[22] Dickman CA, Papadopoulos SM, Crawford NR, Brantley AG, Gealer RL. Comparative Mechanical Properties of Spinal Cable and Wire Fixation Systems. Spine (Phila Pa 1976). 1997;22:596-604.

[23] Slikkerveer A, de Wolff FA. Pharmacokinetics and Toxicity of Bismuth Compounds. Med Toxicol Adverse Drug Exp. 1989;4:303-23.

[24] Canena J, Reis J, Pinto AS, Santos AM, Leitao J, Pinheiro T, et al. Distribution of Bismuth in the Rat after Oral Dosing with Ranitidine Bismuth Citrate and Bismuth Subcitrate. J Pharm Pharmacol. 1998;50:27983.

[25] Lee SP, Lim TH, Pybus J, Clarke AC. Tissue Distribution of Orally Administered Bismuth in the Rat. Clin Exp Pharmacol Physiol. 1980; 7:319-24.

[26] Taylor EG, Klenerman P. Acute Renal Failure after Colloidal Bismuth Subcitrate Overdose. Lancet. 1990;335:670-1.

[27] Briand GG, Burford N. Bismuth Compounds and Preparations with Biological or Medicinal Relevance. Chem Rev. 1999;99:2601-58.

[28] Sun H, Li H, Harvey I, Sadler PJ. Interactions of Bismuth Complexes with Metallothionein(li). J Biol Chem. 1999;274:29094-101.

[29] Roberts HW, Toth JM, Berzins DW, Charlton DG. Mineral Trioxide Aggregate Material Use in Endodontic Treatment: A Review of the Literature. Dent Mater. 2008;24:149-64.

[30] Torabinejad M, Parirokh M. Mineral Trioxide Aggregate: A Comprehensive Literature Review--Part li: Leakage and Biocompatibility Investigations. J Endod. 2010;36:190-202.

[31] Deb S, Abdulghani S, Behiri JC. Radiopacity in Bone Cements Using an Organo-Bismuth Compound. Biomaterials. 2002;23:3387-93.

[32] Hernandez L, Fernandez M, Collia F, Gurruchaga M, Goni I. Preparation of Acrylic Bone Cements for Vertebroplasty with Bismuth Salicylate as Radiopaque Agent. Biomaterials. 2006;27:100-7.

[33] Braz MG, Marcondes JP, Matsumoto MA, Duarte MA, Salvadori DM, Ribeiro DA. Genotoxicity in Primary Human Peripheral Lymphocytes after Exposure to Radiopacifiers in Vitro. J Mater Sci Mater Med. 2008;19:601-5.

[34] Rodilla V, Miles AT, Jenner W, Hawksworth GM. Exposure of Cultured Human Proximal Tubular Cells to Cadmium, Mercury, Zinc and Bismuth: Toxicity and Metallothionein Induction. Chem Biol Interact. 1998;115:71-83. 


\section{Chapter 3}

[35] Zeferino EG, Bueno CE, Oyama LM, Ribeiro DA. Ex Vivo Assessment of Genotoxicity and Cytotoxicity in Murine Fibroblasts Exposed to White Mta or White Portland Cement with 15\% Bismuth Oxide. Int Endod J. 2010;43:843-8.

[36] Sano Y, Satoh H, Chiba M, Okamoto M, Serizawa K, Nakashima H, et al. Oral Toxicity of Bismuth in Rat: Single and 28-Day Repeated Administration Studies. J Occup Health. 2005;47:293-8.

[37] Bradley B, Singleton M, Lin Wan Po A. Bismuth Toxicity--a Reassessment. J Clin Pharm Ther. 1989;14:423-41.

[38] Serfontein WJ, Mekel R. Bismuth Toxicity in Man Ii. Review of Bismuth Blood and Urine Levels in Patients after Administration of Therapeutic Bismuth Formulations in Relation to the Problem of Bismuth Toxicity in Man. Res Commun Chem Pathol Pharmacol. 1979;26:391-411. 


\section{Supplement to Chapter}

\section{Wear Characterization of Radiopaque UHMWPE Cables: an Observational Study}

Alex K. Roth, Karlien Boon-Ceelen, Harold Smelt, Bert van Rietbergen, Paul C. Willems, Lodewijk W. van Rhijn, Jacobus J. Arts

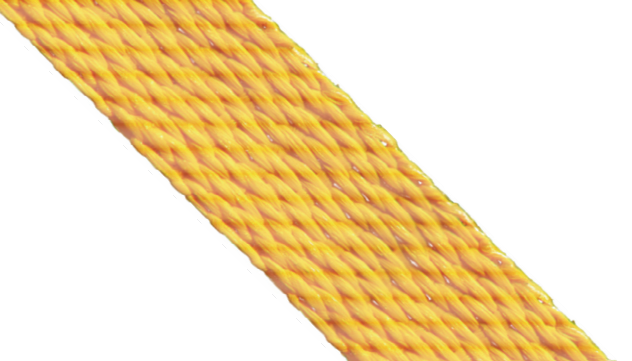




\section{INTRODUCTION}

Growth-guidance constructs for the treatment of early onset scoliosis (EOS) rely on free-sliding anchor members for longitudinal spinal growth. Articulation between the sliding anchor members and the spinal rod thus continually takes place, inevitably leading to wear particle generation. For the Luque trolley, the Shilla system, and the LSZ-4D system, metal-on-metal articulation occurs between the anchor members and the spinal rod, with reports of extensive metallosis encountered upon revision, increased metal ion blood concentrations, and sinus and seroma formation necessitating reoperation [1-8]. The presence of metallic wear particles is worrisome as the elicited macrophage-mediated inflammatory response may lead to osteolysis and subsequent instrumentation failure through implant loosening $[9,10]$. A recent casereport has described aseptic loosening of a pedicle screw with soft-tissue reactivity and inflammation due to metallic wear debris in an adolescent idiopathic scoliosis (AIS) patient after spinal fusion [11]. Furthermore, soft-tissue reactivity and inflammation described as late-onset operative site pain accounted for the highest number of revision cases (8\% or 14 patients) in a single-center cohort of AIS patients [12]. Fusion is intended for adolescent scoliosis patients, and therefore only micro-motion is expected to occur between construct components. For early onset scoliosis patients, micro- and macro-motion occur, which is expected to result in a higher metallic wear debris burden and a potential increase in the incidence of wear debris related complications.

The use of ultra-high molecular weight polyethylene (UHMWPE) sublaminar wires as sliding anchors in a growth-guidance construct for EOS patients eliminates the potential for metallic wear debris generation. Although UHMWPE is more susceptible to wear, polyethylene wear particles are typically much less reactive than metallic wear particles [13]. Furthermore, friction between UHMWPE and metal is widely known to be much lower than for metal-on-metal articulation. Little is known about the wear behavior of UHMWPE fibers articulating with metal surfaces. Therefore, the objective of this study is to perform a preliminary observational wear characterization for radiopaque UHMWPE sublaminar wires. Special attention is paid to the bismuth oxide particles within the radiopaque UHMWPE subliminar wires, which in theory could as third-body wear particles and accelerate the wear process.

Radiopaque UHMWPE cables may also prove beneficial as cerclage cables for fracture fixation, and complex primary or revision total joint arthroplasty. Low fatigue strength, cable fraying and fragmentation leading to non-union, third-body particle generation leading to accelerated component wear, bone destruction around the cable area, and injury to the surgical team by sharp cut cable ends are all drawbacks inherent to the use of metal cables as cerclage cables[14-17]. Cerclage cables for plate fixation are loaded in circumferential direction, and wear is expected to occur at the sites of contact with the plate edges. Since the radius of curvature of bone plate edges is typically much 
smaller than the radius of spinal rods, we reasoned that higher contact stresses, and thus a harsher wear scenario would be encountered during articulation with a compression plate in comparison to a spinal rod. For this reason, we characterized wear after a dynamic tensile loading regime was applied to a UHMWPE cable wrapped around a stainless steel compression plate. Wear was quantified gravimetrically and scanning electron microscopy (SEM) was used to analyze contact surfaces and potential particles generated. As this study is the first of its kind, its nature is purely observational.

\section{MATERIALS AND METHODS}

\section{Material specification}

The previously described radiopaque $4 \mathrm{~mm}$ wide woven UHMWPE sublaminar cables made with Dyneema Purity ${ }^{\circledR}$ Radiopaque fibers were used in this study. All cables were ethylene oxide sterilized before all tests.

\section{Mechanical loading test setup}

Radiopaque UHMWPE cables $(n=5)$ were subjected to a mechanical loading protocol using an electrodynamic material testing machine (MTS Acumen 3, MTS, Eden Prairie, MN, USA). Cyclic loading between 50-500 N was applied at a frequency of $5 \mathrm{~Hz}$ for 1 million cycles. Testing was performed at room temperature, under dry conditions, with the set-up in a closed chamber. Mechanical tests were performed using looped samples. A modified double-looped sliding knot was used to secure the UHMWPE cables, in accordance with a previous animal study [18]. The double-looped sliding knot is tied off using a single square knot throw, tensioned using a custom tensioning device to $550-600 \mathrm{~N}$, and finally tied-off using six additional square knot throws.

A custom set of fixtures was used; the lower grip holds a cylindrical pin with a diameter of $30 \mathrm{~mm}$, while the upper grip was custom made to hold a generic stainless steel fixation plate (Synthes, type 226.09 (4.5 mm Broad DCP ${ }^{\circledR}$ Plate, 9 Holes, $151 \mathrm{~mm}$ ) or type 226.14 (4.5 mm Broad DCP ${ }^{\circledR}$ Plate, 14 Holes, $231 \mathrm{~mm}$ )). The most likely locations for wear are the edges of the bone plate, which have a relatively small radius of curvature (approx. $1.5 \mathrm{~mm}$, Figure 2). Before testing, all bone plates were cleaned in a sonification bath using a medical surfactant cleaner (neodisher ${ }^{\circledR}$ MediClean forte, Dr. Weigert Nederland BV, Assen, The Netherlands), rinsed with acetone, and then dried with paper tissue. Aluminum foil was placed underneath the lower cylindrical pin to collect possibly produced wear particles. 


\section{Wear quantification}

Wear rate was quantified gravimetrically using a mass balance (AE200, Mettler-Toledo, Greifensee, Switzerland), by determining the mass of the cable loops before and after subjection to the mechanical loading protocol. A mean of five repeated mass measurements was taken. An untested reference sample was placed within the same closed chamber as the test sample and was weighed at the same time points. Comparison between the loaded sample and the unloaded reference sample was made using Wilcoxon Signed-Rank test for related samples. Statistical significance was set at $p<0.05$. Statistical analyses were performed using standard software (IBM SPSS Statistics, Version 21.0; IBM Corp, Armonk, NY).
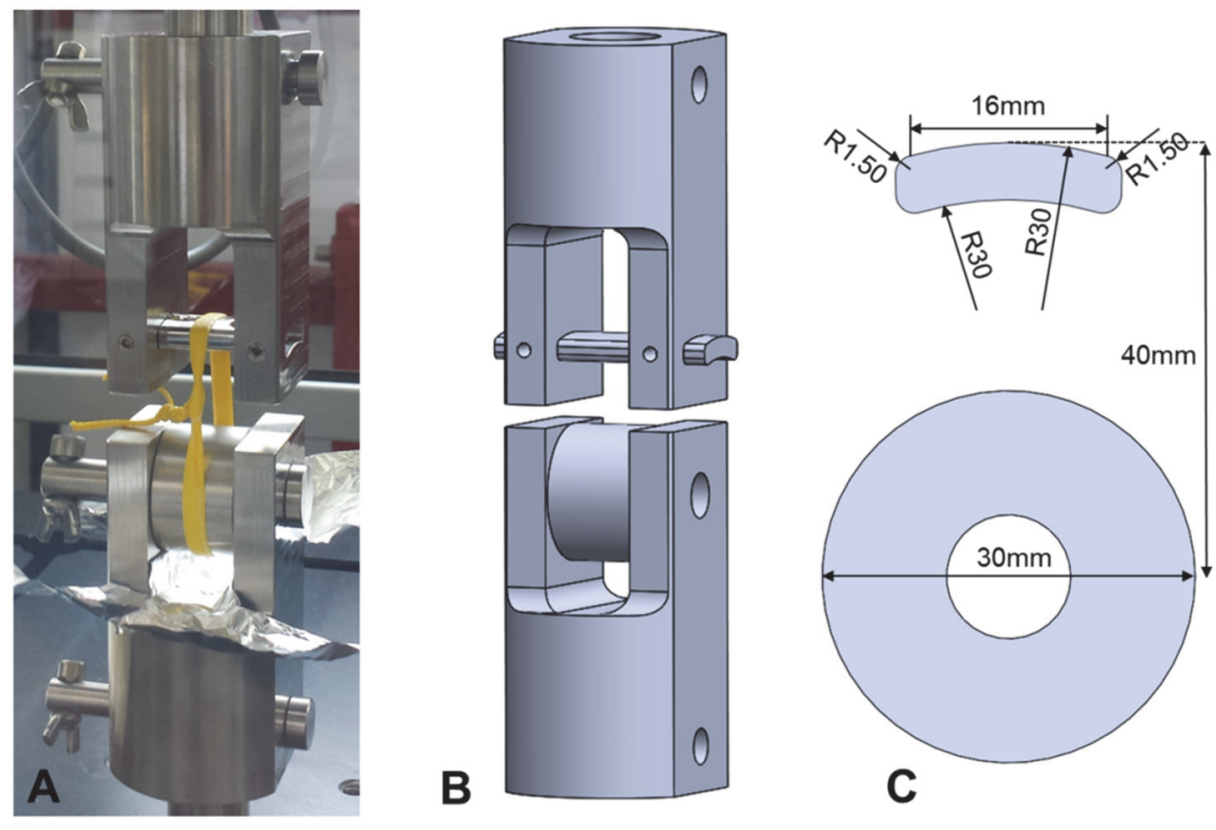

Figure 1 - The wear test setup, showing (A) the physical test setup, (B) the schematic design, and (C) the dimensions of the contact surfaces.

\section{Wear particle analysis}

Size and shape/morphology of collected wear particles was analyzed using Scanning Electron Microscopy (SEM). The bone plate, contact surface of the cerclage cables, and the cylindrical pin were also analyzed using SEM. Chemical composition of large particles $(>40 \mu \mathrm{m})$ was determined using Fourier Transform Infrared spectroscopy (FT- 
IR) to check whether they are polyethylene particles containing bismuth oxide. For smaller particles, SEM imaging at a higher acceleration voltage (5-10kV) was performed, as bismuth oxide particles can be easily identified in this manner.

\section{RESULTS}

All tested cables withstood 1 million cycles of loading without failure. Macroscopic inspection showed no fiber fraying or gross damage. Creases in the UHMWPE cables were clearly visible at the site of contact between the cable and the fixation plate edge (Figures 2A). Closer inspection showed that the creases formed as a result of compression and fusion of UHMWPE fibers at the site of contact with the bone plate (Figure 2B, 2C). Slight fraying and fibrillation damage was occasionally observed, most often near the edges of fused segments or near the cable edges. Similar patterns were also observed in untested reference samples, so this phenomenon is likely at least partly attributable to the weaving process. Mean gravitational wear amounted to $0.1 \pm$ $0.2 \mathrm{mg}$. No significant differences were observed when comparing the mass changes of loaded test samples to the unloaded reference samples $(P=1.000)$.

Accumulations of bismuth oxide were observed near the contact points with the metal fixation plate edges, usually in depressed or peripheral areas (Figure 2D, 2E). Clear abrasion marks, with topical damage to fused filaments were observed at higher magnifications (Figure 3A, magnification 1,000 times). Wear of bismuth oxide aggregates also occurred through abrasion (Figure 3B, magnification 10,000 times). Generally, the bismuth oxide particles remained confined within the UHMWPE structure; a few bismuth oxide particles appeared to be more loosely embedded in the fibers (Figure 3C) and some particles were observed within crevices and surface irregularities of the metal bone plates (Figure 3D). No typical bismuth oxide particles (bright, spherically shaped) or UHMWPE particles were encountered on the lower cylindrical loading pin and the aluminum particle collection foil, as determined by FTIR and/or SEM. 


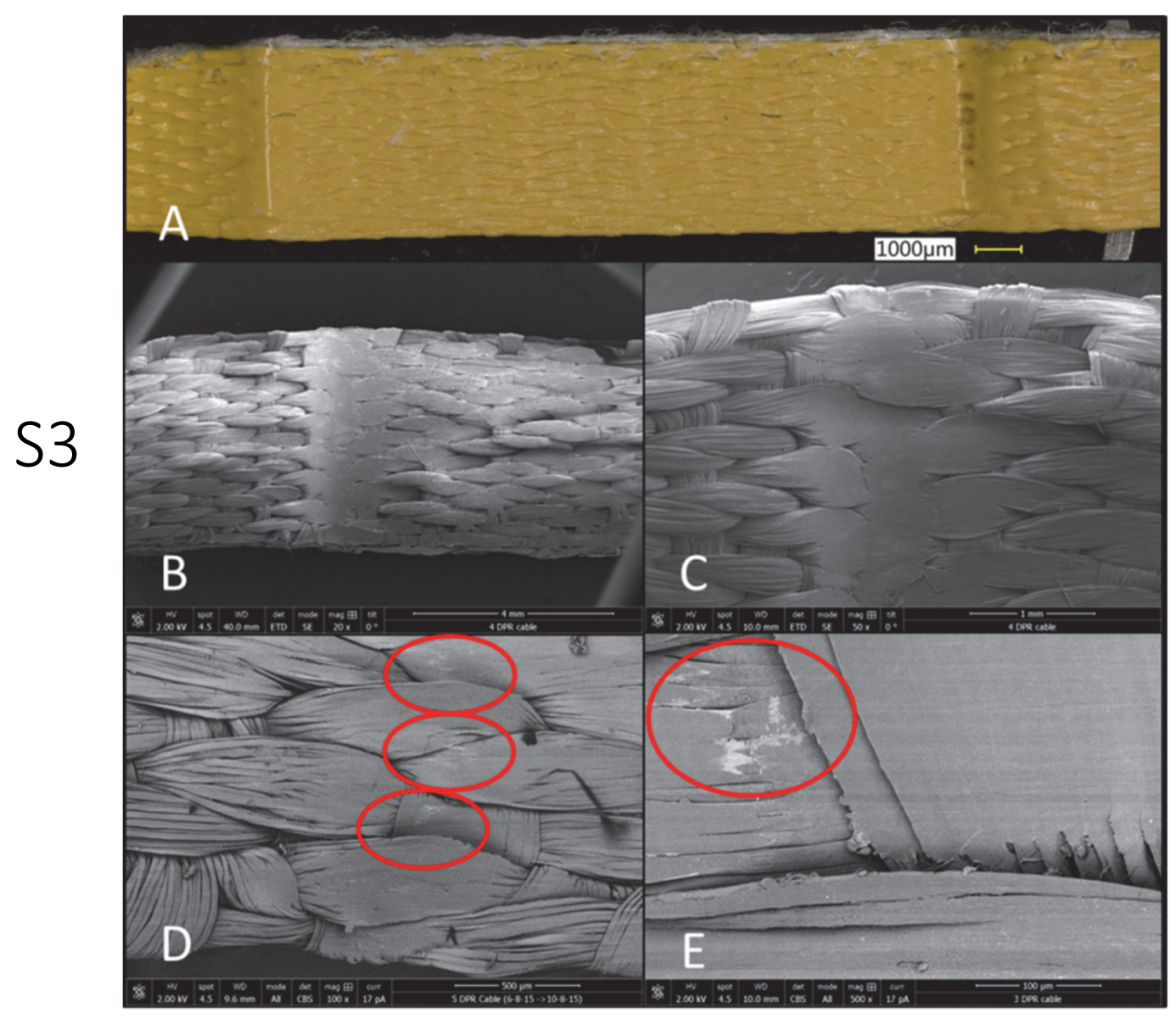

Figure 2 - (A) Macroscopic photograph of the DPR cable after sustaining the loading protocol. (B,C) SEM image showing fused and compressed fibers. (D,E) Examples of aggregation and piling up of bismuth oxide particles. 


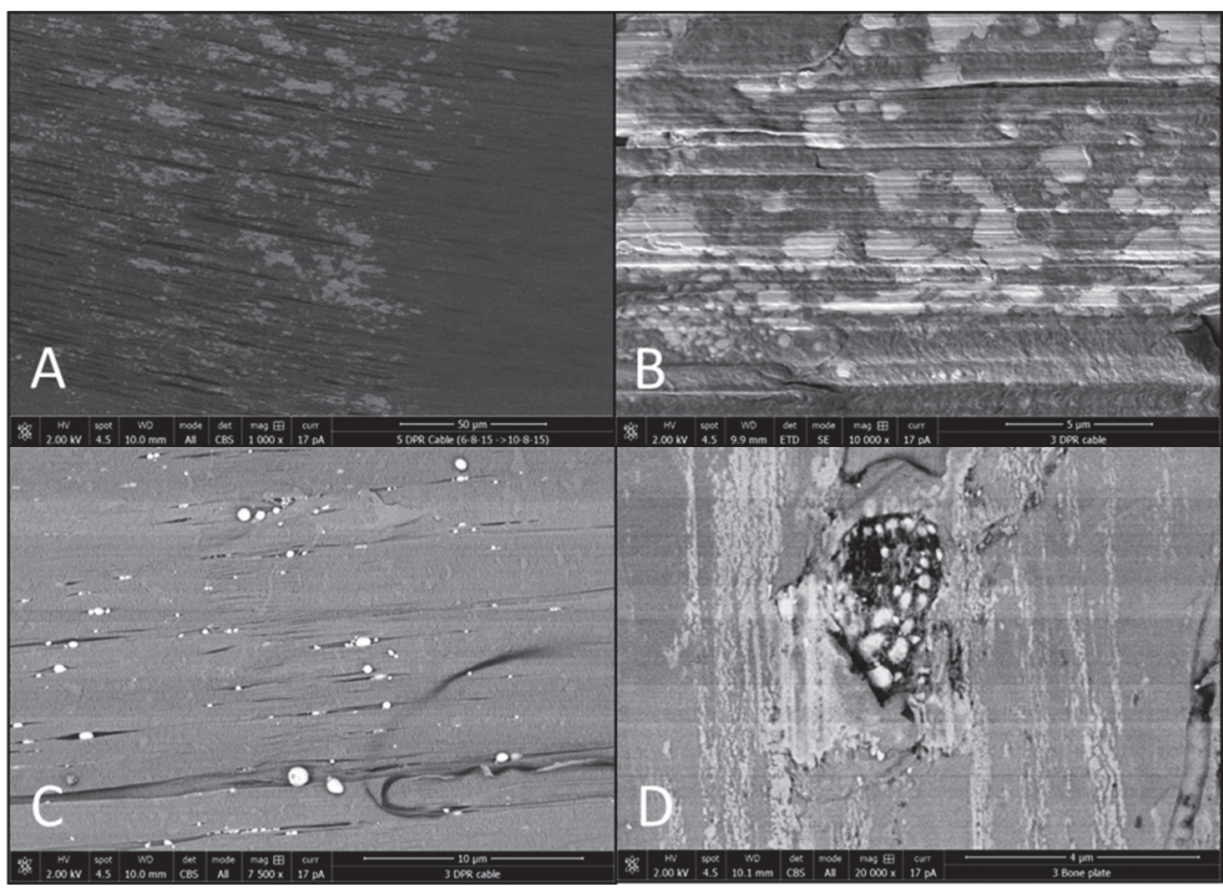

Figure 3 - $(A, B)$ More detailed SEM image showing bismuth oxide aggregation with abrasion and flattening of bismuth oxide particles. (C,) Spherical bismuth oxide particle loosening occasionally occurred through UHMWPE fiber surface wear. (D) Loose, spherical bismuth oxide particles also collect in micro surface irregularities in bone plate.

\section{DISCUSSION}

The objective of this study was to perform a preliminary observational wear characterization for radiopaque UHMWPE sublaminar wires. We observed no substantial damage as a result of wear after the applied loading regime. However, unidirectional loading has been applied to mimic clinical application of the cables as cerclage cables, whereas multidirectional loading of the cables would be required to provide an adequate representation of spinal deformity correction for EOS patients.

Compression and fusion of individual UHMWPE fibers without further substantial damage occurred at the sites of contact with the bone plates. This phenomenon was described earlier in a similar test by Sarin et al [19]. As accumulations of bismuth oxide were usually observed in depressed or peripheral areas, bismuth oxide particles do not appear to act as third-body particles and therefore will likely not accelerate the wear process. Fiber-on-fiber abrasion resistance has been assessed previously for polyester 
(PET), poly-ether ether ketone (PEEK), titanium, nylon, and UHMWPE fibers [20]. UHMWPE fibers proved to be the most wear resistant. To our knowledge, no other publications describe the wear behavior of UHMWPE fibers for medical applications. Failure as a result of abrasive wear, or wear debris-induced osteolysis have thus never been described for UHMWPE fibers.

The occasional damage that was observed was mostly of fibrillar nature, and was also observed in untested reference samples. Therefore we concluded that this damage could at least partly be a result of the weaving process. Green et al. have shown that phagocytosable UHMWPE particles between 0.3-10 $\mu \mathrm{m}$ in size are biologically most active [21]. Matthews et al. demonstrated that submicron sized wear particles elicit a substantially greater macrophage response, and are most critical [22]. As the fibrillar particles were not in this size range, it is unlikely that large amounts of such small particles will be generated in vivo and a highly active macrophage response to UHMWPE cable wear debris is not expected to occur.

It is important to note that this study has some limitations. The weaving process may have already induced damage prior to cable testing, which was not characterized for each individual sample. Instead a separate group of reference cables was used. Furthermore, possible damage to the fixation plate was not assessed using SEM beforehand either. A polished stainless steel fixation plate was used as abrasive surface. Beforehand, the low edge radius $(\sim 1.5 \mathrm{~mm})$ was reasoned to result in high contact stress magnitudes. The surface roughness of the fixation plate was not measured, but was deemed typical of routinely used compression plates. Worse cases may potentially be encountered with slightly damaged fixation plates or different surface finishes. Ideally, a mass balance of higher resolution (>0.1 mg) would have been used to be able to detect finer mass differences between loaded and unloaded reference samples. The most important limitations relate to the applied unidirectional load regime. The applied dynamic tensile loading regime results predominantly in circumferential forces, acting along the longitudinal fiber direction. UHMWPE fibers may be much more susceptible to wear when loads perpendicular to the fiber direction are encountered. Although the applied loading regime may be relevant for clinical application as a cerclage cable, this is not representative of the complex loading regime encountered when the UHMPWE cables are used as sliding anchors in a growth-guidance construct for the treatment of EOS. Therefore, we must be cautious in translating these results towards this clinical application.

Representative in vitro wear tests should be conducted prior to clinical introduction of the proposed construct for EOS patients. There are no standardized testing protocols available specific for growth-guidance type constructs. Existing standardized testing protocols (ISO 12189, ASTM F1717, ASTM F2624) may be adapted to assess growthguidance constructs, but the exact magnitudes of applied rotations in displacement- 
control remain disputed. We have developed a spine analog based on the ISO 12189 and ASTM F1717 test standards (Figure 4), but wear testing is yet to be performed. A six degree of freedom joint test machine is needed to apply combined loading protocols.

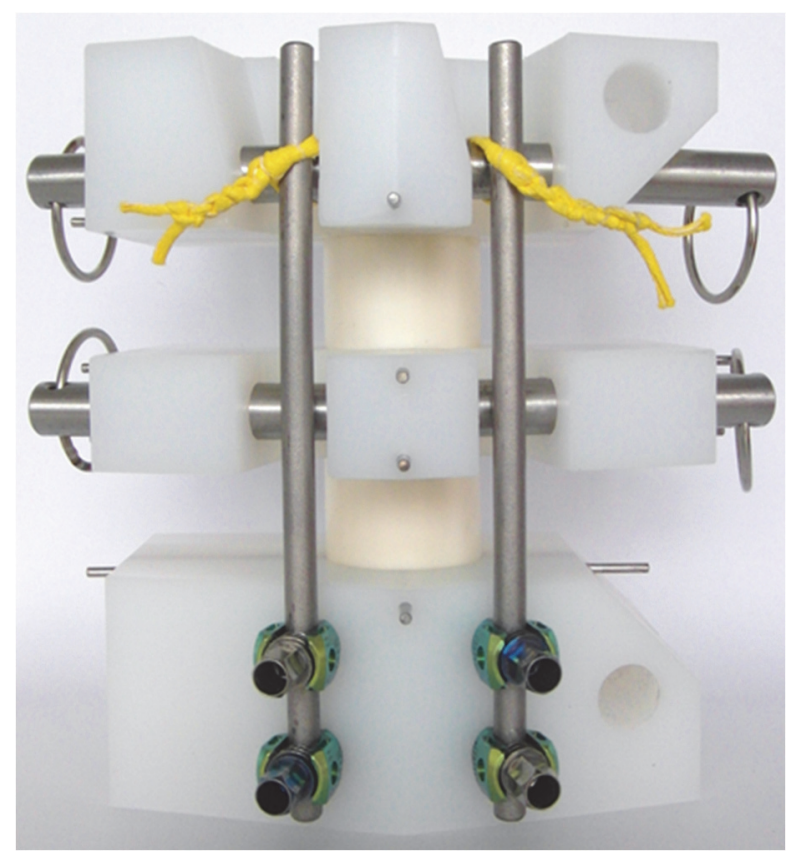

S3

Figure 4 - The spine analog test setup developed adapted from the ASTM F1717 and ISO 12189 test standards for the evaluation of wear. 


\section{REFERENCES}

[1] Lukina E, Kollerov M, Meswania J, Wertheim D, Mason P, Wagstaff P, et al. Analysis of Retrieved Growth Guidance Sliding Lsz-4d Devices for Early Onset Scoliosis and Investigation of the Use of Nitinol Rods for This System. Spine (Phila Pa 1976). 2015;40:17-24.

[2] Lukina E, Laka A, Kollerov M, Sampiev M, Mason P, Wagstaff P, et al. Metal Concentrations in the Blood and Tissues after Implantation of Titanium Growth Guidance Sliding Instrumentation. Spine J. 2016;16:380-8.

[3] Mardjetko SM, Hammerberg KW, Lubicky JP, Fister JS. The Luque Trolley Revisited. Review of Nine Cases Requiring Revision. Spine (Phila Pa 1976). 1992;17:582-9.

[4] McCarthy RE, Luhmann S, Lenke L, McCullough FL. The Shilla Growth Guidance Technique for EarlyOnset Spinal Deformities at 2-Year Follow-Up: A Preliminary Report. J Pediatr Orthop. 2014;34:1-7.

[5] McCarthy RE, McCullough FL. Shilla Growth Guidance for Early-Onset Scoliosis: Results after a Minimum of Five Years of Follow-Up. J Bone Joint Surg Am. 2015;97:1578-84.

[6] McCarthy RE, Sucato D, Turner JL, Zhang H, Henson MA, McCarthy K. Shilla Growing Rods in a Caprine Animal Model: A Pilot Study. Clin Orthop Relat Res. 2010;468:705-10.

[7] Pratt RK, Webb JK, Burwell RG, Cummings SL. Luque Trolley and Convex Epiphysiodesis in the Management of Infantile and Juvenile Idiopathic Scoliosis. Spine (Phila Pa 1976). 1999;24:1538-47.

[8] Rinsky LA, Gamble JG, Bleck EE. Segmental Instrumentation without Fusion in Children with Progressive Scoliosis. J Pediatr Orthop. 1985;5:687-90.

[9] Cunningham BW, Orbegoso CM, Dmitriev AE, Hallab NJ, Sefter JC, Asdourian P, et al. The Effect of Spinal Instrumentation Particulate Wear Debris. An in Vivo Rabbit Model and Applied Clinical Study of Retrieved Instrumentation Cases. Spine J. 2003;3:19-32.

[10] Hallab NJ, Cunningham BW, Jacobs JJ. Spinal Implant Debris-Induced Osteolysis. Spine (Phila Pa 1976). 2003;28:S125-38.

[11] Botolin S, Merritt C, Erickson M. Aseptic Loosening of Pedicle Screw as a Result of Metal Wear Debris in a Pediatric Patient. Spine (Phila Pa 1976). 2013;38:E38-42.

[12] Cook S, Asher M, Lai SM, Shobe J. Reoperation after Primary Posterior Instrumentation and Fusion for Idiopathic Scoliosis. Toward Defining Late Operative Site Pain of Unknown Cause. Spine (Phila Pa 1976). 2000;25:463-8.

[13] Kaufman AM, Alabre Cl, Rubash HE, Shanbhag AS. Human Macrophage Response to Uhmwpe, Tialv, Cocr, and Alumina Particles: Analysis of Multiple Cytokines Using Protein Arrays. J Biomed Mater Res A. 2008;84:464-74.

[14] Bauer TW, Ming J, D'Antonio JA, Morawa LG. Abrasive Three-Body Wear of Polyethylene Caused by Broken Multifilament Cables of a Total Hip Prosthesis. A Report of These Cases. J Bone Joint Surg Am. 1996;78:1244-7.

[15] Silverton CD, Jacobs JJ, Rosenberg AG, Kull L, Conley A, Galante JO. Complications of a Cable Grip System. J Arthroplasty. 1996;11:400-4.

[16] Altenburg AJ, Callaghan JJ, Yehyawi TM, Pedersen DR, Liu SS, Leinen JA, et al. Cemented Total Hip Replacement Cable Debris and Acetabular Construct Durability. J Bone Joint Surg Am. 2009;91:1664-70. 
[17] Hop JD, Callaghan JJ, Olejniczak JP, Pedersen DR, Brown TD, Johnston RC. The Frank Stinchfield Award. Contribution of Cable Debris Generation to Accelerated Polyethylene Wear. Clin Orthop Relat Res. 1997:20-32.

[18] Bogie R, Roth A, Faber S, de Jong J, Welting T, Willems P, et al. Novel Radiopaque Uhmwpe Sublaminar Wires in a Growth-Guidance System for the Treatment of Early Onset Scoliosis: Feasibility in a Large Animal Study. Spine (Phila Pa 1976). 2014.

[19] Sarin V.K. MTM, Hack B. A Novel Iso-Elastic Cerclage Cable for Treatment of Fractures. ORS. Washington D.C.2005. p. Poster No. 0739.

[20] Giordano MA, Schmid SR. Evaluation of Individual Fiber Wear Resistance Using Accelerated Life Testing. Tribology Transactions. 2012;55:140-8.

[21] Green TR, Fisher J, Stone M, Wroblewski BM, Ingham E. Polyethylene Particles of a 'Critical Size' Are Necessary for the Induction of Cytokines by Macrophages in Vitro. Biomaterials. 1998;19:2297-302.

[22] Matthews JB, Besong AA, Green TR, Stone MH, Wroblewski BM, Fisher J, et al. Evaluation of the Response of Primary Human Peripheral Blood Mononuclear Phagocytes to Challenge with in Vitro Generated Clinically Relevant Uhmwpe Particles of Known Size and Dose. J Biomed Mater Res. 2000;52:296-307. 
Supplement to Chapter 3

S3 


\section{ABSTRACT}

Study Design: In vivo analysis in an ovine model.

Objective: To evaluate the feasibility of radiopaque UHMWPE sublaminar wires in a growth-guidance spinal system by assessing stability, biocompatibility and growth potential.

Summary of Background Data: Several growth-guidance systems have been developed for the treatment of early onset scoliosis (EOS). The use of gliding pedicle screws and metal sublaminar wires during these procedures can cause metal-on-metal debris formation and neurological deficits. Novel radiopaque UHMWPE wires are introduced to safely facilitate longitudinal growth and provide stability in a growth-guidance system for EOS.

Method: Twelve immature sheep received posterior segmental spinal instrumentation; pedicle screws were inserted at L5 and radiopaque UHWMPE (bismuth trioxide) wires were passed sublaminarly at each level between L3 and T11 and fixed to dual cobaltchromium rods. Four age-matched, unoperated animals were evaluated to serve as a control group. Radiographs were taken to measure growth of the instrumented segment. After 24 weeks, the animals were sacrificed and the spines were harvested for histological evaluation and high resolution peripheral quantitative computed tomography (HR-pQCT) analysis.

Results: No neurological deficits occurred and all instrumentation remained stable. One animal died from an unknown cause. Substantial growth occurred in the instrumented

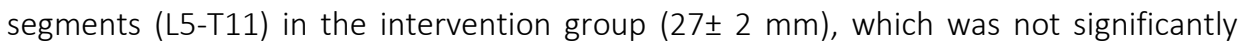
different to the control group, $(30 \pm 4 \mathrm{~mm}, \mathrm{p}=0.42)$. HR-pQCT analysis clearly showed safe routing and fixation of the UHMWPE wires and instrumentation. Despite the noted growth, ectopic bone formation with the formation of bony bridges was observed in all animals. Histology revealed no evidence of chronic inflammation or wear debris.

Conclusion: This study shows the first results of radiopaque UHMWPE sublaminar wires as part of a growth-guidance spinal system. UHMWPE sublaminar wires facilitated nearnormal longitudinal spinal growth. All instrumentation remained stable throughout follow-up; no wire breakage or loosening occurred and no adverse local tissue response to these wires was observed. 


\section{INTRODUCTION}

Challenging issues are faced in the management of early onset scoliosis (EOS). In the last decades, it has become apparent that early surgery aiming simply to attain a straight spine is not sufficient $[1,2]$. Early definitive fusion may not only lead to a short trunk and disproportionate body stature, but also restricts volumetric growth of the thoracic cage and can restrict pulmonary development [3].

Growth-guidance or self-lengthening rod systems are an alternative to distraction based growth preservation systems, such as growing rods and the vertical expandable prosthetic titanium rib (VEPTR) for the surgical treatment of EOS [1, 4]. A major advantage of growth-guidance systems is the marked decrease in subsequent operative procedures and associated hospitalization. Therefore, growth-guidance systems may be especially suitable for neuromuscular type EOS patients, who often suffer from significant medical comorbidities [5, 6]. Examples of growth-guidance systems are the Shilla system [7] and a modern Luque trolley [8], which both rely on gliding pedicle screws and/or sliding titanium sublaminar wires. Animal and in vitro studies have shown that wear at the screw-rod interface in the Shilla system caused considerable amounts of metallic wear debris formation in the surrounding tissue [7, 9]. Furthermore, placement of thoracic pedicle screws can be difficult due to distorted vertebral anatomy which is often seen in scoliosis patients [10]. In these technically demanding cases sublaminar wires can be a valuable alternative [11]. The use of metal wires in the original Luque trolley system did not lead to reliable spinal growth after surgery [8, 12, 13] and has been frequently associated with a high incidence of neurological complications [14-16].

We propose the use of novel radiopaque ultra-high molecular weight polyethylene (UHMWPE) woven wires as an alternative to gliding pedicle screws or titanium sublaminar wires for use in a growth-guidance system for EOS. The flat and broad shape of the woven UHMWPE sublaminar wires allow for distribution of contact forces over a greater area, thereby (theoretically) increasing corrective force and lowering risk of wire pull-out in comparison to metal wires $[17,18]$. The soft and flexible properties of polymeric wires help avoid neurological injury during insertion or removal of the sublaminar wires. Despite the increased contact surface, UHMWPE wires exhibit lower friction during longitudinal sliding along metal rods as compared to titanium sublaminar wires in an in vitro test setup (internal data, not published). Furthermore, as no metalon-metal articulation occurs, the possible consequences of excessive metallic wear particles are not an issue.

We recently performed a pilot study in which we tested spinal instrumentation with UHMWPE sublaminar wires in an immature ovine model [19]. This study showed that the UHMWPE sublaminar wires had excellent handling properties and that all 
instrumentation remained stable and intact. We experienced no neurological complications and UHMWPE sublaminar wire biocompatibility in the spinal canal was confirmed using histology. Most importantly, substantial spinal growth after instrumentation was observed. Radiolucency of the UHMWPE sublaminar wires limited the possibility for postoperative radiologic assessment in our initial pilot study. In the current study, we instrumented immature ovine spines using novel radiopaque UHMWPE sublaminar wires, in which bismuth trioxide particles were blended into each fiber. The goal of this study was to assess potential for growth-allowance by quantifying spinal growth after instrumentation with UHMWPE sublaminar wires in immature sheep and by making a comparison to unoperated, age-matched control animals. Furthermore, histology was performed to analyze the local tissue response to these novel radiopaque UHMWPE sublaminar wires.

\section{MATERIALS AND METHODS}

\section{Material specifications}

The sublaminar wire used in this study is a $4 \mathrm{~mm}$-wide woven UHMWPE wire made with Dyneema Purity Radiopaque ${ }^{\circledR}$ fibers (DSM Biomedical B.V., Geleen, the Netherlands). Bismuth trioxide particles were blended into each fiber for radiopacity $\left(\mathrm{Bi}_{2} \mathrm{O}_{3}, 20 \%\right.$ wt. additive) [20]. All UHMWPE wires were ethylene oxide sterilized. Dynamic fatigue failure test in a servo-hydraulic testing frame showed that the cables could endure 5 million cycles with a load of $1350 \mathrm{~N}$ without failure.

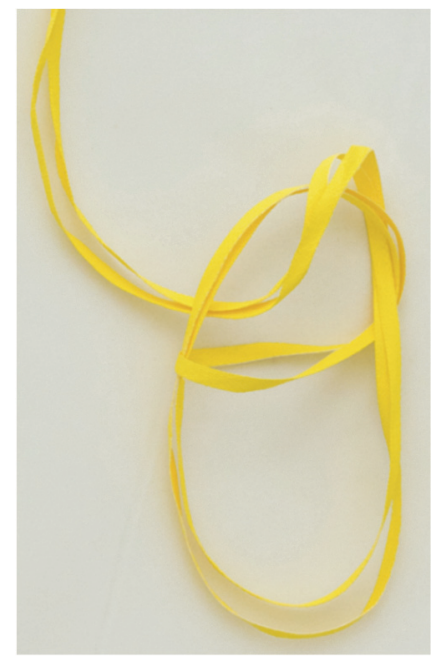

Figure 1-4 mm-wide radiopaque UHMWPE sublaminar wire and the double loop sliding knot with extra pass used to secure the wire. 


\section{Surgical procedure}

All animal procedures were approved by the Animal Ethical Committee of the Maastricht University Medical Centre (approval number: DEC 2011-122). Twelve immature Texelaar sheep (ewes, 18 weeks old, weighing $20.1 \pm 3.1 \mathrm{~kg}$ ) were subjected to surgery, while four age-matched, animals $(24.8 \pm 2.8 \mathrm{~kg})$ served as radiographic control. Antibiotics (amoxicillin/clavulan acid 1.2 gr.) were administered intravenously preoperatively. Each animal was sedated with intravenous administration of thiopental (25 mg/kg), and anesthesia was maintained using $1 \%$ to $2 \%$ isoflurane. Pain medication was given and adjusted if needed during surgery (remifentanyl $1 \mu \mathrm{g} / \mathrm{kg}$ per minute intravenously). Electrocardiogram registration, ventilation curves, oxygen saturation level and heart rate were continuously monitored. After a posterior midline incision was made from T11 to L5, the transverse processes and the facet joints were minimally exposed by partially detaching the erector spinae using electrocautery. Under fluoroscopic guidance, two pedicle screws $(4.75 \mathrm{~mm}$ diameter, $20 \mathrm{~mm}$ length, Solera', Medtronic) were inserted into the $L 5$ vertebral body. The ligamentum flavum was opened interlaminarly and partially removed with a punch, leaving the spinous processes intact. In this manner the laminae of $T 12$ to $L 3(T 12, T 13, L 1, L 2, L 3)$ were exposed without violation of the dura mater, and UHMWPE wires were subsequently passed sublaminarly. In sheep, facet joints at upper thoracic levels overlap dorsoventrally, making sublaminar wire passage difficult. For this reason, lumbar and lower thoracic levels were selected for instrumentation. Dual cobalt chromium plus rods $(4.75 \mathrm{~mm})$ were placed along the spine and fixed using setscrews at the attachments. A double-loop sliding knot secured the wires to the rods (as used by Saito et al. [21] and Takahati et al. [22], but modified by an additional pass of wire ends through the loop). A single throw square knot was placed over the sliding knot, tension was applied using a custom-made tensioning device, and the knot was ultimately secured with 5 -throw square knots (Figure 1-2). The wound was closed in layers. Postoperative pain management (buprenorphine $6 \mu \mathrm{g} / \mathrm{kg}$, carprofen $1 \mathrm{ml} / \mathrm{kg}$ intramuscularly) was provided until the animals returned to activities. Antibiotic treatment was administered postoperatively intramuscularly 6 hours after surgery.

X-rays were taken directly postoperatively and subsequently at four-week intervals under light tiletamine-zolazepam $(8 \mathrm{mg} / \mathrm{kg}$ ) sedation until sacrifice at 24 weeks. Euthanization was performed using pentobarbital overdose (200 mg/kg). After sacrifice, the spines were harvested and High Resolution Peripheral Quantitative Computed Tomography scans (HRpQCT) were acquired. The spines were cleaned of soft tissue and processed for macroscopical and histological analysis. 


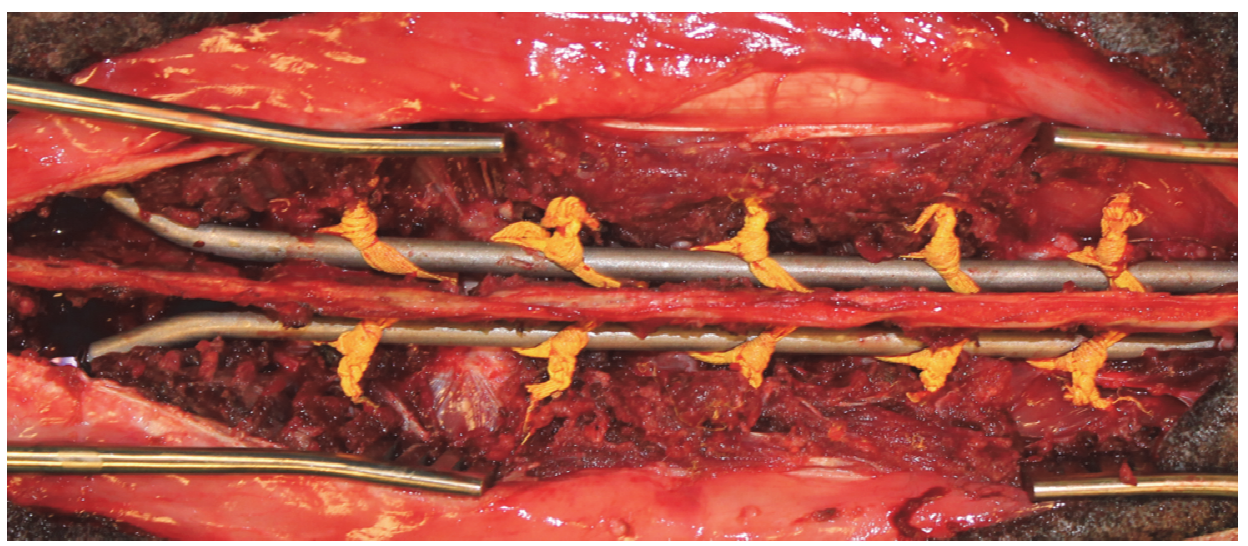

Figure 2 - Intraoperative view of spinal instrumentation prior to wound closure.

\section{Radiography and spinal length measurement}

Routine dorsoventral and lateral radiographs were acquired directly postoperatively and subsequently at four-week intervals under light tiletamine-zolazepam (8 mg/kg) sedation until sacrifice at 24 weeks by pentobarbital overdose $(200 \mathrm{mg} / \mathrm{kg}$ ). Length of the operated segment was determined based on lateral radiographs using a custom written MATLAB code. A radiopaque ruler was placed on the spinal midline during radiographic acquisition and was used to calibrate the images. Edges of each individual vertebral body were subsequently manually selected. Length of the operated segment was defined as the summation of the individual vertebrae and the intermediate intervertebral discs.

\section{High Resolution Peripheral Quantitative Computed Tomography}

HRpQCT was performed to analyze routing and stability of the laminar wires and to assess orthotopic bone formation and facet joint changes. HR-pQCT scans were made using clinical in vivo settings (XtremeCT, Scanco Medical AG, Switzerland; effective energy $60 \mathrm{kVp}$, tube current $900 \mu \mathrm{A}, 100 \mathrm{~ms}$ integration time, isotropic voxel size 82 $\mu \mathrm{m})$. Prior to HR-pQCT scanning, rods were removed from harvested spines by sawing through the L4/L5 intervertebral disc, and subsequently sliding levels L4-T12 in cranial direction. 


\section{Histology}

The vertebrae of two spines were dissected for macroscopic and histological evaluation. Instrumented vertebrae were fixed in formalin and embedded in polymethyl methacrylate (Technovit 9100). Transverse sections with a thickness of $60 \mu \mathrm{m}$ were made with a Leica microtome and stained with Masson-Goldner's trichrome and Hematoxyline and Eosin (HE). Sections were analyzed for granulation tissue formation and inflammatory response.

\section{Statistical analysis}

Measurements were performed twice for each image by two individual observers. Inter and intra-observer reliability was assessed using the Intraclass Correlation Coefficient (ICC). Comparisons between the instrumented group and control group were performed using an unpaired Student's t-test. All statistical tests were 2-tailed, and a pvalue $<0.05$ was considered to be significant. All analyses were performed using SPSS software, version 19.0 .

\section{RESULTS}

All animals tolerated the procedure well and no intra-operative neurological injury occurred during pedicle-screw placement or during sublaminar wire passage. The animals were ambulatory within 12 hours. One animal died 3 weeks postoperatively, with no clear cause of death as determined during autopsy. The animal presumably suffered from heat stroke. The other animals experienced no major complications during the 24 weeks follow-up.

Instrumentation remained stable in all animals. The animals in the operated group showed marked growth of the operated segments, with sliding of the UHMWPE laminar wires along the rods. In most animals, the most cranially placed wires slid off of the rods (Figure 3). Quantitatively, the mean length of the operated segment in the experimental group increased by $27 \pm 2 \mathrm{~mm}$, compared to $30 \pm 4 \mathrm{~mm}$ in the control group after 24 weeks ( $P=0.42$, Figure 4). In both groups, growth ceased approximately 20 weeks postoperatively. In terms of normalized growth, both growth curves showed a similar pattern (16\% growth in the experimental group versus $17 \%$ in the control group). Growth measurement showed high inter- and intra-observer reliability, with an ICC of 0.94 and 0.99 respectively. 


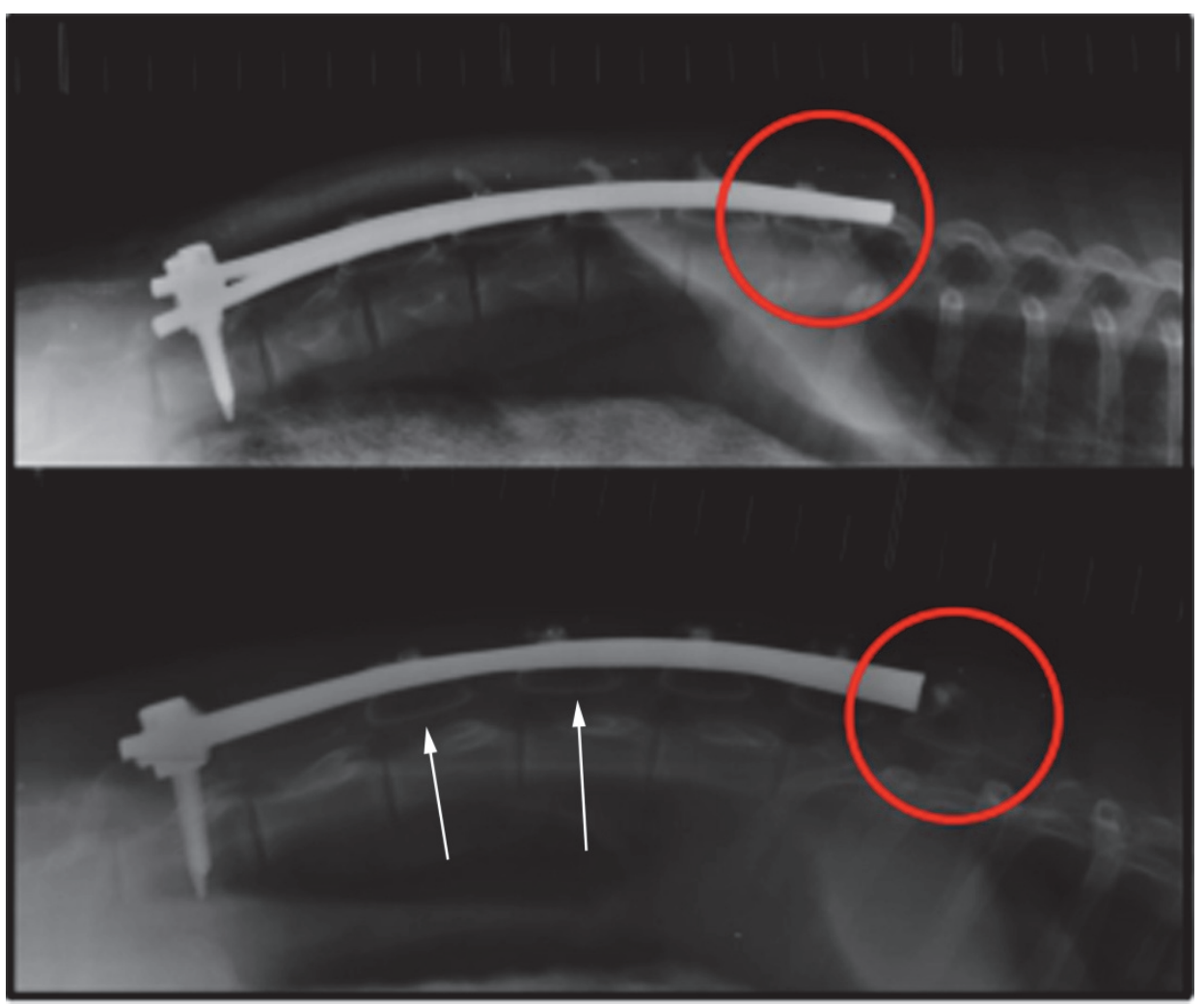

Figure 3 - Direct post-operative (upper) and 24-weeks post-operative lateral radiograph (lower) of the instrumented sheep spine. Marked growth of the instrumented segment has occurred as illustrated by sliding of the most cranial UHMWPE sublaminar wire (red circle). Novel radiopaque UHMWPE sublaminar wires are clearly visible on radiography (arrows).

Removal of the spinal rods was easy, indicating that no bone apposition directly onto the rods had occurred. Subsequent manual palpation detected loss of range of motion of the instrumented levels in all cases. HR-pQCT images revealed interlaminar ectopic bone formation, which did not completely bridge the interlaminar space (Figure 5D). This bone formation did not lead to compression of the dura or encroachment of the spinal canal. Bone formation originating from the spinous process, rounding the spinal rod was also observed (Figure $5 \mathrm{~A}, \mathrm{C}$ ). In some cases, a bony bridge between the spinous process and the facet joint was formed (Figure $5 \mathrm{~A}, \mathrm{~B}$ ). Although joint space narrowing was observed, the facet joint generally did not completely fuse.

Macroscopic inspection at harvest showed no signs of wire fraying or discoloration of surrounding tissues. Histological analysis revealed no significant pathological changes; UHMWPE sublaminar wires in the epidural space were encapsulated by fibrous tissue 
with no signs of chronic inflammatory reactions (Figure 6). No foreign body giant cells were observed and no fragmentation of the UHMWPE wires occurred. Polarized light microscopy assessment of plastic embedded saw sections did not reveal UHMWPE wear particles.

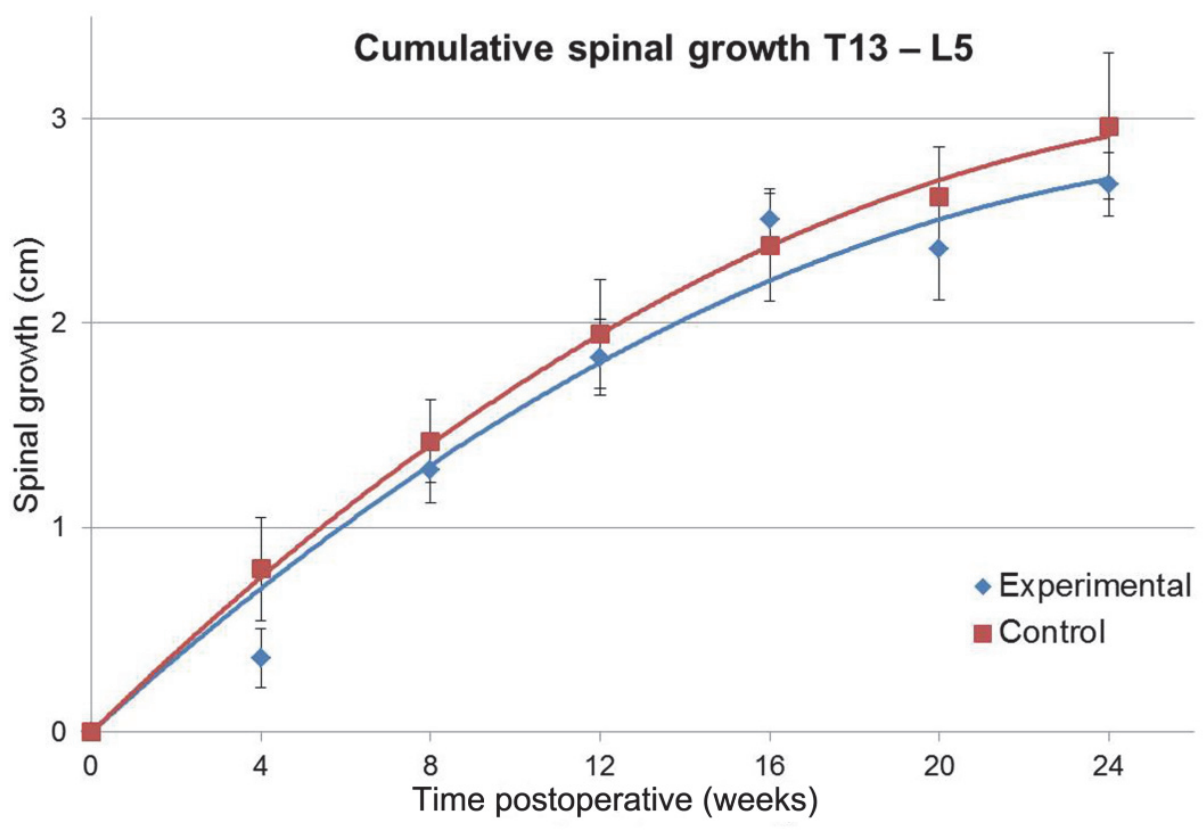

Figure 4 - Average growth $(\mathrm{cm})$ and standard deviation values of the experimental group and control group. Both curves show a similar pattern with cessation of growth around 20 weeks. 
A

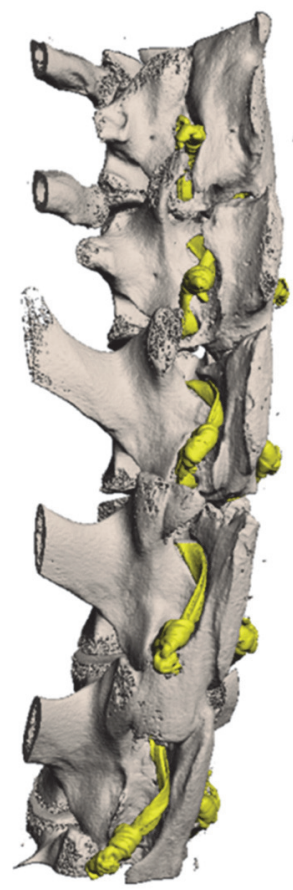

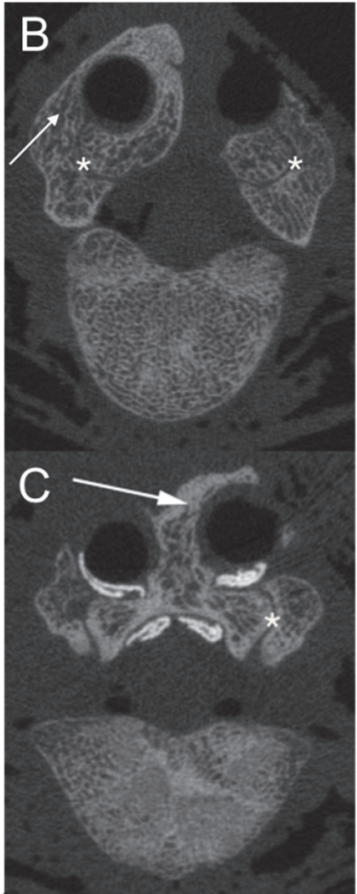

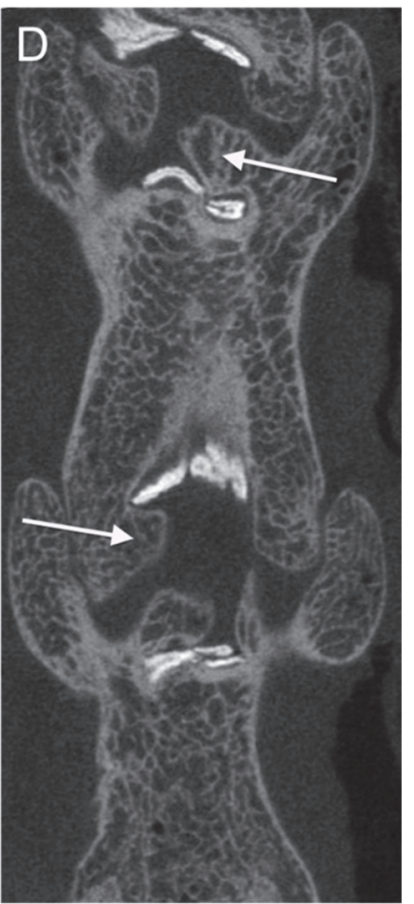

Figure 5 - (A) 3-D reconstruction of a HR-pQCT scan of an intervention group spine after extraction of the rods. The formation of a bony bridge between the facet joint and spinous process is observed at the lower lumbar level. (white arrow) (B) Transversal image at the level of the bony bridge as seen in the 3-D reconstruction. Ectopic bone formation has occurred around the rod (arrow), leaving the facet joint intact. (asterisk). (C) Transversal image showing the sublaminar wires in the spinal canal, ectopic bone formation (arrow) starting to encircle the rod and facet joints (asterisk). (D) Coronal HR-pQCT image, clearly visualizing the radiopaque UHMWPE wires around the laminae. Interlaminar ossification is seen in proximity to the UHMWPE wire (arrows). 


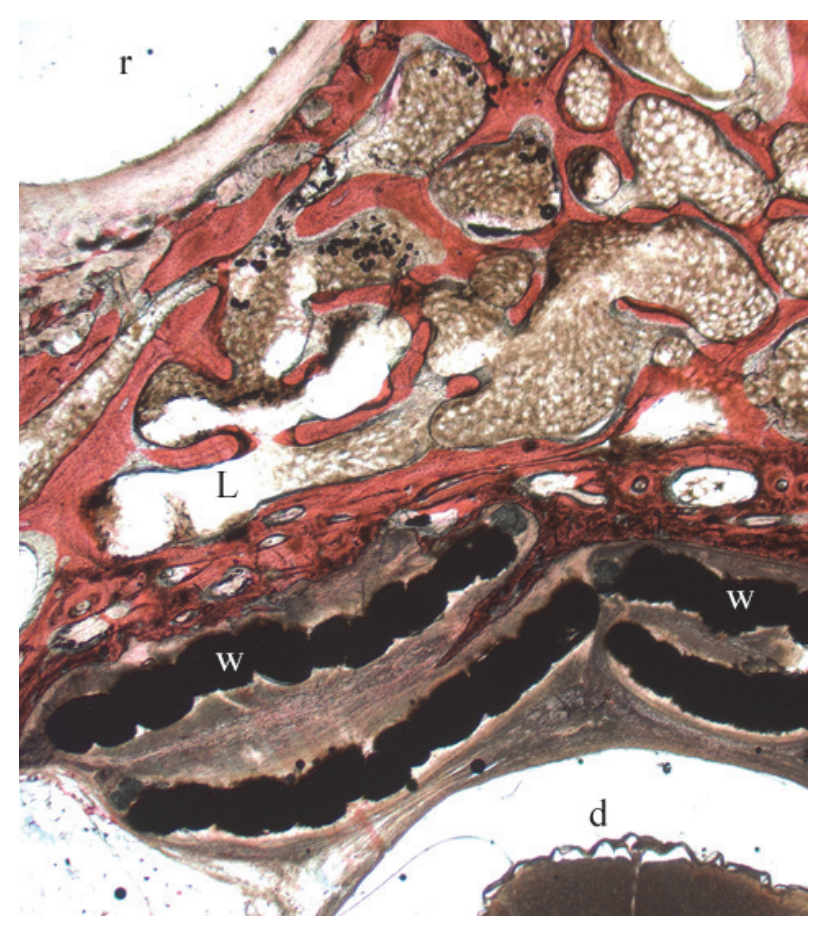

Figure 6 - Histologic section (hematoxylin and eosin staining, magnification 2.5x). Rod space ( $r$ ) with fibrous layer is shown in de upper left. The two double layer UHMWPE sublaminar wires (w) are positioned against the lamina (L). The dura (d) is shown to be thin and partially retracted.

\section{DISCUSSION}

In this study, we propose the use of radiopaque UHMWPE sublaminar wires as an alternative to gliding pedicle screws or metal sublaminar wires in a growth-guidance system for EOS treatment. Instrumentation with UHMWPE sublaminar wires did not seem to limit longitudinal spinal growth. At present, UHMWPE sublaminar wires are already clinically used in hybrid constructs for spinal fusion in adolescent scoliosis patients in Japan $[17,22,23]$. Wire radiolucency precludes the possibility for direct postoperative radiological follow-up. The first in vivo experience with radiopaque UHMWPE wires is presented in this study. Novel radiopaque UHMWPE sublaminar wires allow for postoperative radiological assessment and thus allow for more widespread application of UHMWPE sublaminar wires in spinal deformity correction, and as we propose here in a growth-guidance system for the treatment of EOS.

The inherent low friction properties of the UHMWPE wire facilitate longitudinal sliding along the rods without the potentially catastrophic effects of metallic wear particles in 
developing children. Currently investigated growth-guidance systems show wear-debris accumulation in surrounding soft tissue as a result of metal-on-metal articulation [7-9]. The long-term consequences of metallic wear particles in the pediatric spine are unknown. The effects of UHMWPE wear particles, although potentially severe, are less detrimental and require a larger volume. Till date only few case reports have described inflammation due to UHMWPE wear in spine [24].

The fact that no foreign body giant cells were observed and no fragmentation of the UHMWPE wires occurred in this study are encouraging. Polarized light microscopy assessment of plastic embedded saw sections did not reveal UHMWPE wear particles. Standardized in vitro wear assessment will performed in the near future and will elucidate the amount and size of wear debris generated after in vivo placement in an animal model.

Data from our earlier study supported biocompatibility of (radiolucent) UHWMPE wires [19]. The biological reaction to the novel radiopaque UHMWPE sublaminar wire, with bismuth trioxide particles blended into each fiber, was similar to the radiolucent UHMWPE wire and comparable to what has been described for other polymeric sublaminar wires [25]. Histological evaluation showed that the UHMWPE sublaminar wire was encapsulated by fibrous tissue and caused no chronic inflammatory reactions. Furthermore, macroscopic and histology evaluation did not show fraying of the UHMWPE sublaminar wires. Damage to the UHMWPE sublaminar wire is not expected, and so far not observed, as the ultimate tensile strength and fatigue strength for the UHWMPE wire including the knot are superior to currently used sublaminar wires (unpublished data; $2250 \mathrm{~N}$, and $1350 \mathrm{~N}$ (run-out at 5 million cycles) respectively). Although the first indication of biocompatibility was positive, local and systemic effects of the bismuth trioxide radiopacifier will be subject to further investigation.

With regard to the surgical treatment of EOS, it remains difficult to extrapolate the attained growth to a prolonged time period in children as growth velocity in an animal model is much higher as in the growing child. Pediatric T1-S1 growth is approximately $1 \mathrm{~cm} /$ year between the age of $5-10$, and $1.8 \mathrm{~cm} /$ year between the age of 10 and skeletal maturity [26]. In our ovine model, the operated segment alone (7 vertebrae) grew approximately $3 \mathrm{~cm}$ in 24 weeks. Due to the limited number of animals in the control group, we could not attain sufficient statistical power needed to make a fair comparison between the operated and the control groups. We deemed the use of more control animal subjects unethical, as we considered small differences to be clinically irrelevant in this early stage of research. The cessation of growth in both the experimental and control group at around 20 weeks postoperatively are as expected from growth curves described in the literature [27]. In this study, five consecutive levels were instrumented with sublaminar wires. We aimed to illustrate the potential for continued growth after spinal instrumentation with UHMWPE sublaminar wires at five consecutive levels to 
provide substantial resistance to growth. From a clinical perspective, optimal results in terms of attained growth and correction may be attained with fewer UHWMPE sublaminar wire fixation points at distal and proximal ends, combined with intended fusion at the apex, as proposed for the Shilla system. Spinal growth after instrumentation with the Shilla system was described in a caprine study by McCarthy et al [7]. An average spinal growth of $48 \mathrm{~mm}$ across 14 instrumented levels was achieved in this study over a similar time period. Although no direct comparison to our study can be made due to differences in age, species and instrumentation, growth per instrumented segment is similar in our study $(0.34 \mathrm{~cm} /$ segment versus 0.38 $\mathrm{cm} /$ segment in our study respectively).

Despite the noted growth, interlaminar ectopic bone formation and occurrence of bony bridging between the facet joints and spinous processes were seen to a certain extent in all animals. This observation revealed an atypical fusion pattern. During the approach, spinous processes were not removed and effort was made to disrupt spinal musculature as little as possible. However, some degree of periosteal stripping is inevitable for sublaminar wire passage due to dissection of the flaval ligament. The typical bone formation pattern was not noticeable on conventional postoperative radiographs, and could only be noted post-mortem after removal of the cobalt-chromium rods due to diffraction on $\mathrm{CT}$. Therefore we were not able to determine the time of onset of bone formation. The resulting ectopic bone formation was expected based on similar findings that have been encountered with the Luque trolley [12]. However, fusion rates are typically much higher in quadruped models than rates seen clinically [28]. It has been suggested that spinal loading is higher in quadrupeds due to a higher vertebral bone density, and for that reason the mechanical stimuli to form new bone are also much stronger [29]. Facet joint changes are likely a result of changes in mechanical loading of the facet joints brought on by the instrumentation. The thoracolumbar facets joints in sheep are normally rounded, encompassing joints, which provide resistance to both dorsal and ventral shear, as well as to torsion [30]. Load shift from the facets to posterior instrumentation in combination with the periosteal damage has presumably resulted in the observed changes around the facets.

Cahill et al. [31] reported high rates (89\%) of spontaneous fusion after growing-rod surgery in an immature patient group, even when instrumentation is not placed directly on the spine and bone is not exposed. Betz et al. [32] reported no difference in fusion rates between groups with and without graft material in a randomized trial in adolescent scoliosis patients. Both observations have led to the idea that immobilization of the spine alone can lead to spontaneous spinal fusion in immature patients. With that in mind, the aim during surgical treatment of EOS with a growth-guidance system should be to attain maximum growth before the occurrence of fusion, which may ultimately occur after ectopic bone formation. 
Karol et al. specifically stressed the importance of attaining sufficient thoracic spinal height; pulmonary function in early fused patients was severely diminished when the thoracic spinal height did not reach $22 \mathrm{~cm}$ [33]. Thoracic cage volume has reached only $30 \%$ of the expected volume at maturity by the age of 8 and only $50 \%$ by the age of 10 [26]. Restriction of thoracic cage volumetric growth limits further pulmonary development [3]. The use of growth-guidance systems may be preferred over growing rods in neuromuscular EOS patients due to the expected marked decrease in operative procedures; complication rates are typically much higher in neuromuscular scoliosis patients due to serious comorbidities.

The first in vivo experience with novel radiopaque UHMWPE sublaminar wires as part of a growth-guidance system for EOS is promising; instrumentation remained stable, no adverse local tissue response to the wires was observed, and substantial longitudinal spinal growth was facilitated. Further research into systemic biocompatibility is required, and corrective ability should be tested in an experimental scoliosis large animal model to allow for clinical application of novel UHMWPE sublaminar wires in EOS. 


\section{REFERENCES}

[1] Tis JE, Karlin LI, Akbarnia BA, Blakemore LC, Thompson GH, McCarthy RE, et al. Early Onset Scoliosis: Modern Treatment and Results. J Pediatr Orthop. 2012;32:647-57.

[2] Akbarnia BA. Management Themes in Early Onset Scoliosis. J Bone Joint Surg Am. 2007;89 Suppl 1:4254.

[3] Vitale MG, Matsumoto H, Bye MR, Gomez JA, Booker WA, Hyman JE, et al. A Retrospective Cohort Study of Pulmonary Function, Radiographic Measures, and Quality of Life in Children with Congenital Scoliosis: An Evaluation of Patient Outcomes after Early Spinal Fusion. Spine (Phila Pa 1976). 2008;33:1242-9.

[4] Gomez JA, Lee JK, Kim PD, Roye DP, Vitale MG. "Growth Friendly" Spine Surgery: Management Options for the Young Child with Scoliosis. The Journal of the American Academy of Orthopaedic Surgeons. 2011;19:722-7.

[5] Reames DL, Smith JS, Fu KM, Polly DW, Jr., Ames CP, Berven SH, et al. Complications in the Surgical Treatment of 19,360 Cases of Pediatric Scoliosis: A Review of the Scoliosis Research Society Morbidity and Mortality Database. Spine (Phila Pa 1976). 2011;36:1484-91.

[6] Sharma S, Wu C, Andersen T, Wang Y, Hansen ES, Bunger CE. Prevalence of Complications in Neuromuscular Scoliosis Surgery: A Literature Meta-Analysis from the Past 15 Years. Eur Spine J. 2013;22:1230-49.

[7] McCarthy RE, Sucato D, Turner JL, Zhang H, Henson MA, McCarthy K. Shilla Growing Rods in a Caprine Animal Model: A Pilot Study. Clin Orthop Relat Res. 2010;468:705-10.

[8] Ouellet J. Surgical Technique: Modern Luque Trolley, a Self-Growing Rod Technique. Clin Orthop Relat Res. 2011;469:1356-67.

[9] Singh V, Simpson J, Rawlinson J, Hallab N. Growth Guidance System for Early-Onset Scoliosis: Comparison of Experimental and Retrieval Wear. Spine (Phila Pa 1976). 2013;38:1546-53.

[10] Zhu F, Sun X, Qiao J, Ding Y, Zhang B, Qiu Y. Misplacement Pattern of Pedicle Screws in Pediatric Patients with Spinal Deformity: A Computed Tomography Study. J Spinal Disord Tech. 2014;27:431-5.

[11] Raney EM. Hooks and Wires--Tried and True Plus How To: Posna1-Daycourse, April 29, 2009. J Pediatr Orthop. 2011;31:S81-7.

[12] Mardjetko SM, Hammerberg KW, Lubicky JP, Fister JS. The Luque Trolley Revisited. Review of Nine Cases Requiring Revision. Spine (Phila Pa 1976). 1992;17:582-9.

[13] Pratt RK, Webb JK, Burwell RG, Cummings SL. Luque Trolley and Convex Epiphysiodesis in the Management of Infantile and Juvenile Idiopathic Scoliosis. Spine (Phila Pa 1976). 1999;24:1538-47.

[14] Cervellati S, Bettini N, Bianco T, Parisini P. Neurological Complications in Segmental Spinal Instrumentation: Analysis of 750 Patients. Eur Spine J. 1996;5:161-6.

[15] Dove J. Segmental Wiring for Spinal Deformity. A Morbidity Report. Spine (Phila Pa 1976). 1989;14:22931.

[16] Johnston CE, 2nd, Happel LT, Jr., Norris R, Burke SW, King AG, Roberts JM. Delayed Paraplegia Complicating Sublaminar Segmental Spinal Instrumentation. J Bone Joint Surg Am. 1986;68:556-63.

[17] Murakami H, Yamazaki K, Attallah-Wasif ES, Tsai KJ, Shimamura T, Hutton WC. A Biomechanical Study of 3 Different Types of Sublaminar Wire Used for Constructs in the Thoracic Spine. J Spinal Disord Tech. 2006;19:442-6. 


\section{Chapter 4}

[18] Mazda K, Ilharreborde B, Even J, Lefevre Y, Fitoussi F, Pennecot GF. Efficacy and Safety of Posteromedial Translation for Correction of Thoracic Curves in Adolescent Idiopathic Scoliosis Using a New Connection to the Spine: The Universal Clamp. Eur Spine J. 2009;18:158-69.

[19] Bogie R, Voss L, Arts JJ, Lataster LM, Willems PC, Brans B, et al. Uhmwpe Sublaminar Wires in Posterior Spinal Instrumentation: Stability and Biocompatibility Assessment in an Ovine Pilot Study. J Spinal Disord Tech. 2014.

[20] Ceelen K VC, Bremer L, Simmelink J. . Development of a High-Strength, Biocompatible, Radiopaque Uhmwpe Fiber. 24th European Conference on Biomaterials. Dublin, Ireland2011.

[21] Saito R, Hase H, Mikami Y, Tsuji Y, Ikeda T, Osawa T, et al. Clinical Study of a Modified Brooks Technique for Atlanto-Axial Subluxation Using Polyethylene Tape. J Spinal Disord Tech. 2006;19:11-7.

[22] Takahata M, Ito M, Abumi K, Kotani Y, Sudo H, Ohshima S, et al. Comparison of Novel Ultra-High Molecular Weight Polyethylene Tape Versus Conventional Metal Wire for Sublaminar Segmental Fixation in the Treatment of Adolescent Idiopathic Scoliosis. J Spinal Disord Tech. 2007;20:449-55.

[23] Imagama S, Ito Z, Wakao N, Ando K, Hirano K, Tauchi R, et al. Posterior Surgery for Adolescent Idiopathic Scoliosis with Pedicle Screws and Ultra-High Molecular Weight Polyethylene Tape: Achieving the Ideal Thoracic Kyphosis. J Spinal Disord Tech. 2012.

[24] Austen S, Punt IM, Cleutjens JP, Willems PC, Kurtz SM, MacDonald DW, et al. Clinical, Radiological, Histological and Retrieval Findings of Activ- $L$ and Mobidisc Total Disc Replacements: A Study of Two Patients. Eur Spine J. 2012;21 Suppl 4:S513-20.

[25] Grobler LJ, Gaines RW, Kempff PG. Comparing Mersilene* Tape and Stainless Steel Wire as Sublaminar Spinal Fixation in the Chagma Baboon (Papio Ursinus). Iowa Orthop J. 1997;17:20-31.

[26] Dimeglio A, Canavese F. The Growing Spine: How Spinal Deformities Influence Normal Spine and Thoracic Cage Growth. European spine journal : official publication of the European Spine Society, the European Spinal Deformity Society, and the European Section of the Cervical Spine Research Society. 2012;21:64-70.

[27] Roth AK, Bogie R, Jacobs E, Arts JJ, van Rhijn LW. Large Animal Models in Fusionless Scoliosis Correction Research: A Literature Review. Spine J. 2013;13:675-88.

[28] Kanayama M, Cunningham BW, Sefter JC, Goldstein JA, Stewart G, Kaneda K, et al. Does Spinal Instrumentation Influence the Healing Process of Posterolateral Spinal Fusion? An in Vivo Animal Model. Spine (Phila Pa 1976). 1999;24:1058-65.

[29] Smit TH. The Use of a Quadruped as an in Vivo Model for the Study of the Spine - Biomechanical Considerations. Eur Spine J. 2002;11:137-44.

[30] Boszczyk BM, Boszczyk AA, Putz R. Comparative and Functional Anatomy of the Mammalian Lumbar Spine. Anat Rec. 2001;264:157-68.

[31] Cahill PJ, Marvil S, Cuddihy L, Schutt C, Idema J, Clements DH, et al. Autofusion in the Immature Spine Treated with Growing Rods. Spine (Phila Pa 1976). 2010;35:E1199-203.

[32] Betz RR, Petrizzo AM, Kerner PJ, Falatyn SP, Clements DH, Huss GK. Allograft Versus No Graft with a Posterior Multisegmented Hook System for the Treatment of Idiopathic Scoliosis. Spine (Phila Pa 1976). 2006;31:121-7.

[33] Karol LA, Johnston C, Mladenov K, Schochet P, Walters P, Browne RH. Pulmonary Function Following Early Thoracic Fusion in Non-Neuromuscular Scoliosis. J Bone Joint Surg Am. 2008;90:1272-81. 


\section{Supplement to Chapter}

\section{Longitudinal Sliding Friction between a Sublaminar Wire and a Spinal Rod: UHMWPE Cables versus Metal Cables}

Alex K. Roth, Anna Dobrowolska, Jacobus J. Arts, Bert van Rietbergen 


\section{INTRODUCTION}

Disappointing growth results have historically been attained in the treatment of early onset scoliosis with the Luque trolley. Spinal growth reached only 32-35\% of expected growth in the instrumented segments in three different studies [1-3]. The Luque trolley utilizes metal sublaminar wires as sliding anchor members. The limited growth results can be partly attributed to the required subperiosteal exposure required for the insertion of sublaminar wires. Sliding anchor members in a growth-guidance system for the treatment of early onset scoliosis experience constant resistance to longitudinal growth induced by friction between the anchor member and a spinal rod. We believe that the large magnitude of friction between the metal sublaminar wires and the spinal rod plays an important role as well. The purpose of the current study is to quantify the coefficient of friction (COF) between various sublaminar wires and various metal spinal rods in longitudinal friction. A comparison between a woven radiopaque ultra-high molecular weight polyethylene (UHMWPE) sublaminar wire and a twisted titanium cable and between titanium, stainless steel, and cobalt chromium spinal rods is made.

\section{MATERIALS AND METHODS}
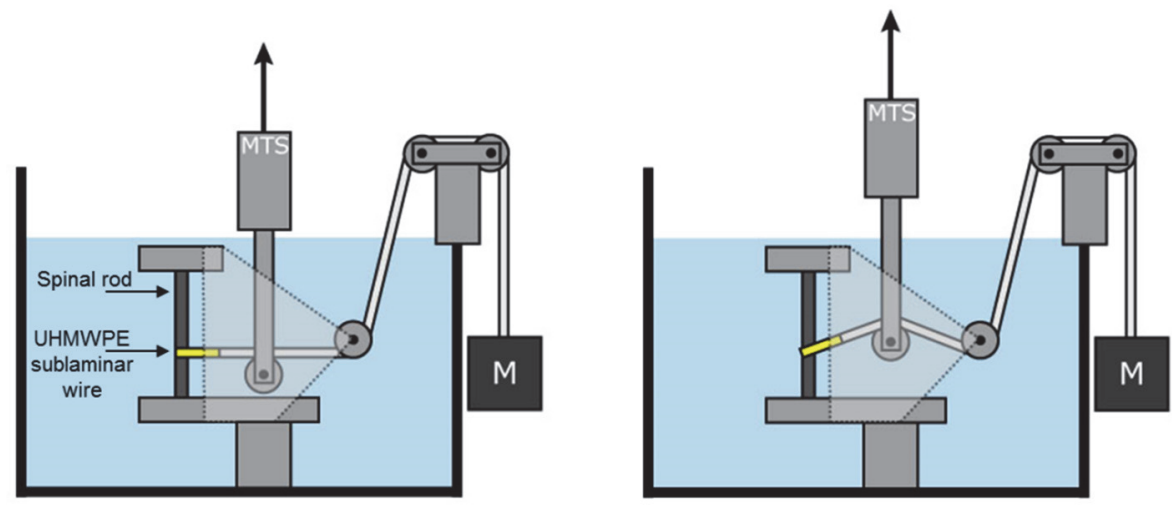

Figure 1 - Schematic illustration of the testing rig used to quantify the static COF.

A specifically designed testing rig was used to measure the static COF between the various sublaminar wires and spinal rods. The working principle of the testing rig is illustrated in Figure 1: a sublaminar wire is secured around the spinal rod as would be done clinically. A second connecting wire is threaded through a series of pulleys and secured to a known mass at the other end, producing a normal force along the length of the wire direction perpendicular to the longitudinal axis of the spinal rod $\left(F_{n}\right)$. The first 
pulley in the series is attached to a material testing machine (Zwick, Ulm, Germany), and will travel upwards with a constant prescribed speed when the test is started. The test ends when the sublaminar wire slides along the spinal rod in longitudinal direction. The force required for the vertical displacement is recorded constantly throughout the test.

The moment of longitudinal sliding can be clearly identified in a force-displacement graph (Figure $2 \mathrm{~A}$ ). The static $\operatorname{COF}\left(\mu_{s}\right)$ is subsequently calculated according to:

$$
\mu_{s}=\tan \alpha=\frac{y}{x}
$$

where, $\alpha$ is the critical angle of friction, with $y$ the vertical displacement until the onset of sliding, and $x$ the horizontal distance between the longitudinal axis of the spinal rod and the vertical axis of the travelling pulley (Figure $2 \mathrm{~B}$ ).
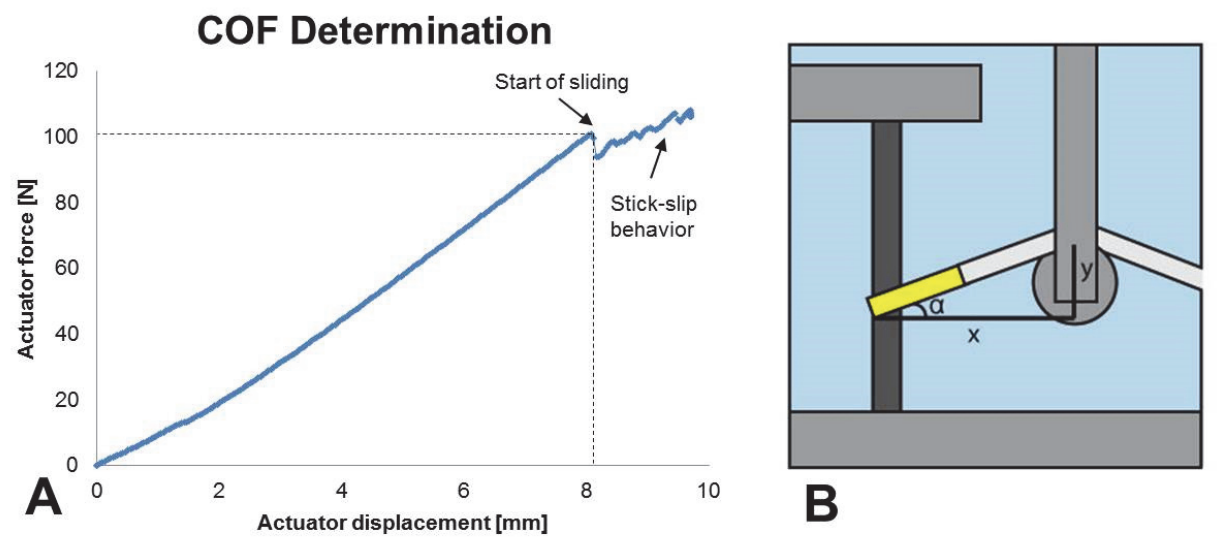

Figure 2 - (A) A typical force-displacement curve as observed during each measurement. (B) The vertical displacement $y$ and the horizontal distance $x$ determine the critical angle of friction $\alpha$.

Two different sublaminar wires were tested: (1) a radiopaque $4 \mathrm{~mm}$ wide woven UHMWPE sublaminar cable made with Dyneema Purity ${ }^{\circledR}$ Radiopaque fibers (DSM Biomedical, Geleen, the Netherlands) and (2) a titanium sublaminar cable (Atlas ${ }^{\circledR}$ cable system, Medtronic Inc, Memphis, USA). Three different spinal rods were tested: (1) a $5.5 \mathrm{~mm}$ diameter titanium alloy $\left(\mathrm{Ti}_{6} \mathrm{Al}_{4} \mathrm{~V}\right)$ rod, (2) a $5.5 \mathrm{~mm}$ diameter stainless steel (316L) rod, and (3) a $4.75 \mathrm{~mm}$ diameter cobalt chromium alloy rod. All rods were manufactured and supplied by Medtronic Inc. Memphis, USA. The surface roughness of the rods was characterized using a dual head confocal-laser interferometer. The parameter $R_{a}$, which provides the arithmetic average of surface deviations, is used to quantify the surface roughness for both a line profile and an area. Prior to each test, each sample was cleaned with ethanol. Each test was performed in a water bath at 
$37^{\circ} \mathrm{C}$. At least three measurements were performed for each combination of rod and sublaminar wire type.

\section{RESULTS}

The COF for the radiopaque UHMWPE wires in contact with the stainless steel and titanium rods is approximately $50 \%$ lower in comparison to the titanium cables. In contact with cobalt chromium rods, this difference is less marked (65\%). For both wire types, the COF is lowest in contact with stainless steel rods. All calculated COF values are provided in Table 1.

\section{$\operatorname{COF}\left(\mu_{s}\right)-200 \mathrm{~N}$ preload}

\begin{tabular}{c|cc}
\hline Rod & Radiopaque UHMWPE sublaminar wires & Titanium Atlas $^{\circledR}$ cable $^{-1}$ \\
\hline Titanium & $0.29 \pm 0.04$ & $0.62 \pm 0.04$ \\
\hline Stainless Steel & $0.21 \pm 0.01$ & $0.39 \pm 0.03$ \\
\hline Cobalt chromium & $0.37 \pm 0.04$ & $0.57 \pm 0.01$ \\
\hline
\end{tabular}

Table 1 - Static coefficient of friction values between various rods and two different sublaminar wires in longitudinal sliding.

A surface roughness comparison for the three evaluated rods is provided in Figure 3. The surface roughness, characterized using the parameter $R_{a}$, is lowest for the cobalt chromium rods, and the highest for the titanium rods. Surprisingly, the COF is not correlated to the surface roughness for the tested rods. The size of surface irregularities appears to be much smaller for the cobalt chromium rods, whereas they appear to be similarly sized for the titanium and stainless steel rods.

\begin{tabular}{|c|c|c|c|c|c|}
\hline \multicolumn{2}{|c|}{ Titanium } & \multicolumn{2}{|c|}{ Stainless Steel } & \multicolumn{2}{|c|}{ Cobalt chromium } \\
\hline Area & Ra $5.521 \mu \mathrm{m}$ & Area & $\mathrm{Ra} 4.761 \mu \mathrm{m}$ & Area & Ra $4.353 \mu \mathrm{m}$ \\
\hline Line & $\mathrm{Ra} 4.228 \mu \mathrm{m}$ & Line & Ra $4.045 \mu \mathrm{m}$ & Line & Ra $3.655 \mu \mathrm{m}$ \\
\hline
\end{tabular}

Figure 3 - Surface characterization of the various spinal rods. Surface roughness is quantified by averaging along a $2 \mathrm{~mm}$ line or averaging over $2 \times 0.5 \mathrm{~mm}$ area using an optical measurement system. 


\section{DISCUSSION}

Longitudinal friction between a sublaminar wire and a spinal rod may influence spinal growth in a growth-guidance system for the treatment of EOS. Exchanging metal cables for UHMWPE sublaminar cables as sliding anchors in a growth-guidance construct results in a reduction of longitudinal sliding friction by approximately 50\%, which may considered as a substantial improvement However, disappointing growth results attained with the Luque may also be attributed to the subperiosteal exposure required for wire insertion. Access to the spine typically involves detaching the erector spinae muscles using electrocautery. Extra care is taken in fusionless scoliosis correction surgery to maintain extraperiosteal dissection [4], as subperiosteal exposure may result in heterotopic ossification. Subperiosteal exposure is unavoidable with placement of sublaminar wires, as it requires excision of the flaval ligament. Interlaminar heterotopic ossification may lead to spontaneous spinal fusion, as was often encountered during Luque trolley revision procedures [1, 2]. Although exchanging metal cables for UHMWPE cables will have a beneficial effect on spinal growth, additional measures are required to prevent interlaminar heterotopic ossification as a result of subperiosteal exposure.

The unfavorable effects of heterotopic ossification may be diminished by reducing the number of levels instrumented with sublaminar wires. In comparison to metal cables, UHMWPE cables offers vastly improved fatigue strength, which presents the opportunity for introducing non-segmental constructs. Furthermore, anti-adhesive barrier gels may be introduced in the interlaminar space after sublaminar wire passage or indomethacin may potentially be administered post-operatively. Anti-adhesive barrier gels act as a hydrophilic physical barrier, preventing influx of osteoprogenitor cells from decorticated bone, and have been shown to inhibit intended spinal fusion in animal models [5]. Indomethacin is a cyclooxygenase-1 specific nonsteroidal antiinflammatory drug, which has been shown to inhibit bone-healing and spinal fusion [6, 7].

Based on the presented results, stainless steel rods appear to be preferably used in a growth-guidance construct for EOS patients, while cobalt chromium rods appear to be preferentially avoided. However, all rods were tested as supplied by the manufacturer. The tested cobalt chromium rod were glass bead blasted by the manufacturer in order to increase the surface roughness for improved set screw grip, which resulted in the high coefficient of friction. Polishing the rods to a very low surface roughness, as is typically done for articulating orthopedic implants, will likely reduce friction and will minimize wear particle generation. The influence of a very fine surface roughness on the COF should be evaluated. Furthermore, construct stiffness, possible rod fracture, and osteoconductivity of rod materials must also be considered when selecting the rod metal alloy. The bending stiffness of a rod is a function of the materials' elastic modulus, 
its radius to the fourth power, and inversely proportional to the square of its length. The choices of metal alloy and rod diameter thus have a great influence on rod stiffness. Stainless steel has an elastic modulus of approximately $190 \mathrm{GPa}$, compared to $116 \mathrm{GPa}$ for titanium alloy, and $210 \mathrm{GPa}$ for CoCr alloys [8]. Similar differences exist between the rods in terms of yield strength. Smaller diameter rods $(3.5 \mathrm{~mm}$ or $4.5 \mathrm{~mm}$ ) may be susceptible to fracture, especially titanium rods in ambulatory patients weighing more than $30 \mathrm{~kg}$ [9]. Furthermore, titanium exhibits superior osteoconductivity in comparison to other metals [10]. Bone apposition is known to occur directly to the surface of titanium, while we observed the formation of a fibrous layer between bone and the cobalt chromium rods in the animal study presented in Chapter 4. If heterotopic ossification and bone apposition to titanium rods do occur, longitudinal spinal growth is likely to be impeded. For these reasons it appears that stainless steel or polished cobalt chromium rods may be preferred in a growth-guidance construct for EOS patients.

\section{REFERENCES}

[1] Mardjetko SM, Hammerberg KW, Lubicky JP, Fister JS. The Luque Trolley Revisited. Review of Nine Cases Requiring Revision. Spine (Phila Pa 1976). 1992;17:582-9.

[2] Pratt RK, Webb JK, Burwell RG, Cummings SL. Luque Trolley and Convex Epiphysiodesis in the Management of Infantile and Juvenile Idiopathic Scoliosis. Spine (Phila Pa 1976). 1999;24:1538-47.

[3] Rinsky LA, Gamble JG, Bleck EE. Segmental Instrumentation without Fusion in Children with Progressive Scoliosis. J Pediatr Orthop. 1985;5:687-90.

[4] Klemme WR, Denis F, Winter RB, Lonstein JW, Koop SE. Spinal Instrumentation without Fusion for Progressive Scoliosis in Young Children. J Pediatr Orthop. 1997;17:734-42.

[5] Zou X, Li H, Egund N, Lind M, Bunger C. Inhibition of Spinal Fusion by Use of a Tissue Ingrowth Inhibitor. Eur Spine J. 2004;13:157-63.

[6] Long J, Lewis S, Kuklo T, Zhu Y, Riew KD. The Effect of Cyclooxygenase-2 Inhibitors on Spinal Fusion. J Bone Joint Surg Am. 2002;84-A:1763-8.

[7] Riew KD, Long J, Rhee J, Lewis S, Kuklo T, Kim YJ, et al. Time-Dependent Inhibitory Effects of Indomethacin on Spinal Fusion. J Bone Joint Surg Am. 2003;85-A:632-4.

[8] Ratner BD. Biomaterials Science : An Introduction to Materials in Medicine. San Diego: Academic Press; 1996.

[9] McCarthy RE, McCullough FL. Shilla Growth Guidance for Early-Onset Scoliosis: Results after a Minimum of Five Years of Follow-Up. J Bone Joint Surg Am. 2015;97:1578-84.

[10] Benzel EC, Francis TB. Spine Surgery : Techniques, Complication Avoidance, and Management. 3rd ed. Philadelphia, PA: Elsevier/Saunders; 2012. 


\section{ABSTRACT}

Study Design: An in vitro biomechanical study in porcine thoracic spine segments comparing range of motion in segmental versus multiple non-segmental UHMWPE sublaminar wire constructs.

Objective: To determine the effect of varying instrumentation (wire) density in an UHMWPE sublaminar wire construct for early onset scoliosis (EOS) patients in order to find an optimal wire density which allows maximum growth while still providing adequate correction and fixation.

Summary of Background Data: UHMWPE sublaminar wires in a segmental construct did not negatively affect longitudinal spinal growth over a 24 week period in an ovine model; application in growth-guidance system for EOS may therefore be feasible. In order to avoid ectopic bone formation as much as possible, a reduction of instrumented levels, without affecting spinal stabilization, is desirable.

Methods: Range of motion (ROM) of nine porcine thoracic spines (T6-T14) was determined in flexion/extension (FE), lateral bending (LB) and axial rotation (AR) up to $\pm 4 \mathrm{Nm}$. Tests were performed for the uninstrumented spine, in a segmental construct with UHMWPE sublaminar wires and dual pedicle screws at the most caudal level, and in four non-segmental constructs which were attained by stepwise removal of the most caudal wire.

Results: Segmental instrumentation led to a decrease in total ROM by approximately $70 \%$ for both FE and LB. A stepwise increase in ROM with decreasing number of consecutively instrumented levels was most clearly observed in LB. However, consistent significant but also relevant substantial differences in ROM for both FE and LB were noted only when comparing two and one consecutively instrumented end levels $(P<0.05)$.

Conclusions: A construct with two consecutive end levels instrumented with UHMWPE sublaminar wires seems to provide the best balance between spinal stabilization and minimizing the number of instrumented levels and thereby surgical exposure, which is crucial for allowing longitudinal growth. 


\section{INTRODUCTION}

Clinical management of early onset scoliosis (EOS), which manifests itself between birth and the age of five [1], is challenging. Early spinal fusion will halt longitudinal spinal growth and volumetric thoracic cavity development, which in turn will adversely affect pulmonary alveolar development [2]. Not only is health related quality of life substantially impacted $[3,4]$, early spinal fusion may potentially lead to thoracic insufficiency syndrome [5], and is associated with severely increased mortality [6].

Traction based systems such as growing rods and the vertical expandable prosthetic titanium rib (VEPTR) have traditionally been used in the surgical treatment of EOS [1]. The frequently required surgical lengthening procedures (6 to 9 month intervals) place huge physical and psychosocial burdens on patients and their families, and generate high costs of healthcare [7-9]. Magnetic growing rods have been introduced as an alternative to traditional growing rods as they can be easily lengthened during outpatient clinic visits without the need for repeated surgeries [10, 11].

However, magnetic growing rods are relatively expensive in procurement and are rather bulky, which may cause instrumentation prominence and pain [11]. Furthermore, screw pullout and rod fractures are frequently occurring associated complications [11, 12].

Growth-guidance systems are a relatively cheap, one-stage alternative operative treatment for EOS patients and rely on free longitudinal sliding of vertebrae along spinal rods for growth allowance [13]. The Luque-trolley, utilizing metal sublaminar wires and $\mathrm{L}$ - or U-shaped rods was the first of such systems, but failed to produce reliable spinal growth results $[14,15]$. More recently a modern Luque trolley and the Shilla system have been introduced [16-18]. Both systems rely on gliding metal rods through the heads of pedicle screws and/or metal sublaminar wires. Hence metal-on-metal articulation occurs with both systems, with metallic wear particle debris formation as a consequence [17, 19]. We have previously introduced novel (radiopaque)ultra-high molecular weight polyethylene (UHMWPE) woven wires as an alternative to gliding pedicle screws or titanium sublaminar wires for application in a growth-guidance system for treatment of EOS $[20,21]$. In such a construct, pedicle screw fixation at either the apex or the distal (lumbar) end would prevent rods from migrating, while UHMWPE wires at both the proximal and distal ends or at the apex and the proximal end would allow for guided growth. We have previously demonstrated that such a segmental construct does not adversely affect spinal growth over a 24 week period in an ovine model [20]. UHMWPE wires instead of metal wires or open pedicle screws offer the advantage of decreased friction and thereby increased potential for longitudinal growth (internal data, not shown). Furthermore, UHWMPE wear debris elicits a less aggressive macrophage response as compared to titanium or cobaltchromium wear debris [22]. 
Sublaminar wire passage requires some degree of periosteal stripping as the flaval ligament requires sectioning for wire placement, and may lead to ectopic bone formation with subsequent possible growth impediment. In order to preserve as much growth as possible in EOS patients, it is obvious that subperiosteal exposure must be kept to a minimum and thus that non-segmental sublaminar wire constructs would be preferred over segmental constructs. Due to the substantially higher fatigue strength in UHMWPE sublaminar wires as compared to metal wires (1550 N (unpublished internal data) versus a maximum of $300 \mathrm{~N}$ for stainless steel wires [23]), segmental instrumentation with sublaminar wires is no longer necessary to maintain instrumentation integrity over the long term. However, sufficient levels should be instrumented in order to provide adequate spinal stabilization and deformity correction. This study is an in vitro biomechanical comparison of segmental versus different non-segmental UHMWPE sublaminar wire growth-guidance type constructs in extracted porcine thoracic spine segments. Our objective is to find the right number of consecutive construct end levels to be instrumented with UHMWPE sublaminar wires in order to attain an optimal balance between allowing maximum growth and providing adequate correction and fixation of the spinal column in EOS patients.

\section{MATERIAL AND METHODS}

Nine porcine spines, with live animal weight ranging between $80-90 \mathrm{~kg}$, were obtained from a local slaughterhouse. Thoracic spine segments (T7-T14) were cleaned of all soft tissue and musculature while preserving ligaments and approximately $4 \mathrm{~cm}$ of ribs on both sides. Spine segments were wrapped in saline soaked gauze and frozen at $-20{ }^{\circ} \mathrm{C}$, until they were thawed at $4{ }^{\circ} \mathrm{C}$ for at least 24 hours prior to testing.

The upper and lower end-vertebrae were embedded in cups fitting the testing device using a low melting temperature alloy (Cerrolow-147; 48\% bismuth, 25.6\% lead, 12\% tin, 9.6\% Cadmium, and $4 \%$ indium). Four screws were driven into the upper and lower end-plates of the end levels for adequate fixation in the cups. Three light emitting diode (LED) markers were rigidly fixated to the anterior surface of each vertebral body at levels T8-T13.

A custom made four-point bending setup was used to test each specimen in flexion/extension (FE), lateral bending (LB), and axial rotation (AR) up to a $\pm 4 \mathrm{Nm}$ peak moment. This test setup (Figure 1 ) has been used previously to test human and animal spinal segments and is described in more detail elsewhere [24, 25]. In order to precondition the segments and to minimize viscoelastic effects, segments were tested for three continuous cycles. Data from the third cycle was analyzed. This setup was driven by an Instron material testing system (Instron 8872; Instron Corp. Norwood, MA, USA). A three-dimensional motion capturing system with a single array of three cameras 
(Optotrak 3020; Northern Digital Inc., Waterloo, ON, USA) was used to record motion of the LED markers. The axes of the Optotrak system were aligned with the anatomic axes of the spinal segments before testing. A custom written script (MATLAB; MathWorks, Natick, MA, USA) was used to transform positional data into relative segmental rotations.

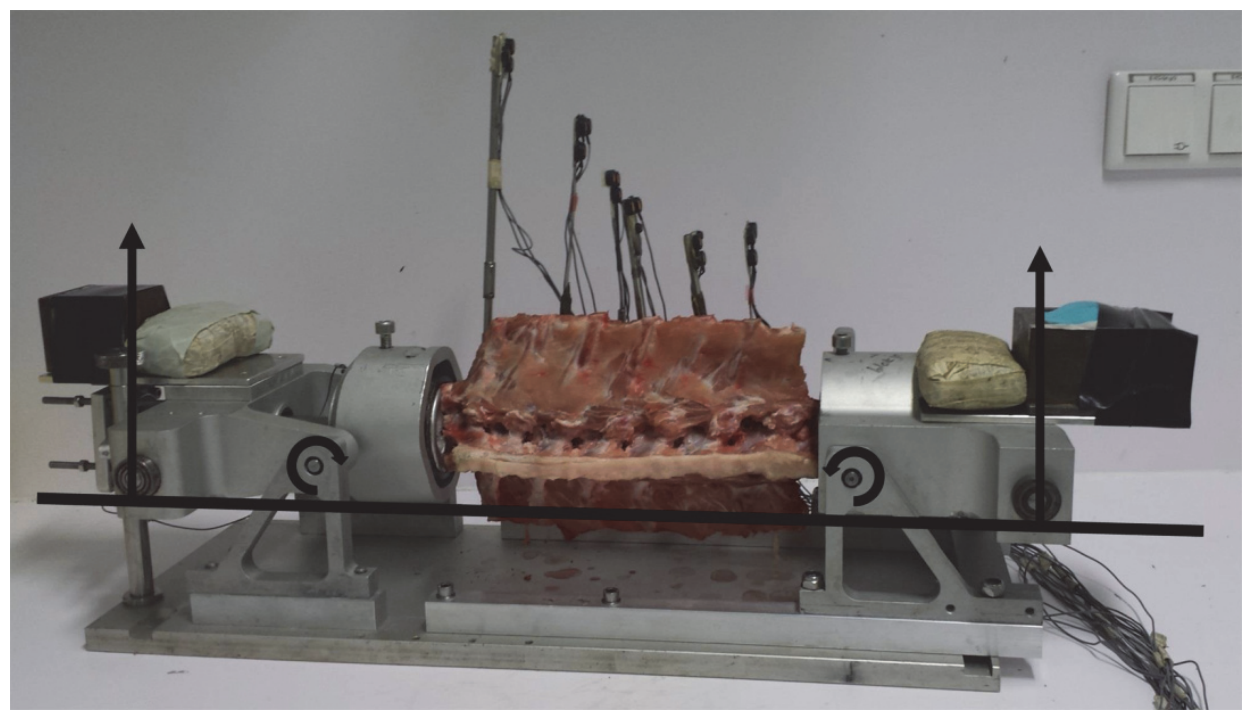

Figure 1 - Four-point bending test setup for the application of flexion/extension, lateral bending, and axial rotation to multilevel spine segments. A standard material testing machine applied load to the point indicated by the arrow for FE and LB, while the circular arrows represent the pivot points. For FE, the spine segment was rotated 90 degrees. For AR, torque was applied using a metal wire to the left cup. LED markers were fixed to each vertebral body, and tracked using a 3D motion capturing system.

All spines were tested in seven consecutive conditions, which are illustrated schematically in Figure 2. First, the uninstrumented spine was tested in all three loading directions. Subsequently, a segmental hybrid construct was introduced in each spine. Dual pedicle screws (Solera MAS, $30 \mathrm{~mm}$ length, $4.0 \mathrm{~mm}$ diameter; Medtronic Inc, Memphis, TN, USA) were placed at T13. The flaval ligament was sectioned from T12/T13 to T7/T8 and woven UHMWPE sublaminar wires made with Dyneema Purity ${ }^{\circledR}$ fibers (DSM Biomedical, Geleen, the Netherlands) were passed sublaminarly at levels T8-T12. Dual $4.75 \mathrm{~mm}$ cobalt-chromium rods with a length of $18 \mathrm{~cm}$ were fixed to the pedicle screws by standard set screws. Rods were bent lightly in order to match the slight kyphotic profile of the porcine thoracic spine. UHMWPE sublaminar wires were then secured using a double-loop sliding knot, which was tensioned to approximately $300 \mathrm{~N}$ using a custom made tensioner device and subsequently reinforced using multiple square knots as described previously [20]. All wires were tied and tensioned in the same order, starting with level T12. The spine was kept in neutral position using a custom 
made rig during instrumentation introduction. The spine instrumented with UHMWE sublaminar wires was tested in each loading direction, and subsequently the sublaminar wires at the most caudal level were removed using a scalpel and tested again. This stepwise removal and testing process was repeated so that ultimately four different non-segmental constructs had been tested (conditions 3-6). Finally, the uninstrumented spine was tested again to test for mechanical property changes caused by soft tissue degradation or moisture loss which may occur during the total required test time. Spines were regularly sprayed using saline to prevent moisture loss.
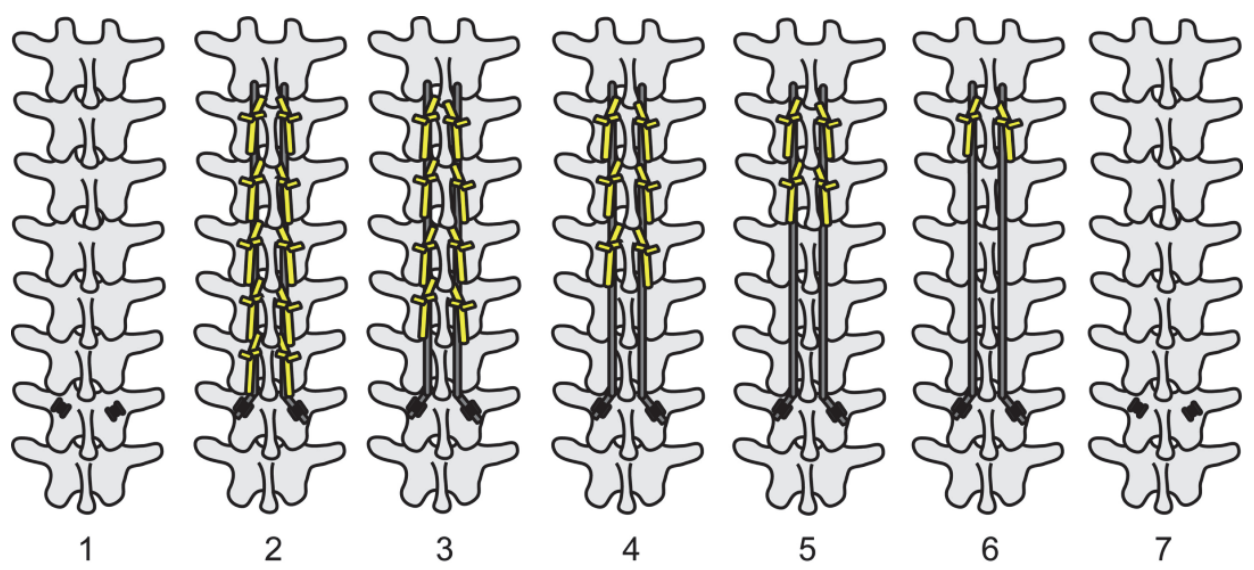

Figure 2 - Schematic representation of the seven tested conditions and test order: (1) the uninstrumented spine (2) segmental instrumentation with pedicle screws at T13 and UHMWPE sublaminar wires at T8-12 (3-6) non-segmental instrumentation with 4, 3, 2 and 1 consecutive end levels instrumented with UHMWPE sublaminar wires respectively, and (7) the uninstrumented spine was tested again to check for timedependent changes in tissue mechanical properties.

Comparisons of ROM for each of the seven conditions were made using paired $t$ tests in each loading scheme (flexion, extension, and axial rotation). Statistical significance was set at $P<0.05$. Statistical analyses were performed using standard software (IBM SPSS Statistics, Version 21.0; IBM Corp, Armonk, NY). 


\section{RESULTS}

The mean ROM for all seven conditions in FE, $L B$, and $A R$ are presented in Table 1 and Figures $3 \mathrm{~A}, 3 \mathrm{~B}$, and $3 \mathrm{C}$ respectively. Mean total ROM was $49.3 \pm 8.3^{\circ}$ in FE and $49.1 \pm$ $7.3^{\circ} \mathrm{LB}$ in the uninstrumented condition. Segmental instrumentation led to a statistically significant decrease in total ROM by approximately $70 \%$ for both FE and LB (mean total ROM of $13.2 \pm 5.7^{\circ}(P<0.001)$ and $15.3 \pm 4.9^{\circ}(P<0.001)$ respectively). A stepwise increase in ROM with decreasing number of consecutively instrumented levels was most clearly observed in LB. Statistically significant differences were noted between conditions 2 and $3\left(15.3 \pm 4.9^{\circ}\right.$ vs. $\left.16.7 \pm 5.1^{\circ}(P=0.002)\right)$, between conditions 4 and 5 $\left(17.0 \pm 4.7^{\circ}\right.$ vs. $\left.17.9 \pm 4.1^{\circ}(P=0.002)\right)$, and between conditions 5 and $6\left(17.9 \pm 4.1^{\circ}\right.$ vs. $\left.21.9 \pm 4.5^{\circ}(P=0.002)\right)$. In $\mathrm{FE}$, a statistically significant increase in ROM was observed when the number of consecutively instrumented levels was decreased from two levels to one (condition 5 vs. 6 ; FE: $13.9 \pm 3.7^{\circ}$ vs. $17.8 \pm 5.9^{\circ}(P=0.017)$ ). In AR, the mean total ROM was $14.1 \pm 3.6^{\circ}$ in the uninstrumented condition. Full segmental instrumentation led to a mere $20 \%$ decrease in total ROM in AR $\left(14.1 \pm 3.6^{\circ}\right.$ vs. $11.2 \pm 2.4^{\circ}(P=0.005)$ ). The only statistically significant difference in the instrumented conditions in $A R$ was seen between five consecutive instrumented levels and a single instrumented level (conditions 2 and 6). No statistically significant differences between conditions 1 and 7 were found in all loading directions (FE $49.3 \pm 8.3^{\circ}$ vs. $49.4 \pm 10.7^{\circ}(P=0.868)$, LB $49.1 \pm$ $7.3^{\circ}$ vs. $48.9 \pm 10.4^{\circ}(P=0.904)$, AR $14.1 \pm 3.6^{\circ}$ vs. $\left.15.5 \pm 2.8^{\circ}(P=0.197)\right)$.

The contribution of each individual level to the total ROM for every condition in FE, LB, and $A R$ are presented in Figures $4 A, 4 B$, and $4 C$ respectively. In both $F E$ and $L B$, the contribution of each level is approximately equal in the uninstrumented conditions. In all instrumented conditions, gradual motion transition at the upper instrumented level was observed; the contribution of the upper instrumented level (T8-T9) towards the total ROM was statistically significantly greater than all other levels. In LB, an even more gradual transition was observed, with statistically significant differences in ROM between all three upper instrumented levels (T8-T9, T9-T10, and T10-T11). 
A Total ROM - Flexion/Extension

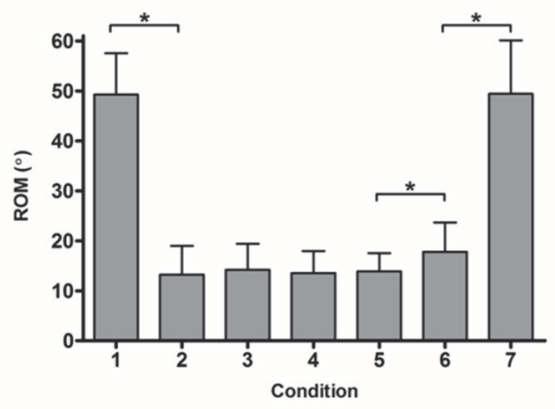

B Total ROM - Lateral Bending

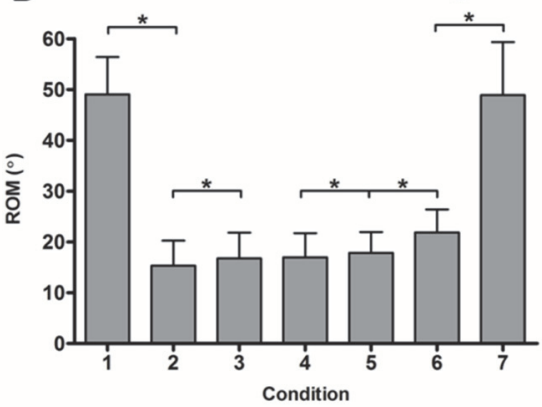

C Total ROM - Axial Rotation

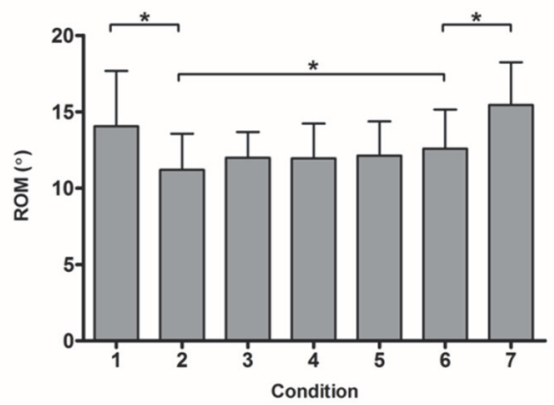

Figure 3 - Mean total ROM ( \pm standard deviation) for each of the seven tested conditions in (A) flexion/extension, (B) lateral bending, and (C) axial rotation.

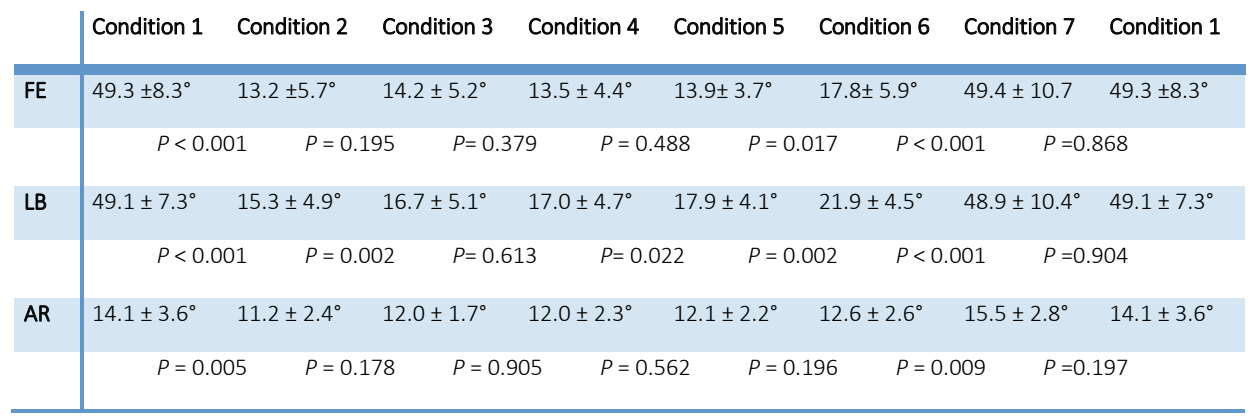

Table 1 - Mean total range of motion (ROM) in flexion extension (FE), lateral bending (LB) and axial rotation $(A R)$, and statistical comparison between each consecutive test condition. 

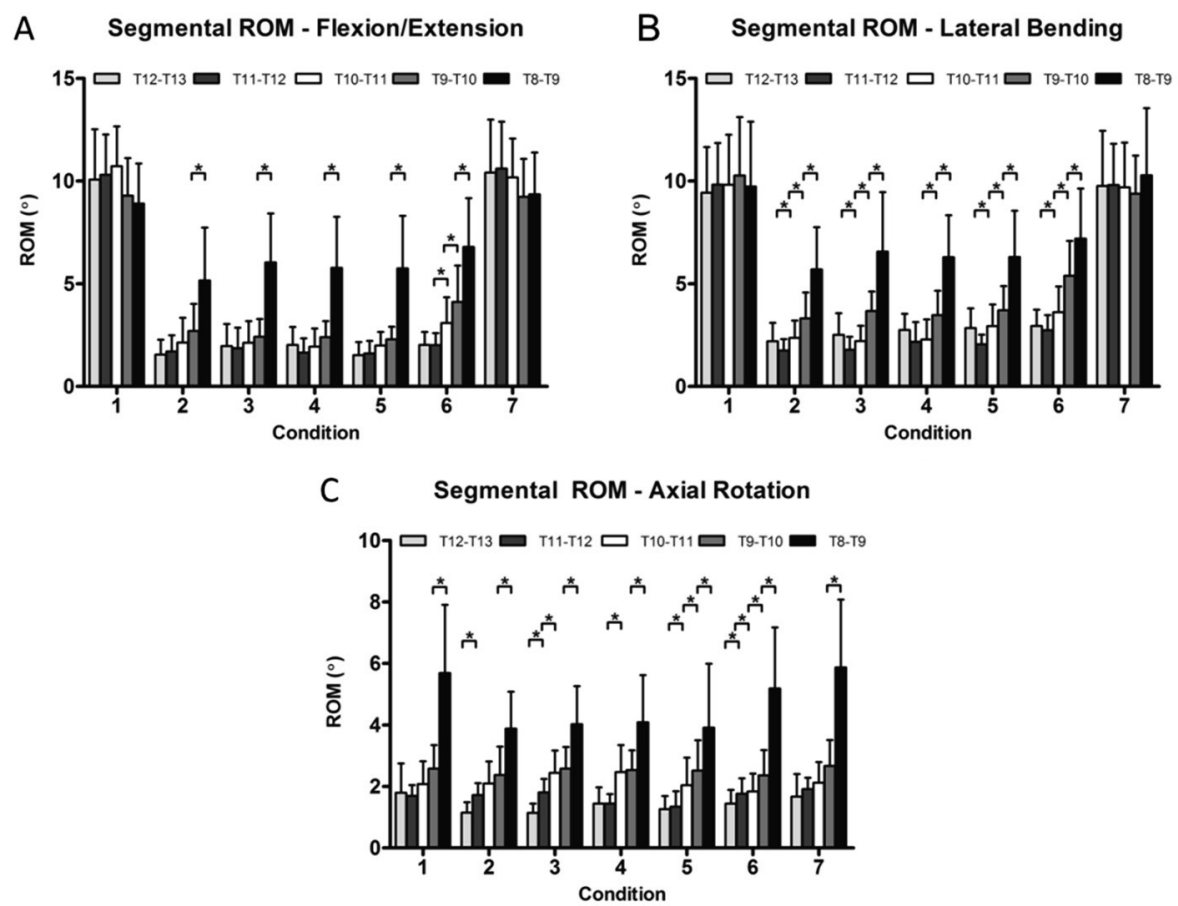

Figure 4. Mean contribution of each individual level to the total ROM ( \pm standard deviation) for each of the seven tested conditions in (A) flexion/extension, (B) lateral bending, and (C) axial rotation.

\section{DISCUSSION}

In this study, we quantified the changes in ROM in porcine thoracic spine segments brought on by varying sublaminar wire implant density in segmental and non-segmental UHMWPE sublaminar wire growth-guidance type constructs for EOS patients. In this manner, we assessed the number of consecutively instrumented end levels required for an optimal balance between minimizing the number of instrumented levels (and thereby surgical exposure) and maximizing spinal stability. As significant and substantial differences in ROM were only noted in both FE and LB between constructs with two and one consecutively instrumented end levels, it appears that a construct with UHMWPE sublaminar wires at two consecutive end levels provides that optimal balance. The clinical relevance of the additional spinal stabilization with three versus two wires can be questioned (less than one degree difference in ROM between conditions 4 and 5 in lateral bending), and therefore instrumenting more levels does not seem to be beneficial in terms of providing substantial additional spinal stabilization. Uncertainty 
with regard to clinical application remains because this study was conducted using healthy porcine spine segments without deformity.

In our opinion, a growth-guidance system for EOS should adhere to the same threepoint principle as is common in bracing therapy; pressure should be exerted at the apex as well as both the proximal and distal ends of the deformity. Apical fixation is crucial for rotational control, which in turn correlates to coronal correction [26], and should always be performed. In our proposed growth-guidance system, pedicle screws are required to provide a stable instrumentation base and prevent rods from migrating, while UHMWPE wires slide along the rod ends. Adhering to the three-point principle, pedicle screws could be placed either at the distal end or at the apex of the deformity as is common with the Shilla system. Placing pedicle screws at the apex allows for superior apical rotational correction in comparison to hooks or wires [27], but is technically more challenging due to distorted pedicle anatomy that is often seen at the apex $[28,29]$. Intended fusion at the distal end of the deformity (usually lumbar levels) may be preferred over intended fusion at the apex (usually thoracic levels) as it would likely retain more thoracic spinal growth. Karol et al. [5] have shown that thoracic spinal length is directly correlated to lung function in EOS patients who have undergone early fusion. We consider the tested constructs relevant for the case in which pedicle screws are fixed at the apex, as the tested segment would represent the top half of the instrumented spine above the apex. Speculatively, a construct with pedicle screw fixation at the distal end is likely to be less rigid. The bending stiffness of a rod is inversely proportional to the square of its length [30], and the increased distance to a rigid fixation site is substantially increased in such a construct. Therefore, sublaminar wire fixation at more levels in total is likely required to attain the same measure of stiffness or such a construct may provide inferior stabilization regardless of the number of wires placed. Ultimately, we would like to make such a biomechanical comparison.

With traditional and magnetic growing rod systems, distraction is applied to the deformed spine only at the proximal and distal ends. Large residual curvature may lead to large stress and bending moments on the rod, subsequent rod breakage and screw pullout. Dannawi et al. [12] postulated that more than $2 \mathrm{~cm}$ of coronal imbalance led to rod breakage in two patients in their case series. We expect that the use of UHMWPE sublaminar wires at the apex, adhering to the three-point principle, in growing rod systems may provide improved deformity correction, and thus decrease the incidence of rod breakage, while still allowing growth.

We only tested different forms of non-segmental instrumentation with sublaminar wires at consecutive levels in this study. Skipping a level between which sublaminar wires are placed, requires surgical exposure to the same degree as is necessary when sublaminar wires are placed at three consecutive levels. The observations that flaval ligament sectioning can lead to ectopic interlaminar bone formation and possibly 
spontaneous fusion led to the need for minimizing the number of instrumented levels. Although very similar, skipping single levels (skipped level instrumentation) was deemed ineffective as this would not reduce flaval ligament sectioning and interlaminar subperiosteal exposure. Therefore we have focused on minimizing the number of consecutive levels instrumented with UHWMPE sublaminar wires in order to reduce surgical exposure and thereby reduce the risk of interlaminar bone formation. The risk of bone formation due to surgical exposure may also be reduced by using electrocautery instead of blunt dissection with a Cobb elevator. Postoperative administration of indomethacin has also been suggested as a means to inhibit spontaneous spinal fusion [31]. However, ectopic bone formation does not necessarily restrict spinal growth. Despite ectopic bone formation, we have observed near normal growth with a segmental UHMWPE sublaminar wire construct in an immature ovine model [20].

A comparison between data from the current study and data from literature [32] for the uninstrumented porcine thoracic spine is given in Table 2. Although different loads were applied (4 Nm in this study vs. $7 \mathrm{Nm}$ in literature [32]), ROM results for all segments in FE and LB are very similar as compared to values found in literature. The small differences regardless of load differences are possibly due to the large stiffness measured in the elastic zone. In axial rotation, stiffness in the elastic zone was considerably lower, and therefore a larger load would have a much greater influence on the measured ROM (stiffness data not shown). The observed difference may also have resulted from flaval ligament sectioning required for sublaminar wire passage, which was done prior to all tests.

The magnitude of ROM in AR was very limited. Total ROM in AR of the porcine thoracic spine is structurally limited in comparison to the human thoracic spine [32]. The biomechanical response of a porcine spine is, due to structural difference, very different from humans. Increasing the load would have given a larger response but still unlike human behavior. To our knowledge, there is no animal model which provides a good representation of the human spine in all directions. Despite low ROM magnitudes, these results seem to hint towards corroboration of earlier observations of limited potential for long-term spinal derotation using sublaminar wires [33]. Furthermore, the results of this study may not be readily translatable to clinical practice as the adult porcine spine without deformity differs biomechanically and dimensionally from hypermobile pediatric spines.

Ultimately, growth needs to be anticipated for EOS patients. Depending on the patient's age and expected remaining growth at the time of surgery, extra rod length or perhaps an extra end vertebra should be instrumented so that two end levels always remain instrumented, even in the case that UHMWPE wires at the most distal or proximal slide off of the rod. 
Range of Motion of porcine spine segments

\begin{tabular}{ccccccc} 
& \multicolumn{2}{c}{ Flexion extension } & \multicolumn{2}{c}{ Lateral Bending } & \multicolumn{2}{c}{ Axial Rotation } \\
\hline & This study & Wilke et & This study & Wilke et al. & This study & Wilke et al. \\
T8-T9 & $8.9 \pm 2.0^{\circ}$ & $8.6 \pm 1.1^{\circ}$ & $9.7 \pm 3.2^{\circ}$ & $12.4 \pm 2.8^{\circ}$ & $5.7 \pm 2.2^{\circ}$ & $12.2 \pm 1.4^{\circ}$ \\
T9-T10 & $9.3 \pm 1.8^{\circ}$ & $6.2 \pm 1.1^{\circ}$ & $10.3 \pm 2.8^{\circ}$ & $8.6 \pm 2.5^{\circ}$ & $2.6 \pm 0.8^{\circ}$ & $10.8 \pm 1.9^{\circ}$ \\
T10-T11 & $10.7 \pm 1.9^{\circ}$ & $8.8 \pm 1.0^{\circ}$ & $9.8 \pm 2.4^{\circ}$ & $10.8 \pm 1.7^{\circ}$ & $2.1 \pm 0.7^{\circ}$ & $5.0 \pm 2.2^{\circ}$ \\
T11-T12 & $10.3 \pm 2.0^{\circ}$ & $9.0 \pm 1.2^{\circ}$ & $9.8 \pm 2.0^{\circ}$ & $11.0 \pm 1.1^{\circ}$ & $1.7 \pm 0.4^{\circ}$ & $5.0 \pm 2.8^{\circ}$ \\
T12-T13 & $10.1 \pm 2.4^{\circ}$ & $10.1 \pm 2.0^{\circ}$ & $9.4 \pm 2.2^{\circ}$ & $10.8 \pm 1.9^{\circ}$ & $1.8 \pm 1.0^{\circ}$ & $3.8 \pm 1.3^{\circ}$ \\
\hline
\end{tabular}

Table 2 - ROM comparison for each individual disc between this study and data from literature by Wilke et al. [32]. Applied moments varied between the current study ( $4 \mathrm{Nm}$ ) and the study by Wilke et al. (7.5 Nm).

\section{CONCLUSIONS}

UHMWPE sublaminar wires as part of a non-segmental, growth-guidance type construct may offer a simple, one-stage solution for EOS patients. These study results suggest that both the proximal and distal construct ends should be instrumented with UHMWPE wires at a minimum of two consecutive levels, while the apex is fixed using pedicle screws, in order to attain adequate stabilization and the best possible rotational control. 


\section{REFERENCES}

[1] Akbarnia BA. Management Themes in Early Onset Scoliosis. J Bone Joint Surg Am. 2007;89 Suppl 1:4254.

[2] Dimeglio A, Canavese F. The Growing Spine: How Spinal Deformities Influence Normal Spine and Thoracic Cage Growth. European spine journal : official publication of the European Spine Society, the European Spinal Deformity Society, and the European Section of the Cervical Spine Research Society. 2012;21:64-70.

[3] Campbell RM, Jr., Smith MD. Thoracic Insufficiency Syndrome and Exotic Scoliosis. J Bone Joint Surg Am. 2007;89 Suppl 1:108-22.

[4] Vitale MG, Matsumoto H, Bye MR, Gomez JA, Booker WA, Hyman JE, et al. A Retrospective Cohort Study of Pulmonary Function, Radiographic Measures, and Quality of Life in Children with Congenital Scoliosis: An Evaluation of Patient Outcomes after Early Spinal Fusion. Spine (Phila Pa 1976). 2008;33:1242-9.

[5] Karol LA, Johnston C, Mladenov K, Schochet P, Walters P, Browne RH. Pulmonary Function Following Early Thoracic Fusion in Non-Neuromuscular Scoliosis. J Bone Joint Surg Am. 2008;90:1272-81.

[6] Pehrsson K, Larsson S, Oden A, Nachemson A. Long-Term Follow-up of Patients with Untreated Scoliosis. A Study of Mortality, Causes of Death, and Symptoms. Spine (Phila Pa 1976). 1992;17:1091-6.

[7] Cahill PJ, Marvil S, Cuddihy L, Schutt C, Idema J, Clements DH, et al. Autofusion in the Immature Spine Treated with Growing Rods. Spine (Phila Pa 1976). 2010;35:E1199-203.

[8] Matsumoto H, Williams BA, Corona J, Comer JS, Fisher PW, Neria Y, et al. Psychosocial Effects of Repetitive Surgeries in Children with Early-Onset Scoliosis: Are We Putting Them at Risk? J Pediatr Orthop. 2014;34:172-8.

[9] Suliman S, Mkabile SG, Fincham DS, Ahmed R, Stein DJ, Seedat S. Cumulative Effect of Multiple Trauma on Symptoms of Posttraumatic Stress Disorder, Anxiety, and Depression in Adolescents. Compr Psychiatry. 2009;50:121-7.

[10] Akbarnia BA, Cheung K, Noordeen H, Elsebaie H, Yazici M, Dannawi Z, et al. Next Generation of GrowthSparing Techniques: Preliminary Clinical Results of a Magnetically Controlled Growing Rod in 14 Patients with Early-Onset Scoliosis. Spine (Phila Pa 1976). 2013;38:665-70.

[11] Cheung KM, Cheung JP, Samartzis D, Mak KC, Wong YW, Cheung WY, et al. Magnetically Controlled Growing Rods for Severe Spinal Curvature in Young Children: A Prospective Case Series. Lancet. 2012;379:1967-74.

[12] Dannawi Z, Altaf F, Harshavardhana NS, El Sebaie H, Noordeen H. Early Results of a Remotely-Operated Magnetic Growth Rod in Early-Onset Scoliosis. Bone Joint J. 2013;95-B:75-80.

[13] Skaggs DL, Akbarnia BA, Flynn JM, Myung KS, Sponseller PD, Vitale MG, et al. A Classification of Growth Friendly Spine Implants. J Pediatr Orthop. 2014;34:260-74.

[14] Mardjetko SM, Hammerberg KW, Lubicky JP, Fister JS. The Luque Trolley Revisited. Review of Nine Cases Requiring Revision. Spine (Phila Pa 1976). 1992;17:582-9.

[15] Pratt RK, Webb JK, Burwell RG, Cummings SL. Luque Trolley and Convex Epiphysiodesis in the Management of Infantile and Juvenile Idiopathic Scoliosis. Spine (Phila Pa 1976). 1999;24:1538-47.

[16] McCarthy RE, Luhmann S, Lenke L, McCullough FL. The Shilla Growth Guidance Technique for EarlyOnset Spinal Deformities at 2-Year Follow-Up: A Preliminary Report. J Pediatr Orthop. 2014;34:1-7. 


\section{Chapter 5}

[17] McCarthy RE, Sucato D, Turner JL, Zhang H, Henson MA, McCarthy K. Shilla Growing Rods in a Caprine Animal Model: A Pilot Study. Clin Orthop Relat Res. 2010;468:705-10.

[18] Ouellet J. Surgical Technique: Modern Luque Trolley, a Self-Growing Rod Technique. Clin Orthop Relat Res. 2011;469:1356-67.

[19] Singh V, Simpson J, Rawlinson J, Hallab N. Growth Guidance System for Early-Onset Scoliosis: Comparison of Experimental and Retrieval Wear. Spine (Phila Pa 1976). 2013;38:1546-53.

[20] Bogie R, Roth A, Faber S, de Jong J, Welting T, Willems P, et al. Novel Radiopaque Uhmwpe Sublaminar Wires in a Growth-Guidance System for the Treatment of Early Onset Scoliosis: Feasibility in a Large Animal Study. Spine (Phila Pa 1976). 2014.

[21] Bogie R, Voss L, Arts JJ, Lataster LM, Willems PC, Brans B, et al. Uhmwpe Sublaminar Wires in Posterior Spinal Instrumentation: Stability and Biocompatibility Assessment in an Ovine Pilot Study. J Spinal Disord Tech. 2014.

[22] Kaufman AM, Alabre Cl, Rubash HE, Shanbhag AS. Human Macrophage Response to Uhmwpe, Tialv, Cocr, and Alumina Particles: Analysis of Multiple Cytokines Using Protein Arrays. J Biomed Mater Res A. 2008;84:464-74.

[23] Dickman CA, Papadopoulos SM, Crawford NR, Brantley AG, Gealer RL. Comparative Mechanical Properties of Spinal Cable and Wire Fixation Systems. Spine (Phila Pa 1976). 1997;22:596-604.

[24] Busscher I, van der Veen AJ, van Dieen JH, Kingma I, Verkerke GJ, Veldhuizen AG. In Vitro Biomechanical Characteristics of the Spine: A Comparison between Human and Porcine Spinal Segments. Spine (Phila Pa 1976). 2010;35:E35-42.

[25] Busscher I, van Dieen JH, Kingma I, van der Veen AJ, Verkerke GJ, Veldhuizen AG. Biomechanical Characteristics of Different Regions of the Human Spine: An in Vitro Study on Multilevel Spinal Segments. Spine (Phila Pa 1976). 2009;34:2858-64.

[26] Di Silvestre M, Lolli F, Bakaloudis G, Maredi E, Vommaro F, Pastorelli F. Apical Vertebral Derotation in the Posterior Treatment of Adolescent Idiopathic Scoliosis: Myth or Reality? Eur Spine J. 2013;22:313-23.

[27] Fu G, Kawakami N, Goto M, Tsuji T, Ohara T, Imagama S. Comparison of Vertebral Rotation Corrected by Different Techniques and Anchors in Surgical Treatment of Adolescent Thoracic Idiopathic Scoliosis. J Spinal Disord Tech. 2009;22:182-9.

[28] Liljenqvist UR, Allkemper T, Hackenberg L, Link TM, Steinbeck J, Halm HF. Analysis of Vertebral Morphology in Idiopathic Scoliosis with Use of Magnetic Resonance Imaging and Multiplanar Reconstruction. J Bone Joint Surg Am. 2002;84-A:359-68.

[29] Senaran H, Shah SA, Gabos PG, Littleton AG, Neiss G, Guille JT. Difficult Thoracic Pedicle Screw Placement in Adolescent Idiopathic Scoliosis. J Spinal Disord Tech. 2008;21:187-91.

[30] Schmidt H, Heuer F, Wilke HJ. Which Axial and Bending Stiffnesses of Posterior Implants Are Required to Design a Flexible Lumbar Stabilization System? J Biomech. 2009;42:48-54.

[31] Riew KD, Long J, Rhee J, Lewis S, Kuklo T, Kim YJ, et al. Time-Dependent Inhibitory Effects of Indomethacin on Spinal Fusion. J Bone Joint Surg Am. 2003;85-A:632-4.

[32] Wilke HJ, Geppert J, Kienle A. Biomechanical in Vitro Evaluation of the Complete Porcine Spine in Comparison with Data of the Human Spine. Eur Spine J. 2011;20:1859-68.

[33] Wood KB, Olsewski JM, Schendel MJ, Boachie-Adjei O, Gupta M. Rotational Changes of the Vertebral Pelvic Axis after Sublaminar Instrumentation in Adolescent Idiopathic Scoliosis. Spine (Phila Pa 1976). 1997;22:51-7. 


\section{ABSTRACT}

Growth-guidance constructs are an alternative to growing rods for the surgical treatment of early onset scoliosis (EOS). Non-segmental constructs containing ultra-high molecular weight polyethylene (UHMWPE) sublaminar wires have been proposed as an improvement to the traditional Luque trolley. Ideally, a construct with the optimal UHMWPE sublaminar wire density, offering the best balance between providing adequate spinal fixation and minimizing surgical exposure, is designed preoperatively for each individual patient.

The objective of the current study was to compare the effects of different segmental or non-segmental UHMWPE sublaminar wire constructs on the biomechanical behavior of a patient-specific finite element (FE) model of the spine. A parametric FE model of the thoracolumbar spine has been previously developed, but exhibited unrealistic biomechanical behavior. Therefore, biomechanical behavior of the healthy L4-L5 segment was first calibrated in comparison to literature data. Next, whole thoracolumbar spine behavior was successfully verified. Rods, screws, and sublaminar wires were implemented in the model and a previously performed in vitro evaluation of segmental versus non-segmental UHMWPE wire constructs was replicated in silico.

Good agreement between in vitro biomechanical tests and FE simulations was observed in terms of the decrease in range of motion (ROM) as a result of instrumentation introduction. The stepwise increase in total ROM with decreasing number of wires at the construct ends was less prominent in silico. Longitudinal sliding of UHMWPE wires along rods during bending movements should be incorporated into the model for improved similarity between in vitro and in silico results. Important first steps in the implementation and validation of a growth-guidance construct for EOS patients in a patient-specific FE model of the spine have been made in this study. 


\section{INTRODUCTION}

Growth-guidance systems are an alternative to distraction-based techniques for the surgical treatment of early onset scoliosis (EOS), with the perceived advantage of reducing the number of subsequent surgical procedures [1]. The Luque trolley is considered to be the original growth-guidance system, with spinal growth possible through longitudinal sliding of segmental metal sublaminar wires along spinal rods [2, 3]. However, disappointing growth results were often attained as a consequence of spontaneous spinal fusion resulting from the required subperiosteal exposure $[4,5]$. High friction between the metal wires and the rods are also believed to limit spinal growth. Ultra-high molecular weight polyethylene sublaminar wires (UHMWPE) were introduced as an alternative to metal sublaminar wires for application in a growthguidance system for the treatment of EOS [6]. Compared to metal wires, UHMWPE sublaminar wires have a number of advantages: the coefficient of friction between the sublaminar wires and the spinal rod is greatly reduced, bone contact area and thereby potential correction forces are increased, the risk of neurological injury is reduced and the fatigue strength is substantially increased. The substantially greater fatigue strength is especially of great clinical importance, as it allows for the introduction of nonsegmental sublaminar wire constructs, i.e. wires attached to only a limited number of vertebral levels rather than to all levels. Non-segmental constructs are preferred over segmental constructs since the risk of interlaminar bone formation and spontaneous spinal fusion are greatly reduced by minimizing subperiosteal exposure. We have previously evaluated the effect of varying the number of instrumented proximal or distal levels with UHMWPE wires on in vitro spine segment range of motion (ROM) [7]. In this manner, the optimal number of proximal and distal UHMWPE sublaminar wires in a construct with pedicle screws at the apex was determined. However, part of the complexity in the treatment of EOS lies with the large variation in the patient population; curve type, curve magnitude, apical axial rotation, age, expected residual growth, and ambulatory state are all factors to take into account during the preoperative planning stage [8]. Furthermore, in vitro biomechanical testing does not take the spinal deformity into account.

Finite element (FE) modeling offers the potential for patient-specific preoperative planning of growth-guidance systems for EOS patients. With this objective in mind, a FE model containing a parametric vertebral geometry definition has previously been developed [9]. The advantage of such a parametric model is that the geometry can be tailored to the patient by changing a limited number of parameters. This is much faster and more robust than traditional FE-meshing approaches that create a mesh directly from a CT scan [10], at cost of providing less geometric detail. The main goal of the current study is to extend and validate this previously developed model in order to make it possible to assess the effect of UHMWPE sublaminar wire density variation on 
the biomechanical behavior of the spine in the FE model. In a first step towards this goal, more realistic non-linear material properties for the intervertebral discs (IVD) are implemented to better represent the non-linear relationship between the applied bending moment and vertebral rotation as reported in literature. Validation will be performed at both the single-segment level and the multi-segment level by comparing results to literature. In a second step, the proposed growth-guidance construct, consisting of spinal rods, pedicle screws, and UHMWPE sublaminar wires, is implemented into the model. The range of motion in the three bending directions is compared for segmental and two non-segmental constructs. The validity of the biomechanical behavior of the instrumented spine is assessed by comparing the attained in silico results to a previously performed in vitro study in which the same segmental and non-segmental constructs were compared [7].

\section{MATERIALS AND METHODS}

\section{Parametric finite element model}

\section{Geometry}

The three-dimensional osseo-ligamentous mesh geometry is generated using a customdeveloped algorithm in Matlab (Matlab R2013a, The Mathworks, Natick, MA, USA). Parametric definitions are used to define the size (width and depth) and orientation (coronal, sagittal and transverse plane rotations) of the vertebral endplates. Endplate shape is defined using an equation as defined by Mizrahi et al.[11], with variations per spinal level as defined by Langrana et al. [12]. Vertebral body geometry is generated through interpolation between the vertebral endplates. Intervertebral disc geometry is generated through interpolation between superior and inferior endplates of adjacent levels. Anterior and posterior disc/vertebral body heights, as well as posterior element size and morphology definitions may also be adapted through simple value alteration. In this manner, patient-specific geometries can easily be generated. Throughout the current study, literature values for adult spinal dimensions were taken for all dimensional parameter values [13-18]. Mesh examples are shown in Figure 1.

\section{Material properties}

The vertebral bodies, posterior elements, and cartilaginous endplates were modeled as isotropic linear elastic materials. A two-parameter hyperelastic Mooney-Rivlin formulation was used to define the mechanical properties of the IVD (nucleus pulposus and the annulus fibrosus ground substance), instead of a linear elastic formulation defined by Meijer et al. [19] in order to attain more typical nonlinear behavior. The annulus fibrosus contains linear elastic circumferential tension-only fibers oriented at $+30^{\circ}$ and $-30^{\circ}$ relative to the transverse plane, with a volume ratio of $16 \%$. Facet joints 
were modelled as parallel surfaces with straight profiles in all planes with an initial gap of $0.6 \mathrm{~mm}$. Frictional contact with a friction coefficient of 0.01 was defined between adjacent facet joint surfaces. Seven ligaments, modeled using tension-only truss elements are defined per motion segment. Non-linear behavior was defined using a piecewise stress-strain definition. An overview of initial material properties is given in Table 1.
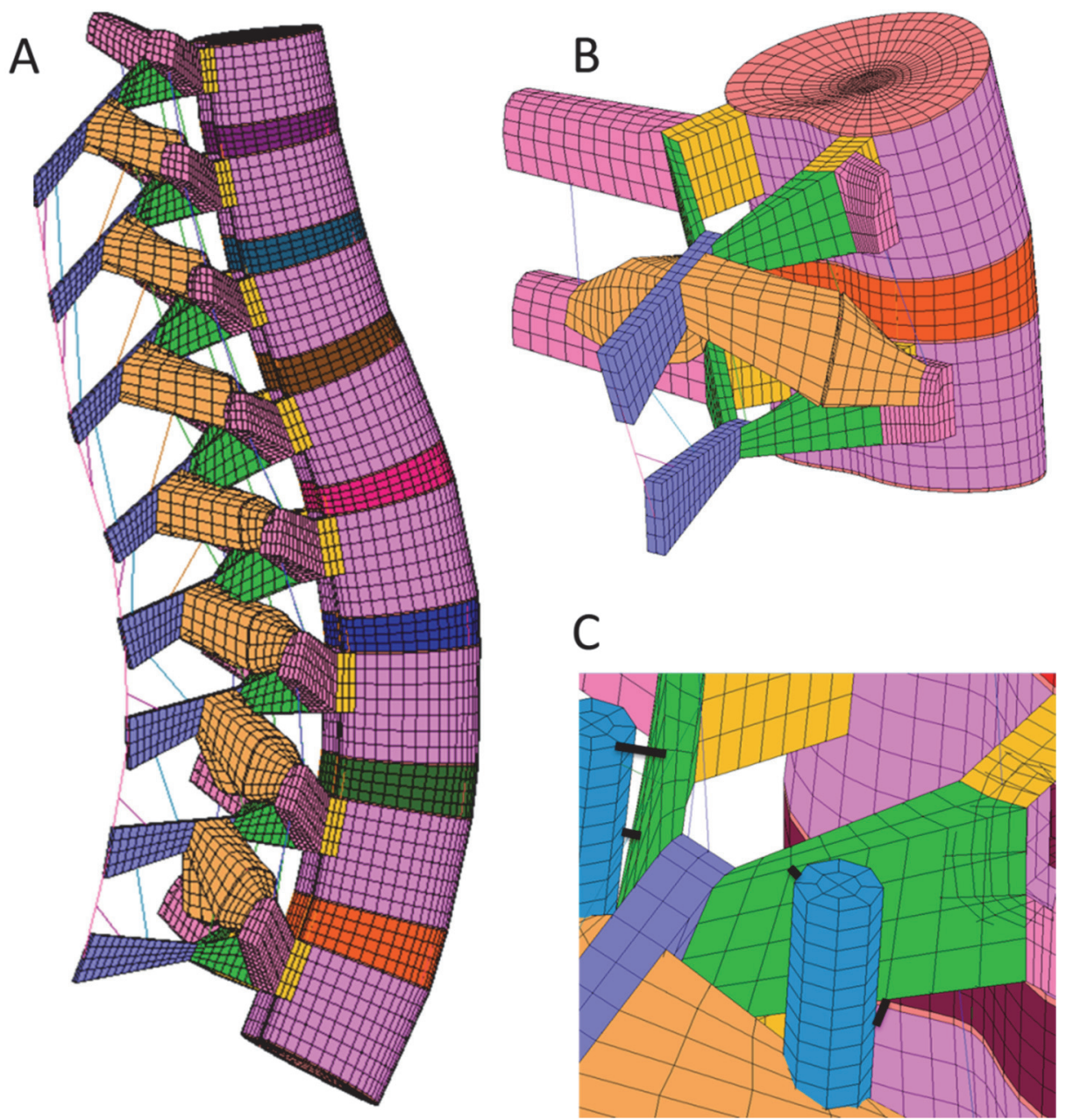

Figure 1 - (A) The T9-L4 thoracolumbar spine segment mesh. (B) The L4-L5 motion segment mesh. (C) Sublaminar wires are modelled as truss elements connecting the rod and the lamina at two locations. 


\section{Chapter 6}

\begin{tabular}{lll} 
Anatomical Structure & Material parameters & References \\
\hline Vertebral body & Isotropic linear elastic, E=3,000MPA, v=0.3 & {$[20,21]$} \\
\hline Vertebral posterior elements & Isotropic linear elastic, E=12,000MPA, v=0.3 & {$[22,23]$} \\
Cartilaginous endplates & Isotropic linear elastic, E=50 MPa, v=0.4 & {$[24]$} \\
Annulus ground substance & Mooney-Rivlin $\mathrm{c}_{10}=0.18, \mathrm{c}_{01}=0.045$ & {$[25]$} \\
Annulus fibers & Linear elastic, E=450MPa, v=0.3 & {$[23]$} \\
& Tension-only rebar elements & {$[26]$} \\
Nucleus pulposus & Mooney-Rivlin $\mathrm{C}_{10}=0.12, \mathrm{C}_{01}=0.09$ & {$[9,23,27$,} \\
Ligaments & Stress-strain curve (see Table 2) & $28]$ \\
\hline
\end{tabular}

Table 1 - Initial material property definitions

Ligaments were modeled using three linear elastic regions using a stress-strain curve definition. The seven modeled ligaments in anteroposterior direction are: the anterior longitudinal ligament $(A L L)$, the posterior longitudinal ligament (PLL), the facet joint capsular ligaments $(\mathrm{CL})$, the intertransversal ligaments $(\mathrm{ITL})$, the flaval ligament $(\mathrm{FL})$, the interspinous ligaments (ISL), and the supraspinous ligaments (SSL). The ligaments' cross sectional areas (CSA) and the initial regional stiffness definitions are provided in Table 2

\begin{tabular}{llllllll} 
& CSA [mm $\left.{ }^{2}\right]$ & $\begin{array}{l}\text { Strain } \\
\text { region 1 } \\
{[-]}\end{array}$ & $\begin{array}{l}\text { Stiffness } \\
\text { region 1 } \\
{[\mathrm{MPa}]}\end{array}$ & $\begin{array}{l}\text { Strain } \\
\text { region 2 } \\
{[-]}\end{array}$ & $\begin{array}{l}\text { Stiffness } \\
\text { region 2 } \\
{[\mathrm{MPa}]}\end{array}$ & $\begin{array}{l}\text { Strain } \\
\text { region 3 } \\
{[-]}\end{array}$ & $\begin{array}{l}\text { Stiffness } \\
\text { region 3 } \\
{[\mathrm{MPa}]}\end{array}$ \\
\hline ALL & 66 & $0.00-0.12$ & 12.1 & $0.12-0.45$ & 29.9 & $0.45-0.58$ & 15.1 \\
\hline PLL & 26 & $0.00-0.09$ & 19.2 & $0.09-0.34$ & 45.4 & $0.34-0.45$ & 14.6 \\
\hline $\mathrm{CL}$ & 30 & $0.00-1.00$ & 0.24 & $1.00-2.00$ & 0.6 & $2.00-3.00$ & 0.2 \\
\hline ITL & 2 & $0.00-0.09$ & 273.6 & $0.09-0.15$ & 1342 & $0.15-0.17$ & 450.8 \\
\hline FL & 39 & $0.00-0.05$ & 40 & $0.05-0.50$ & 52.4 & $0.50-0.58$ & 16 \\
\hline ISL & 40 & $0.00-0.12$ & 9.6 & $0.12-0.30$ & 21.2 & $0.30-0.40$ & 10 \\
\hline SSL & 30 & $0.00-0.12$ & 14.4 & $0.12-0.30$ & 32 & $0.30-0.40$ & 15.2 \\
\hline
\end{tabular}

Table 2 - Initial ligament material property definitions 


\section{Material property calibration}

\section{Single level (L4-L5) calibration}

The in vitro study by Heuer et al. [29] provides the necessary data to perform a stepwise validation of FE models of the L4-L5 motion segment. In Heuer et al.'s study, a stepwise successive reduction of functional spinal structures was performed. The spinal structures were resected in posteroanterior order: SSL, IL, FL, CL, vertebral arches, PLL, and finally the ALL. Range of motion (ROM) and the neutral zone (NZ) were determined for intact specimens and after each successive structure resection at bending moments of $1,2.5,5,7.5$ and $10 \mathrm{Nm}$. In the current study, functional spinal structures are successively added in reverse order, and a comparison with literature data is made at each step. Material properties of the IVD ( $c_{10}$ and $c_{01}$ ) and ligaments (stiffness) were adapted to obtain the best possible agreement between FE-results and literature data. Each parameter was first varied by a factor 2 in order to bring FE-results in better agreement with the literature values (increased or decreased depending on initial under- or overestimation). This procedure was repeated until no further improvement was found. For ligaments, strain region definitions remained constant, and only the stiffness value in these regions was adapted. A general rule of $c_{10}=4 c_{01}$ was followed for the IVD Mooney-Rivlin formulations in accordance with Schmidt et al.[26].

\section{Whole spine behavior verification}

To verify the accuracy of the model's prediction of the range of motion (ROM) of the whole spine in different bending modes, a multi-level spine segment was modeled and the calculated range of motion was compared to data describing biomechanical behavior of all human spinal levels published by White and Panjabi [30]. The modeled segment consists of an eight-level thoracolumbar spinal segment (T9-L4). To represent these loading modes in the FE-model, the caudal endplate of the tested segment was fully constrained, while an $8 \mathrm{Nm}$ moment was applied to the cranial endplate in different directions. Displacement constraining boundary conditions were also applied to the cranial endplate to prevent out-of-plane motion, thereby reducing computational time.

\section{Growth-guidance construct implementation}

The proposed growth-guidance construct contains three components: spinal rods, pedicle screws, and UHMWPE sublaminar wires. The previously described customdeveloped algorithm also generates the mesh geometry for the spinal rods. The sagittal profile of the spinal rods matches the sagittal profile of the spine at the corresponding levels. In the current study, rods were assigned a straight profile in the coronal plane. The geometry and material properties of the rods were assigned to correspond to the in vitro study [7], in which $4.75 \mathrm{~mm}$ diameter cobalt-chromium rods were used. Isotropic 
linear elastic material properties ( $E=210 \mathrm{GPa}, \mathrm{v}=0.3$, [31]) were thus assigned. Pedicle screws are not physically generated in the model, but are modeled by assigning a rigid tie constraint between the rod and the lamina of the corresponding spinal level. UHMWPE sublaminar wires are modeled using line elements, fixing the rod to the lamina medially at the cranial laminar end and laterally at the caudal laminar end. A Young's modulus of $19 \mathrm{GPa}$ was defined for the UHMWPE sublaminar wires, in accordance with in vitro measurements performed in Chapter 3.

\section{Segmental versus non-segmental constructs}

An in vitro comparison of segmental versus non-segmental constructs growth-guidance type constructs with a variation in the number of construct end levels instrumented with UHMWPE sublaminar wires has been previously performed in Chapter 5 [7]. Significant and substantial differences were only found between segmental constructs (sublaminar wires at five levels), non-segmental constructs with sublaminar wires at two end levels, and non-segmental constructs with sublaminar wires at one end level. For this reason, only these constructs are modelled in the current study. A schematic illustration of the four compared conditions is provided in Figure 2.

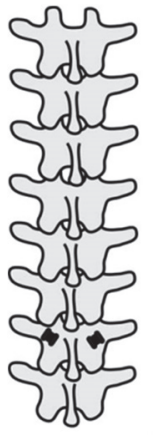

Control

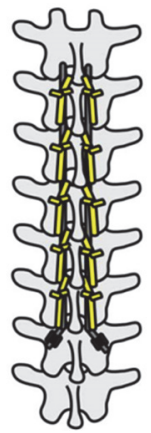

5 wires

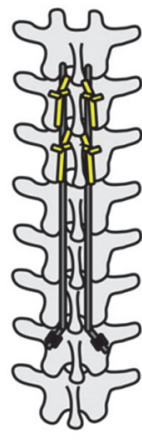

2 wires

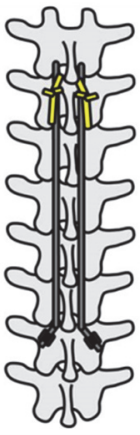

1 wire

Figure 2 - Schematic illustration of the four conditions simulated using the FE model.

The previously described in vitro study was performed with porcine spine segments with bending moments up to $4 \mathrm{Nm}$. Similarity between human and porcine spine segment anatomy and biomechanical behavior is greatest for lower thoracic/upper lumbar spine segments, where the porcine lower thoracic spine provides a good representation of the lower thoracic/upper lumbar spine [32]. The in vitro study was performed using T7-T14 porcine spine segments, whereas the current finite element study is performed with T9-L4 thoracolumbar segments. Loads of $7.5 \mathrm{Nm}$ are typically recommended for testing spine segments [33]. However, loads may be reduced by half 
if segments are osteoporotic or very flexible. As the porcine spine segments were very flexible, a bending moment of $4 \mathrm{Nm}$ was applied in the in vitro study, whereas a bending moment of $8 \mathrm{Nm}$ is applied in the current in silico study as results are compared to human data with similar loads. All simulations were performed in Marc/Mentat (version 2014.0.0, MSC Software Corporation, Newport Beach, CA) with a standard multifrontal sparse solver using large strain analysis.

\section{RESULTS}

\section{L4-L5 material property calibration}

The calibrated material properties for the intervertebral disc and the different ligaments are provided in Table 3. The effect of MR parameter value variation for the nucleus pulposus was not very substantial, and therefore values were left unadapted from the study by Schmidt et al [26]. Lower MR parameters were required for the annulus fibrosus in comparison to the study by Schmidt et al. [26]. A substantially higher value in comparison to the start value (1200 MPa vs. $450 \mathrm{MPa}$ ) was required for the annulus fiber stiffness in order to attain a best fit to literature data. All ligaments required adapted material properties.

Intervertebral disc material properties

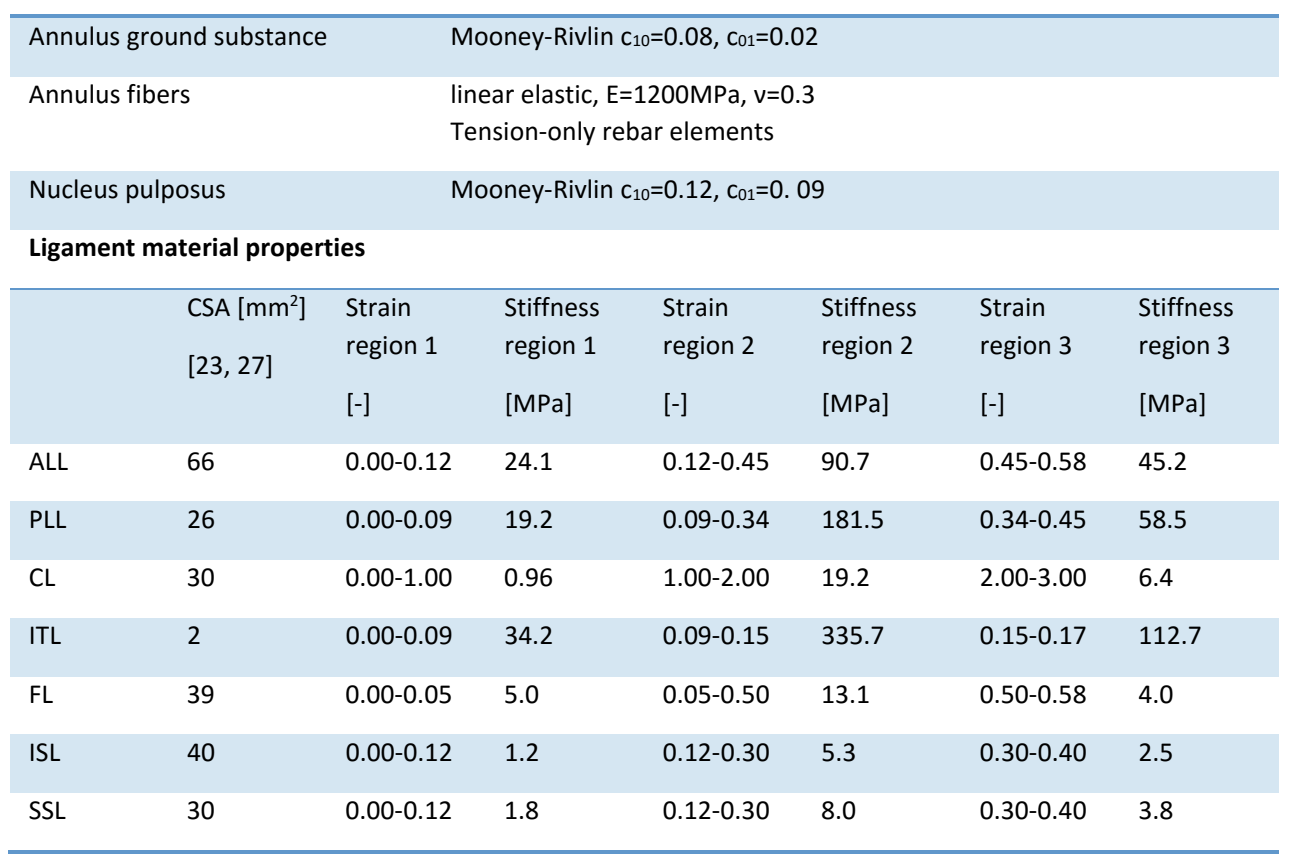

Table 3 - Final ligament material property definitions 
Bending moment-rotation curves for simulations with the calibrated material properties are shown in Figure 3. In flexion, the range of motion is underestimated in comparison to mean literature values, while it is slightly overestimated in extension. Slight underestimations of ROM are also observed in axial rotation and lateral bending. Spinal biomechanical behavior remains within the standard deviations (dotted lines) of the in vitro biomechanical study in all bending directions, indicating that material properties have been satisfactorily calibrated.
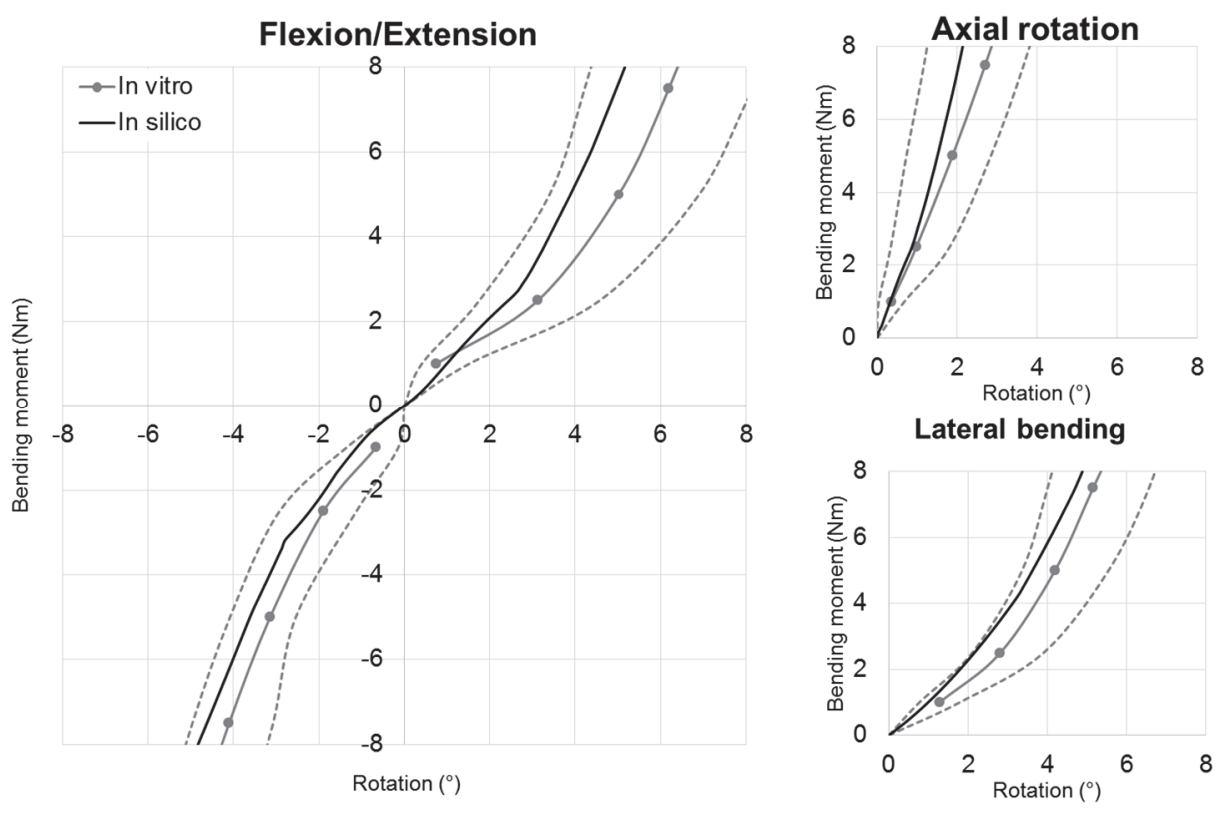

Figure 3 - Bending moment versus rotation curves in flexion extension, axial rotation, and lateral bending for the FE model with optimized material properties compared to in vitro data from Schmidt et al., which includes standard deviations in the dashed line.

\section{Whole spine behavior verification}

A comparison of the in vitro and in silico range of motion for a thoracolumbar spine segment (T9-L4) in flexion/extension, combined lateral bending (left and right combined), and combined axial rotation is provided in Figure 4. Overall, satisfactory agreement between the in silico behavior and reported literature values is attained as the ROM remains mostly with the limits of the reported standard deviations. In flexion/extension, the in silico ROM is lower in comparison to the in vitro values. This is predominantly due to the previously mentioned observation that the ROM in flexion is underestimated by the FE model. A general trend towards decreasing ROM can be 
observed in the caudal-cranial direction for both in vitro and in silico biomechanical spinal behavior in flexion/extension.
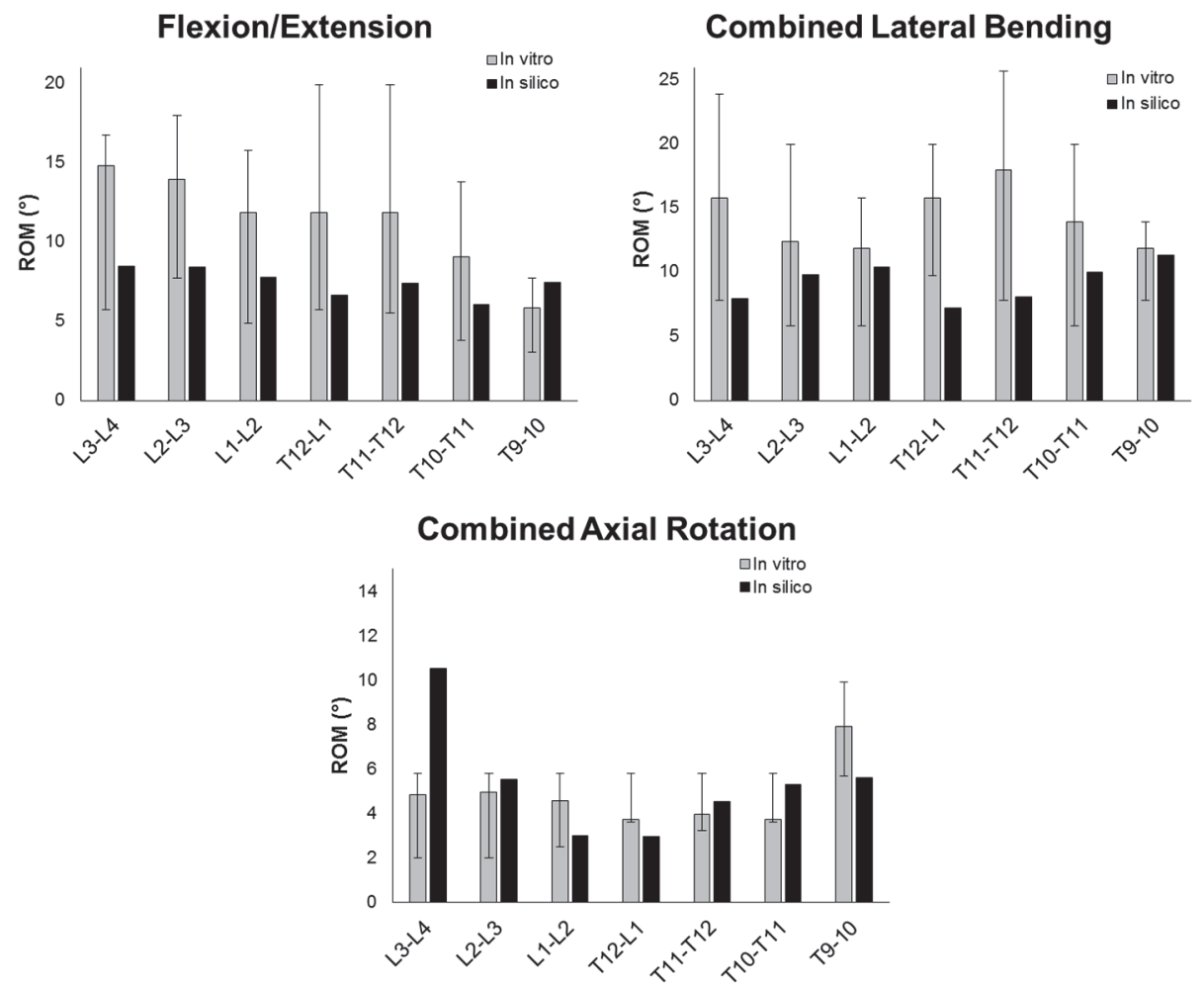

Figure 4 - In vitro versus in silico comparison of the range of motion for thoracolumbar spine segments in flexion/extension, lateral bending, and axial rotation.

Differences between in vitro and in silico segmental ROM are observed in lateral bending for the T12-L1 and T11-T12 levels and to a lesser extent the L3-L4 level. At the thoracolumbar junction, some geometrical anomalies related to the transverse processes are present in the FE model geometry to allow for future addition of the ribs. We presume that this results in slightly stiffer local behavior. In axial rotation, a spike in the ROM is observed at the L3-L4 level. This spike is due to deformation of the posterior vertebral elements at the junction of the lamina and the spinous process. The laminar height is under sized in the FE model. 
Segmental versus non-segmental growth-guidance constructs

A comparison between in vitro and in silico total ROM in the different bending directions for the four different constructs with varying wire densities is provided in Figure 5. Data is normalized to account for interspecies differences and differences in the magnitude of applied bending moments. Good agreement in the magnitude of the decrease in ROM as a result of implant introduction is observed between the in vitro and in silico studies. However, the characteristic stepwise increase in ROM with decreasing wire density as observed in the in vitro study is not as distinctly observed in the in silico study. The biomechanical effect of sublaminar wires at a single level appears to be overestimated.

Total ROM - Flexion/Extension

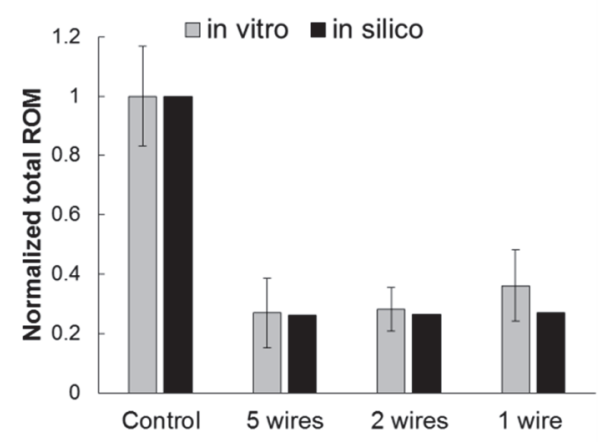

Total ROM - Axial rotation

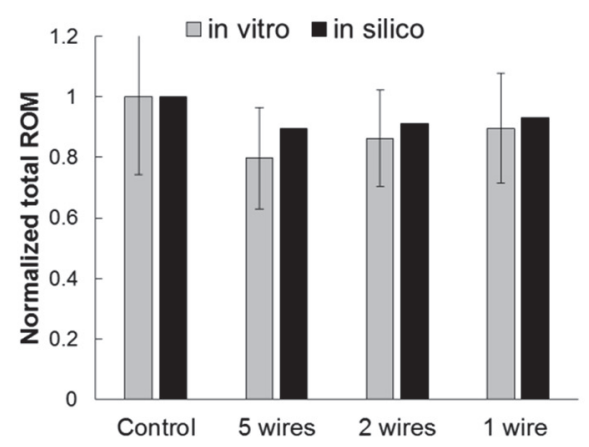

Total ROM - Lateral bending
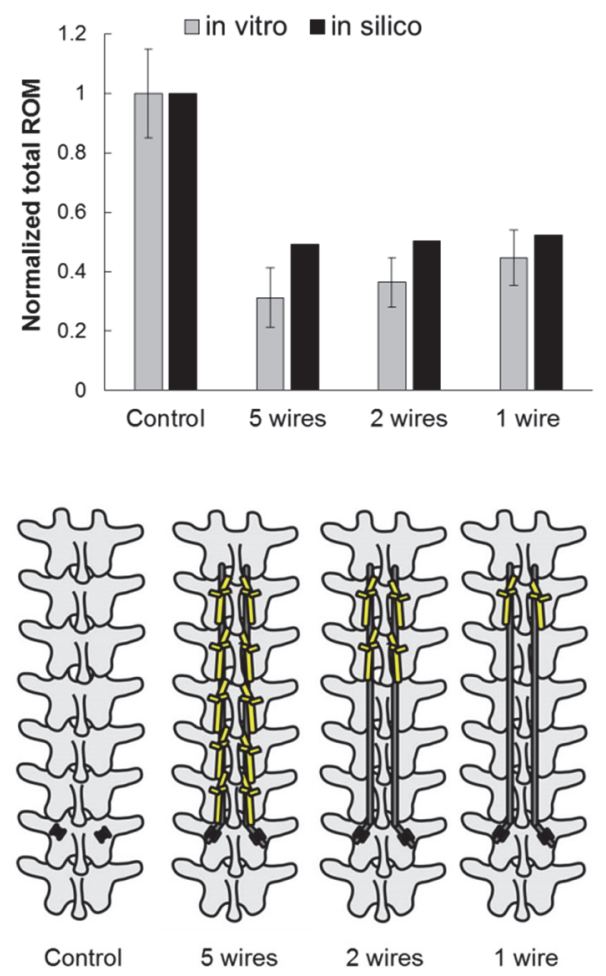

Figure 5 - Comparison between the in vitro and in silico total range of motion for the evaluated constructs with varying wire densities in flexion/extension, lateral bending and axial rotation. In vitro data is taken from Roth et al. A schematic illustration of the evaluated constructs is also provided. 
The mean contribution of each individual level towards the total ROM is provided in Figure 6. Similar trends in the distribution of ROM between levels are seen for in vitro and in silico results, with increases in ROM towards the upper most level. In flexion/extension, a spike in the ROM is observed at the most caudal level (L2-L3). This is likely due to inadequate constraints imposed on the rods as a representation for the pedicle screws at this level, which allows for excessive motion. The effects of geometrical anomalies at the thoracolumbar junction are again most predominantly exhibited during lateral bending, where a decrease in the ROM is observed at the T11T12 and T12-L1 levels. In axial rotation, a non-physiological spike is observed at the most caudal level, presumably due to deformation occurring within the posterior vertebral elements again.
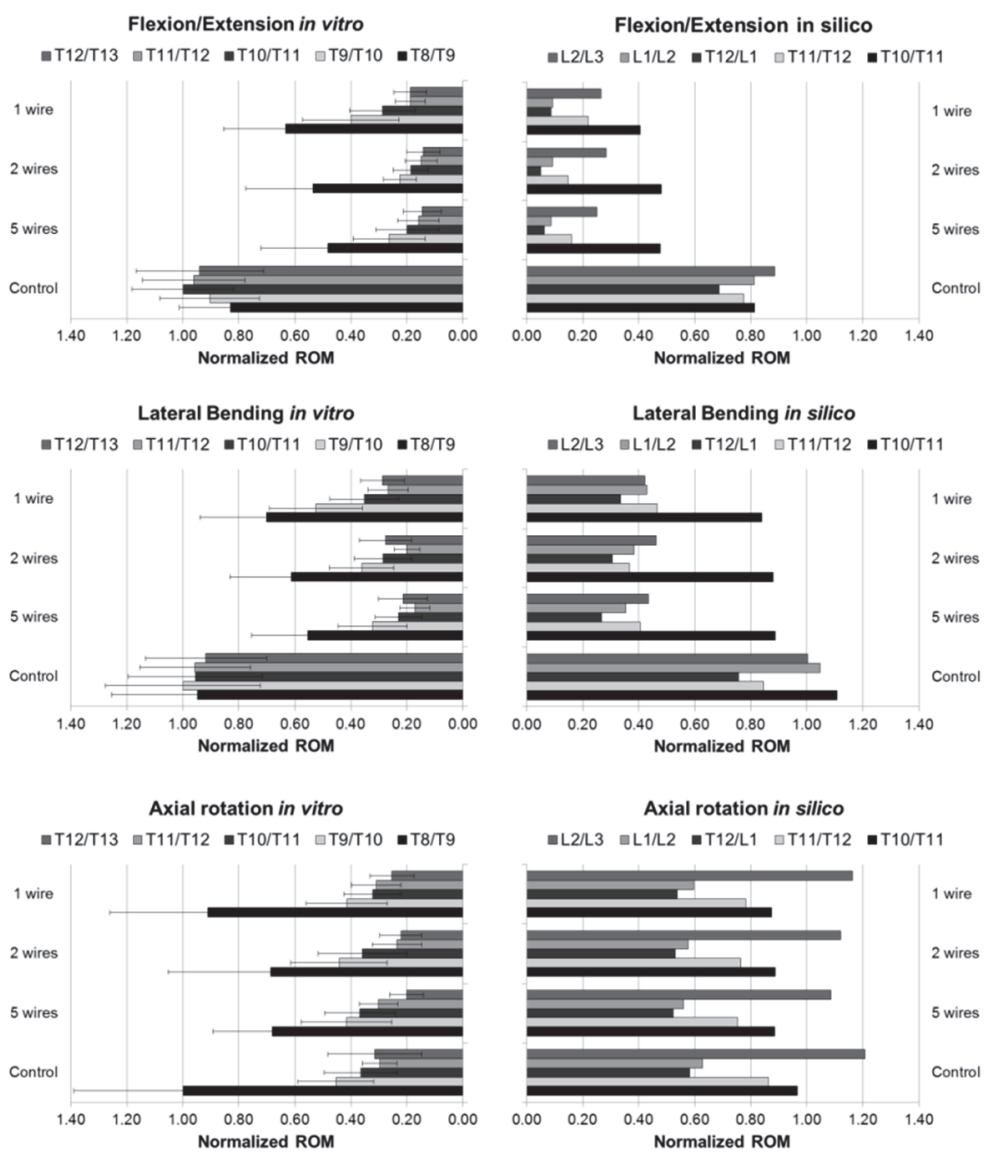

Figure 6 - In vitro versus in silico comparison of the mean contribution of each individual level to the total ROM ( \pm standard deviation) for each of the for tested conditions in (A) flexion/extension, (B) lateral bending, and (C) axial rotation. 


\section{DISCUSSION}

In this study, we first optimized the behavior of the L4-L5 segment of a parametric thoracolumbar spine FE model by iteratively adapting the material properties at each step of a motion segment build-up consisting of successive addition of functional spinal structures. Second, we verified the biomechanical behavior of an eight-level thoracolumbar spine segment by analyzing approximate ROM magnitudes and trends in ROM differences across spinal levels with acceptable margins. We finally used the optimized and verified FE model of a thoracolumbar spine segment to assess the effect of segmental and non-segmental UHMWPE sublaminar wire constructs on the biomechanical behavior of the spine. Good agreement was attained between in vitro and in silico studies concerning the magnitude of the ROM decrease after segmental instrumentation introduction. However, the characteristic stepwise increase in ROM with decreasing wire density as observed in the in vitro study is not as distinctly observed in the in silico study. The biomechanical effects of sublaminar wires at a single spinal level appear to be overestimated in the FE model. We have observed slight longitudinal sliding of the UHWMPE sublaminar wires along the spinal rods during spinal motion. In our opinion, the absence of this phenomenon in the FE model is the main reason for the differences in the biomechanical effects of UHMWPE sublaminar wire density variation between the in vitro and the in silico studies.

The first step in the material property calibration process consisted of adjusting the Mooney-Rivlin (MR) parameter values for the intervertebral disc (annulus fibrosus and nucleus pulposus) and the stiffness values for the annulus fibrosus fibers in a body-discbody segment only. The calibrated MR parameters in our study correspond to a Young's modulus of 0.6 MPa, while the MR parameters as attained by Schmidt et al. correspond to a Young's modulus of $1.35 \mathrm{MPa}$ [34]. Relative to experimentally determined values of 4.2 MPa [23], this further decrease is acceptable. Calibrated stiffness values for the annulus fibrosus fibers were similar to the values found by Schmidt et al., who used the data described by Shirazi-Adl et al. [35]. Figure $6 \mathrm{H}$ shows that the calibrated fiber stiffness value in our study is very similar to the value determined experimentally by Shirazi-Adl et al. between 0-3\% strain.

The optimized material properties for ligaments are also mostly within the broad range of experimentally determined values reported in literature $[23,27,35-40]$. A comparison between the calibrated mechanical properties and reported literature values is provided in Figure 7. The stiffness of the supraspinous ligament and the interspinous are at the low end of the range found in literature, although the stiffness values stay within the margins presented in literature below 30\% strain. The calibrated mechanical properties of the facet capsular ligaments are vastly lower than reported literature values, probably as a compensatory requirement for modeling the facet joints 
as flat surfaces. Overall, the calibrated mechanical properties of the different spinal ligaments show sufficient agreement with literature values.

A Anterior Longitudinal Ligament

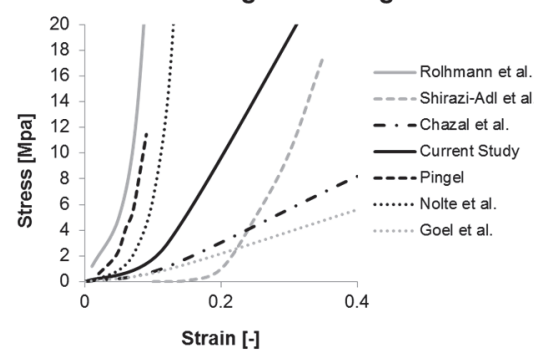

C

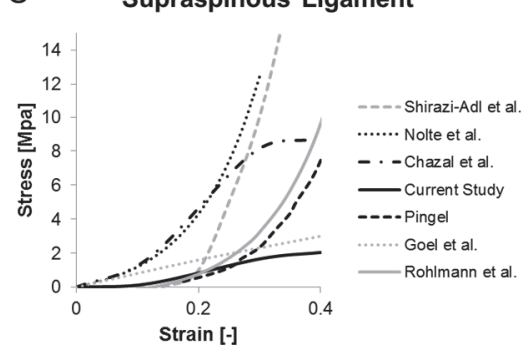

E

E Flaval Ligament

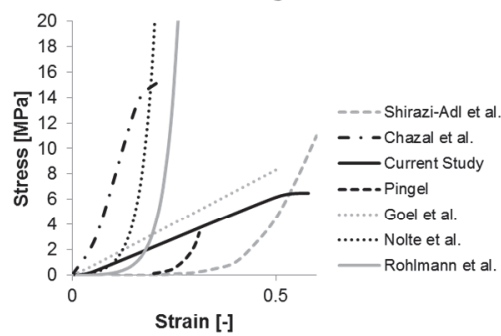

G

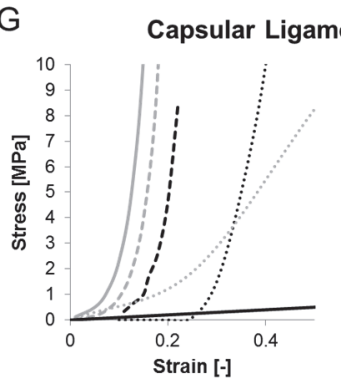

B Posterior Longitudinal Ligament

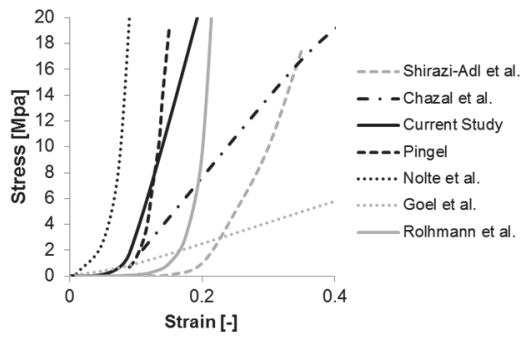

$\mathrm{D}$

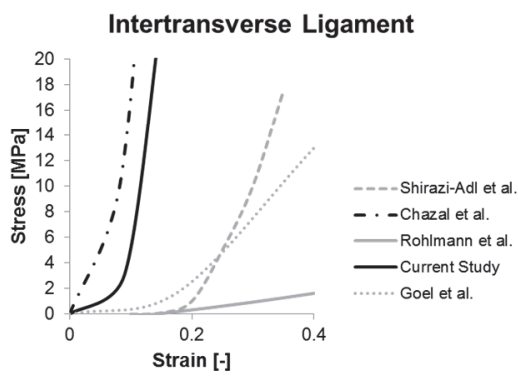

$\mathrm{F}$

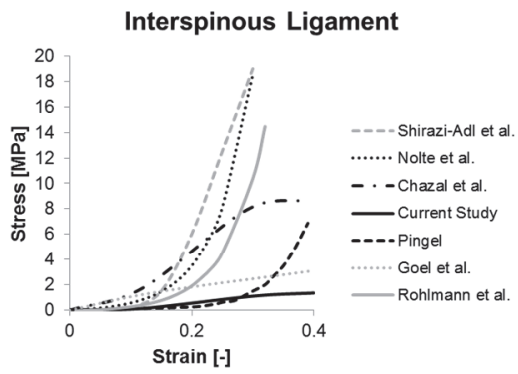

$\mathrm{H}$

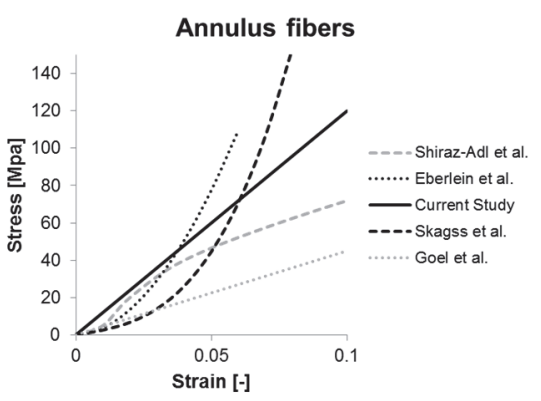

Figure 7 - Comparison between the calibrated mechanical properties of different functional spinal structures and a range of their values presented in literature. 
The model geometry still requires some improvement. First, the laminar height does not describe the true anatomical value very well. We attempted to compensate for the undersized laminar height by assigning a relatively high Young's modulus for all posterior elements (12 GPa). However, deformation within the posterior elements still occurred, which exhibited a noticeable impact on results in axial rotation. It would thus be favorable to adapt the mesh generation algorithm to attain a larger laminar height. The facet joint attachments, currently branching out from the spinous process for the superior facet joint and from the transverse process for the inferior facet joint, do not resemble their true anatomical locations. False facet origin locations also cause the spinal rods and facet joint attachments to intersect each other. As no contact is defined between the spinal rods and the facet joints, the intersecting features do not cause any issues.

A second improvement with respect to the growth-guidance construct components is necessary. Excessive motion was observed at levels adjacent to the level instrumented with pedicle screws. It appears that the constraints imposed on the rods as a means to artificially model pedicle screw fixation are insufficient. A possible solution involves prescribing a rigid tie-constraint between the rod and the center of the vertebral body instead of between the rod and the lamina. Physically incorporating pedicle screws into the model may also prove of additive value in the future, as it would allow for broader application of the FE model. Patient-specific preoperative construct planning may also be of great value for degenerative scoliosis patients, whom require revision as a result of instrumentation break-out in 9-17\% of all cases [41, 42]. Prediction of screw-bone interface stresses, with correlation of these values to screw break-out, would be necessary next steps in this process.

A limitation of this study is the comparison of a human thoracolumbar spine FE model to porcine in vitro data, limiting a truly fair validation. Porcine spine segments show a much narrower interspecimen variation and are much more readily available; hence porcine spine segments were selected. Due to a much higher flexibility, porcine spine segments were loaded with bending moments of $4 \mathrm{Nm}$, while the human FE model was loaded with bending moments of $8 \mathrm{Nm}$. This was done in accordance with recommendations posed by Wilke et al. [33] and findings by Busscher et al. [32]. ROM magnitudes within the same range were thus attained for the in vitro and in silico studies. Another discrepancy between the in vitro and in silico studies is that the FE model did not contain rib attachments, while the spine segments in the in vitro study contained intact costovertebral joints and approximately $4 \mathrm{~cm}$ of ribs. Finally, the thoracolumbar porcine spine segment contained a straight sagittal profile, whereas the modeled human segment contained a natural lumbar lordosis. Despite these discrepancies, we believe a reasonable comparison between the two situations can be made. 
In the current study, parameter values for adult spinal dimensions were used. The in vitro study from which the validation data was taken was performed using porcine spines with animal weights of approximately 80-90 kg. Prescribing adult spinal dimensions in the FE model was deemed the most suitable approach, as these dimensions approximate the porcine spinal dimensions more closely. In order to model scoliosis correction in EOS patients in the future, juvenile spinal dimensions will be need to be used. Juvenile and pre-adolescent spinal dimensions and the effect of dimensional variations on the biomechanical behavior of the spine have been previously described $[19,43,44]$, so this transition will be fairly straightforward.

We have taken the first steps towards the goal of developing a patient-specific preoperative planning tool which could aid in the selection of growth-guidance construct component composition for EOS patients. The FE model could also be used to predict load magnitudes within wires, and thus provide insight into the possible effects of creep. Further insight into implant related complications such as rod fracture and screw or wire pullout can also be attained using this model.

\section{CONCLUSION}

Important steps in the implementation and validation of a growth-guidance construct for EOS patients in a patient-specific FE model of the spine have been made in this study. Growth-guidance construct components have been successfully implanted into the FE model, which resulted in good agreement with the previously performed in vitro study in terms of the magnitude of the ROM decrease. Some further improvements in the patient-specific mesh generation algorithm are suggested to improve results. Ultimately, application as a preoperative planning tool is envisioned, with the goal of providing a surgeon with more insight into the effects of construct component variations, 


\section{REFERENCES}

[1] Gomez JA, Lee JK, Kim PD, Roye DP, Vitale MG. "Growth Friendly" Spine Surgery: Management Options for the Young Child with Scoliosis. J Am Acad Orthop Surg. 2011;19:722-7.

[2] Luque ER. Paralytic Scoliosis in Growing Children. Clin Orthop Relat Res. 1982:202-9.

[3] Luque ER. Segmental Spinal Instrumentation for Correction of Scoliosis. Clin Orthop Relat Res. 1982:1928.

[4] Mardjetko SM, Hammerberg KW, Lubicky JP, Fister JS. The Luque Trolley Revisited. Review of Nine Cases Requiring Revision. Spine (Phila Pa 1976). 1992;17:582-9.

[5] Pratt RK, Webb JK, Burwell RG, Cummings SL. Luque Trolley and Convex Epiphysiodesis in the Management of Infantile and Juvenile Idiopathic Scoliosis. Spine (Phila Pa 1976). 1999;24:1538-47.

[6] Bogie R, Roth A, Faber S, de Jong J, Welting T, Willems P, et al. Novel Radiopaque Uhmwpe Sublaminar Wires in a Growth-Guidance System for the Treatment of Early Onset Scoliosis: Feasibility in a Large Animal Study. Spine (Phila Pa 1976). 2014.

[7] Roth AK, van der Veen AJ, Bogie R, Willems PC, van Rietbergen B, van Rhijn LW, et al. Range of Motion in Segmental Versus Nonsegmental Ultrahigh Molecular Weight Polyethylene Sublaminar Wire Growth Guidance Type Constructs for Early-Onset Scoliosis Correction. Spine (Phila Pa 1976). 2015;40:E1212-8.

[8] Akbarnia BA. Management Themes in Early Onset Scoliosis. J Bone Joint Surg Am. 2007;89 Suppl 1:4254.

[9] Meijer GJM. Development of a Non-Fusion Scoliosis Correction Device : Numerical Modelling of Scoliosis Correction Http://Doc.Utwente.NI/78273. Enschede2011.

[10] Breau C, Shirazi-Adl A, de Guise J. Reconstruction of a Human Ligamentous Lumbar Spine Using Ct Images--a Three-Dimensional Finite Element Mesh Generation. Ann Biomed Eng. 1991;19:291-302.

[11] Mizrahi J, Silva MJ, Keaveny TM, Edwards WT, Hayes WC. Finite-Element Stress Analysis of the Normal and Osteoporotic Lumbar Vertebral Body. Spine (Phila Pa 1976). 1993;18:2088-96.

[12] Langrana NA, Kale SP, Edwards WT, Lee CK, Kopacz KJ. Measurement and Analyses of the Effects of Adjacent End Plate Curvatures on Vertebral Stresses. Spine J. 2006;6:267-78.

[13] Chanchairujira K, Chung CB, Kim JY, Papakonstantinou O, Lee MH, Clopton P, et al. Intervertebral Disk Calcification of the Spine in an Elderly Population: Radiographic Prevalence, Location, and Distribution and Correlation with Spinal Degeneration. Radiology. 2004;230:499-503.

[14] Panjabi MM, Oxland T, Takata K, Goel V, Duranceau J, Krag M. Articular Facets of the Human Spine. Quantitative Three-Dimensional Anatomy. Spine (Phila Pa 1976). 1993;18:1298-310.

[15] Masharawi Y, Rothschild B, Dar G, Peleg S, Robinson D, Been E, et al. Facet Orientation in the Thoracolumbar Spine: Three-Dimensional Anatomic and Biomechanical Analysis. Spine (Phila Pa 1976). 2004;29:1755-63.

[16] Gilad I, Nissan M. Sagittal Evaluation of Elemental Geometrical Dimensions of Human Vertebrae. J Anat. 1985;143:115-20.

[17] Panjabi MM, Takata K, Goel V, Federico D, Oxland T, Duranceau J, et al. Thoracic Human Vertebrae. Quantitative Three-Dimensional Anatomy. Spine (Phila Pa 1976). 1991;16:888-901.

[18] Panjabi MM, Goel V, Oxland T, Takata K, Duranceau J, Krag M, et al. Human Lumbar Vertebrae. Quantitative Three-Dimensional Anatomy. Spine (Phila Pa 1976). 1992;17:299-306. 
[19] Meijer GJ, Homminga J, Hekman EE, Veldhuizen AG, Verkerke GJ. The Effect of Three-Dimensional Geometrical Changes During Adolescent Growth on the Biomechanics of a Spinal Motion Segment. J Biomech. 2010;43:1590-7.

[20] Smit TH, Odgaard A, Schneider E. Structure and Function of Vertebral Trabecular Bone. Spine (Phila Pa 1976). 1997;22:2823-33.

[21] Shirazi-Adl A, Drouin G. Nonlinear Gross Response Analysis of a Lumbar Motion Segment in Combined Sagittal Loadings. J Biomech Eng. 1988;110:216-22.

[22] Tadano SK, K. Ukai T. Computer Simulation of Idiopathic Scoliosis Initiated by Local Asymmetric Growth Force in a Vertebral Body. In: Power HH, RT., editor. Computer Simulations in Biomedicine. Southampton1995. p. 369-76.

[23] Goel VK, Monroe BT, Gilbertson LG, Brinckmann P. Interlaminar Shear Stresses and Laminae Separation in a Disc. Finite Element Analysis of the L3-L4 Motion Segment Subjected to Axial Compressive Loads. Spine (Phila Pa 1976). 1995;20:689-98.

[24] Lu YM, Hutton WC, Gharpuray VM. Can Variations in Intervertebral Disc Height Affect the Mechanical Function of the Disc? Spine (Phila Pa 1976). 1996;21:2208-16; discussion 17.

[25] Schmidt H, Heuer F, Drumm J, Klezl Z, Claes L, Wilke HJ. Application of a Calibration Method Provides More Realistic Results for a Finite Element Model of a Lumbar Spinal Segment. Clin Biomech (Bristol, Avon). 2007;22:377-84.

[26] Schmidt H, Heuer F, Simon U, Kettler A, Rohlmann A, Claes L, et al. Application of a New Calibration Method for a Three-Dimensional Finite Element Model of a Human Lumbar Annulus Fibrosus. Clin Biomech (Bristol, Avon). 2006;21:337-44.

[27] Chazal J, Tanguy A, Bourges M, Gaurel G, Escande G, Guillot M, et al. Biomechanical Properties of Spinal Ligaments and a Histological Study of the Supraspinal Ligament in Traction. J Biomech. 1985;18:167-76.

[28] Little JS, Khalsa PS. Material Properties of the Human Lumbar Facet Joint Capsule. J Biomech Eng. 2005;127:15-24.

[29] Heuer F, Schmidt H, Klezl Z, Claes L, Wilke HJ. Stepwise Reduction of Functional Spinal Structures Increase Range of Motion and Change Lordosis Angle. J Biomech. 2007;40:271-80.

[30] White AA, Panjabi MM. Clinical Biomechanics of the Spine. 2nd ed. Philadelphia: Lippincott; 1990.

[31] Ratner BD. Biomaterials Science : An Introduction to Materials in Medicine. San Diego: Academic Press; 1996.

[32] Busscher I, van der Veen AJ, van Dieen JH, Kingma I, Verkerke GJ, Veldhuizen AG. In Vitro Biomechanical Characteristics of the Spine: A Comparison between Human and Porcine Spinal Segments. Spine (Phila Pa 1976). 2010;35:E35-42.

[33] Wilke HJ, Wenger K, Claes L. Testing Criteria for Spinal Implants: Recommendations for the Standardization of in Vitro Stability Testing of Spinal Implants. Eur Spine J. 1998;7:148-54.

[34] Zander T, Rohlmann A, Klockner C, Bergmann G. Influence of Graded Facetectomy and Laminectomy on Spinal Biomechanics. Eur Spine J. 2003;12:427-34.

[35] Shirazi-Adl A, Ahmed AM, Shrivastava SC. Mechanical Response of a Lumbar Motion Segment in Axial Torque Alone and Combined with Compression. Spine (Phila Pa 1976). 1986;11:914-27.

[36] Eberlein R, Holzapfel GA, Frohlich M. Multi-Segment Fea of the Human Lumbar Spine Including the Heterogeneity of the Annulus Fibrosus. Computational Mechanics. 2004;34:147-63. 


\section{Chapter 6}

[37] Nolte LP, MM. Oxland, TR. Biomechanical Properties of Lumbar Spinal Ligaments. In: Heimke G. Soltesz UL, AJC., editor. Advances in Biomaterials, Volume 9. Amsterdam: Elsevier Science Publishers B.V.; 1990.

[38] Pingel T. Beitrag Zur Herleitung Und Numerischen Realisierung Eines Mathematischen Modells Der Menschlichen Wirbelsaule. Bochum1991.

[39] Rohlmann A, Zander T, Schmidt H, Wilke HJ, Bergmann G. Analysis of the Influence of Disc Degeneration on the Mechanical Behaviour of a Lumbar Motion Segment Using the Finite Element Method. J Biomech. 2006;39:2484-90.

[40] Skaggs DL, Weidenbaum M, latridis JC, Ratcliffe A, Mow VC. Regional Variation in Tensile Properties and Biochemical Composition of the Human Lumbar Anulus Fibrosus. Spine (Phila Pa 1976). 1994;19:1310-9.

[41] Maier S, Smith JS, Schwab F, Obeid I, Mundis G, Klineberg E, et al. Revision Surgery after Three-Column Osteotomy in 335 Adult Spinal Deformity Patients: Inter-Center Variability and Risk Factors. Spine (Phila Pa 1976). 2014.

[42] Pichelmann MA, Lenke LG, Bridwell KH, Good CR, O'Leary PT, Sides BA. Revision Rates Following Primary Adult Spinal Deformity Surgery: Six Hundred Forty-Three Consecutive Patients Followed-up to TwentyTwo Years Postoperative. Spine (Phila Pa 1976). 2010;35:219-26.

[43] Meijer GJ, Homminga J, Veldhuizen AG, Verkerke GJ. Influence of Interpersonal Geometrical Variation on Spinal Motion Segment Stiffness: Implications for Patient-Specific Modeling. Spine (Phila Pa 1976). 2011;36:E929-35.

[44] Peters JR, Chandrasekaran C, Robinson LF, Servaes SE, Campbell RM, Jr., Balasubramanian S. Age- and Gender-Related Changes in Pediatric Thoracic Vertebral Morphology. Spine J. 2015;15:1000-20 


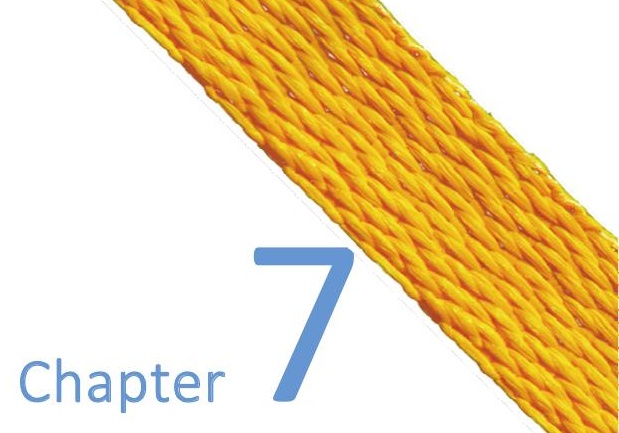

Large Animal Models in Fusionless Scoliosis

Correction Research: a Literature Review

Spine J. 2013 Jun;13(6):675-88

Alex K. Roth, Rob Bogie, Eva Jacobs, Jacobus J. Arts, Lodewijk W. van Rhijn 


\section{ABSTRACT}

Background Context: Numerous prenatal, systemic or local procedures have been described which have created an experimental scoliosis within different animal species. Compression-based fusionless scoliosis correction devices have been used to induce scoliosis (inverse approach) as an indication for their potential corrective efficacy in large animals. Deformities which most closely approximate the three-dimensional nature of an idiopathic-like scoliosis have been created in large animals using a posterior spinal tether. Fusionless scoliosis correction devices have subsequently been tested in these models.

Purpose: To provide an overview of large animal models used for preclinical testing of fusionless scoliosis correction devices and to describe recent advances in the creation of an idiopathic-like scoliosis large animal model.

Study Design: Literature review of large animal models in fusionless scoliosis correction research.

Methods: MEDLINE electronic database was searched for studies in which large animal models for spinal or vertebral growth modulation or the creation of an experimental scoliosis were described. The literature search was limited to articles written in the English language.

Results: The pig appears to be the most suitable animal species for preclinical testing of fusionless scoliosis correction devices due to its large growth potential and the possibility for early weaning. With the inverse approach, it is difficult to gain insight into the possible corrective efficacy of the tested device and therefore a two-step approach is preferred. Using a posterior spinal tether, persistent spinal deformities are attained when the deformity has approximately doubled in comparison to the postoperative measure in a time span of approximately 12 weeks. Sufficient tether midline off-set is required to render rib procedures unnecessary.

Conclusions: An idiopathic-like scoliosis animal model can be created using a posterior spinal tether in a fully reversible procedure. Experimental results will need to be reproduced in order to establish a standard, idiopathic-like scoliosis large animal model. 


\section{INTRODUCTION}

Scoliosis is a complex three-dimensional spinal deformity which is seen in $3-5 \%$ of the adolescent population [1]. The most common type of scoliosis (80-85\%) is adolescent idiopathic scoliosis (AIS), which presents shortly before or during puberty. The etiology is unknown and presumably multifactorial (genetic, environmental etc.). The risk of deformity progression is increased during periods of rapid skeletal growth due to the effects of asymmetric loading on growth rate; bone growth is suppressed by increased compression and accelerated by tensile forces acting on the endochondral growth plate (Hueter-Volkmann principle). A spinal deformity thus leads to asymmetric loading and growth, resulting in deformity progression in a 'vicious cycle' as was proposed by Stokes et al. [2].

The standard treatment for deformities not responding to conservative bracing therapy has been spinal fusion with the goal of acquiring stable correction. However, before surgical intervention in the growing spine is considered, the expected remaining growth in the spine and the thoracic cage must be taken into account. The thoracic cage has only reached approximately $50 \%$ of its mature volume by age ten [3], and early fusion can hinder lung development [4]. Possible occurrence of the crankshaft phenomenon, progression of the spinal deformity due to continued growth in the anterior portion of the spine while the posterior portion is fused, also discourages early spinal fusion $[5,6]$. Disproportionate stature and a shortened trunk may also result from early fusion.

In order to avoid these issues, surgical techniques and instrumentation are being developed which aim to achieve fusionless scoliosis correction. Fusionless scoliosis correction devices can be classified according to the mechanism by which spinal and thoracic cage growth is modulated: distraction-based (vertical expandable prosthetic titanium rib (VEPTR), growing rods), compression-based (vertebral body staple, anterior spinal tether) or growth-guidance systems (Luque trolley or Shilla technique) [7]. Controlling the deformity in all three dimensions is the largest challenge in the design of new fusionless scoliosis correction devices. To test the efficacy of new fusionless scoliosis correction devices in a preclinical stage, a consistent large animal model representative of an idiopathic scoliosis is ideally used. However, no such large animal model is naturally occurring.

In the past, animal models have been extensively used in attempts to clarify the etiology of scoliosis by inducing scoliosis using various prenatal, systemic or local procedures, as was reviewed in 2011 by Janssen et al. [8]. Compression-based fusionless scoliosis devices have also been used to induce a scoliotic deformity as an inverse analog to the corrective procedure as means to show their potential corrective efficacy. This approach has been dubbed the inverse approach [9]. Tests have also been performed in animals using a two-step approach; a structural, idiopathic-like scoliosis is created in a 
first procedure and later corrected using the proposed scoliosis correction device in a second procedure. Although many different methods have been used to create a scoliosis, only posterior spinal tethering produces significant, progressing deformities that approximate the three-dimensional nature of the deformity as seen in idiopathic scoliosis [10].

An overview of large animal models used for preclinical testing of fusionless scoliosis correction devices was given in 2005 by Braun et al. [10]. In recent years, advances towards a more consistent idiopathic-like scoliosis large animal model have been made and newly proposed fusionless scoliosis correction strategies have been tested using the inverse approach. Therefore, the purpose of this literature review is to provide an up-to-date overview of large animal models used in fusionless scoliosis correction research. The technical details which play an important role in the development of a consistent, idiopathic-like scoliosis animal model will also be reviewed as we will implement these lessons in the setup of an idiopathic-like scoliosis model at our own institution.

\section{METHODS}

The MEDLINE online database was consulted using the following search terms: (scoliosis OR ((spinal OR vertebral) AND (growth modulation))) AND (experimental OR animal model) up until July 2012. The search was limited to studies in large animals and articles published in the English language. References of retrieved articles and relevant review articles were checked to identify additional studies.

The titles and abstracts of the resulting citations ( $n=594)$ were scanned by two separate authors. A meeting was held to reach consensus on the articles to be included $(n=27)$. In the case of disagreement, a third author was consulted. Figure 1 illustrates the search terms, and the subsequent classification of included articles as used in this literature review. Included articles were first classified based on one of two methodological approaches which are followed; the inverse approach $(n=13)$ or the two-step approach $(n=14)$. With the inverse approach, the proposed method of surgical treatment is used to create a spinal deformity as an inverse analog to the corrective treatment. In this case, achieving spinal growth modulation is used as a first indication for possible success in scoliosis correction. For studies utilizing the inverse approach, the studies were subsequently classified according to the targeted growth plate: the neurocentral cartilage or the longitudinal vertebral epiphyseal plate. The two-step approach requires a fully reversible procedure to create a consistent, idiopathic-like scoliosis in a growing animal. These criteria have only been met using a posterior spinal tether [10]. However, technical details vary considerably and will be compared. 


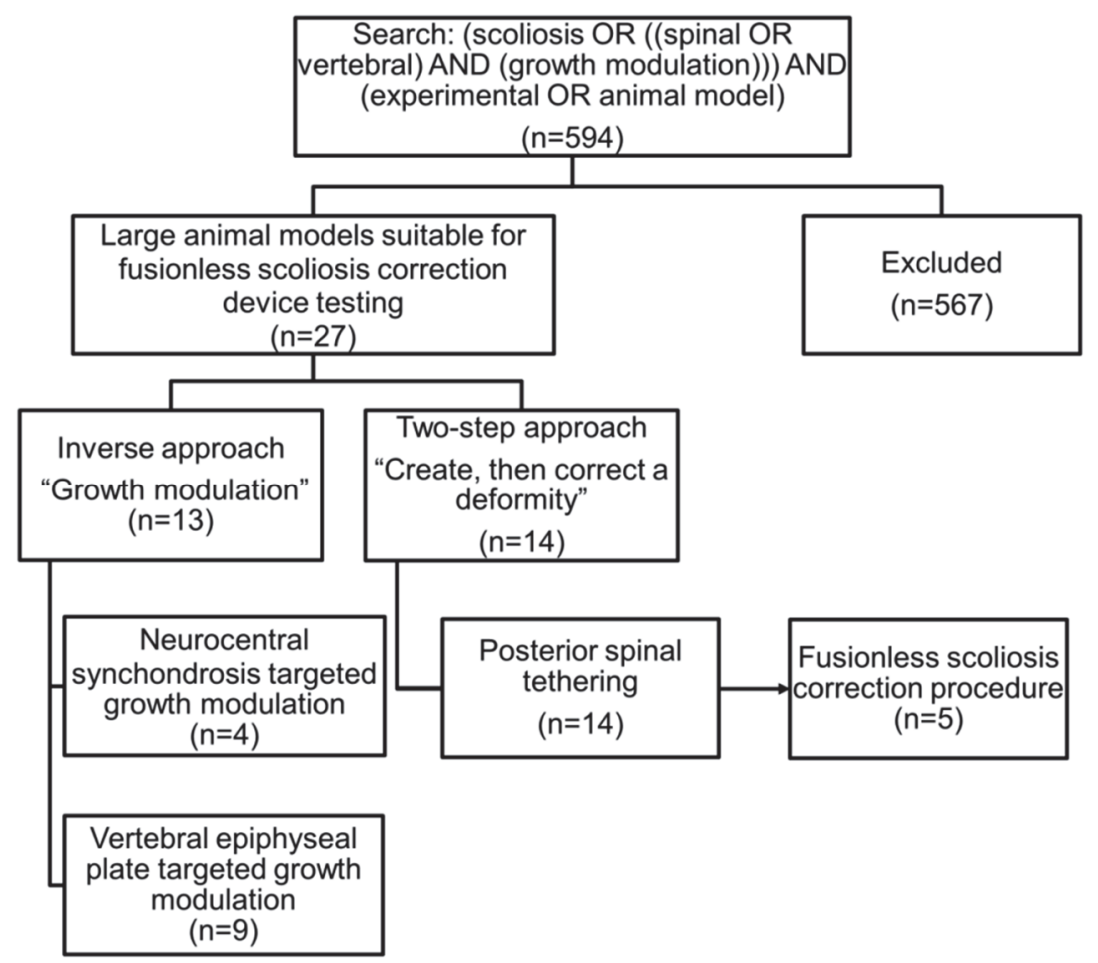

Figure 1 - Flowchart illustrating the search terms, number of resulting publications, and the classification according to methodological approach.

\section{RESULTS}

An overview of important characteristics of studies utilizing the inverse approach to test fusionless scoliosis correction devices in large animals is given in Table 1 . Table 2 summarizes the results and the most important characteristics of the idiopathic-like scoliosis models in large animals created using a posterior spinal tether.

\section{Inverse approach}

\section{Growth modulation by epiphysiodesis of the neurocentral cartilage}

In 1980, an experimental scoliosis was created by selective epiphysiodesis of the neurocentral cartilage in immature pigs by Beguiristain et al. [11]. Unilateral pedicle screws were introduced in four or five consecutive, midthoracic levels and animals were followed for a period ranging between 4 and 12 months. Structural scoliotic deformities varying between $10^{\circ}$ and $80^{\circ}$ developed. 
Zhang and Sucato $[12,13]$ successfully created scoliotic deformities with unilateral pedicle screw epiphysiodesis of the neurocentral cartilage by using two screws in the right pedicle between T7 and T14 in 1-2 month old pigs. After 6 weeks, the mean spinal deformity measured $35^{\circ}$. Attempts were made to correct the deformity by placing another two screws in the left pedicle in 3 animals, while 3 animals were not treated. Ultimately, the deformity measured $34^{\circ}$ in the untreated group while deformity was corrected to a mean of $20^{\circ}$ at 17 weeks postoperatively in the treated group.

Caballero et al. [14] have performed growth modulation by hemicircumferential electrocoagulation of the neurocentral cartilage, inferior and superior epiphyseal endplates, and a combination of the above at T5-T9 in 4-week old pigs. The largest deformities $\left(19^{\circ}\right)$ were created in animals in which only the neurocentral cartilage was injured, in comparison to $12^{\circ}$ in the group with epiphyseal endplate injury and $13^{\circ}$ in the combined lesion group.

\section{Growth modulation by epiphysiodesis of the vertebral epiphyseal plates}

In 1950, Nachlas and Borden [35] were the first to use fusionless spine implants to create a deformity in a large animal model. A lumbar vertebral body staple spanning multiple (3-4) segments was used to create and subsequently also correct a deformity in immature dogs. Although no deformity measures were given, and staple dislodgement or breakage occurred regularly, this work pioneered fusionless scoliosis device testing in animal models.

Newton et al. have extensively studied growth modulation using an anterolateral thoracic tether in calves [15-17] and mini-pigs [18, 19]. In the calf model, anterior vertebral body screws were placed at levels T6-T9, with a flexible stainless steel tether connecting all levels. With the calf model, a mean coronal deformity measuring $37^{\circ}$ was created. The rapid growth rate of the calves led to severe deformities considering only 4 levels are involved. This unsuspected outcome in the calf model prompted a change towards a miniature pig model, which has a more similar growth rate compared to the human adolescent. Using a similar procedure, a vertebral staple-screw construct was applied over four consecutive vertebrae, connected by a polyethylene tether in 7 month old mini-pigs. The mean Cobb angle from T8 to T11 was approximately $15^{\circ}$ after six months and $30^{\circ}$ after twelve months. The influence of intraoperative tether tensioning was also studied, and proved to cause an increased coronal Cobb angle during the first 6 postoperative months. At later time points, this effect disappeared with the final coronal Cobb angle (T8-T11) being $28^{\circ}$ in the pretensioned group and $27^{\circ}$ in the untensioned group at 12 months postoperatively. There was no screw pull-out or screw ploughing in either group, which indicates that intraoperative tensioning of the tether was safe. 


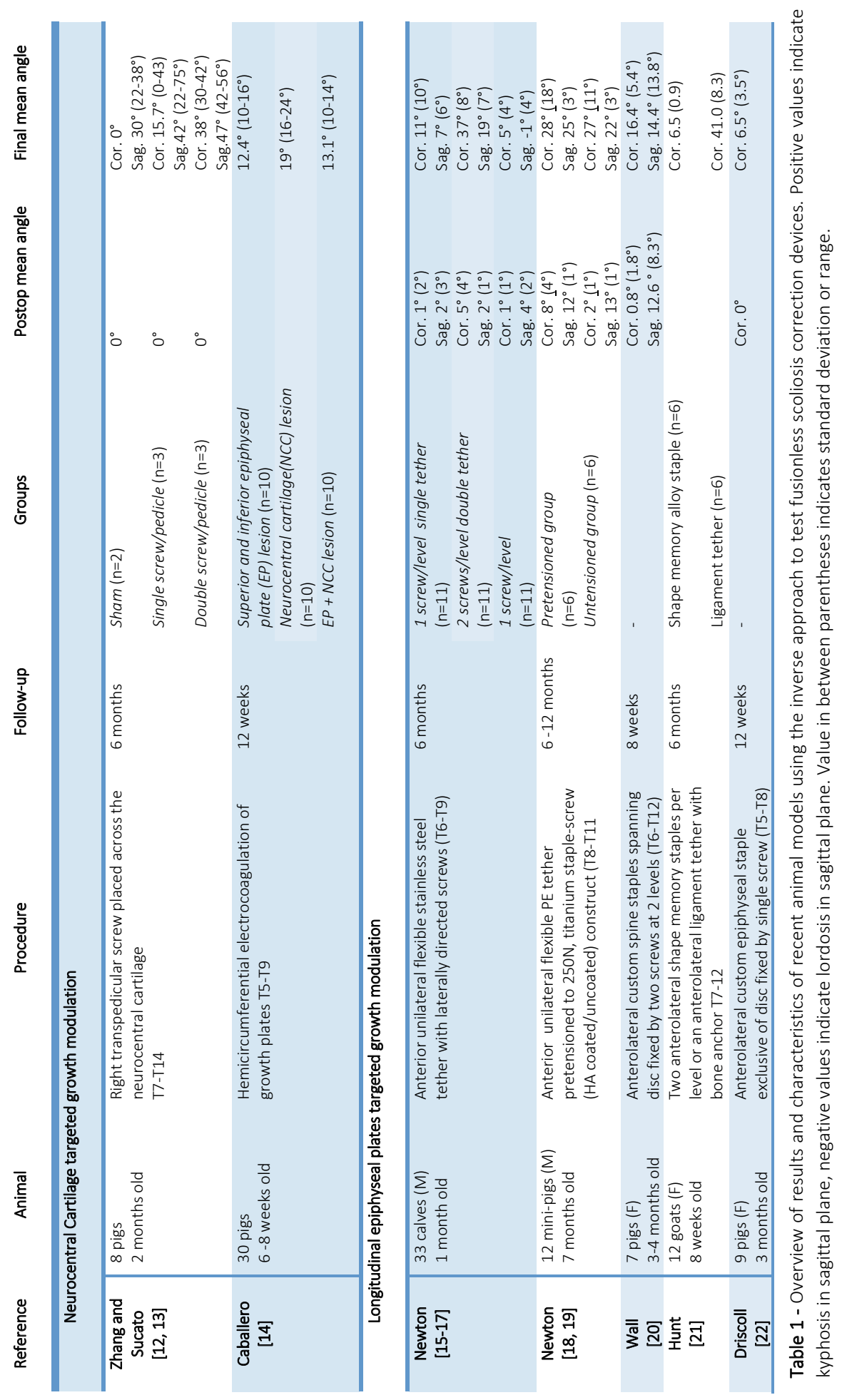




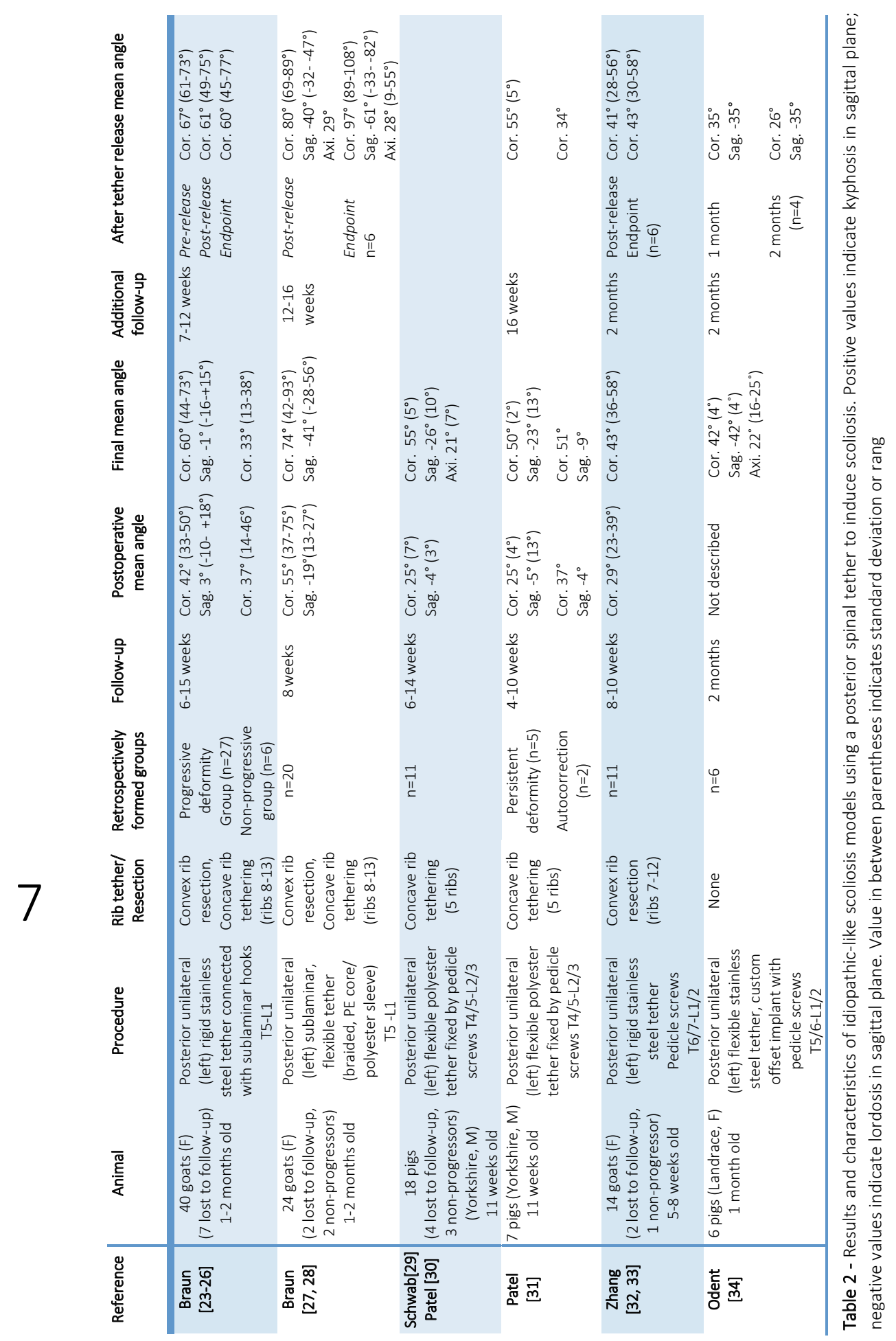


Wall et al. [20] have introduced six custom anterolateral spine staples between T6 and T12 in pigs approximately 3-4 months of age. Each staple spanned the disc and was fixed using two bone screws. After 8 weeks, a mean coronal plane deformity of $16^{\circ}$ was attained.

Hunt et al. [21] have tested two different fusionless scoliosis correction devices in goats to assess their influence on the health of the disc. Anterior shape memory alloy staples or an anterior ligament tether with bone anchors were placed at each level between T7 and T12 in 8 week old goats. After a 6 month follow-up, the deformity measured $7^{\circ}$ in the staple group and $41^{\circ}$ in the ligament tether group.

Driscoll et al. [22] performed epiphysiodesis of longitudinal growth plate by inserting custom anterolateral spine staples exclusive of the disc fixed by a single screw. A single epiphyseal device was inserted at levels T5-T8 in four 3-month old pigs. After a followup period of 12 weeks, the final deformity measured only a mean of $7^{\circ}$ in the coronal plane.

\section{Two-step approach}

Creating an idiopathic-like scoliosis via a posterior spinal tether

Smith and Dickson first described a posterior, sublaminar spinal tether to create a structural scoliosis in a rabbit model in 1987 [36]. However, rapid deformity progression was attributed to spinal cord damage resulting from an intended muscle release procedure with a soldering iron instead of growth modulation. Within the last decade, a posterior spinal tether has been used to create idiopathic-like scoliosis in different large animal species. The experimental technique has advanced considerably so that the resulting deformities are becoming more similar to an idiopathic-like scoliosis.

Braun et al. were the first to develop a consistent scoliotic deformity in a goat model using a posterior spinal tether [26]. The operative procedure consisted of implanting a rigid posterior tethering fixed by sublaminar hooks (T5-L1), combined with concave rib tethering and convex rib resection procedures. The goats (1-2 months old) developed progressive, structural lordoscoliotic curves with a mean Cobb angle of $60^{\circ}$ in the coronal plane after 6-15 weeks. In the sagittal plane, the mean kyphotic Cobb angle was $11^{\circ}$ preoperatively and changed to a $1^{\circ}$ lordotic curve after follow-up. The curves were markedly more rigid, before and after removal of the posterior tether in comparison to the curves usually seen in AIS. Furthermore, the curve progression was to some extent unpredictable, with 6 out of 33 goats (18\%) failing to develop progressive curves [26]. In order to address these limitations, the rigid tether and laminar hooks were replaced by a flexible, unilateral tether with sublaminar anchoring [28]. Again, the posterior tether was accompanied by concave rib tethering and convex rib resection. Using the flexible tether, very large deformities were obtained with a mean Cobb angle of $74^{\circ}$ over an 
eight week tethering period [27]. Moreover, a high progression of mean thoracic lordosis (from $11^{\circ}$ kyphosis pre- to $41^{\circ}$ lordosis postoperatively) was seen, and the average maximum axial rotation was $28^{\circ}$. The more severe deformities and the quick progression rate can largely be attributed to the postoperative coronal Cobb angle; with the rigid tether the deformity measured $42^{\circ}$ postoperatively, compared to $55^{\circ}$ with the flexible tether. The extremely large deformities in both planes were more than is typical for AIS. Furthermore, the curves were still quite rigid as was seen in the model using the rigid tether. The high curve rigidity was therefore attributed to the more pyramidal shape of the goat thorax compared to the more cubical shape of the human thorax.

After creation of the deformities, correction using different fusionless scoliosis correction devices was also performed in both the rigid and flexible tether models [24, $25,27,37,38]$. Treatment consisted of the placement of either anterior shape memory alloy staples or a flexible anterior ligament tether with bone anchors. In the rigid tether deformity model, stapled goats corrected from $52^{\circ}$ to $45^{\circ}$ for a correction of $13 \%$. In the flexible tether model, stapled goats showed deformity progression: from $76^{\circ}$ posttreatment to $94^{\circ}$ at endpoint. Using an anterior loop ligament tether, deformity progressed mildly: from $62^{\circ}$ post-treatment to $70^{\circ}$ at endpoint.

In 2007, Zhang et al. [32, 33] created scoliotic deformities in immature goats (5-8 weeks old) by inserting a rigid, posterior tether with unilateral pedicle screws combined with convex rib resection. The tether was anchored at two adjacent levels for stable fixation (T6-7, L1-2). The deformity measured a mean of $29^{\circ}$ postoperatively, and progressed to $43^{\circ}$ after a follow-up period of up to ten weeks [32, 33]. Although CT analysis was performed, the authors only described the deformity in the coronal plane while no measure was given for the axial or sagittal plane deformity. In comparison to the model described by Braun et al. using a rigid tether, the main difference described by Zhang et al. is that pedicle screws were used instead of laminar hooks and the rib tether was omitted.

In 2009, Schwab et al. [29] created scoliotic deformities in 11 week old Yorkshire pigs through unilateral posterior ligament tethering of the spine combined with ipsilateral ribcage tethering. The tether was anchored at two adjacent levels (T4-5, L2-3) via pedicle screws. After eleven weeks, the mean Cobb angle was $55^{\circ}$ and the mean lordosis was $24^{\circ}$ (compared to respectively $24^{\circ}$ and $3^{\circ}$ kyphosis preoperatively). The average maximum axial rotation was $20^{\circ}$ [30].

Odent et al. [34] created a porcine thoracic scoliosis model by applying a custom offset implant fixed on two adjacent vertebral levels with unilateral pedicle screws at T5-T6 and L1-L2. The implants were connected by a flexible stainless steel cable in six 1 month old Landrace pigs. As a pilot, different types of offset implants were tested using finite element analysis. The final offset implant design was chosen based on the highest lateral translation of the apex vertebra for identical loads placed on the tether. All 
tethered spines developed a significant progressive curve. The mean Cobb angle was approximately $42^{\circ}$ in the coronal plane, and a $42^{\circ}$ lordotic deformity was attained at 2 months postoperatively. The average maximum axial rotation was $22^{\circ}$. Growth of the $L 4$ vertebrae was extrapolated to calculate the expected spine growth if no tether had been placed. The variation between the expected spinal growth and the measured spinal growth never exceeded 3\%, and therefore it was concluded that the tether did not affect spinal growth and true growth modulation had occurred. No direct postoperative deformity measures were given, which makes comparison to other models more difficult.

\section{Necessity for rib tether/resection}

Early experimental scoliosis animal models have stressed the role of the ribs and the costovertebral joints in the development of scoliotic deformities. Langenskiold and Michelsson were to the first to produce severe scoliotic deformities in a rabbit model using a unilateral rib resection technique [39]. Karaharju first described a porcine scoliosis model in 1967, and achieved progressive lordoscoliotic curves by using a similar technique. Unilateral rib resection of approximately eight centimeters on the dorsal side followed by suturing of the rib to the spinous process led to severe scoliotic deformations in most animals. In spines effected by costal resection only, the deformity progression did not continue regularly over time [40]. Sanders et al. used the technique described by Langenskiold and Michelsson to create an experimental scoliosis in goats and subsequently corrected the deformity using shape memory alloy rods in 1993 [41]. However, both large animals models were not clinically relevant models for a scoliotic spine due to extensive violation of both costovertebral and costotransverse joints, and likely disruption of the disc annulus due to removal of the rib head on the convex side. Furthermore, exposure of the posterior elements to allow tethering of the ribs to the spinous process likely violated the facet joints and lamina and may have promoted ectopic bone formation.

Before their first successful experiments, Braun et al. first conducted a pilot study in eleven immature goats and found that a substantially progressive scoliotic deformity was not created by a spinal tether alone [26]. Furthermore, two additional goats underwent convex rib resection (ribs 8-13) combined with concave rib tethering (ribs 813) resulting in no significant spinal deformity. Therefore, Braun et al. developed a model in which an asymmetric posterior spinal tether was combined with concave rib tethering and convex rib resection with minimal violation of the spinal and costal elements.

Schwab et al. [29] also performed a pilot study and concluded that rib resection was not necessary for the progression of the deformity. They noted that rib resection led to rapid healing and fusion of the convex ribs, which inhibited curve progression and 
added to the overall morbidity of the animal. Ultimately, Schwab et al. successfully opted for left rib tethering and left posterior tethering with pedicle screws.

Odent et al. [34] acquired significant spinal deformities in immature pigs without rib resection or tethering. A custom offset implant was used to generate a longer moment arm to increase the effective moment working on each vertebra. Essentially, the rib tether creates an additional moment working on the spine in the coronal plane, while rib resection decreases spine stiffness on the contralateral side. Apparently, the increased moment arm in the coronal plane generated by the offset implant renders rib procedures unnecessary.

There are some obvious disadvantages regarding both rib tethering and rib resection procedures. The extent of the thoracoplasty is associated with an increase of the postoperative morbidity (up to $30 \%$ of all animals) [33]. Thoracic procedures make the animal model less suitable for pulmonary parameter analysis [34]. Rib tethering provokes a periosteal reaction with bone formation around the tether, making rib tether release unconceivable so that complete reversibility of the index procedure is not possible. In the future, thoracic scarring with extensive paraspinal fibrosis may also limit the ability to test new methods of correction.

\section{Deformity persistence after posterior spinal tether removal}

An important criterion for a representative idiopathic-like scoliosis model is that the created scoliotic deformity is progressive or at least persistent; it should not autocorrect after reversal of the procedure. The animal model should be in accordance with the 'vicious cycle' theory as proposed by Stokes et al. [2]; lateral spinal curvature produces asymmetrical loading of the immature spine which in turn causes asymmetrical growth and hence progressive wedge deformity. However, the threshold values for the vicious cycle theory have not been determined and therefore the time point at which the tether is released has been somewhat arbitrary.

Braun et al. have tested fusionless spinal implants following experimental scoliosis creation using both a flexible and a rigid tether and included a tether release group to serve as a control. No consistent, clearly defined endpoint for the tethering period was defined in the studies performed by Braun et al. In the rigid tether model, a deformity was created in a time period ranging between 6-15 weeks. The mean coronal Cobb angle was $67^{\circ}, 61^{\circ}$ immediately post release, and $60^{\circ}$ after $7-12$ additional weeks. In a separate study [23], 15 goats were operated on using the same procedure. The tether was released in all animals after 12 weeks, and animals were followed for an additional 4 weeks. The authors attempted to retrospectively predict which curves were progressive based on the contribution of vertebral wedging to the overall curve. A significant difference was seen in percentage vertebral wedging between the progressive deformity group and the non-progressive group at the time of tether 
release. Therefore the authors proposed a threshold of 55.3\% contribution of vertebral wedging to the total deformity as an independent predictor of curve progression. Using this threshold, it would have been possible to predict $85 \%$ of progressors and $88 \%$ of non-progressors. Until now, this has been the only study to retrospectively determine a threshold for deformity progression in an animal model. More severe scoliotic deformities were created by Braun et al. using a flexible tether, with a mean deformity of $79.5^{\circ}$ after 8 weeks. These deformities progressed to a mean angle of $97^{\circ}$ after an additional follow-up of 12-16 weeks following tether release. These more malignant curves clearly have surpassed the thresholds for a progressive deformity, but these acquired deformities are not representative of a typical idiopathic scoliotic deformity which would be eligible for fusionless scoliosis surgery.

In the porcine model described by Schwab et al., a final coronal Cobb angle of $50^{\circ}$ was used as a criterion for the tethering endpoint. Patel et al. [31] studied the persistence of a created deformity after the release of the spinal tether in 7 animals. Five animals showed persistent deformities, while the curve showed autocorrection in two animals. In the autocorrective group, a larger postoperative Cobb angle was seen $\left(33^{\circ}\right.$ and $40^{\circ}$ ) compared to the persistent deformity group (mean of $24.8^{\circ} \pm 3.7^{\circ}$ ). Therefore, progression to $50^{\circ}$ took just a mean of 4.3 weeks for the two animals in the autocorrective group. Presumably, the threshold defined by Braun et al. [23], a contribution of vertebral body wedging of $55 \%$ to the total deformity, was not met at the time of tether release in the autocorrective group in the study described by Patel et al.

Odent et al. also performed a tether release, albeit in only four animals. The mean coronal Cobb angle of the deformity was $49^{\circ}$ prerelease ( 2 months postoperatively), and autocorrected by approximately $30 \%$ after 1 month to a mean of $35^{\circ}$ and by approximately $50 \%$ to a mean of $26^{\circ}$ after 2 months. The authors stated that curve regression in the first month is likely due to disc viscoelastic behavior. The scoliotic deformities were created over a relatively short time period of two months, and no immediate post-operative deformity measures were available, making comparison to other models difficult. Therefore we suggest that radiographic analysis should be performed both pre- and post-operatively. Furthermore, a rib tether was not used to create the deformity in this study. The inability to perform rib tether release in other models likely helps in sustaining a higher deformity measure following spinal tether release.

\section{Rigid vs. flexible spinal tether}

Both rigid and flexible posterior tethers have been used to create scoliotic deformities in animal models. A rigid, stainless steel, posterior tether was used in the first series of studies described by Braun et al. [26] and in the studies described by Zhang et al. [32, 33]. A much higher spinal rigidity in the experimental goat model compared to a typical 


\section{Chapter 7}

idiopathic scoliotic curve led to the use of a flexible tether instead of the rigid tether by Braun et al. [28]. Histologic analysis of the growth plate and the intervertebral disc to evaluate possible unintended fusion was not performed. Rationally, a flexible tether allows for more spinal motion with a more dynamic nature during normal locomotion as compared to a rigid tether. Therefore, the risk of unintended fusion is lowered. In a rat tail model, asymmetrical dynamic loading of an external fixator created significantly greater wedge deformities as compared to the statically loaded group [42]. Hence, a representative structural scoliotic deformity can possibly be created in a shorter time period with a flexible tether than would be possible with a rigid tether.

Flexible tethers consisting of different materials have been used. A flexible stainless steel tether was used by Odent et al. Polyester (Schwab et al.), polyethylene (Newton et al.) and polyester/polyethylene hybrid constructs (Braun et al.) have also been used as a flexible spinal tether. The advantage of using a flexible stainless steel tether is its radiopacity, enabling tracking of tether location and integrity. However, a steel cable causes a hard stop to motion, with abrupt load transfer possibly leading to instrumentation break-out. Braun et al., as well as Schwab et al. included a radiopaque titanium thread within the polyester tether. Using this method, radiopacity is maintained while a more elastic tether is used. 

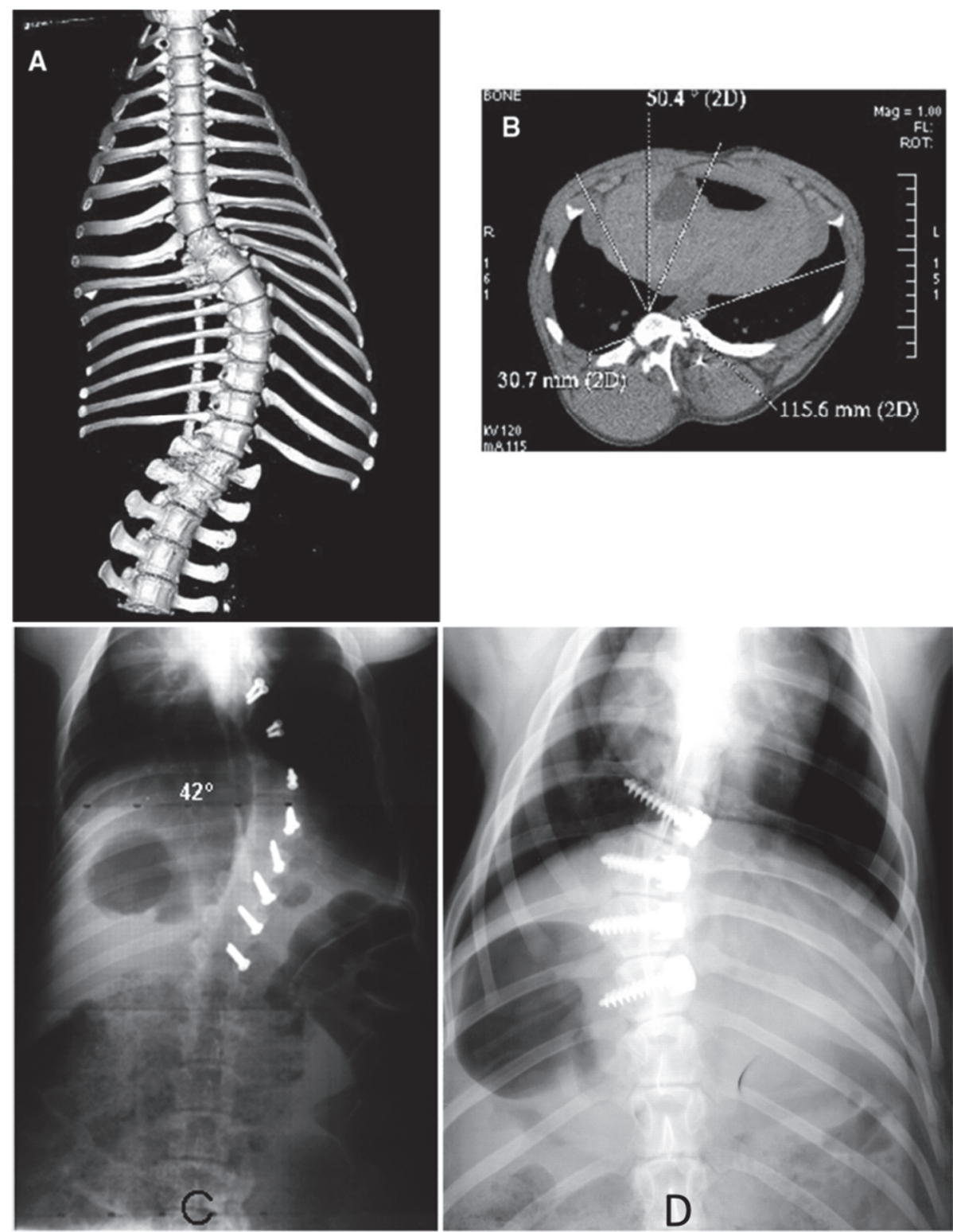

Figure 2 - (A) Three dimensional reconstruction of computed tomography (CT) scan of a representative deformity created using a custom offset implant in a porcine model (anterior view). Reproduced with permission from Odent et al. [34]. (B) Axial slice illustrating rotational deformity in the axial plane at thoracic level. Reproduced with permission from Odent et al. [34]. (C) Anterioposterior radiograph showing results after 6 months of neurocentral cartilage targeted growth modulation using double pedicle screws at T7/T14 in a goat model. Reproduced with permission from Zhang and Sucato. [12] (D) Anterioposterior radiograph demonstrating the deformity creation after anterior tethering of the porcine spine. Reproduced with permission from Newton et al. [18]. 


\section{DISCUSSION}

Two methodologically different approaches have been commonly used for the preclinical testing of fusionless scoliosis correction devices in large animals: the inverse approach and the two-step approach. The inverse approach may be suitable for testing fusionless scoliosis correction devices which rely on compression-based growth modulation, but not for the testing of distraction-based or growth-guiding fusionless scoliosis correction devices (growing rods, VEPTR or Shilla, Luque trolley techniques). Furthermore, the ability of the proposed device to modulate spinal growth may be used as an indication of its corrective potential, but only speculations regarding its corrective efficacy can be made using the inverse approach. Much larger compressive forces are needed to reverse the asymmetric load distribution present in a deformed spine and subsequently neutralize vertebral wedging through compression-based growth modulation as compared to creating load asymmetry through compression when inducing a scoliotic deformity. Considering the limitations involved with the inverse approach, utilizing a two-step approach with posterior spinal tethering as an index procedure appears to be the preferred approach towards establishing a universal model for the preclinical testing of fusionless scoliosis correction device. However, careful planning and consideration are required to attain an idiopathic-like scoliosis animal model fulfilling all set requirements using a posterior tether. Key aspects that require consideration include tether anchoring technique, the potential need for additional rib procedures, tether material, and species selection (regarding timing of the procedures and overall comparative anatomy).

Stable tether fixation is commonly achieved by anchoring the tether at two adjacent levels which can be intentionally fused. Advances in the procedural technique have led to the omission of rib procedures; Schwab et al. have first shown that rib resection is not required and Odent et al. have later shown that the rib tether may also be omitted when sufficient tether offset from the spinal midline is maintained. A flexible tether is preferred over a rigid tether in order to only attain growth modulation in the desired planes (lordoscoliosis) while maintaining maximum spinal mobility. A persistent deformity can be attained in approximately 12 weeks when the deformity has approximately doubled in value as compared to the postoperative measure.

Regardless of which approach is used, the testing of fusionless scoliosis correction devices can be performed in whatever large animal species is deemed appropriate. However, the degree of success (measured by the final Cobb angle of the deformity) depends on a number of aspects; the timing of the first intervention in relation to age, the postoperative Cobb angle and the magnitude of the growth expected during the follow up period in the chosen species. Using the two-step approach, the timing of the interventions becomes very crucial and requires serious planning. The first intervention (posterior tether or fusionless spine implant placement) is ideally performed in young 
animals as soon as is deemed safe in order to exploit as much of the early growth phase as possible. Growth curves normalized by mature body weight for some specific breeds of pig, sheep, goat, and the mini-pig are shown in Figure 3 to illustrate the onset of the growth spurt. For the shown breeds of sheep, pigs and goats, the maximum growth velocity occurs at around 3-4 months of age and growth velocity declines afterwards. Generally, the animals in the reviewed articles were operated on at an age of around 12 months old, just before the onset of the early growth spurt, with no recurrent issues regarding instrumentation break-out. Using the two-step approach, the corrective intervention must take place with enough growth potential remaining. $80-90 \%$ of the expected growth (by weight) has already occurred in the goat, sheep and pig by the age of approximately 9 months necessitating early intervention and limiting the time available to create and subsequently correct a deformity in these animals. Mini-pigs show a much more constant growth velocity and continue to grow over a longer time period. The use of mini-pigs may provide a solution if this time window is not deemed long enough.
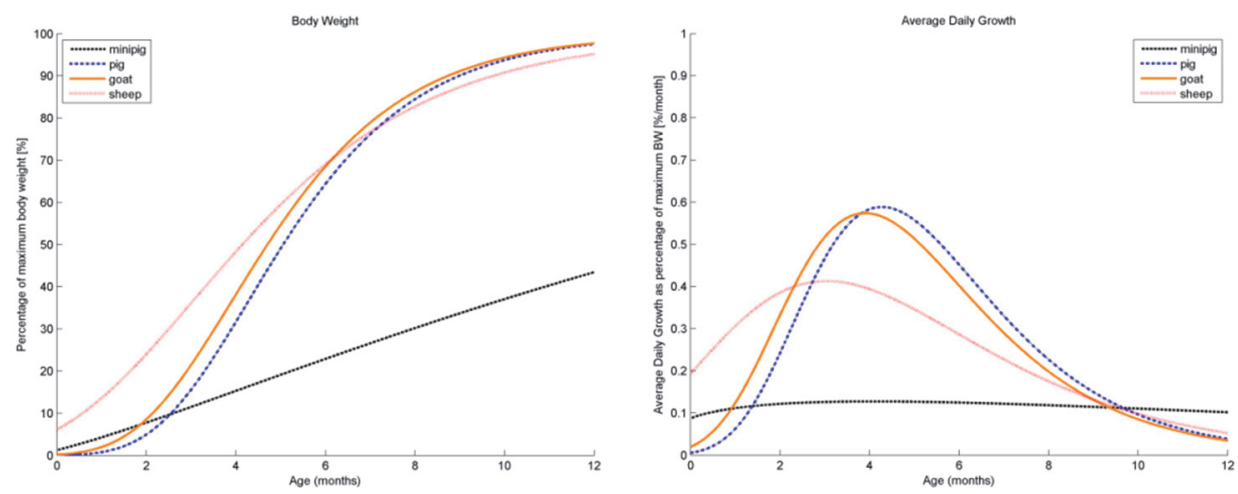

Figure 3 - Body weight and average daily growth curves expressed as percentage of the maximum body weight for Göttingen mini-pig, Yorkshire pig, Young Hair goat, and Suffolk sheep. Growth curves acquired from Gompertz or Richards growth function as determined in literature (mini-pig [45], Yorkshire pig [46], Young Hair goat [47], and Suffolk sheep [48]).

In terms of magnitude, pigs show the largest growth potential with spinal length increasing from approximately $25 \mathrm{~cm}$ in one month old animals to $75 \mathrm{~cm}$ in 6 month old animals. A calf spine is representative of the adult human spine at 6-8 weeks of age, but grows very quickly, reaching $270 \mathrm{~cm}$ at adulthood [43]. Therefore, the calf spine is not considered a relevant model for testing fusionless spine implants designed to treat adolescent idiopathic scoliosis. The large magnitude of growth seen in the pig is the reason why it is often used as test subject, but it also has its disadvantages. The tether 
fixation must be able to accommodate the large load changes encountered during the rapid growth phase. A solid tether anchor was attained by intended fusion of two levels in the studies by both Schwab et al and Odent et al. Furthermore, the rapid weight gain (60-70 kg at 6 months of age) seen in the domestic pig may pose handling problems. Braun et al. have shown that large deformities can be also be attained in animal species with lesser growth potential. However, large postoperative deformities were required to achieve a successful model in the goat. The same is likely necessary in sheep. The spine length of a new-born sheep is approximately $25 \mathrm{~cm}$ and increases to $55 \mathrm{~cm}$ in an adult sheep (18 months) [44].

Some general differences between the human spine and spines of different animal species need to be kept in mind when spine instrumentation is tested in an animal model. Whereas the human spine consists of 12 thoracic vertebrae, the goat and calf spines consist of 13 thoracic vertebrae, the pig spine of 15 thoracic vertebrae and the sheep between 12 and 14 thoracic vertebrae [49]. Furthermore, the pig and calf spine consist of 6 lumbar vertebrae, while the goat and sheep spine consists of 6 or 7 vertebrae in comparison to the 5 lumbar vertebrae in the human spine [49-52]. As in humans, the cervical spine consists of 7 vertebrae in all compared animal species. Compared to the human spine, the pig spine shows more cervical lordosis and less pronounced thoracic kyphosis and lumbar lordosis [50]. The curvature in the lumbar spine of the sheep, calf and goat is slightly kyphotic rather than lordotic [44, 49-52].

Not all spine instrumentation developed for human use may suitable for use in an animal model due to anatomical dimension differences between an animal and the human spine. Both the anterioposterior vertebral depth and the vertebral body width are smaller than the respective human dimensions for the pig, goat, calf and sheep. Due to the smaller vertebral body size in animals, care must be taken when inserting pedicle screws as they may extend out of the vertebral body on the anterior or lateral side. Pedicle width and height are generally similar to the human adult pedicle width for the goat, calf and pig. However, the use of pedicle screws in very young animals requires extra caution. Care must also be taken when using instrumentation spanning the lamina (laminar hooks or wires) due to a smaller spinal canal width and depth in the pig, goat, calf and sheep spine compared to the human spine. As in the human spine, the spinal canal width increases from the cranial to caudal direction in these animals. However, spinal canal depth decreases in this direction in the pig and sheep spine [49-52]. Vertebral body height is generally larger in quadrupeds than in humans and leads to no further concern.

In quadrupeds, spinous process length is substantially larger in the high thoracic region as compared to in the human spine. In the calf, pig and sheep spine, the spinous process in the cervical and thoracic regions can be two to three times longer than in the human spine $[50,51]$. The large spinous process may hinder placement of sublaminar 
instrumentation and therefore require damage to the posterior elements, promoting unintended fusion in the upper thoracic spine. The transverse processes are generally less pronounced in the cervical and thoracic vertebrae for the calf, sheep and pig spine compared to the human spine. In the lumbar region, the transverse process tends to be more pronounced that in the human spine $[50,51]$, which may hinder the development of a rotational deformity in this region.

Ex vivo biomechanical testing of explanted scoliotic spines with and without instrumentation is being performed more often. The range of motion (ROM) of different animal spines in comparison to the human spine deserves consideration as well in that case. In all animal species and in humans, the range of motion in axial rotation is larger in the lumbar than in the cervical or thoracic regions. The most pronounced difference in segmental range of motion between the human and all animal species is seen in flexion/extension. In the human spine, flexion moments generally originate in the lumbar spine, with relatively large absolute values of ROM in flexion/extension in the lumbar region. In all animal species, the range of motion in flexion/extension is fairly constant over all levels and much smaller than in humans in absolute sense [53]. This is largely due to the fact that in the human spine the facet joint surfaces at $\mathrm{L} 3$ are oriented at an angle of more than $60^{\circ}$ relative to the frontal plane, compared to an angle of less than $30^{\circ}$ in the quadruped spine [43]. Figure 4 compares lumbar vertebral morphometry and spinal segmental range of motion in the spines of humans and different animal species.

Practical aspects also need to be considered when choosing an appropriate animal species. In comparison to the sheep and goat, there is no cyclical breeding in the pig and calf, which means the pig and calf are available all year-round. Early weaning is possible in the pig at around 3 weeks of age, while weaning in sheep is typically done around 8 weeks of age. Early intervention in the sheep and goat likely requires housing of the animal's mother as well, which would increase costs. 


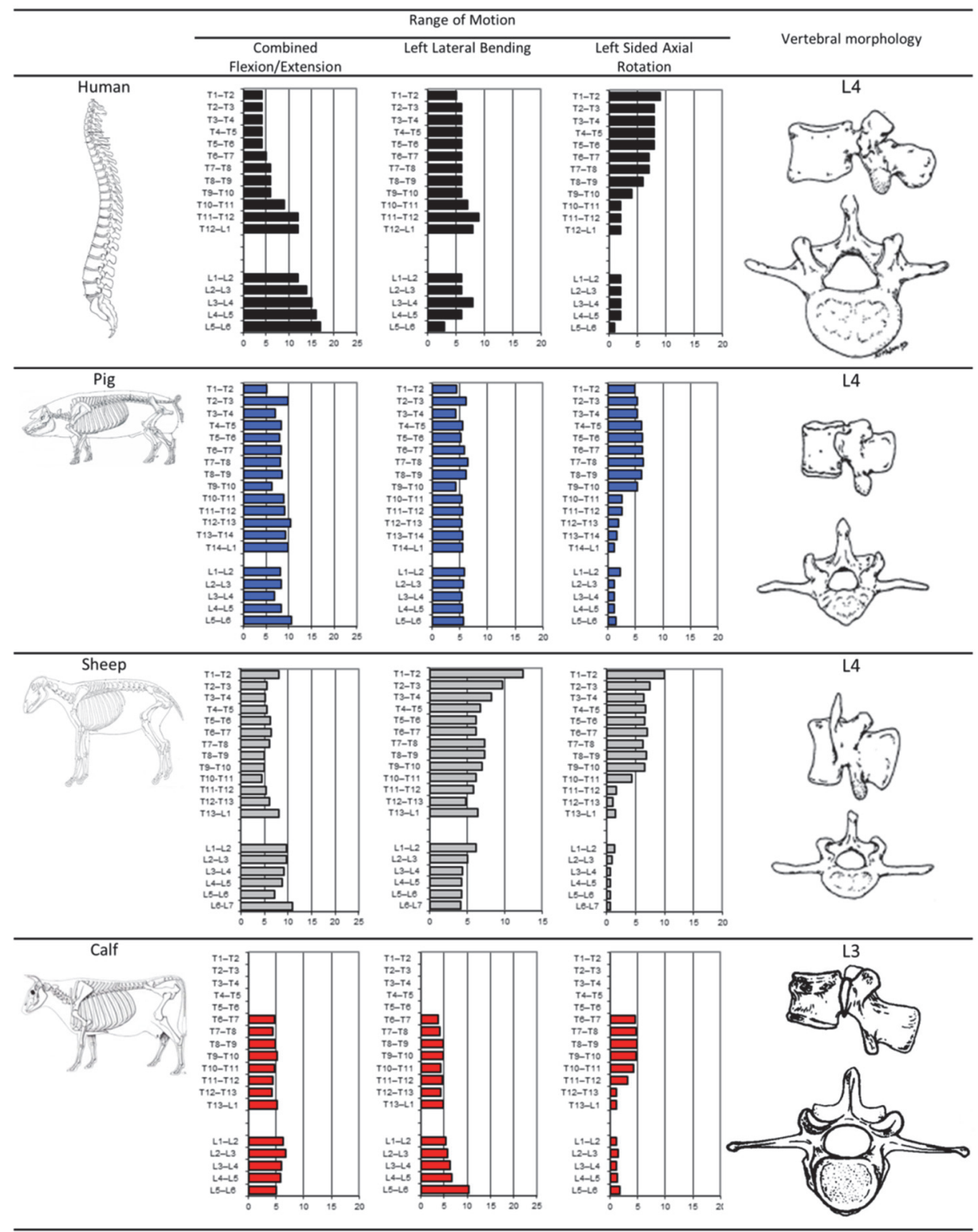

Figure 4 - Segmental range of motion (ROM) and vertebral morphology for humans and for the pig, sheep and goat. Human ROM data from White and Panjabi [55]; animal ROM data from Wilke et al. [51, 56, 57]. Vertebral morphology illustrations reprinted with permission and adapted from McLain et al. [58] and Cotteril et al. [43]. 
There are some differences between human and animal spines that may have consequences for the interpretation of experimental results, with the most important difference being the density of the trabecular bone. The architecture of bone and its mechanical function are closely related: bone adapts to its mechanical loads. Due to the fact that the human spine is mainly loaded by axial compression, the bone architecture is oriented from endplate to endplate. The quadruped spine is also mainly loaded by axial compression, due to the dynamic contraction and relaxation of the horizontally orientated musculature on opposing sides of the spinal midline. The axial compression in the quadrupeds may be even higher compared to the human because of a higher anisotropy of trabecular bone architecture and a higher overall bone density [54]. Because of the higher bone mineral density, quadruped vertebrae are stronger than human vertebrae, and pedicle screws inserted in quadruped vertebrae have a higher fixation strength compared to screws inserted into human vertebrae [54].

It is not to be forgotten that there are some fundamental differences between animal models and true adolescent idiopathic scoliosis. By definition, a scoliotic deformity created using a mechanical tether cannot be classified as being idiopathic, although it shares many characteristics of an idiopathic scoliotic curve. Quadrupedal locomotion in all animal species is responsible for different spinal loading patterns as compared to humans, and likely for the fact that idiopathic scoliosis is naturally non-occurring in the animal world. Care should be taken in the interpretation of results found in an animal model and especially when transferring results from animal models to the human situation. For example, due to the higher bone mineral density, pedicle screws have better fixation in quadrupeds. On the other hand, due to increased spinal loading, the safety of spinal instrumentation with respect to strength may be underestimated [54].

\section{CONCLUSION}

The inverse approach does not provide the necessary insight into the potential corrective efficacy of a novel fusionless scoliosis correction device and is only suitable for compression-based devices. Therefore, creating an idiopathic-like scoliosis using a posterior spinal tether and subsequent correction using the proposed fusionless scoliosis correction device in a two-step approach is the preferred method of testing for novel fusionless scoliosis correction devices. The pig appears to be the most suitable test species due to its large growth potential and early availability due to the possibility of weaning at 3 weeks of age. The index procedure (tether placement) should be completely reversible and therefore no rib tether should ideally be used. However, due to limited test subjects, experimental results need to be reproduced in larger animal populations. 


\section{REFERENCES}

[1] Boos NAM. Spinal Disorders: Fundamentals of Diagnosis and Treatment. Verlag Berlin Heidelberg New York: Springer; 2008.

[2] Stokes IA, Burwell RG, Dangerfield PH. Biomechanical Spinal Growth Modulation and Progressive Adolescent Scoliosis--a Test of the 'Vicious Cycle' Pathogenetic Hypothesis: Summary of an Electronic Focus Group Debate of the Ibse. Scoliosis. 2006;1:16.

[3] Dimeglio A, Canavese F. The Growing Spine: How Spinal Deformities Influence Normal Spine and Thoracic Cage Growth. European spine journal : official publication of the European Spine Society, the European Spinal Deformity Society, and the European Section of the Cervical Spine Research Society. 2012;21:64-70.

[4] Campbell RM, Jr., Hell-Vocke AK. Growth of the Thoracic Spine in Congenital Scoliosis after Expansion Thoracoplasty. J Bone Joint Surg Am. 2003;85-A:409-20.

[5] Hefti FL, McMaster MJ. The Effect of the Adolescent Growth Spurt on Early Posterior Spinal Fusion in Infantile and Juvenile Idiopathic Scoliosis. The Journal of bone and joint surgery British volume. 1983;65:247-54.

[6] Dubousset J, Herring JA, Shufflebarger H. The Crankshaft Phenomenon. Journal of pediatric orthopedics. 1989;9:541-50.

[7] Gomez JA, Lee JK, Kim PD, Roye DP, Vitale MG. "Growth Friendly" Spine Surgery: Management Options for the Young Child with Scoliosis. The Journal of the American Academy of Orthopaedic Surgeons. 2011;19:722-7.

[8] Janssen MM, de Wilde RF, Kouwenhoven JW, Castelein RM. Experimental Animal Models in Scoliosis Research: A Review of the Literature. The spine journal : official journal of the North American Spine Society. 2011;11:347-58.

[9] Schmid EC, Aubin CE, Moreau A, Sarwark J, Parent S. A Novel Fusionless Vertebral Physeal Device Inducing Spinal Growth Modulation for the Correction of Spinal Deformities. European spine journal : official publication of the European Spine Society, the European Spinal Deformity Society, and the European Section of the Cervical Spine Research Society. 2008;17:1329-35.

[10] Braun JT, Akyuz E, Ogilvie JW. The Use of Animal Models in Fusionless Scoliosis Investigations. Spine (Phila Pa 1976). 2005;30:S35-45.

[11] Beguiristain JL, De Salis J, Oriaifo A, Canadell J. Experimental Scoliosis by Epiphysiodesis in Pigs. International orthopaedics. 1980;3:317-21.

[12] Zhang H, Sucato DJ. Unilateral Pedicle Screw Epiphysiodesis of the Neurocentral Synchondrosis. Production of Idiopathic-Like Scoliosis in an Immature Animal Model. The Journal of bone and joint surgery American volume. 2008;90:2460-9.

[13] Zhang H, Sucato DJ. Neurocentral Synchondrosis Screws to Create and Correct Experimental Deformity: A Pilot Study. Clinical orthopaedics and related research. 2011;469:1383-90.

[14] Caballero A, Barrios C, Burgos J, Hevia E, Correa C. Vertebral Growth Modulation by Hemicircumferential Electrocoagulation: An Experimental Study in Pigs. European spine journal : official publication of the European Spine Society, the European Spinal Deformity Society, and the European Section of the Cervical Spine Research Society. 2011;20 Suppl 3:367-75. 
[15] Newton PO, Farnsworth CL, Faro FD, Mahar AT, Odell TR, Mohamad F, et al. Spinal Growth Modulation with an Anterolateral Flexible Tether in an Immature Bovine Model: Disc Health and Motion Preservation. Spine (Phila Pa 1976). 2008;33:724-33.

[16] Newton PO, Faro FD, Farnsworth CL, Shapiro GS, Mohamad F, Parent S, et al. Multilevel Spinal Growth Modulation with an Anterolateral Flexible Tether in an Immature Bovine Model. Spine (Phila Pa 1976). 2005;30:2608-13.

[17] Newton PO, Fricka KB, Lee SS, Farnsworth CL, Cox TG, Mahar AT. Asymmetrical Flexible Tethering of Spine Growth in an Immature Bovine Model. Spine (Phila Pa 1976). 2002;27:689-93.

[18] Newton PO, Upasani VV, Farnsworth CL, Oka R, Chambers RC, Dwek J, et al. Spinal Growth Modulation with Use of a Tether in an Immature Porcine Model. J Bone Joint Surg Am. 2008;90:2695-706.

[19] Newton PO, Farnsworth CL, Upasani VV, Chambers RC, Varley E, Tsutsui S. Effects of Intraoperative Tensioning of an Anterolateral Spinal Tether on Spinal Growth Modulation in a Porcine Model. Spine (Phila Pa 1976).36:109-17.

[20] Wall EJ, Bylski-Austrow DI, Kolata RJ, Crawford AH. Endoscopic Mechanical Spinal Hemiepiphysiodesis Modifies Spine Growth. Spine. 2005;30:1148-53.

[21] Hunt KJ, Braun JT, Christensen BA. The Effect of Two Clinically Relevant Fusionless Scoliosis Implant Strategies on the Health of the Intervertebral Disc: Analysis in an Immature Goat Model. Spine. 2010;35:371-7.

[22] Driscoll M, Aubin CE, Moreau A, Wakula Y, Sarwark JF, Parent S. Spinal Growth Modulation Using a Novel Intravertebral Epiphyseal Device in an Immature Porcine Model. European spine journal : official publication of the European Spine Society, the European Spinal Deformity Society, and the European Section of the Cervical Spine Research Society. 2012;21:138-44.

[23] Braun JT, Akyuz E. Prediction of Curve Progression in a Goat Scoliosis Model. J Spinal Disord Tech. 2005;18:272-6.

[24] Braun JT, Hines JL, Akyuz E, Vallera C, Ogilvie JW. Relative Versus Absolute Modulation of Growth in the Fusionless Treatment of Experimental Scoliosis. Spine (Phila Pa 1976). 2006;31:1776-82.

[25] Braun JT, Ogilvie JW, Akyuz E, Brodke DS, Bachus KN. Fusionless Scoliosis Correction Using a Shape Memory Alloy Staple in the Anterior Thoracic Spine of the Immature Goat. Spine (Phila Pa 1976). 2004;29:1980-9.

[26] Braun JT, Ogilvie JW, Akyuz E, Brodke DS, Bachus KN, Stefko RM. Experimental Scoliosis in an Immature Goat Model: A Method That Creates Idiopathic-Type Deformity with Minimal Violation of the Spinal Elements Along the Curve. Spine (Phila Pa 1976). 2003;28:2198-203.

[27] Braun JT, Akyuz E, Udall H, Ogilvie JW, Brodke DS, Bachus KN. Three-Dimensional Analysis of 2 Fusionless Scoliosis Treatments: A Flexible Ligament Tether Versus a Rigid-Shape Memory Alloy Staple. Spine (Phila Pa 1976). 2006;31:262-8.

[28] Braun JT, Ogilvie JW, Akyuz E, Brodke DS, Bachus KN. Creation of an Experimental Idiopathic-Type Scoliosis in an Immature Goat Model Using a Flexible Posterior Asymmetric Tether. Spine (Phila Pa 1976). 2006;31:1410-4.

[29] Schwab F, Patel A, Lafage V, Farcy JP. A Porcine Model for Progressive Thoracic Scoliosis. Spine (Phila Pa 1976). 2009;34:E397-404.

[30] Patel A, Schwab F, Lafage V, Obeidat MM, Farcy JP. Computed Tomographic Validation of the Porcine Model for Thoracic Scoliosis. Spine (Phila Pa 1976).35:18-25. 


\section{Chapter 7}

[31] Patel A, Schwab F, Lafage R, Lafage V, Farcy JP. Does Removing the Spinal Tether in a Porcine Scoliosis Model Result in Persistent Deformity? A Pilot Study. Clin Orthop Relat Res.469:1368-74.

[32] Zhang Y, Wang Y, Zheng G, Zhang X, Zhang R, Zhang W. Unilateral Pedicle Screws Asymmetric Tethering: An Innovative Method to Create Idiopathic Deformity. J Orthop Surg Res. 2007;2:18.

[33] Zhang YG, Zheng GQ, Zhang XS, Wang Y. Scoliosis Model Created by Pedicle Screw Tethering in Immature Goats: The Feasibility, Reliability, and Complications. Spine (Phila Pa 1976). 2009;34:2305-10.

[34] Odent T, Cachon T, Peultier B, Gournay J, Jolivet E, Elie C, et al. Porcine Model of Early Onset Scoliosis Based on Animal Growth Created with Posterior Mini-Invasive Spinal Offset Tethering: A Preliminary Report. Eur Spine J.20:1869-76.

[35] Nachlas IW, Borden JN. Experimental Scoliosis; the Role of the Epiphysis. Surgery, gynecology \& obstetrics. 1950;90:672-80.

[36] Smith RM, Dickson RA. Experimental Structural Scoliosis. The Journal of bone and joint surgery British volume. 1987;69:576-81.

[37] Braun JT, Akyuz E, Ogilvie JW, Bachus KN. The Efficacy and Integrity of Shape Memory Alloy Staples and Bone Anchors with Ligament Tethers in the Fusionless Treatment of Experimental Scoliosis. J Bone Joint Surg Am. 2005;87:2038-51.

[38] Braun JT, Hoffman M, Akyuz E, Ogilvie JW, Brodke DS, Bachus KN. Mechanical Modulation of Vertebral Growth in the Fusionless Treatment of Progressive Scoliosis in an Experimental Model. Spine (Phila Pa 1976). 2006;31:1314-20.

[39] Langenskiold, Michelsson JE. Experimental Progressive Scoliosis in the Rabbit. J Bone Joint Surg Br. 1961;43-B:116-20.

[40] EO. K. Deformation of Vertebrae in Experimental Scoliosis. Acta Orthop Scand. 1967;105:7-79.

[41] Sanders JO, Sanders AE, More R, Ashman RB. A Preliminary Investigation of Shape Memory Alloys in the Surgical Correction of Scoliosis. Spine (Phila Pa 1976). 1993;18:1640-6.

[42] Akyuz E, Braun JT, Brown NA, Bachus KN. Static Versus Dynamic Loading in the Mechanical Modulation of Vertebral Growth. Spine. 2006;31:E952-8.

[43] Cotterill PC, Kostuik JP, D'Angelo G, Fernie GR, Maki BE. An Anatomical Comparison of the Human and Bovine Thoracolumbar Spine. J Orthop Res. 1986;4:298-303.

[44] Hasler C, Sprecher CM, Milz S. Comparison of the Immature Sheep Spine and the Growing Human Spine: A Spondylometric Database for Growth Modulating Research. Spine (Phila Pa 1976).35:E1262-72.

[45] Kohn F, Sharifi AR, Simianer H. Modeling the Growth of the Goettingen Minipig. Journal of Animal Science. 2007;85:84-92.

[46] Koivula M, Sevon-Aimonen ML, Stranden I, Matilainen K, Serenius T, Stalder KJ, et al. Genetic (Co)Variances and Breeding Value Estimation of Gompertz Growth Curve Parameters in Finnish Yorkshire Boars, Gilts and Barrows. Journal of Animal Breeding and Genetics. 2008;125:168-75.

[47] Tatar AM, Tekel N, Ozkan M, Baritci I, Dellal G. The Determination of Growth Function in Young Hair Goat. Journal of Animal and Veterinary Advances. 2009;8:213-6.

[48] Lewis RM, Emmans GC, Dingwall WS, Simm G. A Description of the Growth of Sheep and Its Genetic Analysis. Animal Science. 2002;74:51-62.

[49] Sheng SR, Wang XY, Xu HZ, Zhu GQ, Zhou YF. Anatomy of Large Animal Spines and Its Comparison to the Human Spine: A Systematic Review. Eur Spine J. 2010;19:46-56. 
[50] Busscher I, van der Veen AJ, van Dieen JH, Kingma I, Verkerke GJ, Veldhuizen AG. In Vitro Biomechanical Characteristics of the Spine: A Comparison between Human and Porcine Spinal Segments. Spine (Phila Pa 1976). 2010;35:E35-42.

[51] Wilke HJ, Kettler A, Claes LE. Are Sheep Spines a Valid Biomechanical Model for Human Spines? Spine (Phila Pa 1976). 1997;22:2365-74.

[52] Dyce KM, Sack WO, Wensing CJG. Textbook of Veterinary Anatomy. 4th ed. St. Louis, Mo.: Saunders/Elsevier; 2010.

[53] Alini M, Eisenstein SM, Ito K, Little C, Kettler AA, Masuda K, et al. Are Animal Models Useful for Studying Human Disc Disorders/Degeneration? Eur Spine J. 2008;17:2-19.

[54] Smit TH. The Use of a Quadruped as an in Vivo Model for the Study of the Spine - Biomechanical Considerations. Eur Spine J. 2002;11:137-44.

[55] White lii AA, Panjabi MM. Clinical Biomechanics of the Spine. Philadelphia [etc.]: Lippincott; 1978.

[56] Wilke HJ, Geppert J, Kienle A. Biomechanical in Vitro Evaluation of the Complete Porcine Spine in Comparison with Data of the Human Spine. Eur Spine J.20:1859-68.

[57] Wilke HJ, Krischak ST, Wenger KH, Claes LE. Load-Displacement Properties of the Thoracolumbar Calf Spine: Experimental Results and Comparison to Known Human Data. Eur Spine J. 1997;6:129-37.

[58] McLain RF, Yerby SA, Moseley TA. Comparative Morphometry of L4 Vertebrae: Comparison of Large Animal Models for the Human Lumbar Spine. Spine (Phila Pa 1976). 2002;27:E200-6. 
Chapter 7

7 


\section{ABSTRACT}

Study Design - In vivo analysis in a porcine model.

Objectives - To develop a porcine experimental scoliosis model representative of early onset scoliosis (EOS) with the use of a radiopaque UHMWPE posterior spinal tether.

Summary of Background Data - Large animal experimental scoliosis models with substantial growth potential are required to test new fusionless scoliosis correction techniques. Previously described scoliosis models involve rib procedures, which violate the thoracic cage and affect subsequent corrective procedures. Models omitting these rib procedures have experienced difficulties in producing persistent three-dimensional structural deformities representative of EOS.

Methods - Scoliosis was induced in 14 immature pigs using an asymmetric posterior radiopaque UHMWPE spinal tether fixated to an offset device at lumbar and thoracic levels. Radiographs were taken at two-week intervals, and frontal and sagittal Cobb angles were measured. A tether release was performed at 10 week follow-up, and the animals were followed for another 10 weeks.

Results - Four animals suffered complications (infections and/or screw breakout) and were excluded from the study. Eight animals developed progressive curves with mean frontal Cobb angle of $62^{\circ}$. A thoracic lordosis $\left(34^{\circ}\right)$ and a thoracolumbar kyphosis $\left(22^{\circ}\right)$ formed. CT analysis, acquired prior to tether release, showed a mean vertebral rotation of $37^{\circ}$ at the apex with a mean vertebral wedge angle of $10^{\circ}$. After tether release, the frontal Cobb angles decreased to $46^{\circ}$ at 20 weeks follow-up. Sagittal curvature was not substantially affected after tether release.

Conclusions - We describe a large animal scoliosis model, which exhibits a substantial deformity in three planes without the use of rib procedures additional to a posterior spinal tether. The created deformities showed sufficient persistence after tether release. With the management of infection and enhancement of instrumentation stability, the creation of a valid model for testing new devices in fusionless scoliosis surgery seems feasible.

Level of Evidence - Level V. 


\section{INTRODUCTION}

Within the last decades, it has become clear that fusionless surgical scoliosis correction techniques are essential for the treatment of early onset scoliosis (EOS), but their merits and potential are also increasingly explored for the treatment of adolescent idiopathic scoliosis (AIS). For EOS patients, it is imperative to retain longitudinal spine growth, thereby maintaining volumetric thoracic cage growth and lung development [1]. Fusionless scoliosis correction devices for EOS patients may be classified into growthguidance (Shilla and Luque trolley) or distraction based techniques (growing rods, vertical expandable prosthetic titanium rib) [2]. For AIS patients, compression based anterior devices are used to modulate vertebral growth by utilizing the HueterVolkmann principle [3] to slow or halt growth on the convex side of the deformity, thereby attaining gradual curve correction. Examples of such compression-based modulation are the use of vertebral body staples and an anterior spinal tether [2].

The most generic method for the preclinical evaluation of fusionless scoliosis correction devices is utilizing a two-step approach: A structural, idiopathic-like scoliosis is created in a first procedure and later corrected using the proposed scoliosis correction device in a second procedure. Posterior spinal tethering is the preferred index procedure [4], as it produces significant, progressing deformities that most closely approximate the threedimensional nature of the deformity as seen in idiopathic scoliosis (progressive coronal curvature, loss of thoracic kyphosis and axial vertebral rotation) [5-7].

We have previously reviewed large animal models in fusionless scoliosis correction research [8]. The similarity between human and porcine spinal anatomy in addition to the fast, large growth rate makes pigs commonly used animals for experimental scoliosis models. The main differences between models described by different authors are age at index procedure, length of follow-up period, pre-tensioning of the tether, and whether or not rib procedures (rib tethering with or without rib resection) additional to the spinal tether were performed. Rib procedures may lead to high postoperative morbidity and may cause spontaneous rib fusion with a very stiff curve as a result [9]. These irreversible thoracic changes will affect subsequent testing procedures. Odent et al. $[10,11]$ have demonstrated that rib tethering may be omitted when sufficient spinal tether offset is used. However, their described model exhibited substantial loss of deformity, loss of approximately $45 \%$ of the curve magnitude in the frontal plane, after tether release.

The purpose of this study was to create an early onset scoliosis model, without additional rib procedures, in which all three-dimensional scoliosis-like structural changes occur and persist after tether release. A posterior technique with a radiopaque flexible Ultra-High Molecular Weight Polyethylene (UHMWPE) spinal tether with an offset device was used to create a progressive lordo-scoliotic curve. This model should 
ultimately allow for preclinical testing of fusionless scoliosis correction techniques in a growing animal.

\section{MATERIAL AND METHODS}

\section{Surgical procedure}

All animal procedures were approved by the Animal Ethical Committee of the Maastricht University Medical Center (approval no.: DEC 2011-005). A total of 16 immature landrace pigs (female, 8 weeks old, weight range $10-13 \mathrm{~kg}$ ) were included in this study. Each operation was performed under strict sterile conditions. Antibiotics (amoxicillin/clavulan acid $1.2 \mathrm{~g}$ ) were administered intravenously one hour prior to incision and 6 hours postoperatively. After 7 days of acclimatization at the institutional animal facility, the animals were sedated by intravenous administration of thiopental $(10-15 \mathrm{mg} / \mathrm{kg})$, followed by endotracheal intubation and general anesthesia using $1 \%$ to $2 \%$ isoflurane. Pain medication was administered and adjusted if needed during surgery (sufentanyl 10-30 $\mathrm{\mu g} / \mathrm{kg}$ per hour intravenously). Electrocardiogram registration, ventilation curves, temperature, oxygen saturation level and heart rate were continuously monitored. With the animal in prone position, two small midline incisions were made at thoracic and lumbar levels under fluoroscopic control. The transverse processes and the facet joints were minimally exposed unilaterally on the left side by partially detaching the erector spinae using electrocautery.

\section{Instrumentation technique and material specification}

In a pilot study involving two animals, poly-axial pedicle screws (4.5 $\mathrm{mm}$ diameter, 22 $26 \mathrm{~mm}$ length, Vertex ${ }^{\circledR}$, Medtronic) were placed unilaterally at T6-T7 and L1-2 under fluoroscopic guidance. Two custom made offset devices $(28 \mathrm{~mm}$ offset from pedicle screws) were fixed using a $3.2 \mathrm{~mm}$ titanium rod in between each set of adjacent pedicle screws (Figure 1). A $4 \mathrm{~mm}$-wide flat wire woven from ultra-high molecular weight polyethylene (UHMWPE) Dyneema Purity ${ }^{\circledR}$ Radiopaque fibers (DSM Biomedical B.V., Geleen, the Netherlands) was used as a posterior tether. Bismuth oxide $\left(\mathrm{Bi}_{2} \mathrm{O}_{3}\right)$ particles are blended into each individual fiber for radiopacity [12]. The wire was folded in half and the two ends were passed through the cranial offset device and through the loop created in the wire, thereby securing the cranial end of the tether. The caudal end was secured using multiple square knots. In these initial two animals, the UHMWPE tether was placed under tension before fixation. This created a Cobb angle of approximately $20^{\circ}$. After 4 weeks, screw breakout was observed at both caudal and cranial levels with loss of deformity. The large offset in combination with pre-tensioning of the tether was assumed to be the reason for this early failure. For this reason, in the definitive series of 
animals $(n=14)$ the construct was altered slightly. First the thoracic offset device was secured using three instead of two thoracic pedicle screws (T5-T7), and the lumbar instrumentation was reinforced with a UHMWPE sublaminar wire [13]. Furthermore, no pretension was applied to the tether and the offset was reduced to $20 \mathrm{~mm}$. In the first four animals, proximal fixation was located at levels T5-T7 with caudal fixation on L1-L2. After experiencing problems reaching the deep cranial thoracic vertebra because of thick musculature in these first four procedures, the proximal fixation site was moved to levels T7-T9 and distal fixation site to L2-L3.

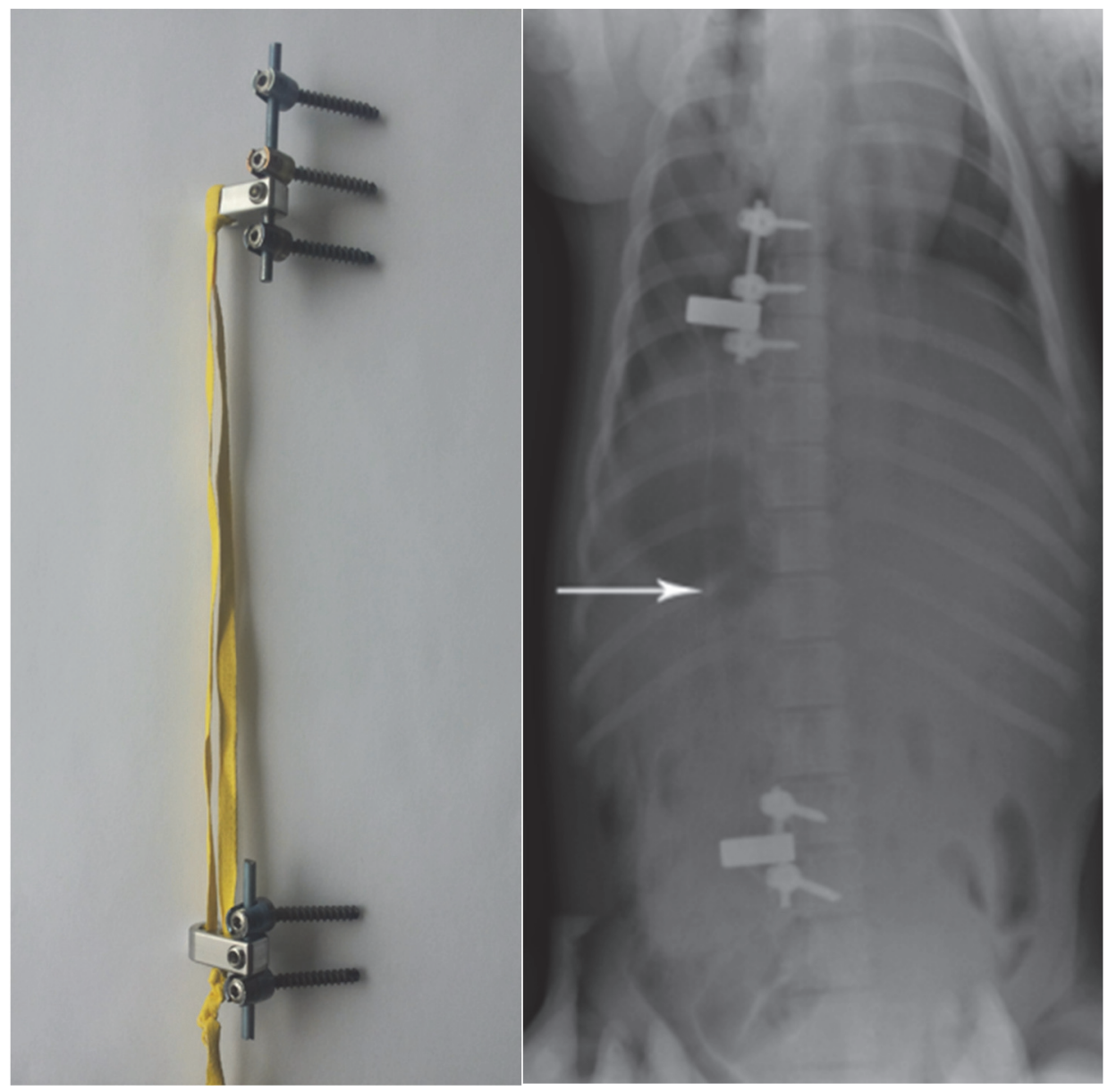

Figure 1 - (A) Offset devices with rods, pedicle screws and the radiopaque UHMWPE double loop tether. (B) Offset device implanted in the porcine spine. The radiopaque tether (arrow) is attached to the offset devices without any tension. 


\section{Observation, radiology and tether release}

The wound was ultimately closed in layers. Post-operative pain management (buprenorphine $0,05 \mathrm{mg} / \mathrm{kg}$, carprofen $2-4 \mathrm{mg} / \mathrm{kg}$ intramuscularly) was provided until the animals had returned to activities ad libitum. Antibiotic treatment was administered intramuscularly 6 hours after surgery. Initially, no post-operative wound dressing was applied. However, as 3 out of the first 4 animals developed postoperative wound infections, the wound was dressed using an iodide film, which was kept in place for three days post-operatively. No more wound infections occurred in the subsequent animals.

One animal with a profound infection was euthanized because of instrumentation failure and observed animal discomfort. In the other animals with wound infections, the infection was controlled with the administration of antibiotics (amoxicillin/clavulan acid $1.2 \mathrm{~g}$ ) for several days and wound lavage without loss of the curvature.

Plain full spine radiographs were taken directly postoperatively and subsequently at two-week intervals under light tiletamine-zolazepam $(8 \mathrm{mg} / \mathrm{kg}$ ) sedation. Routine supine dorsoventral and lateral radiographs were acquired to assess curve progression. Frontal and sagittal Cobb angles were measured at each radiological assessment. Radiographs were also analyzed for positioning and possible pullout or breakage of the instrumentation.

\section{Tether release and CT Analysis}

At 10 week follow-up and upon reaching a frontal Cobb angle of minimally $40^{\circ}$, a tether release was performed in eight animals. The radiopaque tether was localized under fluoroscopy and cut through a minimal stab incision at the caudal end. Animals were followed for another 10 weeks with radiographs every 2 weeks and euthanization was performed using pentobarbital overdose $(200 \mathrm{mg} / \mathrm{kg}$ ). After sacrifice, the spines were harvested.

Computed tomography (CT) scans were acquired prior to tether release at 10 weeks follow-up under general anesthesia (Siemens SOMATOM Definition Flash, Erlangen, Germany). 3D reconstructions of each spine were obtained to assess vertebral rotation, rib hump and apical vertebra wedging. Rib hump elevation located the convex side was considered a positive result for the model. Vertebral rotation was measured relative to the anterior mid-line of the body [14, 15]. Rotation and rib hump were assessed by analyzing a transversal CT-slice at the level of the apex vertebra using the Synedra View program (Synedra, Innsbruck). The position of the apical vertebra was determined in three planes. Apical vertebral wedging was measured from the 
reconstructed coronal $\mathrm{CT}$ images. Convex and concave heights for each apical vertebra were also determined.

\section{RESULTS}

Of the 14 animals included within the definitive surgical protocol, one animal died as a result of respiratory distress after extubation. Autopsy did not reveal any other cause of death. No neurological complications occurred during all surgeries. Mean weight gain was approximately $5 \mathrm{~kg} /$ week. Eight animals developed a structural complex 3D scoliotic curvature with a chest wall deformity and a positive rib hump elevation. In this group, the mean Cobb angle at 10 week follow-up was $62^{\circ}$ (range $43-72^{\circ}$ ) in the frontal plane (Figure 2). In the sagittal plane, a thoracolumbar kyphosis developed between the anchor sites $\left(22^{\circ}\right.$ range $\left.7-44^{\circ}\right)$, and a thoracic lordosis formed at the anchor levels $\left(35^{\circ}\right.$ range $21-53^{\circ}$ ), presumably as a result of continued anterior growth (crankshafting) (Figure 3). In five animals, a long-segment curvature (11-12 vertebrae in the curvature) with large Cobb angles (mean 68.3 ${ }^{\circ}$ ) developed. In three animals, a shorter (5-6 vertebrae in the curvature) thoracic curve (mean $51.9^{\circ}$ ) developed probably due to an epiphysiolysis or fracture of one vertebra, which was observed in both anchor location groups (T5-4-3/L1-2 and T7-6-5/L2-3). In three animals, screw breakout or slippage of the knot securing the tether was observed, resulting in loss of the curvature and therefore these animals were sacrificed. In two animals, the cause of this failure was not determined. The other case had developed a postoperative infection with the observation of radiolucency around the screws. Loosening of the screws eventually resulted in failure of instrumentation. The final two animals developed curves with Cobb angles of $31^{\circ}$ and $34^{\circ}$, which did not progress any further due to unknown reasons. These animals were also subsequently sacrificed. CT scanning and subsequent tether release was performed in the eight animals that developed progressive structural scoliosis. These animals were followed for an additional 10 week time period after tether release (Figure 4). CT imaging revealed structural characteristics of the deformity, with most wedging and axial rotation occurring at the apex of the curvature (Figure 5). The mean apical vertebral rotation was $37.3^{\circ}$ (range $25-54^{\circ}$ ), while substantial apical wedging also occurred: convex height minus concave height measured a mean of $4.2 \mathrm{~mm}$, which resulted in a mean vertebral wedge angle of $10.4^{\circ}$ (range $5.7-17.2^{\circ}$ ) (Figure 6).

After tether release, the frontal Cobb angles immediately decreased from $62^{\circ}$ to $56^{\circ}$ and showed a further decrease at 10 weeks additional follow-up to $46.7^{\circ}$ (Figure 7 , Table 1). In two animals, there was loss of curvature within the mid segments at 20 weeks follow-up. Lateral tilting of the cranial and caudal segments, however, still 


\section{Chapter 8}

resulted in a curvature with persistent thoracic asymmetry. Sagittal profiles did not show substantial changes after tether release (Table 2).

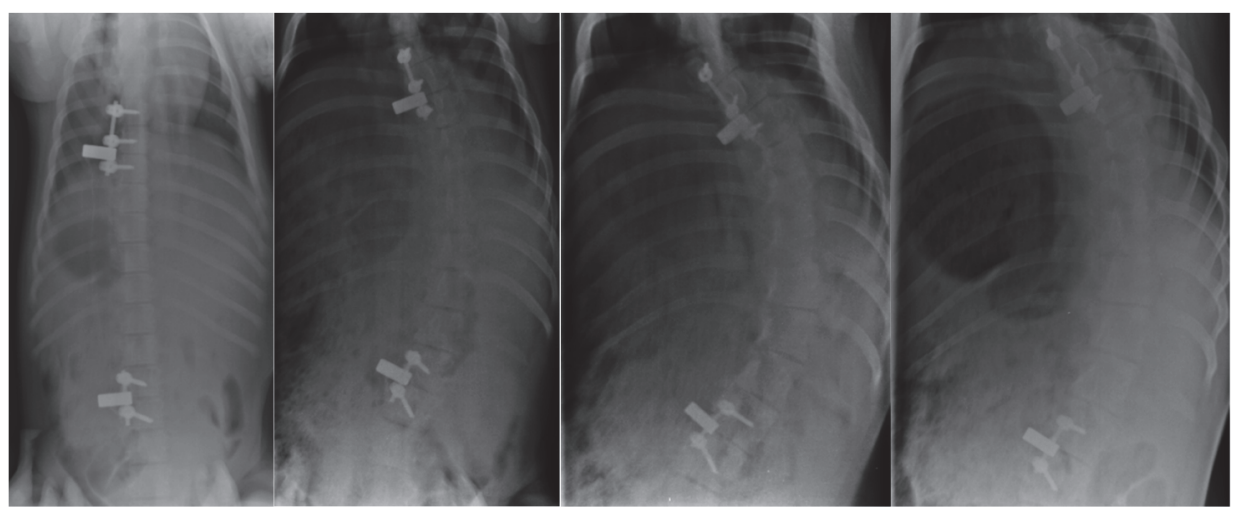

Figure 2 - (A) Instrumentation with straight spine direct postoperatively. (B) 4 week follow-up with the development of a C-type curvature with thoracic asymmetry. (C) 10 week follow-up prior to tether release. (D) 20 weeks follow-up with slight loss of curvature 10 weeks after tether release.

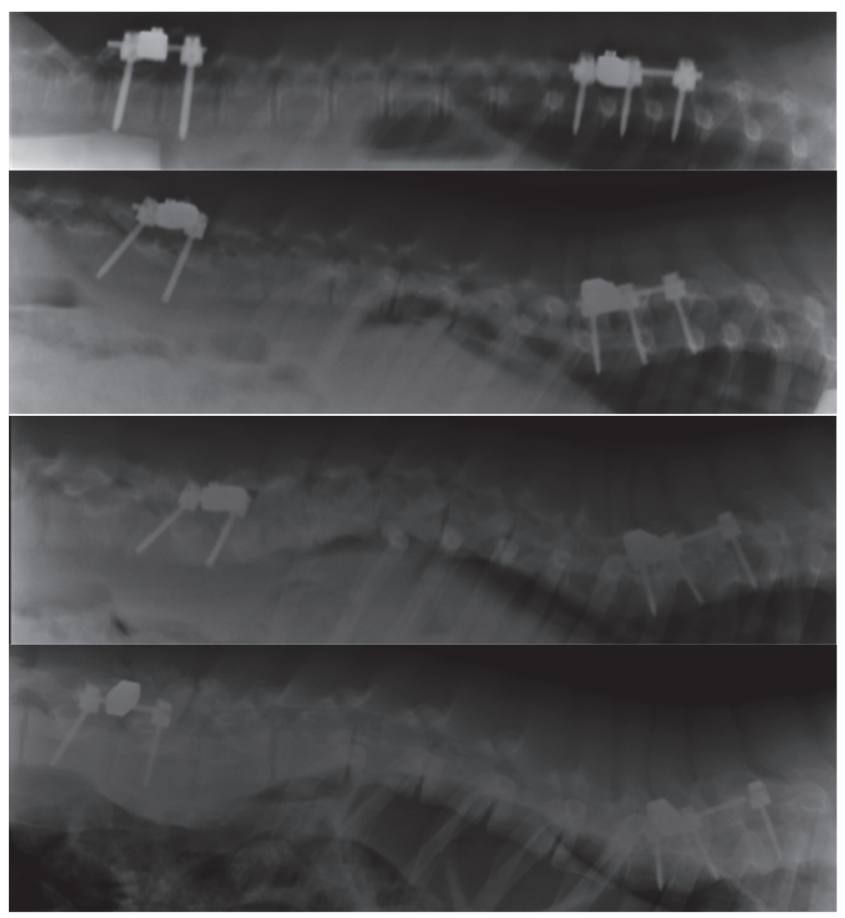

Figure 3 - Lateral x-rays. (A) Instrumentation with nearly straight spine postoperatively. (B) 4 week follow-up with the development of a small thoracic lordosis (C) 10 week follow-up prior to tether release with presence of a thoraco-lumbar kyphosis and thoracic lordosis. (D) 20 weeks follow-up with unchanged curvature 10 weeks after tether release. 


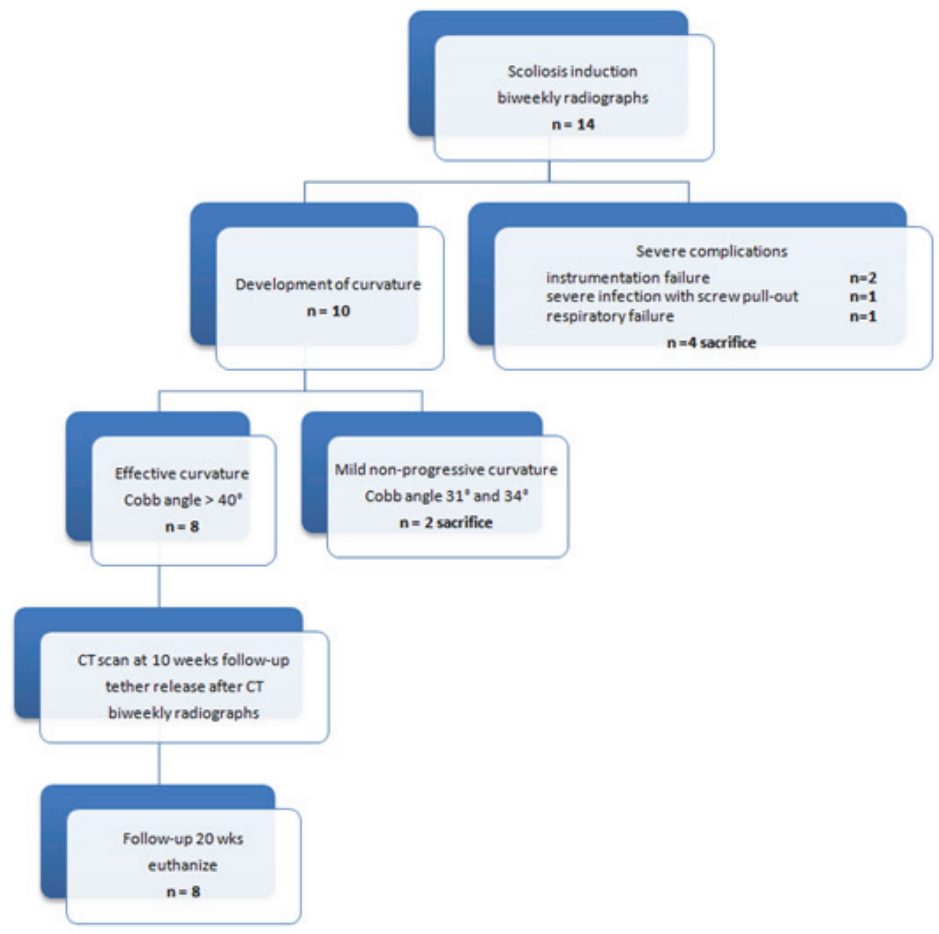

Figure 4 - Flowchart of experimental group.

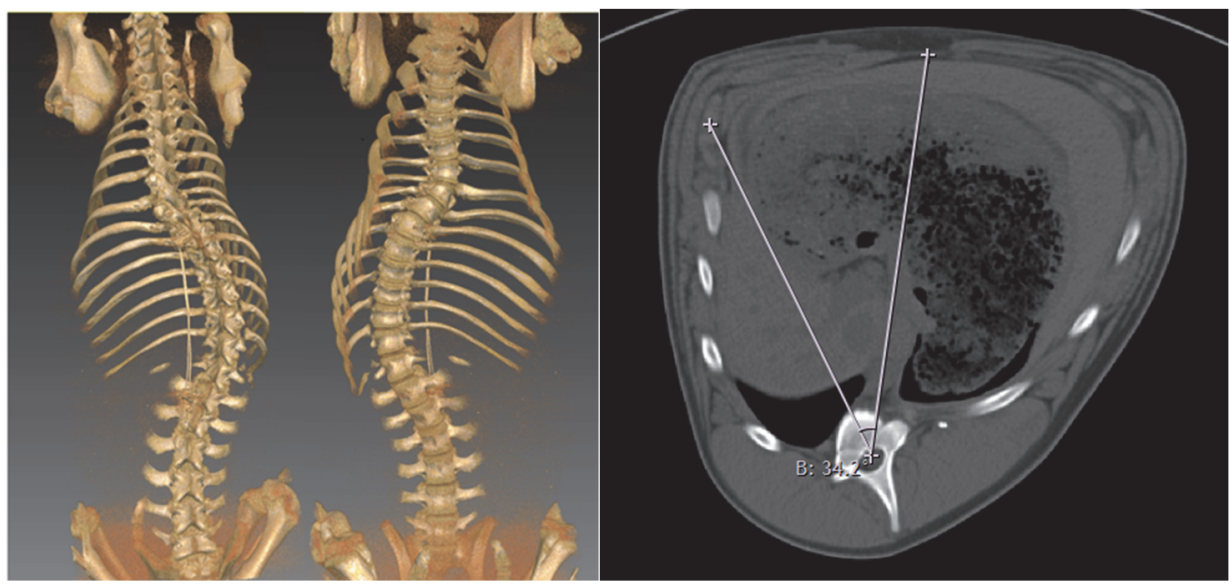

Figure 5 - (A) Frontal (right) and posterior (left) view of a 3-D CT reconstruction of the lordo-scoliotic deformity at 10 weeks follow-up prior to release of the tether. Sagittal reconstruction clearly showing the thoracic asymmetry. (B) Axial CT slice showing how rotation was measured at the level of the apical vertebra by measuring the angle between the anterior midline and the line perpendicular to the transverse processes. 


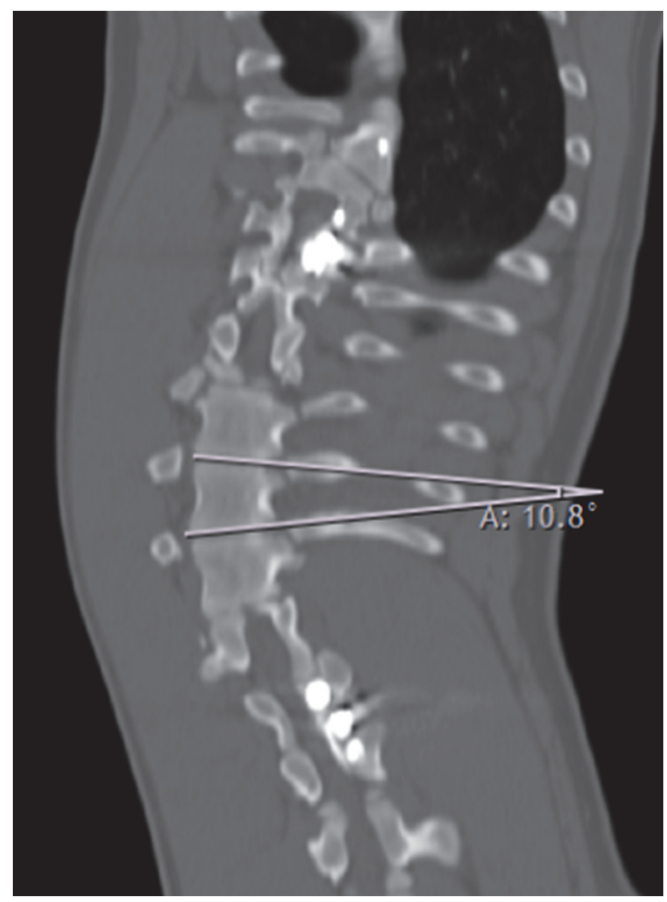

Figure 6 - Coronal reconstructed image showing the wedging of the apical vertebrae.

\section{Cobb angle frontal curve (degrees)}

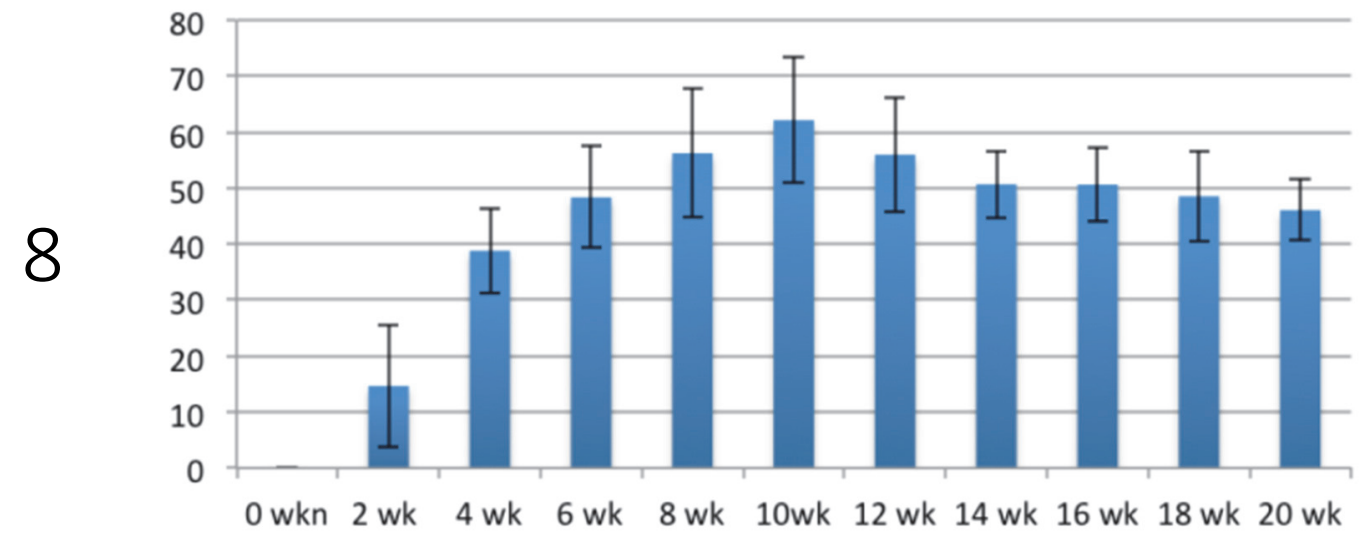

Figure 7 - Evolution of scoliosis after placement of the tether. At 10 week follow-up the tether release is performed. 


\begin{tabular}{|c|c|c|c|c|c|c|c|c|c|c|}
\hline \multirow[t]{3}{*}{ Animal } & \multirow[t]{3}{*}{$\begin{array}{c}\text { Instrumentation } \\
\text { level }\end{array}$} & \multicolumn{3}{|c|}{$\begin{array}{c}\text { Cobb angle } \\
\text { Precut tether } 10 \text { wks }\end{array}$} & \multicolumn{3}{|c|}{$\begin{array}{c}\text { Cobb angle } \\
\text { Post tether release }\end{array}$} & \multicolumn{3}{|c|}{$\begin{array}{l}\text { Cobb angle } \\
\text { End follow-up } 20 \text { wks }\end{array}$} \\
\hline & & \multirow[t]{2}{*}{ frontal } & \multicolumn{2}{|c|}{ sagittal } & \multirow[t]{2}{*}{ frontal } & \multicolumn{2}{|c|}{ sagittal } & \multirow[t]{2}{*}{ frontal } & \multicolumn{2}{|c|}{ sagittal } \\
\hline & & & lordosis & kyphosis & & lordosis & kyphosis & & lordosis & kyphosis \\
\hline 1 & L1-2 / T5-4-3 & 72.4 & 44.1 & 19.8 & 58.2 & 39.1 & 16.6 & 44.5 & 32 & 12 \\
\hline 2 & L1-2 / T5-4-3 & 61.7 & 44 & 20 & 51 & 38.6 & 19.6 & 39.4 & 32.7 & 13.6 \\
\hline 3 & L1-2 / T5-4-3 & 43.3 & 21.4 & 6.8 & 38.6 & 28.5 & 6.8 & 40.7 & 30 & 4.4 \\
\hline 4 & L1-2 / T5-4-3 & 62.8 & 32 & 21 & 62 & $* *$ & 20.3 & 50.3 & $* *$ & 20 \\
\hline 5 & L2-3 / T6-5-4-3* & 75.6 & 29.1 & 15.4 & 65.6 & 51.1 & 15 & 50.7 & 49.4 & 12 \\
\hline 6 & L2-3 / T7-6-5 & 70.7 & 30.2 & 17 & 65.2 & 28.1 & 14.6 & 52.6 & 40.7 & 4.5 \\
\hline 7 & L2-3 / T7-6-5 & 60.9 & 20.1 & 30 & 58.8 & 20.4 & 23.2 & 43.2 & 29.8 & 20 \\
\hline 8 & L2-3 / T7-6-5 & 49.7 & 53.3 & 44 & 48.2 & 35.8 & 31.2 & 51.8 & 36.6 & 33.5 \\
\hline Mean & & 62.1 & 34.3 & 21.8 & 56.0 & 34.5 & 18.4 & 46.7 & 35.9 & 15 \\
\hline
\end{tabular}

Table 1 - Evolution of the Cobb angles before and after tether release and at 10 weeks post tether release. * Extra pedicle screw insertion due to minimal screw support, ** Quality radiographs not suitable for adequate sagittal measurements.

\begin{tabular}{ccccccc}
\hline Animal & Cobb frontal $\left(^{\circ}\right)$ & $\begin{array}{c}\text { Apical } \\
\text { Vertebral } \\
\text { rotation }\left(^{\circ}\right)\end{array}$ & $\begin{array}{c}\text { No. Vertebrae } \\
\text { in curve }\end{array}$ & $\begin{array}{c}\text { Vertebral } \\
\text { wedging }\left(^{\circ}\right)\end{array}$ & $\begin{array}{c}\text { Height Convex } \\
(\mathrm{mm})\end{array}$ & $\begin{array}{c}\text { Height Concave } \\
(\mathrm{mm})\end{array}$ \\
\hline 1 & 72.4 & 44.4 & 11 & 5.7 & 25.9 & 24.4 \\
\hline 2 & 61.7 & 36.2 & 11 & 6.8 & 25.1 & 22.1 \\
\hline 3 & 43.3 & 25.2 & 6 & 8.1 & 26 & 24.2 \\
\hline 4 & 62.8 & 54.4 & 6 & 9.7 & 28.2 & 23.4 \\
\hline 5 & 75.6 & 36.9 & 12 & 16.1 & 26.6 & 19.5 \\
\hline 7 & 70.7 & 43.1 & 11 & 8.5 & 28.8 & 24.7 \\
\hline 8 & 60.9 & 34.6 & 11 & 10.4 & 29 & 25.1 \\
\hline mean & 49.7 & 23.8 & 5 & 17.2 & 25.7 & 21 \\
\hline
\end{tabular}

Table 2 - Spinal parameters with Cobb angle, apical vertebrae rotation and wedging of the different specimen at 10-week follow-up prior to tether release. 


\section{DISCUSSION}

Numerous attempts have been made to create reproducible large animal scoliosis models for preclinical evaluation of fusionless scoliosis correction techniques $[4,8,10$, 14, 16-19]. A representative experimental early onset scoliosis model should exhibit the following features: structural, persistent frontal and sagittal curvatures with sufficient rotation and wedging at the apex of the curvature, and adequate growth potential remaining to perform subsequent correction procedures [8].

Despite experiencing several technical problems in our study, we were able to create a scoliosis-like deformity, progressive while the tether was in situ in eight out of 14 animals without the use of rib tethering procedures. Magnitudes and three-dimensional characteristics of the attained curves showed idiopathic-like features, with a mean Cobb angle of $62^{\circ}$, and a mean vertebral rotation of $37^{\circ}$ at the apex vertebra. The sagittal profile was not predominantly lordotic, and curves were therefore not idiopathic-like in that sense. The three shorter thoracic curves with rigid segments, formed as a result of vertebra fracture or epiphysiolysis, are less idiopathic-like and perhaps more similar to a congenital scoliosis. Such curves would be of limited usefulness for the assessment of fusionless scoliosis correction techniques. The low yield and the low consistency of our model remains a concerning issue. Four animals were sacrificed as a result of instrument failure or infection. Infections were prevented after changing the surgical preparation protocol. Despite not applying tether pretension, screw pullout still occurred in three animals. In one case, osteolysis surrounding the screws caused by infection probably resulted in this loss of fixation at the bone screw interface.

After our pilot study in which pretension was applied to the tether and instrumentation failure occurred within two week postoperatively, we reasoned that pretensioning of the tether causing an immediate scoliosis should not be performed. Schwab et al., however, demonstrated that the larger the initial curve (up to approximately 25 degrees) as induced by applying tension at surgery, the higher the rate of progression was observed [11]. In their study, sublaminar cables were used to reinforce the screws and instrumentation was probably partially protected by an ipsilateral rib tether. Zheng et al. have also described a porcine scoliosis model with the use of a posterior tether in combination with an ipsilateral rib tether [20]. By pretensioning the posterior tether a curvature of $29^{\circ}$ was initiated and progressed to $65^{\circ}$ at an 8 week tethering period. Apparently, the rib tether aids in early induction of the deformity, reduces load on the spinal tether anchors, and helps avoid screw pullout. Our objective was to develop a persistent spinal deformity representative of EOS with the use of a radiopaque UHMWPE posterior tether and without additional rib procedures. We believe a rib tether violates the chest wall structures and causes irreversible ribcage deformity with the formation of ectopic bone and stiff curves as result. Subsequent corrective surgery may therefore be more difficult to perform. By omitting rib 
procedures we aimed to create less rigid curves, especially around the apex, which subsequently resulted in non-progressive curves after tether release. Odent et al. have shown earlier that rib procedures can be omitted [10]. However, release of the tether after 2 months led to a regression of the deformity by $45 \%$ in their study. In our study, the mean frontal Cobb angle decreased from $62.1^{\circ}$ tot $46.7^{\circ}$ over a 10 week period after tether release. Despite the decline of $25 \%$, a substantial deformity ultimately remains which is close to the magnitude which would be considered for surgery. Prior to tether release, the apical vertebrae showed a mean wedge angle of $10^{\circ}$. The emergence of vertebral wedging is necessary for the persistence of scoliotic deformity after tether release. Similarly, in the human spine apical vertebral wedging is an essential factor in the progression of idiopathic scoliosis according to the HueterVolkmann principle [16]. Regression of the deformity can be seen as evidence of a flexible curve, which is a crucial prerequisite for apply growth modulation techniques. The omission of the rib tether exhibited two downsides in a porcine model: the incapability of applying pretension to the tether, and slight curve regression after tether release.

Selection of animal species with anatomy similar to humans' and timing of the procedures are vital factors for creating a successful scoliosis model with sufficiently large Cobb angles [8]. Braun was the first to produce progressive lordo-scoliotic deformities in a goat model. However, large pathological curves were obtained [16, 17]. In addition to the pyramidal shape of the thorax, the relatively small size of the goat's vertebra as compared to the human vertebra, makes the goat model less suitable for implant testing [21]. The porcine spine is most similar to the human spine in terms of vertebral body height and has the largest growth potential compared to other large animals, with a maximum growth velocity around 3-4 months of age [8]. We opted for pigs, reasoning that the large growth potential is required when no pretension is applied to the spinal tether. We performed the initial procedure at 8 weeks of age and a mean weight of $12 \mathrm{~kg}$. This is well before the growth velocity peak, leaving enough residual growth to evaluate the deformity after tether release (and perform a corrective procedure in the future). However, we experienced some handling problems with the animals, who reached a weight of approximately $50 \mathrm{~kg}$ at the time of tether removal and approximately $100 \mathrm{~kg}$ at 6 months of age (sacrifice). Other studies describing experimental scoliosis models report different rates of weight increase in pigs, and different rates of growth of the porcine spine, probably the result of discrepancy between porcine races $[10,11,20]$. The size of our animals during the possible implant test phase (between $50-100 \mathrm{~kg}$ ) is not representative of children under the age of 10 , but allows for conceptual feasibility assessment of fusionless scoliosis correction techniques. The described low yield due to screw pull-out and low consistency (epihphysiolysis) are also probably related to the rapid porcine growth phase. The use of mini-pigs or species with a slower growth rate such as sheep or goats may help avoid 
these problems [10, 22]. Mini-pigs show a constant growth-velocity, but lack a growth spurt and will need longer observational periods [8].

Different types of tether materials have been used and flexible tethers are preferred over a rigid tether in order to maintain spinal mobility and allow for growth modulation in different planes (lordo-scoliosis) [10, 14, 20]. Non-metal flexible tethers are also used although visualization of the integrity of the tether during follow-up is not possible. The use of a flexible, radiopaque UHMWPE tether [13], facilitated percutaneous tether release with a minimally invasive stab incision under fluoroscopic control. The tensioning and potentially loosening of the radiopaque tether could easily be monitored during the postoperative radiological evaluation, with minimal animal discomfort as a result of leaving the tether in place.

It is evident that measures should be taken to minimize the occurrence of wound infections; not only to decrease the incidence of instrumentation failure, but also to decrease overall morbidity. Further limitations of our study include the lack of CT analysis at 20 weeks follow-up. Therefore, we were not able to compare rotational deformity between different time-points. Although we encountered several problems, we were able to create the foundation for a large animal scoliosis model, which exhibits a substantial three-dimensional deformity without the use of rib procedures additional to a posterior spinal tether. The resulting deformities were not progressive, but showed persistence after tether release. The high complication rate remains a concern and poses questions regarding the feasibility of subsequent corrective operative procedures. We conclude that despite extensive research and incorporating previous recommendations from other models, the development of a reproducible experimental scoliosis large animal model without severe complications remains challenging. We would like to emphasize that the current work requires further work and validation prior to adoption, preferably in an animal model with a slower growth rate in order to improve the yield and consistency. 


\section{REFERENCES}

[1] Thompson GH, Lenke LG, Akbarnia BA, et al. Early onset scoliosis: future directions. The Journal of bone and joint surgery American volume 2007;89 Suppl 1:163-6.

[2] Gomez JA, Lee JK, Kim PD, et al. "Growth friendly" spine surgery: management options for the young child with scoliosis. The Journal of the American Academy of Orthopaedic Surgeons 2011;19:722-7.

[3] Schmid EC, Aubin CE, Moreau A, et al A novel fusionless vertebral physeal device inducing spinal growth modulation for the correction of spinal deformities. European spine journal : official publication of the European Spine Society, the European Spinal Deformity Society, and the European Section of the Cervical Spine Research Society 2008;17:1329-35.

[4] Braun JT, Akyuz E, Ogilvie JW. The use of animal models in fusionless scoliosis investigations. Spine. 2005;30:S35-45.

[5] Graf H, Hecquet J, Dubousset J. [3-dimensional approach to spinal deformities. Application to the study of the prognosis of pediatric scoliosis]. Revue de chirurgie orthopedique et reparatrice de l'appareil moteur 1983;69:407-16.

[6] Dubousset J. [Idiopathic scoliosis. Definition--pathology--classification--etiology]. Bulletin de I'Academie nationale de medicine 1999;183:699-704.

[7] Dubousset J. Scoliosis and its pathophysiology: do we understand it? Spine 2001;26:1001.

[8] Roth AK, Bogie R, Jacobs E, et al. Large animal models in fusionless scoliosis correction research: a literature review. The spine journal: official journal of the North American Spine Society 2013;13:675-88.

[9] Zhang YG, Zheng GQ, Zhang XS, et al. Scoliosis model created by pedicle screw tethering in immature goats: the feasibility, reliability, and complications. Spine 2009;34:2305-10.

[10] Odent T, Cachon T, Peultier B, et al. Porcine model of early onset scoliosis based on animal growth created with posterior mini-invasive spinal offset tethering: a preliminary report. European spine journal : official publication of the European Spine Society, the European Spinal Deformity Society, and the European Section of the Cervical Spine Research Society 2011;20:1869-76.

[11] Schwab F, Patel A, Lafage V, et al. A porcine model for progressive thoracic scoliosis. Spine 2009;34:E397-404.

[12] Ceelen K, Vaz C, Bremer L, et al. Development of a high-strength, biocompatible, radiopaque UHMWPE fiber. 24th European Conference on Biomaterials. Dublin, Ireland 2011.

[13] Bogie R, Roth A, Faber S, et al. Novel Radiopaque UHMWPE Sublaminar Wires in a Growth-Guidance System for the Treatment of Early Onset Scoliosis: Feasibility in a Large Animal Study. Spine 2014;39:E1503-9.

[14] Burke JG, Vettorato E, Schoffmann G, et al. Creation of an ovine model of progressive structural lordoscoliosis using a unilateral laminar tether. European spine journal : official publication of the European Spine Society, the European Spinal Deformity Society, and the European Section of the Cervical Spine Research Society 2015;24:1382-90.

[15] Lam GC, Hill DL, Le LH, et al. Vertebral rotation measurement: a summary and comparison of common radiographic and CT methods. Scoliosis 2008;3:16.

[16] Braun JT, Ogilvie JW, Akyuz E, et al. Experimental scoliosis in an immature goat model: a method that creates idiopathic-type deformity with minimal violation of the spinal elements along the curve. Spine 2003;28:2198-203. 


\section{Chapter 8}

[17] Braun JT, Ogilvie JW, Akyuz E, et al. Creation of an experimental idiopathic-type scoliosis in an immature goat model using a flexible posterior asymmetric tether. Spine 2006;31:1410-4.

[18] Moal B, Schwab F, Demakakos J, et al. The impact of a corrective tether on a scoliosis porcine model: a detailed 3D analysis with a 20 weeks follow-up. European spine journal: official publication of the European Spine Society, the European Spinal Deformity Society, and the European Section of the Cervical Spine Research Society 2013;22:1800-9.

[19] Ouellet J, Odent T. Animal models for scoliosis research: state of the art, current concepts and future perspective applications. European spine journal: official publication of the European Spine Society, the European Spinal Deformity Society, and the European Section of the Cervical Spine Research Society 2013;22 Suppl 2:S81-95.

[20] Zheng X, Sun X, Qiu Y, et al. A porcine early-onset scoliosis model created using a posterior mini-invasive method: a pilot study. Journal of spinal disorders \& techniques 2014;27:E294-300.

[21] Braun JT, Akyuz E, Udall H, et al. Three-dimensional analysis of 2 fusionless scoliosis treatments: a flexible ligament tether versus a rigid-shape memory alloy staple. Spine 2006;31:262-8.

[22] Newton PO, Upasani VV, Farnsworth CL, et al. Spinal growth modulation with use of a tether in an immature porcine model. The Journal of bone and joint surgery American volume 2008;90:2695-706. 


\section{SUMMARY}

The goal of this thesis was to develop and evaluate a new growth-guidance type construct for the surgical treatment of EOS which would allow for maximum growth without the disadvantages of metal-on-metal articulation. We have proposed a construct with woven ultra-high molecular weight polyethylene (UHMWPE) sublaminar wires functioning as sliding anchors at the proximal and distal ends of a construct whereas pedicle screws at the apex prevent rod migration and allow for curve derotation. The spinal segments above and below the apex of the curvature are least rotated and deviated from the midline, and thus are the targets for growth-guidance. Ideally, such a construct would allow for a one-stage procedure that will accommodate spinal growth. We hypothesized that the use of UHMWPE sublaminar wires instead of metal wires offers three significant advantages. First, longitudinal sliding friction is expected to be substantially decreased, allowing for increased spinal growth. Second, no metal wear particles will be generated. Finally, the vastly increased fatigue strength of UHMWPE wires in comparison to metal wires allows for non-segmental constructs (skipped-level fixation) without the risk of wire failure, and thus allows for reduced surgical exposure. A full preclinical assessment of the proposed construct was performed in this thesis, with the following defined aims:

To assess the suitability of radiopaque UHMWPE sublaminar wires made with Dyneema Purity ${ }^{\circledR}$ radiopaque fibers for clinical application, from both a mechanical and biological perspective

In Chapter 3, the mechanical properties (tensile stiffness, strength, fatigue strength, creep elongation) of radiopaque UHMWPE sublaminar cables were extensively evaluated and compared to a radiolucent analog UHMWPE cable, a commercial titanium sublaminar wire, and to literature data available for other sublaminar cable or wire systems. The mechanical properties of UHMWPE cables are superior to the compared sublaminar wire systems in terms of tensile and fatigue strength, while possessing stiffness at least comparable to metal cables. Results also showed that the mechanical properties of woven UHMWPE cables were not deleteriously affected by the addition of homogenously dispersed bismuth oxide particles within each fiber. Radiopacity was assessed for the radiopaque UHMWPE cable; radiopacity values in the lateral view were similar to the titanium Atlas ${ }^{\circledR}$ cable, but radiopacity was limited in the frontal view. Limited amounts of bismuth oxide were released through leaching in vitro, which was well below the established tolerable intake. Tissue concentrations lower than therapeutic dosages as used against gastrointestinal disorders and well below toxic levels were discovered after 24 weeks of implantation in sheep. No significant damage to the UHMWPE cable and no substantial amount of wear particles were generated in a preliminary wear analysis in the supplement to Chapter 3 . These results suggest that the 
radiopaque UHMWPE cables may safely be used as a sublaminar wire for spinal deformity correction from a mechanical and toxicological perspective.

To assess the potential for continued spinal growth after instrumentation with radiopaque UHMWPE sublaminar wires

Spinal growth after growth-guidance construct implantation was assessed in an immature sheep model in Chapter 4. Lateral radiographs clearly showed the routing of the radiopaque UHMWPE cable around the laminae which allowed for follow-up of spinal growth. No neurological injuries occurred and UHMWPE cable integrity was maintained during the follow-up period. Instrumentation with UHMWPE sublaminar cables did not limit longitudinal spinal growth in this animal trial; length of the instrumented segment did not differ from unoperated control animals after a period of 24 weeks. In most animals, the cranial wire slid off of the rod during follow-up. Despite the noted growth, facet joint changes and heterotopic bone formation were observed in all animals on high resolution peripheral computed tomography (HR-pQCT) images. Removal of spinal rods prior to HR-pQCT analysis was easy, indicating that no bone apposition directly onto the rods had occurred. Histological evaluation showed that the UHMWPE sublaminar wire was encapsulated by fibrous tissue and caused no chronic inflammatory reactions or osteolysis. In the supplement to Chapter 4, we have shown that selecting radiopaque UHWMPE sublaminar wires in favor of titanium cables decreases longitudinal sliding friction by approximately 50\%. From this study, we concluded that radiopaque UHMWPE wires provide excellent functionality as sliding anchors in a growth-guidance system, although interlaminar orthotopic bone formation as a result of flaval ligament sectioning is a cause for concern as it may lead to spontaneous spinal fusion.

To determine the minimum required number of consecutive construct end levels to be instrumented with UHMWPE sublaminar wires in order to provide adequate correction and fixation of the spinal column while also minimizing surgical exposure for EOS patients

In Chapter 5, an in vitro biomechanical comparison of segmental versus different nonsegmental UHMWPE sublaminar wire growth-guidance type constructs with porcine thoracic spine segments was performed. Sublaminar wire passage requires flaval ligament sectioning for wire placement, which may lead to interlaminar heterotopic bone formation with subsequent possible growth impediment. In order to preserve as much growth as possible in EOS patients, subperiosteal exposure must be kept to a minimum by reducing the number of required wires while simultaneously maintaining adequate correction. Significant and substantial differences in range of motion were only noted in both flexion/extension and lateral bending between constructs with two and one consecutively instrumented end-levels. An optimal balance between minimizing the number of instrumented levels and maximizing spinal stability is thus 
attained in a construct with UHMWPE sublaminar wires at two consecutive end levels. Ultimately, growth needs to be anticipated for EOS patients. Depending on the patient's age and expected remaining growth at the time of surgery, extra rod length or perhaps an extra end vertebra should be instrumented so that two end-levels always remain instrumented, even in the case that UHMWPE wires at the most distal or proximal segment slide off of the rod.

To implement realistic biomechanical behavior of the proposed growth-guidance system in a parametric (patient-specific) finite element (FE) model of the spine

In Chapter 6, the in silico biomechanical behavior of the healthy L4-L5 segment was first calibrated in comparison to in vitro literature data. Second, in silico behavior of the whole thoracolumbar spine was successfully verified. Rods, screws, and sublaminar wires were implemented in the model, and the in vitro biomechanical evaluation of sublaminar wire density variations described in Chapter 5 was replicated in silico. Good agreement between in vitro biomechanical tests and FE simulations was observed in terms of total range of motion (ROM) reduction after construct introduction. The stepwise increase in total ROM with decreasing number of wires at the construct ends was less prominent in silico. Longitudinal sliding of UHMWPE wires along rods during bending movements should be incorporated into the model for improved similarity between in vitro and in silico results. The parametric geometry definition should also be improved to show closer anatomical resemblance. Important first steps in the implementation and validation of a growth-guidance construct for EOS patients in a patient-specific FE model of the spine have been made in this study.

To develop a large animal model for early onset scoliosis in order to be able to test all aspects of the proposed growth-guidance construct

In Chapter 7, an overview of large animal models used for preclinical testing of fusionless scoliosis correction devices was provided and recent advances in the creation of an idiopathic-like scoliosis large animal model were described. We concluded that the preferred method of testing novel fusionless scoliosis correction devices is by first creating a scoliosis using a posterior spinal tether and subsequently correcting the deformity using the proposed fusionless scoliosis correction device in a two-step approach. The pig appears to be a suitable test species due to its large growth potential and early availability, which provides the possibility of operating at 3 weeks of age. The index procedure (tether placement) should be completely reversible and therefore no rib tether should ideally be used. However, a higher rate of deformity regression following tether removal is to be expected when no rib tether is used.

The development of a porcine experimental scoliosis model with a standalone posterior spinal tether was subsequently described in Chapter 8. Although a structural scoliotic curve with a chest wall deformity and a positive rib hump elevation was created in eight out of fourteen animals, substantial complications were frequently encountered. In the 
eight animals with deformity, the mean Cobb angle at 10 week follow-up was $62^{\circ}$ in the coronal plane, while the mean apical vertebral rotation was $37^{\circ}$. Sagittal profiles showed the development of a lordotic curve at the anchor sites due to anterior overgrowth. The created curves were inconsistent, with three animals displaying atypical short thoracic curves. By omitting rib procedures we aimed to create less rigid curves, especially around the apex. However, this approach led to an inconsistent model with low yield. The porcine growth rate was perhaps too rapid, leading to frequent instrumentation failure. We can conclude that the development of a reliable porcine experimental scoliosis model using a posterior spinal tether only was unsuccessful so far.

\section{DISCUSSION \& RECOMMENDATIONS}

\section{The step towards clinical introduction}

U.S. Food and Drug Administration (FDA) 510(k) clearance for the radiopaque UHMWPE cables was applied for and granted based on the results presented in this thesis, along with the complete Dyneema Purity ${ }^{\circledR}$ Masterfile on record with the FDA. The granted FDA $510(k)$ clearance paves the road for clinical introduction in the near future. The radiopaque UHMWPE cable has been approved as a cerclage cable for the following intended applications: spinal applications including sublaminar and intraspinous process wiring for trauma applications, trochanteric reattachment after trochanteric osteotomy following total hip arthroplasty, sternotomy indications including the rewiring of osteotomized sternums, trauma surgery indications including olecranon, ankle, patella and some shoulder fracture rewiring. Although spinal applications are mentioned among the intended applications, use in spinal deformity reconstruction or as an adjunct to spinal fusion are not approved indications, nor is use in a pediatric population. Institutional regulatory board (IRB, i.e. medical ethical committee) approval will thus need to be granted prior to the evaluation of the proposed growth-guidance construct for EOS patients in controlled clinical trials.

The difficulties encountered during the development of the porcine experimental scoliosis model are very illustrative and representative of the difficulties encountered during spinal deformity correction surgery for EOS patients. In our immature porcine model, continued anterior growth occurred at levels instrumented with posterior instrumentation resulting in a local lordosis or rod dislodgement. Instrumentation break-out also occurred frequently as a result of high loads in combination with inferior screw purchase in cartilaginous bone. The original project plan was to evaluate the proposed growth-guidance system in this animal model as a final test case prior to clinical trials. Such a study would have provided valuable insight into the effects of long- 
term loading on curve correction maintenance. However, we believe that our animal model is too unpredictable with a failure rate close to $50 \%$ and not sufficiently representative of early onset scoliosis because of the rapid porcine growth with animals reaching approximately $55 \mathrm{~kg}$ by the time the correction surgery would take place. Thus, we conclude that a rib tether may very well be necessary for a more consistent porcine model for EOS. The elimination of the rib tether may be feasible in animals with a slower growth rate (goats or sheep for example) although the magnitude of the attained deformities will likely be less or increased follow-up times will be necessary.

Animal models provide a good indication of the clinical function of new implants, but caution must be taken when translating attained results to the human case. The limitations of the specific model must be considered for every research question posed. Although an animal trial would have provided more definitive answers relating to the stability of correction in the long-term, we believe that the lack of in vivo evidence should not preclude clinical introduction. However, as some uncertainties regarding the functionality of the proposed growth-guidance system for EOS patients remain, a more careful stepwise introduction in other patient groups should be considered. We believe radiopaque UHMWPE sublaminar cables should be first introduced in hybrid constructs (along with pedicle screws and/or hooks) in adolescent idiopathic scoliosis patients to assess possible loss of correction and biological safety in humans. Radiolucent UHMWPE cables have been successfully used in such constructs in Japan [1].

\section{Mechanical properties of UHMWPE cables}

In this thesis, we have shown that radiopaque UHMWPE sublaminar cables possess a substantially higher tensile strength and fatigue strength, while their stiffness is comparable to the stiffness of metal cables. UHMWPE cables do however exhibit increased creep elongation, which is due to a combination of macroscopic and microscopic effects. Macroscopically, the sliding knot tightens and sets itself. Pretensioning is performed to minimize the macroscopic effects, but does not fully prevent this from occurring. The minor differences observed between the mechanical properties of the radiopaque UHMWPE cable and the radiolucent analog cable are presumed to be a result of these macroscopic knot effects. A slight difference in cable width (approximately $0.1 \mathrm{~mm}$ ) and perhaps a different fiber-on-fiber friction may result in the slight differences in knot tightening behavior. Microscopically, creep also occurs within each individual fiber. UHMWPE is inherently more susceptible to creep than metals, as oriented polyethylene chains slip due to weak van der Waals interactions between chains [2]. In the 72 hour creep tests $\left(37^{\circ} \mathrm{C}\right)$, the macroscopic effects (occurring in the first 30 seconds) accounted for approximately one-third of the total elongation, while the microscopic effects accounted for approximately two-thirds. The choice for UHMWPE as a material thus may have inherent disadvantages. Low creep 
UHMWPE fibers have developed for offshore mooring applications [3], although medical grade equivalents are not available.

The clinical significance of the higher creep elongation in comparison to metal cables remains the biggest uncertainty at this time point, because we do not know the exact magnitude of the loads experienced by the cables in vivo. The finite element (FE) model of the spine including instrumentation could aid in providing such insight when deformity correction is modeled in the future. Important steps towards such applications of the model have been made with the mechanical property optimization and validation process. Attempts were made to quantify the load during the in vitro biomechanical tests with porcine spine segments described in Chapter 5 by using thinfilm force sensors placed between the UHMWPE cable and the rod. During such tests, the load never exceeded $150 \mathrm{~N}$, but those tests merely present an indication of the load magnitude during everyday movement in a straight spine. The continuous load needed to maintain curve correction would be the main reason for creep elongation to occur.

If the effects of creep turn out to be an issue, the square-lashing technique may provide a solution without making adaptations to the cable design, thereby avoiding repeating the regulatory approval process. With the square lashing technique [4], the sublaminar cable is wrapped around the spinal rod twice - once at the superior laminar end and once at the inferior laminar edge (Figure 1). The load is thus distributed among four cable strands instead of two, effectively decreasing the load on each individual fiber.
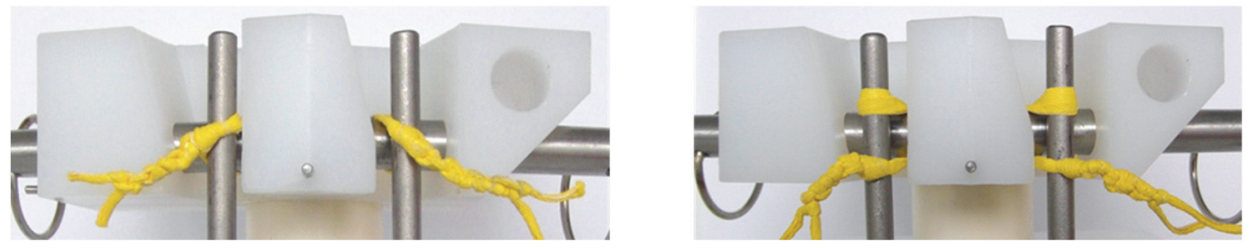

Figure 1 - Illustrative comparison between the standard (left) and square-lashing technique as means to secure sublaminar cables. The horizontal rods represent the laminae in this spine analog setup.

The use of the square-lashing technique may be very appealing as it may also increase the stiffness of the instrumented construct because the number of attachment points is essentially doubled. Furthermore, the pull-out force has been shown to be substantially increased when using this technique [4]. However, this also implies that four instead of two strands will pass through the vertebral foramen, and thus penetration into the spinal canal may be increased. Ideally, the two-doubled stranded cable segments will align side by side so that canal penetration is not increased, but with bilateral, squarelashed sublaminar cables this may not be entirely possible. Further in vitro biomechanical testing is required to quantify the effects of using these two different knotting techniques. 


\section{Wear}

An observational wear assessment pertaining to the application of UHMWPE cables as cerclage cables was performed in a supplement to Chapter 3. However, it is difficult to translate these results towards the application of UHMWPE cables as sublaminar wires in a growth-guidance construct for the treatment of EOS as multidirectional loading and longitudinal sliding were not included in the simplified loading protocol. Therefore, representative in vitro wear tests should be conducted prior to clinical introduction of the proposed construct for EOS patients. There are no standardized testing protocols available specific for growth-guidance type constructs. However, existing standardized testing protocols (ISO 12189, ASTM F1717, ASTM F2624) may be adapted to assess growth-guidance constructs. The exact magnitudes of applied rotations in displacement-control remain disputed. We have developed a spine analog based on the ISO 12189 and ASTM F1717 test standards (Figure 2), but wear testing is yet to be performed. A six degree of freedom joint test machine is needed to apply combined loading protocols.

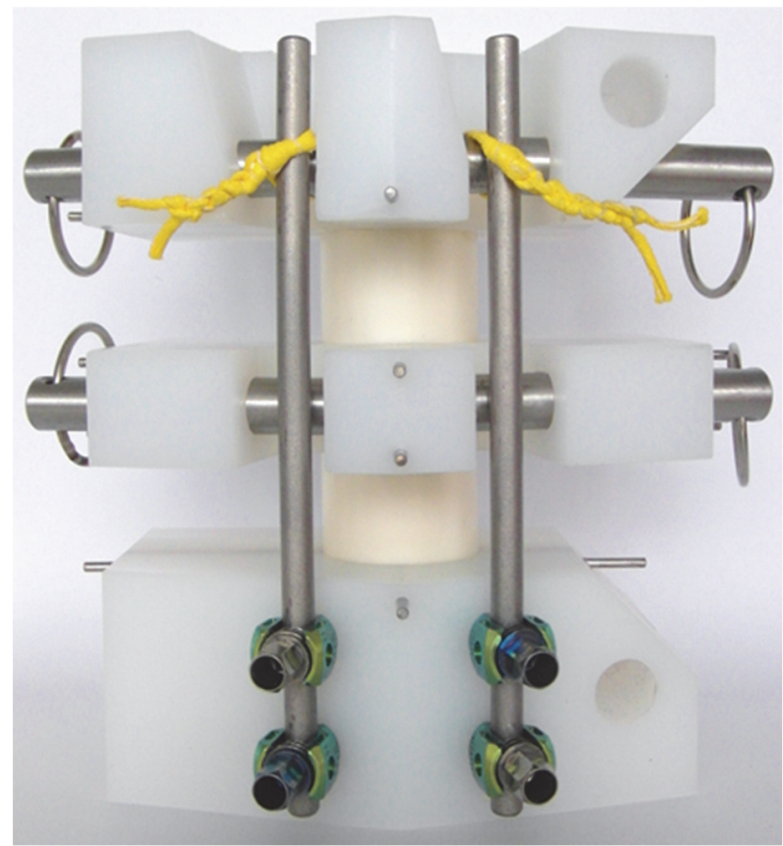

Figure 2 - The developed spine analog test setup adapted from the ASTM F1717 and ISO 12189 test standards for the evaluation of wear. 
Growth-guidance versus growing rods: lessons from the Shilla system

The growth-guidance construct proposed in this thesis is inspired by the Luque trolley and the Shilla system. Based on disappointing growth results attained with the Luque trolley [5-7], growth-guidance systems had long been disregarded as a solution for EOS patients. However, McCarthy et al. have recently published 5 year results for the Shilla system $[8,9]$, which are very encouraging for the revival of growth-guidance concept. As our proposed construct is similar to the Shilla system, lessons learned after more than five years of experience with the Shilla system may be translated towards our proposed construct.

In the original 40 patients treated with the Shilla method, preoperative curves averaged $69^{\circ}$, which were corrected to an average of $25^{\circ}$ after the index procedure. At the latest follow-up or prior to fusion surgery, curves averaged $38^{\circ}$. Thoracic spinal height increased $26 \mathrm{~mm}$ after the index procedure, and an additional $29 \mathrm{~mm}$ due to growth. Space available for lung thus improved by $29 \%$, with a thoracic spinal growth rate of 7.2 $\mathrm{mm} / \mathrm{yr}$. Thoracic spinal height averaged $23.1 \mathrm{~cm}$ at maturity, exceeding the minimum goal of $18 \mathrm{~cm}$ recommended by Karol et al [10]. Respiratory function tests at skeletal maturity confirmed satisfactory thoracic capacity in most patients. The goal of improving and maintaining respiratory function can thus be attained using growthguidance techniques for EOS patients. Although unplanned surgeries were required to address implant related complications, the number of surgical procedures was reduced by approximately $75 \%$ in comparison to the estimated number of procedures that would have been necessary for patients treated with conventional growing rods (GR).

During the Shilla surgical procedure, the apex is fused and fixed using bilateral pedicle screws, with measures taken to prevent the crankshaft phenomenon [11]. The number of fused levels at the apex varies with curve flexibility; two segments can be fused for more flexible curves, while three to four segments are typically fused for stiffer curves. Stiff curves are defined as the inability to bend to $<50^{\circ}$ as on a force bending radiograph. Posterior releases (Ponte osteotomies) with anterior disc removal at intervening levels are typically performed at the apical levels to attain maximal mobility intraoperatively for improved correction. More extensive osteotomies (pedicle subtraction osteotomy or vertebral column resection) may be required to attain flexibility in the stiffest curves. The location of the sliding anchors is chosen in accordance with the guidelines which govern adolescent idiopathic scoliosis surgery (Lenke classification [12]). In ambulatory patients, the lower lumbar levels (below L3) should be avoided. After early experiences with rod fracture, $4.5 \mathrm{~mm}$ diameter rods are presently used for smaller patients, while $5.5 \mathrm{~mm}$ diameter rods are used for patients weighing more than $30 \mathrm{~kg}$. No neurological complications occurred during any of the procedures, corroborating earlier reports on the safety of pedicle screws in juvenile 
patients [13]. The U.S. Food and Drug Administration (FDA) recommend removal of Shilla implants prior to adulthood.

A retrospective multicenter case-match comparison has recently been performed between the first 36 patients treated with the Shilla system and EOS patients treated with conventional dual growing rods from the Growing Spine Study Group database [14]. The increase in T1-S1 length from preoperative values to final follow-up was 6.4 $\mathrm{cm}$ in the Shilla group and $8.7 \mathrm{~cm}$ in the GR rod, which was significantly different. This may be partly attributed to apical fusion necessary for Shilla instrumentation. However, final T1-S1 length was the same in both groups due to a large initial length in the Shilla group. The rates of implant related complications (rod fractures, screw pull-out, implant prominence) were similar for both groups. Implant related complications are typically addressed during planned lengthening procedures in the GR group. Therefore, the number of additional surgeries averaged 1.8 in the Shilla group, and 6.4 in the GR group (including lengthening procedures). However, as the study group concerns the first patients treated with the Shilla system, complications may represent the learning curve in this group. Lessons learned include the use of larger diameter rods to prevent rod fracture, and therefore the complication rate may decrease in the future. Although Shilla instrumentation provides a better postoperative correction, growing rods provide a better Cobb angle correction at long term follow-up. While Cobb angle correction improves slightly due to repetitive distraction in the GR group, correction is partly lost over time in the Shilla group.

No comparison has been made between the two techniques concerning pulmonary function, quality of life or healthcare costs. Repeated anesthetics have been suggested to result in neurological impairment [15], learning disabilities [16], and psychological dysfunction [17]. The latter of these factors are all hypothesized and expected to favor the use of growth-guidance techniques, and future comparison should also be made.

Translating this comparison to our proposed growth-guidance system using UHMWPE sublaminar wires as sliding anchors, we may already draw a few conclusions. Although superior correction is offered by a growth-guidance construct with apical fusion in comparison to GR directly postoperatively, deformity progression may occur during long term follow-up which may necessitate a definitive fusion procedure. Frequent rod fractures may be avoided by abandoning the use of smaller diameter rods. However, screw pull-out or loosening may remain problematic even for our proposed system. Although pull-out comparisons have been made between sublaminar wires and pedicle screws with human cadaveric material, this is a very poor representation for surgery in EOS patients due to very different bone mineral density distributions and open growth plates in juvenile patients. A comparison will thus have to be made between pedicle screws and UHMWPE sublaminar cables with immature porcine vertebrae for example. 
The longitudinal sliding friction study presented in the supplement to chapter 4 provides basic insight into the type of rod which is preferably used in conjunction with UHMWPE sublaminar wires in a growth-guidance construct for EOS patients, although other factors besides low friction must also be considered. Concerning friction, either stainless steel or titanium rods appeared to be preferred. However, all rods were tested as supplied by the manufacturer. The tested cobalt chromium rod was glass bead blasted by the manufacturer to increase the surface roughness for adequate set screw hold. Polishing the rods to a very low surface roughness, as is typically done for articulating orthopedic implants, will likely reduce friction and will minimize wear particle generation. Construct stiffness, possible rod fracture, and osteoconductivity of rod materials must also be considered when selecting the rod metal alloy. The bending stiffness of a rod is a function of the materials' elastic modulus, its radius to the fourth power, and inversely proportional to the square of its length. The choices of metal alloy and rod diameter thus have a great influence on rod stiffness. Stainless steel has an elastic modulus of approximately $190 \mathrm{GPa}$, compared to $116 \mathrm{GPa}$ for titanium alloy, and $210 \mathrm{GPa}$ for CoCr alloys [18]. Similar differences exist between the rods in terms of yield strength. Smaller diameter rods $(3.5 \mathrm{~mm}$ or $4.5 \mathrm{~mm}$ ) may be susceptible to fracture, especially titanium rods in ambulatory patients weighing more than $30 \mathrm{~kg}$ [8]. Furthermore, titanium exhibits superior osteoconductivity in comparison to other metals [19]. Bone apposition is known to occur directly to the surface of titanium, while we observed the formation of a fibrous layer between bone and the cobalt chromium rods in the animal study presented in Chapter 4. If heterotopic ossification and bone apposition to titanium rods do occur, longitudinal spinal growth is likely to be impeded. For these reasons it appears that stainless steel or polished cobalt chromium rods should be preferred.

We presume that the FDA recommends removal of the Shilla implants in order to prevent prolonged patient exposure to metal wear particles. For the patients with wellcontrolled spinal deformities, a construct with UHMWPE sublaminar wires as sliding anchors may not necessarily require removal for this specific reason. In McCarthy's case series, three patients were treated by implant removal alone as a definitive procedure. Removal may provide the benefit of increased spinal motion, although spinal stiffening often occurs due to spinal instrumentation. However, Cahill et al. have reported an autofusion rate of $89 \%$ in patients treated with GR [20]. The effects of implant removal may thus be questioned, and perhaps a removal or definitive fusion procedure may be avoided in certain patients with well-controlled spinal deformities. A recent study has suggested that a definitive fusion procedure may indeed be avoided after growing-rod treatment in subgroups of patients who have satisfactory final alignment and trunk height, a minimal gain in length at the last distraction, and with no clinical or radiographic evidence of implant-related problems [21]. 


\section{UHMWPE sublaminar wires versus non-constraining Shilla screws}

The main reservations surgeons may have with the Shilla system concern the metal-onmetal articulation occurring between the rods and the non-constraining pedicle screws. Metallosis is often encountered upon revision, and spinal growth may potentially be limited as a result of high friction. Metallosis has been reported in all studies describing the Shilla system including preclinical animal trials, but no negative consequences have been described $[8,22,23]$. Although an in vitro wear analysis has shown that the amount of wear particles generated with the stainless steel Shilla system appears to be relatively low [24], metallic wear particles are much more reactive than polyethylene wear particles [25]. The presence of metallic wear particles is worrisome as the elicited macrophage-mediated inflammatory response may lead to osteolysis and subsequent instrumentation failure through implant loosening [26, 27]. A case-report describing aseptic loosening due to metal wear debris induced osteolysis after a spinal fusion procedure in an adolescent scoliosis patient shows that concerns may become reality [28]. Metallosis-associated complications including sinus and seroma formation have been reported in 5 out of 25 patients with the LSZ-4D titanium growth-guidance system [29]. Furthermore, whole blood metal ion content was increased in $90 \%$ of the patients, with titanium content in soft tissue surrounding implants often increased by more than 1,500-fold. The wear resistance of titanium is inferior to stainless steel or cobalt chromium alloys, but its wear particles are more biocompatible [18]. Therefore, it is difficult to translate these results towards the stainless steel Shilla system. Screw pullout or loosening occurred in 9 out of 40 of McCarthy's Shilla patients, although no direct connection to wear debris was reported [8]. The biological effects of metal wear debris generated with the Shilla system will require further evaluation, and the possibility of wear debris induced osteolysis must be considered when complications are encountered.

Metal wear debris is avoided with the use of UHMPE sublaminar wires as sliding anchors, but more invasive subperiosteal exposure is required for their introduction. The required subperiosteal exposure is the main disadvantage of the use of UHMWPE sublaminar wires. Access to the spine typically involves detaching the erector spinae muscles using electrocautery. Extra care is taken in fusionless scoliosis correction surgery to maintain extraperiosteal dissection [30], as subperiosteal exposure may result in heterotopic ossification. Whereas subperiosteal exposure can be avoided using non-constraining Shilla pedicle screws, subperiosteal exposure is unavoidable with placement of sublaminar wires, as it requires excision of the flaval ligament. Interlaminar heterotopic ossification may lead to spontaneous spinal fusion, as was often encountered during Luque trolley revision procedures $[5,6]$. The unfavorable effects of heterotopic ossification may be diminished by minimizing the number of levels instrumented with sublaminar wires. In comparison to metal cables, UHMWPE 
cables offers vastly improved fatigue strength, which presents the opportunity for introducing non-segmental constructs. Reducing the number of levels instrumented in non-segmental versus segmental constructs decreases surgical exposure. During the in vitro biomechanical study presented in Chapter 5, we only tested different forms of non-segmental instrumentation with sublaminar wires at consecutive levels in this study. Skipping a level between which sublaminar wires are placed requires surgical exposure to the same degree as is necessary when sublaminar wires are placed at three consecutive levels. The observations that flaval ligament sectioning can lead to ectopic interlaminar bone formation and possibly spontaneous fusion led to the need for minimizing the number of instrumented levels. Skipping single levels (skipped level instrumentation) was deemed ineffective as this would not reduce flaval ligament sectioning and interlaminar subperiosteal exposure. Therefore, we have focused on minimizing the number of consecutive levels instrumented with UHWMPE sublaminar wires in order to reduce surgical exposure and thereby reduce the risk of interlaminar bone formation. Non-segmental constructs with UHMWPE sublaminar wires are thus expected to lead to improved results in comparison to the traditional Luque trolley.

Additional measures are necessary to prevent heterotopic ossification after sublaminar wire passage in order to attain growth results comparable to those attained with the Shilla system however. Two measures are suggested: anti-adhesive barrier gels may be introduced in the interlaminar space after sublaminar wire passage or indomethacin may potentially be administered post-operatively. Anti-adhesive barrier gels act as a hydrophilic physical barrier, preventing influx of osteoprogenitor cells from decorticated bone, and have been shown to inhibit intended spinal fusion in animal models [31]. Indomethacin is a cyclooxygenase- 1 specific nonsteroidal anti-inflammatory drug, which has been shown to inhibit bone-healing and spinal fusion [32-34]. Indomethacin may possibly also prevent the intended fusion at the apex in our proposed growth-guidance system, so local administration at the construct ends is likely to be preferred over systemic administration. Both methods may be combined by using the anti-adhesive barrier gel as a drug delivery vehicle for indomethacin, which appears feasible due to the hydrophobicity of indomethacin. These measures should be evaluated in animal models prior to clinical adoption.

If these measures prove to be insufficient, other implant designs may be possible to offer an alternative to the metal non-constraining Shilla screws. Pedicle-based sliding anchor members without metal-on-metal articulation appear to form optimal components for a growth-guidance system. The Trolley Gliding Vehicle (TGV) was described by Ouellet et al. The TGV construct design requires two overlapping rods on each side (one fixed at the proximal end, the other at the distal end), with growth possible via side-by-side sliding of the rods at the apex. This means that four rods are implanted, which may cause unnecessary stiffening of the spine or instrumentation prominence. A pedicle-based anchor system for UHMWPE cables may provide a more 
universal system, allowing for both Shilla-type constructs (with rigid fixation at the apex) and TGV-type constructs (with rigid fixation of four rods at proximal and distal ends connected with sliding anchors at the apex). Anchor systems for UHMWPE cables are commonly used in shoulder surgery for glenoid or rotator cuff repairs. Translation towards application of the spine would require upscaling the design and extensive mechanical testing.

\section{New developments: magnetic controlled growing rods}

Magnetic controlled growing rods (MCGR) have been introduced in the last five years as another alternative to conventional GR, also with the objective of avoiding surgical lengthening procedures. With MCGR, lengthening procedures can be performed at the outpatient clinic using an external remote controller, without the need for anesthesia or sedation. The short-term results are promising [35-40]. Initial correction of the major curve is similar to the correction attained with conventional GR, averaging approximately $40 \%$ of the curve magnitude in all patients, while a correction of approximately $50 \%$ is attainable using double rods for flexible curves. Spinal growth (T1$\mathrm{S} 1$ ) is approximately $10 \mathrm{~mm} / \mathrm{yr}$, which is comparable to conventional growing rods, and agrees with the expected average spinal growth in healthy children as described by Dimeglio [41]. Due to the decrease in the number of surgeries, the infection rates and wound-related problem rates are dramatically decreased. However, concerns have been raised about higher instrumentation-related complication rates in comparison to conventional GR $[42,43]$. We must acknowledge that MCGR is still an emerging technology, which may require refinement and further evolvement. Actuator pin fracture resulting in the inability to distract the rods is a frequently occurring complication leading to failure $[43,44]$. The diameter of the actuator pin will be increased by Ellipse Technologies Ltd, the manufacturer of the MCGR as a result. Furthermore, the welding technique has been changed and different measures have been taken to prevent failure to distract [45]. Rod fractures often occur in single-rod constructs, which should thus definitely be avoided [43]. Rod fractures also may occur in dual-rod constructs, often when $>2 \mathrm{~cm}$ of coronal imbalance remains after index surgery [36]. Distraction based implants may cause flattening of the spine, sagittal imbalance and proximal junctional kyphosis requiring revision, which has been reported to occur as often as $22 \%$ (19 out of 88 patients) [46]. Controlling sagittal balance may be more challenging with MCGR in comparison to conventional GR due to the long rigid distractor portion of the MCGR [45]. Until now, only short term follow-up results have been published, with few reports of patients treated until skeletal maturity. The number of encountered complications is expected to increase with longer follow-up times, although the overall complication rates may decrease in the future due to further technical refinement and increased experience with the system. 
Cost-effectiveness analysis has been performed for MCGR systems in comparison to conventional GR systems in the UK [47], France [48], and the USA [49]. In all cases, cost neutrality occurred after approximately 3 years, with costs for implants, index surgery, lengthening procedures, infection- and revision management all taken into account. After three years, the use of MCGR systems is cost saving in comparison to conventional GR systems. Calculated cumulative costs vary per country: in the UK, costs cumulated to $£ 36,094$ for MCGR and £46,040 for conventional GR after 6 years, resulting in £9,946 $(22 \%)$ of potential cost savings per patient. In France, total costs were estimated at $€ 42,752$ for MCGR and $€ 49,067$ for conventional GR after 4 years, which amounts to $€ 6,135$ (13\%) of cost savings. In the USA, calculated cumulative costs were $\$ 166,098$ for MCGR systems and $\$ 126,467$ for conventional growing rods, amounting to $\$ 39,361$ (24\%) potentially saved after 5 years. However, these cost analyses have been performed without data concerning the long-term implant related complication rates. In the only currently available study with long-term follow-up [43], the mean duration of implant survival was 39 months, making MCGR systems cost-effective in only $50 \%$ of cases. As mentioned before, instrumentation related complication rates may decrease due to system improvements and increased familiarity with MCGR systems, which would increase cost effectiveness. However, larger patient cohorts with follow-up times up until skeletal maturity are needed to clearly elucidate the rate of implant related complications and implant survival duration and thereby the potential cost effectivity.

No cost comparison between MCGR and the Shilla systems (or other growth-guidance systems for that matter) has yet been made. As growth-guidance type construct components are much simpler, we expect that the implant procurement costs are much lower in comparison to MCGR. A recent study has shown that the implant related complication rate did not differ between traditional dual growing rods and the Shilla growth-guidance system [14], and that costs for infection- and revision management are at least equal to MCGR. We expect that the cost benefit will thus turn in favor of growth-guidance type constructs, depending on the initial implant procurement costs. Lower expected costs and no required return to hospital for lengthening procedures may be decisive factors to favor growth-guidance systems over MCGR (or conventional GR systems), especially in developing countries. However, again larger patient cohorts with follow-up times up until skeletal maturity are needed for a proper comparison between the Shilla and MCGR systems.

UHMWPE sublaminar wires may perhaps provide added benefit to MCGR (or conventional GR) systems when used at the apex to provide superior correction. Superior correction will decrease post-operative imbalance and thereby the probability of rod fracture. However, the effectivity of measures to prevent interlaminar ossification after flaval ligament section needs to be demonstrated. The effects of the increased magnitude of surgical exposure should be weighed against the benefits of providing improved coronal deformity correction. 


\section{FUTURE CONSIDERATIONS}

\section{Radiopacity}

The very first experiences with a radiopaque polymer cable, designed to enable radiological follow-up, are described in this thesis. Radiopacity is a crucial prerequisite for sliding anchors in a growth-guidance system, as regular radiological follow-up is performed in scoliosis patients to monitor curve magnitude and instrumentation integrity. If curve progression suddenly occurs, it is important to determine if the sliding anchors have possibly grown clear of the rod as the underlying cause. Therefore, we would not recommend the use of radiolucent UHMWPE cables in a growth-guidance construct for EOS patients. The introduction of a radiopaque polymer cable is a revolutionary breakthrough, and may also offer other new opportunities in the whole field of orthopedic surgery.

For the intended application in EOS patients, the low-profile was the most important requirement kept in mind during the cable design process. When radiopaque UHMWPE fibers are used to produce a woven or braided cable, its radiopacity will be highly dependent on the number of fibers used, their structural configuration, and the amount of surrounding tissue at the specific location. Due to the limited thickness of the cable (approximately $0.5 \mathrm{~mm}$ ), radiopacity is limited in anteroposterior radiographs, and hence later radiographs are preferred for follow-up. Hypothetically, increasing the bismuth oxide content within the radiopaque UHMWPE cables would result in a more clearly identifiable cable. However, increasing the bismuth trioxide concentration will have an effect on fiber properties, and would require a new regulatory body approval procedure, including a new in vivo assessment. Hence, the next step will be clinical introduction of the currently available radiopaque UHMWPE cable with $20 \%$ wt. bismuth oxide and regulatory body approval for the intended application as a sublaminar wire for spinal deformity correction.

We have shown that in vitro and in vivo radiopacifier leaching was very limited. Due to the direct proximity of the sublaminar wires to the spinal canal, patients in a first clinical trial investigating the application of radiopaque UHMWPE cables for spinal deformity correction should be carefully monitored, even though FDA 510(k) clearance was granted for the use of the radiopaque UHMWPE cable as a cerclage cable. During the course of the animal trials wherein the cables were implanted as sublaminar wires, we were unable to detect any possible short term neurological side effects (i.e tingling, dizziness) that have been described after the intake of large quantities of therapeutic bismuth compounds. Local spinal fluid concentrations are expected to be much lower for clinical application of UHMWPE cables as a sublaminar wire in comparison to the cases encountered in literature involving an overdose of bismuth compounds (given the minute quantities released in vitro), nevertheless patients and caregivers should be 
aware of the possible occurrence of small neurological side effects in the first clinical study for sublaminar wires. Therefore, the bismuth oxide content in urine could be regularly analyzed to make sure leached radiopacifier particles are cleared, and their presence decreases over time.

If a new regulatory body approval procedure is to be undertaken, some further improvements to the cable design may be considered. Perhaps a cable which has a wide, flat profile at the site of contact with the lamina and a round braided configuration for knotting may provide further improvement to the cable design. The large contact surface for the distribution of force would be maintained with the wide profile, while the round cable may provide a decreased knot size and decreased macroscopic creep elongation effects as a result of improved knot tightening behavior. Arthrex Inc. has shown that this is technically feasible with the FiberTape ${ }^{\circledR}$, which is used for rotator cuff and anterior cruciate ligament repair (Figure 2). Prominence of instrumentation through the skin leading to irritation or wound healing issues is frequently encountered in early onset scoliosis patients [50]. Neuromuscular or syndromic scoliosis patients account for a substantial part of all early onset scoliosis patients, with substantially higher incidences of wound related issues in these EOS subgroups [51]. These patients typically show poor nutritional status, with age-adjusted body weights often falling within the lowest fifth percentile [52]. The thin stature of these patients implies that limited musculature coverage of instrumentation is possible, and thus the knot size and location is of critical importance in a growth-guidance construct for EOS patients. Knot size may potentially also be decreased with round braided cable ends.

Figure 3 - FiberTape ${ }^{\circledR}$ is a $2 \mathrm{~mm}$ width high-strength suture tape. The tapes provide broad compression and increased cut-through resistance. Image courtesy of Arthrex.

\section{Towards a commercial product: the ease of use \& construct additions}

During the preliminary mechanical tests, we have observed that the applied knot and the manner in which it is produced have a tremendous influence on the mechanical properties of the looped cable. Ideal strength and stiffness are attained when the flat, wide woven UHMWPE cable folds neatly within the applied sliding knot so that stress is optimally distributed and pre-tensioning is most effective. Any twists in the cable can 
lead to high local stress concentrations and thus early failure. Lower stiffness values may be attained due to further tightening of the knot upon loading. In order to guarantee safe use of the cable, the knot may very well best be prefabricated and supplied to the surgeon wrapped around a holding device. The surgeon would then only need to pass the cable underneath the lamina, thread the cable ends through the loop hole, remove the knot from the holding device, and apply the pretension.

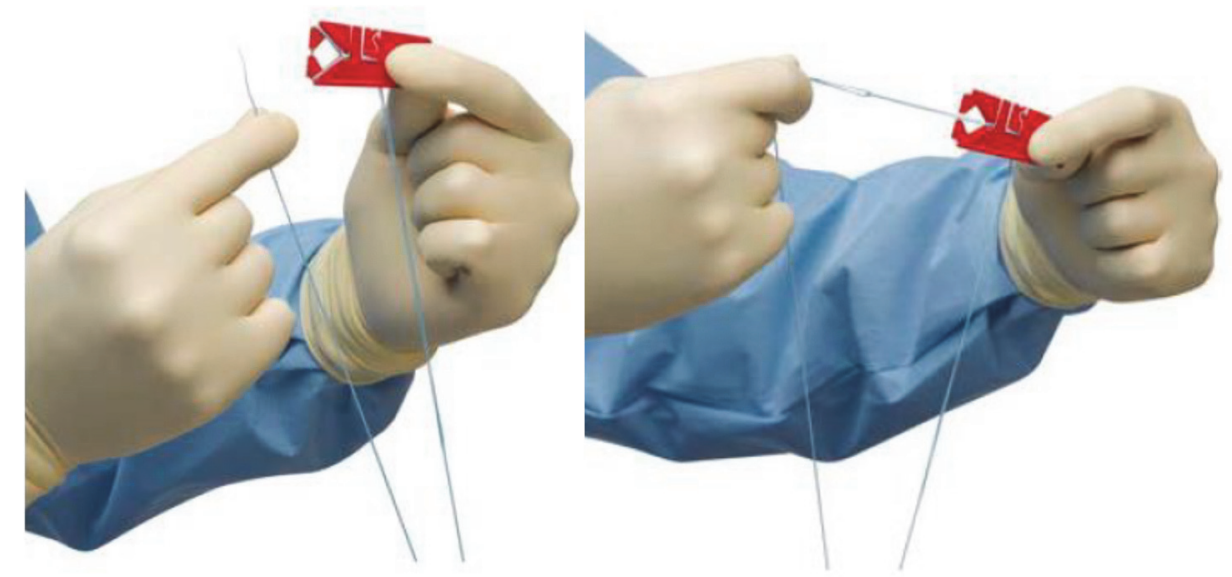

Figure 4 - A prefabricated knot (Gryphon ${ }^{\circledR}$ Proknot $^{\mathrm{TM}}$ suture anchor) on a plastic holding device for application in arthroscopic shoulder surgery. Images courtesy of Depuy-Synthes.

Passing the cable underneath the lamina may be facilitated and expedited by including a malleable metal guide wire within the end of the cable. These considerations are crucial to the potential success of the cable system as they affect the ease of use, required surgical time, and also the safety of the system.

Applying sufficient pretension is also of high importance. A tensioner designed for use with titanium cables was modified to be compatible with wide profile woven cables for use within this project. This tensioner includes an internal spring scale which can be used to visually determine the cable pretension magnitude up to $315 \mathrm{~N}$. This is the absolute maximum recommended pretension for titanium cables, as the cable breaks at not much higher pretension loads. This issue does not need to be considered with the UHMWPE sublaminar cable and therefore a pretension load of $500 \mathrm{~N}$ is recommended. However, careful consideration is still required as the UHMWPE may cut through the lamina at higher pretension loads or in cases of very young patients with cartilaginous bone. 
The use of this modified tensioner was far from optimal from a practical perspective as the cable ends needed to be tied around the end of the tensioner in order to apply pretension. This requires two sets of hands and precludes retensioning as tension was released by severing the cable. Intraoperative retensioning of the cables provides added benefit, as it would allow for gradual curve correction through controlled step-wise tensioning of cables at different spinal levels. Furthermore, this whole process resulted in quite a lot of waste material, as a length of $115 \mathrm{~cm}$ was needed to apply tension, while only approximately $25 \mathrm{~cm}$ was effectively necessary after tensioning. Ideally, multiple material-efficient pretension devices with quick fastening- and release mechanisms and an internal load cell with a scale up to $600 \mathrm{~N}$ would be available during surgery.

Additional components may be added to optimize the growth-guidance system and to further facilitate the surgical procedure. First, a sliding crosslink implant that maintains the distance between the midline and the rods should be developed. As shown in Figure $5 A, B$ sublaminar wires pull the spinal rods towards the midline when the wires are tensioned in comparison to the situation when pedicle screws are used. This results in a decreased moment arm and, as a result, a decreased resistance to axial rotation. By introducing a sliding crosslink, the moment arm can be increased and thereby improved resistance to axial rotation can be attained. The crosslink implant (Figure 5C) should also allow for unrestricted longitudinal sliding along the rod to accommodate spinal growth. Ideally, the crosslink system is to be designed patient-specifically to ensure proper fit.
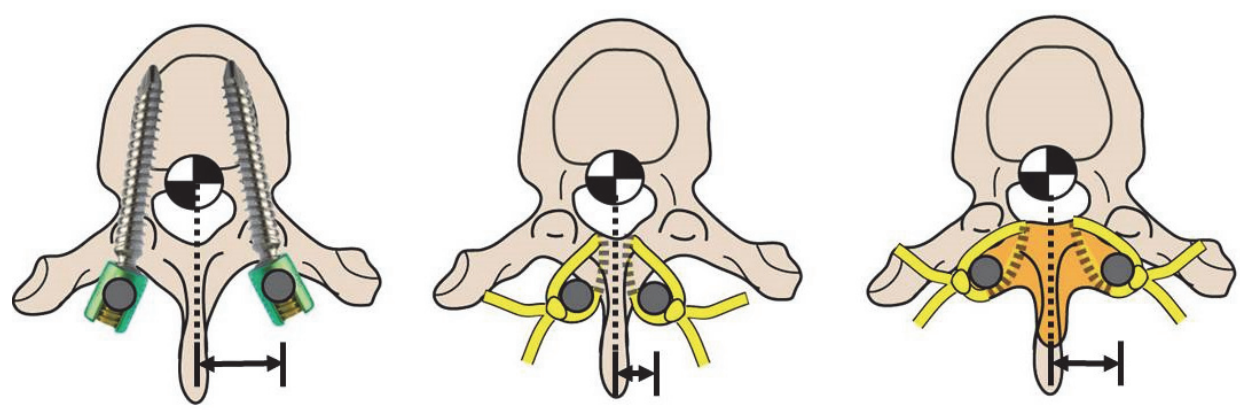

Figure 5 - Schematic drawing illustrating decreased moment arm with sublaminar wires (A,B). A sliding crosslink (C) may help overcome this problem.

Secondly, disposable patient-specific surgical aids may be developed to facilitate pedicle screw placement at the apex. Pedicle anatomy is often distorted at the apex in scoliosis patients $[53,54]$. Very thin pedicles are typically present on the concave side of the 
deformity. The spinal cord is also shifted from its central position towards the concave side, where it rests directly adjacent to the pedicle at the apex [55]. Malpositioned screws thus pose a great risk for disastrous neurological consequences at the apex. Although $2 \mathrm{~mm}$ of spinal canal encroachment is generally considered acceptable in adolescent patients [56,57], this margin is obviously smaller in pediatric patients. Concave-sided screws in the midthoracic region (T4-T8) and convex screws in the lower thoracic region (T11-T12) may also pose significant risk to the descending aorta if they are malpositioned laterally [58]. With little room for error in both lateral and medial directions, disposable patient-specific surgical aids may increase the safety, decrease surgical time, and provide assurance for surgeons with concerns and who are hesitant to place pedicle screws at the apex in pediatric scoliosis patients.

\section{Patient specific preoperative planning using a parametric finite element model}

Further development of the described finite element (FE) model, with patient-specific model geometries may provide a second step towards patient tailored surgical scoliosis treatment. The model mesh is generated using a parametric algorithm which builds up the spine from bottom to top. In order to create a patient-specific mesh, parameters such as vertebral height, width, tilt angle, lateral translation from the midline, and axial rotation would need to be determined for each spinal level preoperatively based on accurate images of the spine. In this manner, the effect of construct component variations on postoperative correction can be simulated prior to surgery, allowing the surgeon to determine the necessary number of levels to be instrumented with sublaminar wires and at which locations crosslinks are required for example. The ribcage has not been included in simulations thus far, although this possibility has been implemented in the mesh generation algorithm. The effect of ribcage addition will need to be validated, and ultimately also requires personalization.

As three-dimensional parameters are required to build a mesh, plain radiographs would not suffice as a basis for parameter acquisition. MRI and CT images would provide all necessary information, with clear preference for MRI due to the high radiation dose associated with a full spinal CT scan. Minimizing exposure to ionizing radiation at each visit is especially crucial for scoliosis patients, as patients undergo frequent radiological assessment throughout their lifetime. Young patients are more vulnerable to the carcinogenic effects of ionizing radiation as they are obviously in their growth phase, and have a higher life expectancy [59]. The EOS imaging system, a low-dose biplanar radiography system, is an attractive alternative to both modalities, but currently it is a rarely available system due to its high initial purchase costs [60]. At the moment, its cost effectiveness in relation to standard X-ray systems is still uncertain. However, if preoperative planning using finite element modeling becomes routine clinical practice, 
low-dose biplanar radiography is certainly the best imaging modality for spine morphometric acquisition.

After patient-specific geometries have been successfully implemented into the model, patient-specific soft tissue material properties will need to be determined and implemented into the model. In order to achieve this, image data from two conditions for which both spinal displacements and the forces causing them are known. The first of these conditions can be provided by standing biplanar radiographs. Bending or fulcrum radiographs do not provide the necessary information for a second condition, as the exact applied spinal load is unknown. The spinal suspension test, where traction loads are applied directly to the spine via the head, has been proposed as a method to quantify the three-dimensional stiffness of the spine [61]. This technique has been successfully used in combination with inverse finite element modeling to determine patient-specific spinal stiffness values in flexion/extension, lateral bending and axial rotation [62].

Considering and understanding the limitations of FE models are even more crucial in comparison to animal models. Material properties, geometries, and loading conditions are always simplified. Extensive validation is required, but certain assumptions are unavoidable. Although a prospective of using FE models as a preoperative planning tool is sketched, this goal may take years to achieve. The FE model may however provide general insight into mechanisms of correction, and provide insight such as the in vivo loads placed on each individual cable for example in the near future.

\section{UHMWPE sublaminar cables for degenerative scoliosis}

Currently, between 9-17\% of patients undergoing surgery for adult spinal deformity (ASD) experience severe instrumentation related problems such as screw pullout or proximal junctional failure necessitating revision surgery $[63,64]$. UHMWPE sublaminar wires may also prove to be of great value for these patients. UHMWPE wires may potentially be used to reinforce pedicle screw fixation as an additive measure or may provide less rigid fixation at the construct end levels in order to prevent junctional level problems. A schematic illustration of a possible construct for use in ASD patients is shown in Figure 6. However, construct variations should be compared based on in vitro biomechanical testing prior to clinical trials. Following the concept of 'topping-off,' a gradual transition in ROM and intradiscal pressures at the junctional levels are the intended outcomes, but should be evidenced prior to in vivo clinical application. 

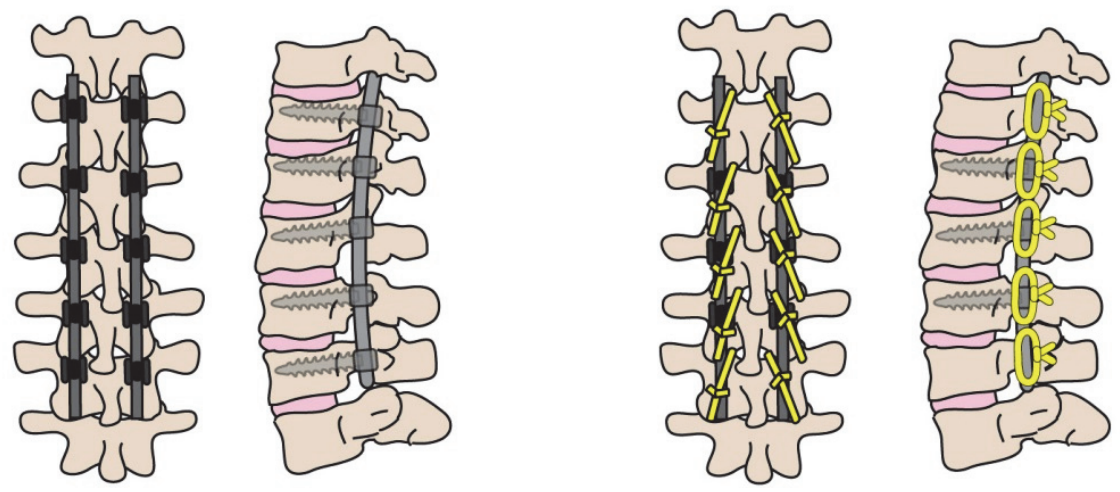

Figure 6 - Two constructs for the treatment of adult spinal deformities: (left) the current golden standard (all pedicle screw constructs) and (right) the proposed new construct with standalone UHMWPE sublaminar wires at the construct end levels, and pedicle screws reinforced with UHMWPE sublaminar wires at the intermediate levels.

In vitro biomechanical testing has shown that the sublaminar wire pull-out strength is independent of bone mineral density (BMD), while the pull-out strength of pedicle screws is strongly correlated to BMD [65]. The lamina of the posterior arch is mostly composed of cortical bone and remains largely unaffected by the thinning and demineralization process associated with osteoporosis. Although biomechanical testing did not reveal any significant differences in pull-out strength, the observed failure mechanism was different for pedicle screws and for pedicle screws augmented with sublaminar wires. Pedicle screws typically failed through screw back-out, which is a frequently described clinical problem in osteoporotic patients. The pedicle screw plus wire groups exhibited failure through pedicle base fracture [66]. To our knowledge, this failure mechanism has never been observed clinically, as the presence of ligaments and muscles will inhibit this mode of failure. This would imply that clinically, the chances of pull-out failure are likely to be reduced by the (additional) use of sublaminar wires. These biomechanical tests were performed using metal sublaminar cables, and should thus be repeated using UHMWPE sublaminar cables. The testing method should also be adapted to prevent pedicle base fracture from occurring. We expect that UHMWPE sublaminar cables will show superior performance to metal cables, as their flat, wide profile should distribute force over a greater area. 

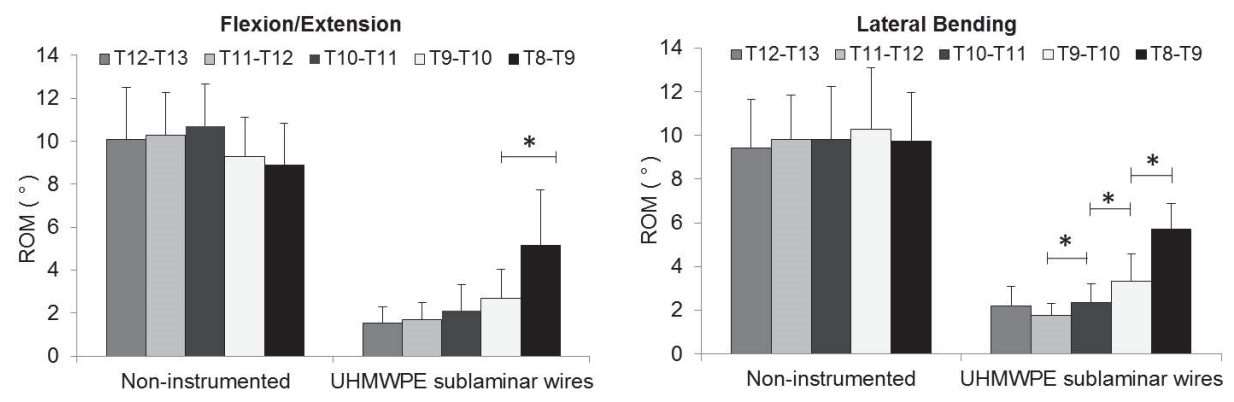

Figure 7 - Range of motion (ROM) in porcine spine segments (T8-T13) without instrumentation and with UHMWPE sublaminar wires at 5 consecutive levels (T8-12) plus pedicle screw fixation at T13 in flexion/extension and in lateral bending.

Current research into preventing screw back-out focuses primarily on the use of PMMA bone cement to augment screw fixation. However, this may lead to additional adjacent level problems due to stiffening of the treated vertebrae. Adjacent level problems (proximal junctional kyphosis or instrumentation break-out) already occur frequently, partly due to the very abrupt transition in terms of range of motion (ROM) between instrumented levels and non-instrumented levels in constructs with pedicle screws only. This introduces stress concentrations at adjacent level vertebrae and at the bone-screw interface of the end levels, which may cause failure requiring revision in ASD patients. Biomechanical tests performed using porcine spine segments in Chapter 5 showed that a gradual transition at the end levels can be attained using UHMWPE sublaminar wires (Figure 7). By using UHMWPE sublaminar wires rather than screws in this patient group, both frequently occurring problems in this patient group may be addressed simultaneously.

\section{FINAL NOTE}

The recommendations and future work discussed here formed the basis for the POSTURE project application submitted to Chemelot InSciTe's Biomedical Research, Testing and Development program. This project application has been granted, and this project will commence in the fall of 2016. Further construct development, the final preclinical prerequisites, and clinical introduction are planned within the duration of this project. 


\section{Chapter 9}

\section{References}

[1] Imagama S, Ito Z, Wakao N, Ando K, Hirano K, Tauchi R, et al. Posterior Surgery for Adolescent Idiopathic Scoliosis with Pedicle Screws and Ultra-High Molecular Weight Polyethylene Tape: Achieving the Ideal Thoracic Kyphosis. J Spinal Disord Tech. 2012.

[2] Govaert LE, Bastiaansen CWM, Leblans PJR. Stress-Strain Analysis of Oriented Polyethylene. Polymer. 1993;34:534-40.

[3] Vlasblom MP, Bosman RLM. Predicting the Creep Lifetime of Hmpe Mooring Rope Applications. OCEANS 20062006. p. 1-10.

[4] Arlet V, Draxinger K, Beckman L, Steffen T. Square-Lashing Technique in Segmental Spinal Instrumentation: A Biomechanical Study. Eur Spine J. 2006;15:1153-8.

[5] Mardjetko SM, Hammerberg KW, Lubicky JP, Fister JS. The Luque Trolley Revisited. Review of Nine Cases Requiring Revision. Spine (Phila Pa 1976). 1992;17:582-9.

[6] Pratt RK, Webb JK, Burwell RG, Cummings SL. Luque Trolley and Convex Epiphysiodesis in the Management of Infantile and Juvenile Idiopathic Scoliosis. Spine (Phila Pa 1976). 1999;24:1538-47.

[7] Rinsky LA, Gamble JG, Bleck EE. Segmental Instrumentation without Fusion in Children with Progressive Scoliosis. J Pediatr Orthop. 1985;5:687-90.

[8] McCarthy RE, McCullough FL. Shilla Growth Guidance for Early-Onset Scoliosis: Results after a Minimum of Five Years of Follow-Up. J Bone Joint Surg Am. 2015;97:1578-84.

[9] Luhmann SJ, McCarthy RE. A Comparison of Shilla Growth Guidance System and Growing Rods in the Treatment of Spinal Deformity in Children Less Than 10 Years of Age. J Pediatr Orthop. 2016.

[10] Karol LA, Johnston C, Mladenov K, Schochet P, Walters P, Browne RH. Pulmonary Function Following Early Thoracic Fusion in Non-Neuromuscular Scoliosis. J Bone Joint Surg Am. 2008;90:1272-81.

[11] Shufflebarger HL, Clark CE. Prevention of the Crankshaft Phenomenon. Spine (Phila Pa 1976). 1991;16:S409-11.

[12] Lenke LG, Betz RR, Harms J, Bridwell KH, Clements DH, Lowe TG, et al. Adolescent Idiopathic Scoliosis: A New Classification to Determine Extent of Spinal Arthrodesis. J Bone Joint Surg Am. 2001;83-A:1169-81.

[13] Harimaya K, Lenke LG, Son-Hing JP, Bridwell KH, Schwend RM, Luhmann SJ, et al. Safety and Accuracy of Pedicle Screws and Constructs Placed in Infantile and Juvenile Patients. Spine (Phila Pa 1976). 2011;36:1645-51.

[14] Andras LM, Joiner ERA, McCarthy RE, McCullough L, Luhmann SJ, Sponseller PD, et al. Growing Rods Versus Shilla Growth Guidance: Better Cobb Angle Correction and T1-S1 Length Increase but More Surgeries. Spine Deformity. 2015;3:246-52.

[15] Loepke AW, Soriano SG. An Assessment of the Effects of General Anesthetics on Developing Brain Structure and Neurocognitive Function. Anesth Analg. 2008;106:1681-707.

[16] Wilder RT, Flick RP, Sprung J, Katusic SK, Barbaresi WJ, Mickelson C, et al. Early Exposure to Anesthesia and Learning Disabilities in a Population-Based Birth Cohort. Anesthesiology. 2009;110:796-804.

[17] Flynn JM, Matsumoto H, Torres F, Ramirez N, Vitale MG. Psychological Dysfunction in Children Who Require Repetitive Surgery for Early Onset Scoliosis. J Pediatr Orthop. 2012;32:594-9.

[18] Ratner BD. Biomaterials Science : An Introduction to Materials in Medicine. San Diego: Academic Press; 1996. 
[19] Benzel EC, Francis TB. Spine Surgery : Techniques, Complication Avoidance, and Management. 3rd ed. Philadelphia, PA: Elsevier/Saunders; 2012.

[20] Cahill PJ, Marvil S, Cuddihy L, Schutt C, Idema J, Clements DH, et al. Autofusion in the Immature Spine Treated with Growing Rods. Spine (Phila Pa 1976). 2010;35:E1199-203.

[21] Jain A, Sponseller PD, Flynn JM, Shah SA, Thompson GH, Emans JB, et al. Avoidance of "Final" Surgical Fusion after Growing-Rod Treatment for Early-Onset Scoliosis. J Bone Joint Surg Am. 2016;98:1073-8.

[22] McCarthy RE, Luhmann S, Lenke L, McCullough FL. The Shilla Growth Guidance Technique for EarlyOnset Spinal Deformities at 2-Year Follow-Up: A Preliminary Report. J Pediatr Orthop. 2014;34:1-7.

[23] McCarthy RE, Sucato D, Turner JL, Zhang H, Henson MA, McCarthy K. Shilla Growing Rods in a Caprine Animal Model: A Pilot Study. Clin Orthop Relat Res. 2010;468:705-10.

[24] Singh V, Simpson J, Rawlinson J, Hallab N. Growth Guidance System for Early-Onset Scoliosis: Comparison of Experimental and Retrieval Wear. Spine (Phila Pa 1976). 2013;38:1546-53.

[25] Kaufman AM, Alabre Cl, Rubash HE, Shanbhag AS. Human Macrophage Response to Uhmwpe, Tialv, Cocr, and Alumina Particles: Analysis of Multiple Cytokines Using Protein Arrays. J Biomed Mater Res A. 2008;84:464-74.

[26] Cunningham BW, Orbegoso CM, Dmitriev AE, Hallab NJ, Sefter JC, Asdourian P, et al. The Effect of Spinal Instrumentation Particulate Wear Debris. An in Vivo Rabbit Model and Applied Clinical Study of Retrieved Instrumentation Cases. Spine J. 2003;3:19-32.

[27] Hallab NJ, Cunningham BW, Jacobs JJ. Spinal Implant Debris-Induced Osteolysis. Spine (Phila Pa 1976). 2003;28:S125-38.

[28] Botolin S, Merritt C, Erickson M. Aseptic Loosening of Pedicle Screw as a Result of Metal Wear Debris in a Pediatric Patient. Spine (Phila Pa 1976). 2013;38:E38-42.

[29] Lukina E, Laka A, Kollerov M, Sampiev M, Mason P, Wagstaff P, et al. Metal Concentrations in the Blood and Tissues after Implantation of Titanium Growth Guidance Sliding Instrumentation. Spine J. 2016;16:380-8.

[30] Klemme WR, Denis F, Winter RB, Lonstein JW, Koop SE. Spinal Instrumentation without Fusion for Progressive Scoliosis in Young Children. J Pediatr Orthop. 1997;17:734-42.

[31] Zou X, Li H, Egund N, Lind M, Bunger C. Inhibition of Spinal Fusion by Use of a Tissue Ingrowth Inhibitor. Eur Spine J. 2004;13:157-63.

[32] Long J, Lewis S, Kuklo T, Zhu Y, Riew KD. The Effect of Cyclooxygenase-2 Inhibitors on Spinal Fusion. J Bone Joint Surg Am. 2002;84-A:1763-8.

[33] Riew KD, Long J, Rhee J, Lewis S, Kuklo T, Kim YJ, et al. Time-Dependent Inhibitory Effects of Indomethacin on Spinal Fusion. J Bone Joint Surg Am. 2003;85-A:632-4.

[34] Caron MM, Emans PJ, Cremers A, Surtel DA, van Rhijn LW, Welting TJ. Indomethacin Induces Differential Effects on in Vitro Endochondral Ossification Depending on the Chondrocyte's Differentiation Stage. J Orthop Res. 2016.

[35] Akbarnia BA, Cheung K, Noordeen H, Elsebaie H, Yazici M, Dannawi Z, et al. Next Generation of GrowthSparing Techniques: Preliminary Clinical Results of a Magnetically Controlled Growing Rod in 14 Patients with Early-Onset Scoliosis. Spine (Phila Pa 1976). 2013;38:665-70.

[36] Dannawi Z, Altaf F, Harshavardhana NS, El Sebaie H, Noordeen H. Early Results of a Remotely-Operated Magnetic Growth Rod in Early-Onset Scoliosis. Bone Joint J. 2013;95-B:75-80. 


\section{Chapter 9}

[37] Heydar AM, Sirazi S, Bezer M. Magnetic Controlled Growing Rods (Mcgr) as a Treatment of Early Onset Scoliosis (Eos): Early Results with Two Patients Had Been Fused. Spine (Phila Pa 1976). 2016.

[38] Hickey BA, Towriss C, Baxter G, Yasso S, James S, Jones A, et al. Early Experience of Magec Magnetic Growing Rods in the Treatment of Early Onset Scoliosis. Eur Spine J. 2014;23 Suppl 1:S61-5.

[39] Keskinen H, Helenius I, Nnadi C, Cheung K, Ferguson J, Mundis G, et al. Preliminary Comparison of Primary and Conversion Surgery with Magnetically Controlled Growing Rods in Children with Early Onset Scoliosis. Eur Spine J. 2016.

[40] Ridderbusch K, Rupprecht M, Kunkel P, Hagemann C, Stucker R. Preliminary Results of Magnetically Controlled Growing Rods for Early Onset Scoliosis. J Pediatr Orthop. 2016.

[41] Dimeglio A, Canavese F. The Growing Spine: How Spinal Deformities Influence Normal Spine and Thoracic Cage Growth. European spine journal : official publication of the European Spine Society, the European Spinal Deformity Society, and the European Section of the Cervical Spine Research Society. 2012;21:64-70.

[42] Teoh KH, Winson DM, James SH, Jones A, Howes J, Davies PR, et al. Do Magnetic Growing Rods Have Lower Complication Rates Compared with Conventional Growing Rods? Spine J. 2016;16:S40-4.

[43] Teoh KH, Winson DM, James SH, Jones A, Howes J, Davies PR, et al. Magnetic Controlled Growing Rods for Early-Onset Scoliosis: A 4-Year Follow-Up. Spine J. 2016;16:S34-9.

[44] Jones CS, Stokes OM, Patel SB, Clarke AJ, Hutton M. Actuator Pin Fracture in Magnetically Controlled Growing Rods: Two Cases. Spine J. 2016;16:e287-91.

[45] Cheung JP, Cahill P, Yaszay B, Akbarnia BA, Cheung KM. Special Article: Update on the Magnetically Controlled Growing Rod: Tips and Pitfalls. J Orthop Surg (Hong Kong). 2015;23:383-90.

[46] Watanabe K, Uno K, Suzuki T, Kawakami N, Tsuji T, Yanagida H, et al. Risk Factors for Proximal Junctional Kyphosis Associated with Dual-Rod Growing-Rod Surgery for Early-Onset Scoliosis. Clin Spine Surg. 2016.

[47] Jenks M, Craig J, Higgins J, Willits I, Barata T, Wood H, et al. The Magec System for Spinal Lengthening in Children with Scoliosis: A Nice Medical Technology Guidance. Appl Health Econ Health Policy. 2014;12:587-99.

[48] Charroin C, Abelin-Genevois K, Cunin V, Berthiller J, Constant H, Kohler R, et al. Direct Costs Associated with the Management of Progressive Early Onset Scoliosis: Estimations Based on Gold Standard Technique or with Magnetically Controlled Growing Rods. Orthop Traumatol Surg Res. 2014;100:469-74.

[49] Su AW, Milbrandt TA, Larson AN. Magnetic Expansion Control System Achieves Cost Savings Compared to Traditional Growth Rods: An Economic Analysis Model. Spine (Phila Pa 1976). 2015;40:1851-6.

[50] Bess S, Akbarnia BA, Thompson GH, Sponseller PD, Shah SA, El Sebaie H, et al. Complications of GrowingRod Treatment for Early-Onset Scoliosis: Analysis of One Hundred and Forty Patients. J Bone Joint Surg Am. 2010;92:2533-43.

[51] Aleissa S, Parsons D, Grant J, Harder J, Howard J. Deep Wound Infection Following Pediatric Scoliosis Surgery: Incidence and Analysis of Risk Factors. Can J Surg. 2011;54:263-9.

[52] Myung KS, Skaggs DL, Thompson GH, Emans JB, Akbarnia BA, Growing Spine Study G. Nutritional Improvement Following Growing Rod Surgery in Children with Early Onset Scoliosis. J Child Orthop. 2014;8:251-6.

[53] Liljenqvist UR, Allkemper T, Hackenberg L, Link TM, Steinbeck J, Halm HF. Analysis of Vertebral Morphology in Idiopathic Scoliosis with Use of Magnetic Resonance Imaging and Multiplanar Reconstruction. J Bone Joint Surg Am. 2002;84-A:359-68. 
[54] Liljenqvist UR, Link TM, Halm HF. Morphometric Analysis of Thoracic and Lumbar Vertebrae in Idiopathic Scoliosis. Spine (Phila Pa 1976). 2000;25:1247-53.

[55] Smorgick Y, Settecerri JJ, Baker KC, Herkowitz H, Fischgrund JS, Zaltz I. Spinal Cord Position in Adolescent Idiopathic Scoliosis. J Pediatr Orthop. 2012;32:500-3.

[56] Hicks JM, Singla A, Shen FH, Arlet V. Complications of Pedicle Screw Fixation in Scoliosis Surgery: A Systematic Review. Spine (Phila Pa 1976). 2010;35:E465-70.

[57] Kim YJ, Lenke LG, Bridwell KH, Cho YS, Riew KD. Free Hand Pedicle Screw Placement in the Thoracic Spine: Is It Safe? Spine (Phila Pa 1976). 2004;29:333-42; discussion 42.

[58] Sarlak AY, Buluc L, Sarisoy HT, Memisoglu K, Tosun B. Placement of Pedicle Screws in Thoracic Idiopathic Scoliosis: A Magnetic Resonance Imaging Analysis of Screw Placement Relative to Structures at Risk. Eur Spine J. 2008;17:657-62.

[59] Kleinerman RA. Cancer Risks Following Diagnostic and Therapeutic Radiation Exposure in Children. Pediatr Radiol. 2006;36 Suppl 2:121-5.

[60] McKenna C, Wade R, Faria R, Yang H, Stirk L, Gummerson N, et al. Eos 2d/3d X-Ray Imaging System: A Systematic Review and Economic Evaluation. Health Technol Assess. 2012;16:1-188.

[61] Buchler P, de Oliveria ME, Studer D, Schumann S, Zheng G, Schneider J, et al. Axial Suspension Test to Assess Pre-Operative Spinal Flexibility in Patients with Adolescent Idiopathic Scoliosis. Eur Spine J. 2014;23:2619-25.

[62] Berger S, de Oliveira M, Schuman S, Schneider J, Studer D, Hasler C, et al. Patient-Specific Spinal Stiffness in Ais: A Preoperative and Noninvasive Method. Eur Spine J. 2015;24:249-55.

[63] Maier S, Smith JS, Schwab F, Obeid I, Mundis G, Klineberg E, et al. Revision Surgery after Three-Column Osteotomy in 335 Adult Spinal Deformity Patients: Inter-Center Variability and Risk Factors. Spine (Phila Pa 1976). 2014.

[64] Pichelmann MA, Lenke LG, Bridwell KH, Good CR, O'Leary PT, Sides BA. Revision Rates Following Primary Adult Spinal Deformity Surgery: Six Hundred Forty-Three Consecutive Patients Followed-up to TwentyTwo Years Postoperative. Spine (Phila Pa 1976). 2010;35:219-26.

[65] Hitchon PW, Brenton MD, Black AG, From A, Harrod JS, Barry C, et al. In Vitro Biomechanical Comparison of Pedicle Screws, Sublaminar Hooks, and Sublaminar Cables. J Neurosurg. 2003;99:104-9.

[66] Paxinos O, Tsitsopoulos PP, Zindrick MR, Voronov LI, Lorenz MA, Havey RM, et al. Evaluation of Pullout Strength and Failure Mechanism of Posterior Instrumentation in Normal and Osteopenic Thoracic Vertebrae. J Neurosurg Spine. 2010;13:469-76. 
Chapter 9

9 


\section{Valorization}

This thesis is the result of the Spineguide project, part of the BioMedical Materials research program, co-funded by the Dutch Ministry of Economic Affairs. Project members from Maastricht University Medical Center, Eindhoven University of Technology, the University of Twente and DSM Biomedical collaborated in this publicprivate partnership, each with their own specific focus within one of the different work packages. This project was driven by the unmet clinical need to provide a surgical solution for a small, but vulnerable and utmost challenging patient group.

The Spineguide project can be considered a very successful project, considering that FDA 510 (k) clearance has been granted for certain specific intended clinical applications of the radiopaque UHMWPE sublaminar wires, thereby opening the doorway to clinical introduction. However, the UHMWPE wires have not been approved as an adjunct to spinal fusion or for application in pediatric patients. Application of the UHMWPE wires as described in this thesis will thus require institutional regulatory board approval for a controlled clinical trial. Moreover, realization has set in that in order for the radiopaque UHMWPE wires to be successfully marketed, a complete treatment system with surgical tools and with additional construct components should be offered, as was discussed in the General Discussion. A new project proposal for the development of a surgical toolset and additional construct components has been submitted to Chemelot InSciTe's (Institute for Science and Technology) Biomedical program entitled PoSTuRE was recently granted approval. Whereas the Spineguide project was primarily focused on the development and preclinical assessment of radiopaque UHMWPE sublaminar wires, this follow-up project (POSTURE: Patient-specific Scoliosis TREatment) will focus on the implementation of the whole treatment concept into clinical practice by further developing the complete surgical system, thereby optimizing ease of use for the surgeon and improving clinical outcome.

The incidence of early onset scoliosis is low, occurring in approximately 1-2 cases per 10,000 people in Europe [1]. Surgical rates for EOS have been reported to be approximately $30 \%-50 \%[2,3]$. With an annual birth rate of 5-6 million in Europe [4], this amounts to $150-600$ potential patients in Europe and 5-18 patients in the Netherlands requiring surgery each year. Such low numbers do not normally provide enticing incentive to drive innovation or a solid basis for a business case for most commercializing parties. $75 \%$ of the total spinal device market is currently held by a total of five different medical device companies, with the largest two accounting for approximately $60 \%$ of the market revenue. Adoption of the developed technology by 
one of the large medical device companies into their spinal portfolios is likely necessary for widespread clinical implementation. In order for this to occur, clinical feasibility results from a small patient cohort are necessary.

Although the commercial market size for EOS patients may not be very large, we do foresee a viable business case when scoliosis patient groups of all ages are targeted. Approximately 29,000 surgeries are performed annually in the USA to correct adolescent idiopathic scoliosis (AIS) [5]. The use of polymer sublaminar cables in hybrid constructs for the surgical treatment of AIS has been proven effective, with good correction of thoracic curves, low loss of correction in the long term, and superior correction in the sagittal plane [6]. We believe that UHMWPE sublaminar wires may also prove of great benefit in adult degenerative scoliosis patients whom often suffer from osteoporosis and as a result pedicle screw breakout and instrumentation failure. Osteoporosis generally leads to decreased bone mass in the anterior column of the spine, while the posterior structures, such as the lamina, remain mostly unaffected. Therefore UHMWPE sublaminar wires may be used as a substitute for pedicle screws or may be used as a means to reinforce pedicle screws. Furthermore, as UHMWPE sublaminar wire fixation leads to slightly less rigid fixation in comparison to pedicle screws, placing UHMWPE at the cranial end levels of the instrumented segment may lead to a decreased incidence of proximal junctional kyphosis (PJK) and its associated problems such as adjacent level fractures or instrumentation failure.

The potential market size for UHMWPE sublaminar wires within adult spinal deformity (ASD) surgery is substantially larger and is also vastly increasing due to the aging population. The number of surgeries performed for adult spinal deformities has doubled in the past decade, from 9,400 in 2000 to more than 20,000 in 2010 in the USA alone [7]. This rapid increase is astonishing, as the frequency of all other spine primary diagnosis codes increased by a mere $20 \%$ over the same time period. These numbers were taken from the Nationwide Inpatient Sample (NIS) database [8], which approximates a $20 \%$ stratified sample of US community hospitals [9]. Therefore, the total number of ASD surgeries can be estimated at 100,000 in the USA alone in 2010, with current numbers at approximately 150,000 if the rapid increase has continued in the past five years. Of these patients, between 9-17\% experience severe instrumentation related problems such as screw pullout or proximal junctional failure that necessitate revision surgery $[10,11]$. The direct costs of revision surgery in adult spinal deformity patients amount to approximately $\$ 67,000$ on average [12]. Decreasing the incidence of severe instrumentation failure related problems and their associated costs is therefore of great clinical and societal importance.

Government funding for this and future projects is justified as the newly proposed growth guidance system may prove to increase quality of life and significantly lower healthcare costs for the treated patients. Cost-effectiveness analyses have been 
performed for magnetically controlled growing rod (MCGR) systems in comparison to conventional growing rod systems (CGRS) in the UK [13]. This study provides valuable insight into the possible healthcare savings which may be attained with the newly proposed growth guidance system. The initial costs for CGRS are approximately $£ 8500$ $(€ 11,500)$. Lengthening costs, consisting of operating room and postoperative care costs, amount to approximately $£ 6,500(€ 7,700)$ annually for CGRS (two procedures per year). For the newly proposed growth guidance system, we expect the initial costs to be similar to the CGRS: approximately $€ 11,500$. However, no lengthening procedures are required. The costs of lengthening procedures have been calculated to amount to approximately $£ 32,500(€ 38,500)$ for the CGRS over a five year period. So, this entire amount can potentially be saved per patient with the newly proposed growth guidance system. Lower expected costs and no required return to hospital for lengthening procedures may be decisive factors to favor growth-guidance systems over MCGR (or conventional GR systems), especially in developing countries. Furthermore, a definitive fusion procedure is usually required to attain maximum correction of the deformity upon reaching skeletal maturity with both CGRS and MCGR. With the newly proposed system, rod fixation in the middle of the curve (apex) is also applied, which would result in superior correction. Therefore, revision procedures are expected to be required less frequently. Most importantly, a definitive fusion procedure can potentially also be avoided due to the superior correction attained with the newly proposed growth guidance system. This would result in further cost savings which amount to an additional $€ 25,000-€ 30,000$ if a definitive fusion procedure can be avoided. Not only in direct costs, but as the quality of life for the patients will increase and the associated morbidity will be less, the indirect health care costs will also be lower.

The POSTURE project intends to demonstrate safety of radiopaque UHMWPE sublaminar wires via a first-in-man study in adult degenerate scoliosis patients. The additional to-be developed instrumentation system components will be tested in animal trials first. If successful, the results of both these studies will justify a trial in juvenile scoliosis patients. These clinical trials are intended to provide proof of safety. Supported by background information on the material (i.e. Dyneema Purity ${ }^{\circledR}$ Radiopaque fiber master-file) and production processes, an application for CE marking or FDA approval can then be submitted. Once approval is obtained, larger scale multi-center (randomized) clinical trials can be initiated. Once efficacy has also been proven, the Spineguide treatment concept can be introduced to market on a global scale. Medtronic is currently the market leader in Spinal Surgery Devices, with well over 35\% market share, and is involved in the project by supporting the development of the surgical tools. This puts them in an ideal position to closely monitor the progress and outcomes of the project. They would be the ideal partner to bring the PoSTuRE treatment system to market, and the close proximity to the project makes opening discussions with them easy. 


\section{REFERENCES}

[1] Debnath UK. Current Concepts in the Management of Early-Onset Idiopathic Scoliosis. Pediatr Health. 2010;4:343-54.

[2] Figueiredo UM, James JI. Juvenile Idiopathic Scoliosis. J Bone Joint Surg Br. 1981;63-B:61-6.

[3] Mannherz RE, Betz RR, Clancy M, Steel HH. Juvenile Idiopathic Scoliosis Followed to Skeletal Maturity. Spine (Phila Pa 1976). 1988;13:1087-90.

[4] European Commission Demography Report. Luxembourg: Publications Office of the European Union, 2015, http://ec.europa.eu/eurostat/documents/3217494/6917833/KE-BM-15-003-EN-N.pdf/76dac4909176-47bc-80d9-029e1d967af62015.

[5] Poitras B, Mayo NE, Goldberg MS, Scott S, Hanley J. The Ste-Justine Adolescent Idiopathic Scoliosis Cohort Study. Part Iv: Surgical Correction and Back Pain. Spine (Phila Pa 1976). 1994;19:1582-8.

[6] Sales de Gauzy J, Jouve JL, Ilharreborde B, Blondel B, Accadbled F, Mazda K. Use of the Universal Clamp in Adolescent Idiopathic Scoliosis. Eur Spine J. 2014;23 Suppl 4:S446-51.

[7] McCarthy I, O'Brien M, Ames C, Robinson C, Errico T, Polly DW, Jr., et al. Incremental Cost-Effectiveness of Adult Spinal Deformity Surgery: Observed Quality-Adjusted Life Years with Surgery Compared with Predicted Quality-Adjusted Life Years without Surgery. Neurosurg Focus. 2014;36:E3.

[8] Healthcare Cost and Utilization Project (Hcup): Overview of the Nationwide Inpatient Sample (Nis). Agency Healthc. Res. Qual. 2014.

[9] Paul JC, Lonner BS, Goz V, Weinreb J, Karia R, Toombs CS, et al. Complication Rates Are Reduced for Revision Adult Spine Deformity Surgery among High-Volume Hospitals and Surgeons. Spine J. 2015;15:1963-72.

[10] Maier S, Smith JS, Schwab F, Obeid I, Mundis G, Klineberg E, et al. Revision Surgery after Three-Column Osteotomy in 335 Adult Spinal Deformity Patients: Inter-Center Variability and Risk Factors. Spine (Phila Pa 1976). 2014.

[11] Pichelmann MA, Lenke LG, Bridwell KH, Good CR, O'Leary PT, Sides BA. Revision Rates Following Primary Adult Spinal Deformity Surgery: Six Hundred Forty-Three Consecutive Patients Followed-up to TwentyTwo Years Postoperative. Spine (Phila Pa 1976). 2010;35:219-26.

[12] McCarthy IM, Hostin RA, O'Brien MF, Fleming NS, Ogola G, Kudyakov R, et al. Analysis of the Direct Cost of Surgery for Four Diagnostic Categories of Adult Spinal Deformity. Spine J. 2013;13:1843-8.

[13] Rolton D, Richards J, Nnadi C. Magnetic Controlled Growth Rods Versus Conventional Growing Rod Systems in the Treatment of Early Onset Scoliosis: A Cost Comparison. Eur Spine J. 2015;24:1457-61. 


\section{Nederlandse samenvatting}

De chirurgische behandeling van 'early onset scoliosis' (EOS, scoliose gekenmerkt door een ontwikkeling van een wervelkolomdeformiteit vóór de leeftijd van tien jaar) is zeer uitdagend en complex. Geïnstrumenteerde spondylodese van de wervelkolom, de gouden standaard in de operatieve behandeling van scoliose bij adolescenten en volwassenen, is geen goede optie voor infantiele en juveniele patiënten aangezien deze procedure de ontwikkeling van de borstkas en longen ernstig kan belemmeren. Derhalve worden veel 'early onset' scoliose patiënten momenteel operatief behandeld met zogenaamde 'growing rods'. 'Growing rods' moeten elke 6 tot 9 maanden operatief worden bijgesteld om lengtegroei van de wervelkolom toe te laten. Deze ingrepen gaan gepaard met vele complicaties en hoge zorgkosten. Bovendien leiden deze frequente ingrepen veelvuldig tot psychosociale stress bij patiënten en ouders. Groeigeleidingssystemen bieden enerzijds fixatie van de wervelkolom en correctie van de deformiteit terwijl anderzijds lengtegroei van het geopereerde traject mogelijk blijft. Zodoende neemt het aantal benodigde (her)operaties drastisch af. Bestaande groeigeleidingssystemen bevatten metalen componenten die langs elkaar heen glijden om groei mogelijk te maken. Dit kunnen metalen kabels of schroeven met niet-volledig fixerende schroefdoppen zijn. De metaal-op-metaal articulatie geeft een relatief hoge weerstand en leidt tot de formatie van slijtagepartikels (metallosis), die een chronische ontsteking en/of schroefuitbraak tot gevolg kunnen hebben.

Dit proefschrift beschrijft de ontwikkeling en de evaluatie van een nieuw groeigeleidingssysteem voor de operatieve behandeling van 'early onset' scoliose waarbij de nadelen van metaal-op-metaal articulatie van de bestaande groeigeleidingssystemen vermeden kunnen worden. Het voorgestelde systeem maakt gebruik van 'ultra-high molecular weight polyethylene' (UHMWPE) sublaminar wires die functioneren als glijdende fixatiepunten voor de proximale en distale uiteinden van de scoliotische bocht. In dit systeem wordt de apex van de scoliotische curve gefixeerd met pedikelschroeven om rotatie correctie te bieden en om migratie van de staven te voorkomen. De wervelkolom segmenten boven en onder de apex zijn het minst geroteerd en verschoven ten opzichte van de verticale midsacrale loodlijn en zijn de segementen waar residuele geleide groei kan plaatsvinden. Idealiter leidt dit systeem door middel van een éénmalige operatieve ingreep tot een effectieve correctie van de deformiteit terwijl verdere groei van de wervelkolom en de borstkas mogelijk blijft. De onderliggende hypothese is dat het gebruik van UHMWPE kabels in plaats van metalen kabels leidt tot drie substantiële voordelen: Allereerst zal de longitudinale glijweerstand 
tussen componenten verlaagd worden om maximale lengtegroei van de wervelkolomsegmenten toe te laten. Ten tweede wordt de vorming van metalen slijtage partikels vermeden omdat er geen wrijving tussen metalen componenten plaatsvindt maar tussen UHMWPE en metaal. Ten derde wordt de operatieve benadering minder invasief doordat de verhoogde vermoeiingssterkte van de UHMWPE kabels (ten opzichte van de metalen kabels) reductie van het aantal geïnstrumenteerde niveaus mogelijk maakt zonder kabelbreuk te riskeren. Dit proefschrift omvat een volledige preklinische evaluatie van het voorgestelde groeigeleidingssysteem voor de behandeling van EOS, met de volgende doelen:

Het evalueren van de veiligheid van het gebruik van radiopaque UHMWPE sublaminar wires voor scoliosiecorrectiechirurgie vanuit een mechanisch en een biologisch oogpunt

In Hoofdstuk 3 zijn de mechanische eigenschappen (stijfheid, treksterkte, vermoeiingssterkte en verlenging door kruip) van radiopaque UHMWPE kabels bepaald en vergeleken met een radiolucente versie van de UHMWPE kabel, een commercieel verkrijgbare titanium sublaminar wire en literatuurwaarden van verschillende andere kabelsystemen. De treksterkte en de vermoeiingsterkte van de UHMWPE kabels zijn substantieel hoger gebleken dan metalen kabels, terwijl ze een vergelijkbare stijfheid bezitten. De resultaten laten zien dat de toevoeging van homogeen verdeelde bismuthoxidedeeltjes binnen de vezels de mechanische eigenschappen van de geweven UHMWPE kabel niet aantast. De radiopaciteit (mate van zichtbaarheid op röntgenfoto's) werd geëvalueerd voor de radiopaque UHMWPE kabel. De radiopaciteit van de UHMWPE kabel was vergelijkbaar met de radiopaciteit van de titanium Atlas $^{\circledR}$ kabel op de laterale röntgenfoto (in de breedte van de kabel), maar de radiopaciteit in het frontale vlak was minder gezien de beperkte dikte van de kabel. Dit impliceert dat enkel laterale opnames geschikt zijn om de integriteit van de UHMWPE laminar wires radiologisch te vervolgen. Beperkte hoeveelheden bismuth-oxide lekten uit de kabel in vitro, maar deze hoeveelheden waren ver beneden de gestelde veilig toelaatbare limiet. Weefselconcentraties lager dan die bij therapeutische doseringen van bismuthhoudende medicijnen tegen gastro-intestinale aandoeningen, werden aangetroffen na een implantatietijd van 24 weken in schapen. Tijdens een preliminaire slijtageanalyse werd geen substantiële schade aan de UHMWPE kabel en derhalve ook geen substantiële hoeveelheid slijtage partikels gevonden, zoals beschreven in het Supplement van Hoofdstuk 3. Deze resultaten samen leiden tot de conclusie dat radiopaque UHMWPE kabels veilig gebruikt kunnen worden voor de correctie van wervelkolomdeformiteiten vanuit een mechanisch, biologisch en toxicologisch oogpunt. 
Het evalueren van het resterende groeipotentieel van de wervelkolom na instrumentatie met een groeigeleidingssysteem met radiopaque UHMWPE sublaminar wires als glijdende fixatiepunten

De groei van de wervelkolom na instrumentatie met het UHMWPE kabel groeigeleidingssysteem in een juveniel schapenmodel is geanalyseerd in Hoofdstuk 4. Laterale röntgenfoto's lieten duidelijk de positionering van de UHMWPE kabels rond de laminae zien. Er waren geen neurologische complicaties en de UHMWPE kabels behielden hun stabiliteit gedurende de volledige follow-up termijn. Het inbrengen van een groeigeleidingssysteem vormde geen belemmering voor verdere groei van de wervelkolom; de lengte van het geïnstrumenteerde segment verschilde niet tussen de experimentele en de controle groep zonder instrumentatie na 24 weken. In de meeste dieren gleden door lengtegroei de kabels van het bovenste geïnstrumenteerde niveau van de staaf af. Morfologische veranderingen aan de facet gewrichten en heterotope botformatie werden echter wel waargenomen op hoge resolutie CT beelden (HR-pQCT), hoewel dit de lengtegroei niet heeft beperkt. Histologische analyse liet zien dat de UHMWPE kabels ingekapseld waren met fibreus weefsel zonder chronische ontstekingsreactie en daarbijhorende osteolyse. In het Supplement van Hoofdstuk 4 werd aangetoond dat met de keuze voor UHMWPE kabels in plaats van titanium kabels de longitudinale glijweerstand met ongeveer 50\% verminderd kan worden. Uit deze studies concludeerden we dat UHMWPE kabels beter functioneren als glijdende fixatiepunten in een groeigeleidingssysteem. Echter behoeft intralaminaire botformatie als gevolg van resectie van het ligamentum flavum aandacht aangezien dit potentieel kan leiden tot spontane fusie van twee aangrenzende niveaus.

Het bepalen van het optimale aantal opeenvolgende wervelkolomsegmenten dat geïnstrumenteerd dient te worden met UHMWPE kabels zodat voldoende correctie en fixatie geboden wordt maar de operatieve invasiviteit en kans op heterotope ossificaties wordt geminimaliseerd

In Hoofdstuk 5 werd een in vitro biomechanische studie uitgevoerd waarbij een variërend aantal niveaus van thoracale varkenswervelkolomsegmenten werd vastgezet met UHMWPE kabels. Resectie van het ligamentum flavum is noodzakelijk voor het plaatsen van sublaminar wires. Echter kan dit mogelijk leiden tot intralaminaire botformatie met spontane fusie en belemmering van de groei als verder gevolg. Subperiostale dissectie moet dus zoveel mogelijk vermeden worden om zoveel mogelijk groei te behouden voor EOS patiënten. Dit impliceert dat er zo min mogelijk niveaus moeten worden geïnstrumenteerd met UHMWPE kabels zonder dat dit ten koste gaat van de fixatie en correctie van de wervelkolom. Significante en substantiële toenames in de 'range of motion' (ROM) voor zowel laterale buiging als flexie/extensie traden pas op bij instrumentatie van minder dan twee geïnstrumenteerde eindniveaus. Een optimale balans tussen het minimaliseren van de operatieve invasiviteit en de geboden stabiliteit 
aan de wervelkolom wordt dus verkregen met een constructie bestaande uit UHMWPE kabels op twee eindniveaus. Uiteindelijk zal de resterende groei van de patiënt in ogenschouw genomen moeten worden; wellicht betekent dit dat één extra niveau geïnstrumenteerd dient te worden om de stabiliteit te waarborgen in het geval dat de kabel van het uiterst geïnstrumenteerde niveau van de staaf afglijdt.

Het implementeren van realistisch biomechanisch gedrag van het groeigeleidingssysteem in een parametrisch (patiënt-specifiek) eindigeelementenmodel van de wervelkolom

Allereerst werd het in silico biomechanisch gedrag van het gezonde L4-L5 wervelkolomsegment gekalibreerd in Hoofdstuk 6. Het biomechanische gedrag van de gehele thoracolumbale wervelkolom werd vervolgens geverifieerd. Schroeven, staven en UHMWPE kabels werden geïmplementeerd in het model en het in vitro biomechanische onderzoek naar variaties in de dichtheid van UHMWPE kabels beschreven in Hoofdstuk 5, werd in silico herhaald. Er werd een redelijke overeenkomst gevonden tussen de in vitro biomechanische test resultaten en de eindige-elementen simulaties wat betreft de totale ROM in flexie/extensie en laterale buiging na het inbrengen van de instrumentatie. De stapsgewijze toename in de ROM bij een afnemend aantal geïnstrumenteerde niveaus zoals werd geobserveerd in de in vitro biomechanische studie werd niet zo prominent geobserveerd in de in silico studie. Het longitudinaal glijden van de UHMWPE kabels langs de staaf tijdens normale fysiologische bewegingen zou in het eindige-elementenmodel moet worden geïncorporeerd voor betere gelijkenis tussen de in vitro en in silico resultaten. Ook zou de parametrische definitie van de geometrie van de posterieure elementen moeten worden verbeterd voor betere anatomische gelijkenis. Desalniettemin, in deze studie zijn belangrijke eerste stappen gezet in de implementatie en de validatie van een groeigeleidingssysteem voor EOS patiënten in een patiënt-specifiek eindige elementen model van de wervelkolom.

De ontwikkeling van een groot proefdiermodel voor 'early-onset' scoliose om een in vivo evaluatie van het ontwikkelde groeigeleidingssysteem te kunnen voltooien

Een overzicht van grote proefdiermodellen beschreven voor de preklinische evaluatie van fusieloze scoliosecorrectietechnieken en recente vooruitgangen in het creëren van idiopathisch-achtige scoliose proefdiermodellen werd gegeven in Hoofdstuk 7. Er werd geconcludeerd dat fusieloze scoliosecorrectietechnieken het best kunnen worden beoordeeld volgens een tweestapsbenadering; tijdens een eerste operatieve procedure dient een scoliose geïnduceerd te worden met behulp van een posterieure spinale spandraad. Na een aantal maanden kan de verkregen deformiteit gecorrigeerd worden met behulp van de te onderzoeken correctie-techniek. Varkens leken de meest geschikte proefdiersoort gezien het snelle en langdurige groeivermogen en de vroege speenleeftijd. De procedure om scoliose te induceren zou volledig reversibel moeten 
zijn; idealiter wordt daarom enkel een posterieure spinale spandraad geplaatst en wordt een spandraad rondom enkele ribben bij voorkeur vermeden. Deze keuze impliceert wel dat een hogere terugval in de ernst van de deformiteit te verwachten is na het verwijderen van de posterieure spinale spandraad.

De ontwikkeling van een varkensmodel voor scoliose, gebruikmakend van enkel een posterieure spinale spandraad, werd vervolgens beschreven in Hoofdstuk 8. Een structurele scoliotische bocht met een thorax deformiteit werd gecreëerd in 8 van de 14 dieren. De Cobbse hoek van deze bochten was gemiddeld $62^{\circ}$ met een axiale rotatie van $37^{\circ}$ op de apex. In het sagittale vlak werden atypische profielen geobserveerd, met lokale lordose rondom de pedikel schroeven die gebruikt waren ter verankering van de spandraad. Dit als gevolg van gecontinueerde anterieure groei van de betreffende wervellichamen. Het aantal wervels dat betrokken was bij de geïnduceerde scoliose was ook inconsistent; 3 dieren vertoonden een atypische korte thoracale bocht. Schroefuitbraak was de voornaamste reden voor falen, maar ook diepe infecties traden frequent op. Door een spandraad rondom de ribben achterwege te laten, werd gepoogd meer flexibele bochten te creëren, met name rond de apex. Deze keuze leidde echter tot een inconsistent model met een lage opbrengst ten gevolge van frequente schroefuitbraak. Wellicht speelde de hoge groeisnelheid van het varken een rol bij het frequent optreden van schroefuitbraak. Er moest geconcludeerd worden dat de ontwikkeling van een geschikt proefdiermodel voor scoliose, gebruikmakend van enkel een posterieure spinale spandraad, tot op heden onvoldoende succesvol is gebleken.

\section{DISCUSSIE EN TOEKOMST}

De resultaten van dit proefschrift en de Dyneema Purity ${ }^{\oplus}$ Masterfile hebben geleid tot FDA 510(k) goedkeuring voor de radiopaque UHMWPE kabel voor een aantal specifieke indicaties. De eerste stappen richting klinische implementatie van het beschreven groeigeleidingsconcept zullen worden genomen in het PoSTuRE project. In dit project gefinancierd door Chemelot InSciTe (Institute for Science and Technology) zullen additionele componenten met een patiënt-specifieke benadering worden ontwikkeld. Zo zal het beschreven eindige-elementenmodel verder worden ontwikkeld en zullen patiëntspecifieke (hulp)implantaten worden ontworpen en gefabriceerd door middel van 3D-printen. Ook zullen de UHMWPE kabels worden getest bij volwassen patiënten lijdend aan degeneratieve scoliose. Schroefuitbraak en wervellichaamsbreuken op aangrenzende overgangsniveaus komen vaak voor bij deze patiënten. UHMWPE kabels kunnen gebruikt worden in combinatie met pedikelschroeven voor extra fixatie om schroefuitbraak tegen te gaan of kunnen een geleidelijkere overgang bieden qua bewegingsvrijheid aan de uiteinden van het geïnstrumenteerde segment om nieuwe problemen op aangrenzende niveaus te voorkomen. Gedurende deze klinische studie 
zal nogmaals de veiligheid van de radiopaque UHMWPE kabels worden geëvalueerd. Het groeigeleidingssysteem met de UHMWPE kabels zal vervolgens ook binnen het POSTURE project klinisch bij EOS patiënten worden geïntroduceerd. Al met al is het Spineguide project zeer succesvol geweest, echter is het onderzoek nog lang niet voltooid! 


\section{List of Publications}

\section{JOURNAL PAPERS}

Bogie R, Roth AK, Willems PC, van der Weegen W, Arts JJ, van Rhijn LW.

The development of a representative porcine early-onset scoliosis model with a standalone posterior spinal tether

Spine Deformity. 2016

Jeuken RM, Roth AK, Peters RJRW, van Donkelaar CC, Thies, JC, van Rhijn LW, Emans PJ Polymers in Cartilage Defect Repair of the Knee: Current Status and Future Prospects. Polymers 2016, 8, 219.

Jacobs E, Saralidze K, Roth AK, de Jong JJ, van den Bergh JP, Lataster A, Brans BT, Knetsch ML, Djordjevic I, Willems PC, Koole LH.

Synthesis and characterization of a new vertebroplasty cement based on gold-containing PMMA microspheres.

Biomaterials. 2016 Mar;82:60-70.

Roth AK, van der Veen AJ, Bogie R, Willems PC, van Rietbergen B, van Rhijn LW, Arts JJ. Range of motion in segmental versus nonsegmental ultrahigh molecular weight polyethylene sublaminar wire growth guidance type constructs for early-onset scoliosis correction.

Spine (Phila Pa 1976). 2015 Dec;40(23):E1212-8.

Bogie R*, Roth AK*, de Faber S, de Jong JJ, Welting TJ, Willems PC, Arts JJ, van Rhijn LW. Novel radiopaque ultrahigh molecular weight polyethylene sublaminar wires in a growth-guidance system for the treatment of early-onset scoliosis: feasibility in a large animal study.

Spine (Phila Pa 1976). 2014 Dec 1;39(25):E1503-9.

${ }^{*}$ Both authors contributed equally

Roth AK, Bogie R, Jacobs E, Arts JJ, van Rhijn LW.

Large animal models in fusionless scoliosis correction research: a literature review.

Spine J. 2013 Jun;13(6):675-88. 


\section{CONFERENCE ABSTRACTS}

Roth AK, Boon-Ceelen K, Smelt H, van Rhijn LW, Arts JJ

Novel radiopaque UHMWPE wires for early onset scoliosis correction: a mechanical assessment

Oral Presentation at the Annual Meeting of the Nordic Spinal Deformity Society (NSDS), 28-8-2015, Amsterdam, NL.

Oral Presentation at the UHMWPE Meeting, Philadelphia, USA, 23-10-2015

Oral presentation at the Annual meeting of the Dutch Orthopedic Association (NOV) 28-1-2016, 's Hertogenbosch, NL.

Roth AK, van der Veen A, Willems PC, Arts JJ, van Rhijn LW.

Influence of stepwise removal of UHWMPE sublaminar wires on segmental stability in long segment instrumentation for early onset scoliosis correction.

Oral presentation at the Annual Meeting of the European Orthopedic Research Society (EORS) Annual Meeting, 3-07-2014, Nantes, France.

Oral presentation at the Annual meeting of the Dutch Orthopedic Association (NOV) 5-2-2015, Maastricht, NL.

Poster presentation at the Annual Meeting of the Orthopedic Research Society (ORS), 28-3-2015, Las Vegas, USA

Roth AK, Bogie R, Willems PC, Welting TJ, de Jong JJ, Arts JJ, van Rhijn LW.

Novel radiopaque UHMWPE sublaminar wires in a growth-guidance system for the treatment of early onset scoliosis: feasibility in a large animal model.

Oral presentation at the Annual meeting of the Dutch Orthopedic Association (NOV)

6-02-2014, Rotterdam, NL.

Oral presentation at the UHMWPE Meeting, Turin, Italy, 12-10-2013.

Oral presentation at the Meeting of the Combined Orthopedic Research Societies (CORS), 16-10-2013, Venice, Italy.

Poster presentation at the Annual Meeting of the Orthopedic Research Society (ORS), 16-03-2014, New Orleans, USA

Jacobs E, Roth AK, Willems PC, Arts JJ, van Rhijn LW.

Thoracic hyperkyphosis correction in Osteoporotic Patients: Polycarbonate urethane Spine implants.

Poster presentation at the Annual Meeting of the Orthopedic Research Society (ORS), 16-03-2014, New Orleans, USA 


\section{Dankwoord}

De leden van de beoordelingscommissie: prof. dr. P.R.G. Brink, prof. dr. R.M. Castelein, prof. dr. P. Habibovic, dr. H. Van Santbrink, prof. dr. ir. G.J. Verkerke. Hartelijk dank voor de tijd en moeite die $u$ heeft genomen om mijn proefschrift te lezen en de bereidheid zitting te nemen in de beoordelingscommissie.

Mijn promotor prof. dr. L.W. van Rhijn, Beste Lodewijk, bedankt voor je immer positieve en optimistische blik met altijd het einddoel in gedachte. Je bent een ware verbinder en hebt me heel veel geleerd over people-management en communicatie. Bedankt voor de open gesprekken en het vertrouwen dat je me hebt geschonken.

Mijn copromotor, dr. P.C. Willems, Beste Paul, bedankt dat ik altijd bij je binnen kon vallen en dat je altijd tijd vrij maakte voor me! Ik heb enorm veel van je geleerd over de klinische kant van jouw prachtig vak, de wervelkolomchirurgie. Het was altijd een genot om met jou inhoudelijk te sparren of gewoon te kletsen over wielrennen of wat dan ook. Ik heb veel zin om met jou de uitdaging aan te gaan die PoSTuRE heet!

Mijn copromotor, dr. J.J.C. Arts, Beste Chris, bedankt voor de kansen en de verantwoordelijkheid die je me hebt gegeven om dit project vorm te geven en mezelf daarbij te ontwikkelen. Je hebt me laten zien hoe veel je kan bereiken met goede persoonlijke relaties en contacten. Dit zal ik zeker meenemen in de toekomst.

Drs. R. Bogie, Beste Rob, je introduceerde me aan de praktische kant van de orthopedische chirurgie waardoor er een hele nieuwe wereld voor me open ging. Ook introduceerde je me aan het mooie Limburgse heuvelland tijdens ons 'overleg'op de racefiets. Met heel veel plezier heb ik op het CPV op OK met je gestaan terwijl we nodige tegenslagen hebben moeten verwerken. Hoewel we het altijd goed konden vinden, ben ik veel te ongeduldig richting jou geweest waarvoor wederom mijn oprechte excuses. Nu zie ik in dat je veel respect verdient voor de wijze waarop jij een drukke baan combineert met een jong gezin, je ambitie in de sportgeneeskunde en een promotieonderzoek er nog naast. Succes met de afronding van jouw proefschrift!

Dr. Ir. B. van Rietbergen, Beste Bert, dankzij jou ben ik in Maastricht bij de Orthopedie terecht gekomen nadat je mijn afstuderen begeleidde op de TU/e. Jouw inbreng wierp vaak ander licht op mijn artikelen en presentaties en was van grote toegevoegde waarde! Je hebt me geleerd problemen te simplificeren en zo snel door te dringen tot de essentie. Bijzonder dat onze samenwerking zal worden voortgezet! 
Dr. ir. K. Boon-Ceelen, Beste Karlien, hartstikke bedankt voor de prettige samenwerking die we hopelijk nog lang zullen voortzetten! We konden altijd open en eerlijk tegen elkaar zijn en dat kon ik zeer waarderen. Ik ben trots op de mijlpalen die we samen hebben bereikt binnen Spineguide, waarbij jij echt de drijvende kracht vanuit DSM Biomedical was! Ook de andere Spineguide consortium leden vanuit DSM Biomedical hartelijk dank voor de fijne en zeer succesvolle samenwerking: Harold Smelt, Lavinia Panella, Sanna Severins, Carola Hansen en Ferry Soeters. In het bijzonder Armand Wintjens, heerlijk om te kunnen kletsen over wielrennen en voetballen tijdens de vele sessie's van knoopjes leggen en kapot maken!

Alle medewerkers van CPV-groot, Sanne Bout, Petra Dijkstra, Joyce Suyk en Huub Souren, bedankt voor al jullie inzet, de gezelligheid en de zeer fijne samenwerking! Prachtig om te zien hoe jullie je werk met veel liefde uitvoeren. Ik heb ontzettend veel van jullie geleerd! Ook dank aan drs. Saskia Seeldrayers voor alle adviezen en inbreng bij alle projecten.

Dr. A.J. van der Veen, Beste Albert, je verwelkomde me met open armen in 'jouw' prachtig lab binnen het VUMC en liet me m'n gang gaan alsof ik er gewoon werkte. Ik genoot erg van de filosofische discussies met je. De combinatie van klassieke muziek en een scalpel in je hand deden je me wel een beetje aan Hannibal Lecter denken, maar je continue oprechte vrolijkheid dan weer helemaal niet. Ook dank aan Puck Vergroesen, Roderick Holewijn en Kaj Emanuel van het VUMC voor de uitwisseling van onderzoekservaringen en voor de gezellige tijden als we elkaar tegen kwamen op congres!

Alle stafleden Orthopedie: prof. dr. Lodewijk van Rhijn, dr. Paul Willems, dr. René ten Broeke, dr. Heleen Staal, drs. Peter Feczko, drs. Mark van den Boogaart, drs. Jan Geurts, drs. Joris Hermus, dr. Adhiambo Witlox en dr. Pieter Emans. Dank voor de zeer waardevolle les om altijd de klinische relevantie in beschouwing te nemen!

De dames van het secretariaat Orthopedie: Wil, Jerney, Chantalle, Marion, Manon en Denise, Bedankt voor jullie geduld en hulp als ik weer eens aankwam met onmogelijke vergaderverzoeken. Ook Caren en Mieke wil ik bedanken voor de vriendelijkheid zodra ik als vreemde eend jullie dagelijkse gang van zaken kwam verstoren.

De dames van het trialbureau Orthopedie: Liesbeth, Margareth, Anita en natuurlijk secretaresse Peters. Bedankt voor de altijd vriendelijke ontvangst en het bieden van een uitlaatklep om alle frustraties te kunnen uiten. Hopelijk blijven jullie net zo vriendelijk als we het Spineguide concept klinisch gaan introduceren in studieverband en ik jullie dus aan het werk ga zetten!

Dank aan alle AIOS orthopedie voor de nuttige inbreng tijdens de pizza meetings en de gezellige borrels! 
Dank aan alle studenten die hebben bijgedragen aan de inhoud van dit proefschrift. Giovanni Paffen en Robin Jacobs, bedankt voor de hulp bij het uitvoeren van de histologie. Meike Smits en Ronald van der Meer, bedankt voor jullie inzet om Spineguide verder te brengen! Ronald, ik kijk er naar uit om met je samen te werken binnen POSTURE!

Van de TU Eindhoven bedank ik ook graag Virginia Ballotta, Marc Kanters en Leon Govaert voor het beschikbaar stellen van apparatuur en hun hulp bij het uitvoeren van de vermoeiingsproeven.

Marion Kuiper van de afdeling Fysiologie. Bedankt voor al je praktische tips en hulp als ik weer ergens gebruik van wilde maken of iets nodig had!

Heren van IDEE - Allereerst de mannen van de werkplaats, Lars Eeuwijk, Paul Verjans en Bart Verhoeven, bedankt voor alle enthousiaste hulp en de bereidheid om mee te willen denken bij alle last-minute problemen waarmee ik aan kwam zetten. Bedankt dat jullie altijd dat stapje extra wilden zetten voor me! Ook dank aan Bart Beulen, Peter Gerits, Pascal Huysmans, Iwan de Jong, Paul Kwant, Paul Laeven en Lars Smeets voor de samenwerking en hulp bij de verschillende projecten.

Erie van de Heuvel, als onze financieel controller kon ik geen fijnere vent wensen. Ik kon altijd bij je binnen lopen en je maakte altijd tijd voor me. Alleen jammer dat je zo goed bent in je werk en me er niet vandoor liet gaan met de binnengehaalde subsidie.

Medewerkers van de afdeling Radiologie: Ralph Eschweiler, Kim Feron, Anke Hersbach, Roland Kersemakers en alle laboranten. Bedankt voor jullie medewerking bij de diverse projecten. Of het nu het plannen van een CT, MRI, of röntgenonderzoek was, ongelooflijk hoe behulpzaam en meedenkend jullie zijn geweest!

Heren van de afdeling Anatomie en Embryologie - Johan Hekking, Leon Huiberts, Arno Lataster en Paul van Dijk. Bedankt voor alle hulp en de prettige samenwerking bij alle projecten tot op heden en in de toekomst! Jullie humor, enthousiasme en de wil om belangeloos te helpen waar mogelijk waardeer ik enorm!

Nancy Sterk en Joost Heijmans van Medtronic . Bedankt voor de hulp bij de uitvoering van alle experimenten! Nancy, we komen elkaar vast nog wel eens tegen bij één of andere loop- of fietstocht!

Het SyCaP consortium: Pieter Emans, Ralph Jeuken, Ruud Peters, Jens Thies, Jac Koenen, René van Donkelaar, Keita Ito, Mieke Nickien, Ashley Heuijerjans en Anne Vrancken. Bedankt voor de prettige samenwerking het afgelopen jaar en op naar alle successen! Ook wil ik Danielle Curfs, Emiel Staring en Chris Duxbury bedanken voor al het onderzoek dat jullie mogelijk maken, eerst onder de vlag van BMM en nu InSciTe.

Kenneth Meijer, Michiel Oosterwaal en Pieter Oomen van de afdeling Bewegingswetenschappen. Bedankt voor de gezelligheid tijdens de cake van de week en 
congressen waar we gazemenlijk heen ging; de hapjes en de drankjes tijdens het CORS in Venetië vormden een waar hoogtepunt!

Collega's van het Laboratory of Experimental Orthopedics - een bij elkaar geraapt zooitje van nerds, ADHD'ers en mafkezen - ik ben trots om hier deel van uit te maken. Allereerst onze grote leider dr. Tim Welting - ik heb het grootste respect voor je omdat je altijd de wetenschap op één stelt, altijd kritisch blijft en zeer integer bent. Daarentegen heb je fantastische humor en een prachtige dark side. Don Surtel, de nestor van de groep en ondertussen deel van het lab meubilair, jouw droge humor en liefde voor speciaalbiertjes zijn zeer aangename kenmerken en onmisbaar voor ons lab! Marjolein Caron, ook langzamerhand meubilair van het lab, je bent een voorbeeld qua teamspirit en doorzettingsvermogen. Ik moet nog steeds de tijd even vinden om onze kamer te behangen met die mooie jungle/beach print. Jim Odekerken, als collega was je al een fantastische leraar. Je hebt me wegwijs gemaakt binnen het proefdier-gebonden onderzoek en voorzien van vele waardevolle tips, waarvoor eeuwige dank! Andy Cremers, ouwe badmintonnert, wij streberige, chaotische onderzoekers kunnen zeker iets oppikken van jouw levensinstelling en geordendheid. Toch zullen we nooit ophouden met alles wat we kunnen doen om jou het leven zuur te maken. Mandy Steinbusch, jouw kleurrijke creaties bij de cake van de week vergeet ik nooit. Ik dwaal mentaal altijd af als jij weer een foto van een $\mathrm{CHH}$-patiënt in de introductie van een presentatie laat zien; wanneer ga je nou eindelijk deze arme midgets helpen? Ufuk Tan Timur, ons sociaal-maatschappelijk project/taxi chauffeur, onze reizen naar Las Vegas en Sorrento vormen de hoogtepunten van mijn wetenschappelijke carrière - op de wetenschappelijke inbreng na dan. Je bent een fantastische kerel en dankzij jou neem ik nu ook altijd m'n föhn mee in m'n handbagage als ik op reis ga en vergeet ik me nooit meer in te smeren met zonnebrandcrème. Marloes Peters, ik leerde je pas goed kennen in Amerika - wat ben ik blij dat ik niet alleen met Ufuk werd opgescheept! Een fantastische ervaring en zeker voor herhaling vatbaar! We hebben heel veel gemeen, persoonlijk en als de de enige BMT'ers zijnde. Mooi om nog nauw met je samen te werken de komende jaren! Eva Jacobs, niemand is zo leuk om voor de gek te houden als jij. Ik zoek nog steeds heel Den Bosch af op zoek naar osteoporotische schapen, maar ik kan ze maar niet vinden. Het was een genot om elke maand sushi te eten met je - nu alweer veel te lang geleden. Ik zou me nooit door jou laten opereren, maar je word een fantastisch orthopedisch chirurg! Ralph Jeuken, de 'work hard - play hard ' mentaliteit delen we en dit maakt ons tot een fantastisch team binnen SyCaP. Waanzinnig om een geneesko te zien met zo'n brede interesse als jij! Nog even die armen een beetje bijtrainen en je wordt een fantastische protheseboer! Pieter Emans, dankzij jou hervond ik mijn enthousiasme voor de R\&D en het onderzoek in het algemeen! Jouw oprechte betrokkenheid en enthousiasme is aanstekelijk. Alle andere collega's die hebben bijgedragen aan mijn fantastische tijd op het lab, Laura Voss, llona Punt, Toon Boselie, Shennah Austen, Guus v.d. Akker, Tessy Castermans en Ellen Ripmeester, bedankt! 
Maarten Janssen, als ik weer eens naar buiten keek en de zon zag schijnen hoefde ik me maar om te draaien en we zaten binnen een uur op de racefiets. Ik vond m'n evenknie in jou als het op sporten en borrelen aankwam en zo werden we heel snel naast collega's ook vrienden. Ik ben je er eeuwig dankbaar voor dat je me introduceerde bij en opnam in een fantastische groep vrienden! Super mooi dat je m'n paranimf wil zijn! Ook dank aan Corinne Spooren-Janssen voor alle hapjes en drankjes die je me over de jaren heen hebt voorgeschoteld - het was een eer om getuige te zijn bij jullie bruiloft!

Het 'Eetclubje Maastricht,' Felix, Rutger, Maarten en Eduard. Allemaal drukke agenda's maar daarom juist mooi om doordeweeks of in het weekend de gedachten te verzetten met goed eten en een pot wijn erbij! Op naar veel nieuwe BBQ's en culinaire hoogtepunten!

De jongens van Stiphout Vooruit, het was altijd heerlijk om m'n hoofd leeg te maken op het voetbalveld en in de kantine naderhand. Zonder deze uitlaatklep was ik allang gek geworden. Speciale dank aan Bjorn, Joost, Bob, Rens, Rob v.d. V, Tommie, Rob v.d H, Geoffrey, Addy, Bjørn, Lars, Michiel en Arjen voor de gezelligheid over de jaren!

Dan nu de belangrijkste mensen: mijn familie. Dankzij onze tijd in Amerika zijn we een zeer hecht gezin geworden met hele fijne tradities. Ik koester alle mooie herinneringen. aan de reizen die we maakten, Thanksgiving (met de Vriesema's), het vieren van kerst, bootje varen en BBQ's. Maar ook gewoon lekker op de bank liggen thuis is ontzettend fijn. Maakt niet uit waar het huis staat, home is where the family is. Ivan, als grote broer ben jij altijd een voorbeeld voor me geweest. Vroeger altijd hoe het niet moest, maar tegenwoordig in positieve zin, zeker omdat we zo anders zijn en ik veel van jouw goede karaktereigenschappen mis. Maaike, nu dan eindelijk echt part of the family en echt een aanwinst! Vanwege de afstand zie ik jullie minder vaak, maar het is altijd gezellig om bij jullie langs te komen in Amsterdam! Kasper, bro, fantastisch al die reizen die we samen hebben gemaakt de afgelopen jaren! Ook wij zijn heel verschillend maar hebben tegelijkertijd ook weer heel veel gemeen. Ik ben er trots op dat je mijn paranimf wil zijn en heb niemand liever naast m'n zijde staan! Kristel, mooi om jou als ons kleine zusje te zien ontwikkelen tot een (bijna) zelfstandige (bijna) volwassen vrouw met bijna een echte baan. Ik ben trots op je! Jos, je hebt het niet makkelijk als vriend van ons klein zusje, maar we zijn blij met je! Oma Annie, niemand vroeg zo vaak naar mijn onderzoek als jij. Dank voor alle SMSjes en de oprechte interesse!

Lieve Pap en Mam, ik wil jullie natuurlijk bedanken voor alle liefde, steun en kansen die jullie mij hebben geboden alle jaren. Het is geen toeval dat wij alle vier zo goed terecht zijn gekomen. Ik ben ontzettend blij met hoe jullie ons hebben opgevoed; jullie hebben altijd alles in het teken van het gezin gezet en er alles aan gedaan om onze dromen waar te maken. Ik houd ontzettend veel van jullie! 
